\title{
APT Blanket System Loss-of-Coolant Accident (LOCA) Based on Initial Conceptual Design - Case 2: with Beam Shutdown Only
}

by

L. L. Hamm

Westinghouse Savannah River Company

Savannah River Site

Aiken, South Carolina 29808

S. Y. Lee

M. A. Shadday

F. G. Smith, III

A document prepared for SENDING TO LANL at , , from - .

\section{DOE Contract No. DE-AC09-96SR18500}

This paper was prepared in connection with work done under the above contract number with the U.S. Department of Energy. By acceptance of this paper, the publisher and/or recipient acknowledges the U.S. Government's right to retain a nonexclusive, royalty-free license in and to any copyright covering this paper, along with the right to reproduce and to authorize others to reproduce all or part of the copyrighted paper. 


\section{DISCLAIMER}

Portions of this document may be illegible in electronic image products. Images are produced from the best available original document. 


\section{APT BLANKET SYSTEM LOSS-OF-FLOW ACCIDENT (LOFA) ANALYSIS BASED ON INITIAL CONCEPTUAL DESIGN -}

\section{Case 2: with Beam Shutdown only}

L. Larry Hamm

Si Young Lee

M. Andy Shadday

Frank G. Smith, III

Westinghouse Savanhah River Company Savannah River Site Aiken, SC 29808

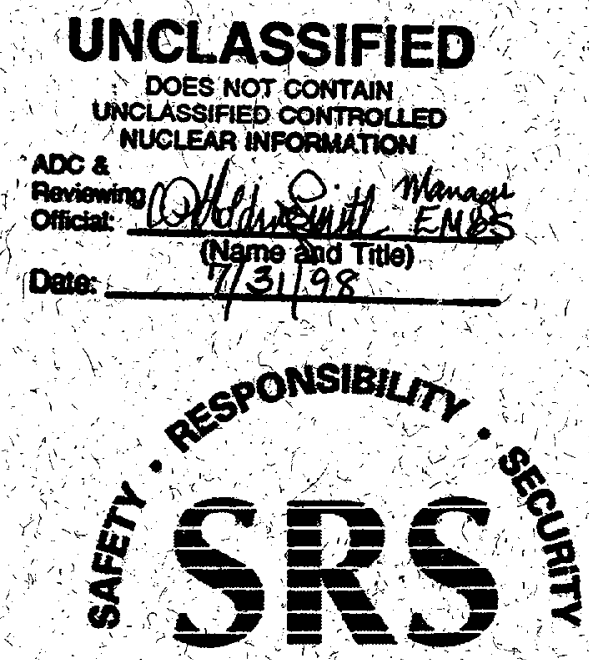




\section{DISCLAIMER}

This report was prepared as an account of work sponsored by an agency of the United States Government. Neither the United States Government nor any agency thereof, nor any of their employees, makes any warranty, express or implied, or assumes any legal liability or responsibility for the accuracy, completeness, or usefulness of any information, apparatus, product, or process disclosed, or represents that its use would not infringe privately owned rights. Reference herein to any specific commercial product, process, or service by trade name, trademark, manufacturer, or otherwise does not necessarily constitute or imply its endorsement, recommendation, or favoring by the United States Government or any agency thereof. The views and opinions of authors expressed herein do not necessarily state or reflect those of the United States Government or any agency thereof.

This report has been reproduced directly from the best available copy.

Available to DOE and DOE contractors from the Office of Scientific and Technical Information, P.O. Box 62, Oak Ridge, TN 37831; prices available from (615) 576-8401.

Available to the public from the National Technical Information Service, U.S. Department of Commerce, 5285 Port Royal Road, Springfield, VA 22161. 
WSRC-TR-98-0085

KEYWORDS:

Accelerator Production of Tritium

Blanket System

Conceptual Design

TRAC Code

FLOWTRAN-TF Code

System Model

Detailed Bin Model

Safety Analysis

RETENTION - Permanent

\section{APT BLANKET SYSTEM LOSS-OF-FLOW ACCIDENT (LOFA) ANALYSIS BASED ON INITIAL CONCEPTUAL DESIGN}

\section{Case 2: with Beam Shutdown only}

SAVANNAH RIVER TECHNOLOGY CENTER

L. Larry Hamm

Si Young Lee

$M$. Andy Shadday

Frank G. Smith, III

Publication Date: July, 1998

Westinghouse Savannah River Company

Savannah River Site

Aiken, SC 29808

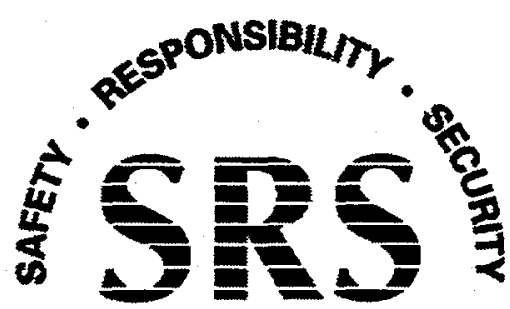

SAVANNAH RIVER SITE

Prepared for the U.S. Department of Energy under Contract No. DE-AC09-96SR18500 
DOCUMENT: WSRC-TR-98-0085

TITLE: APT BLANKET SYSTEM LOSS-OF-FLOW ACCIDENT (LOFA) ANALYSES BASED ON INITIAL CONCEPTUAL DESIGN - Case 2: with Beam Shutdown only

APPROVALS

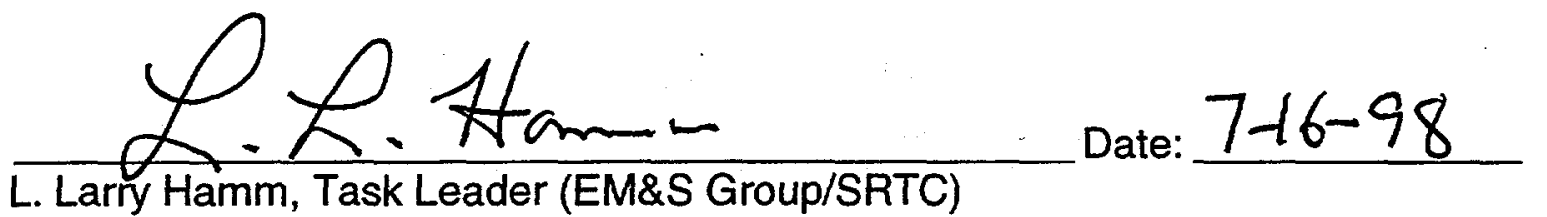

L. Larry Hamm, Task Leader (EM\&S Group/SRTC)
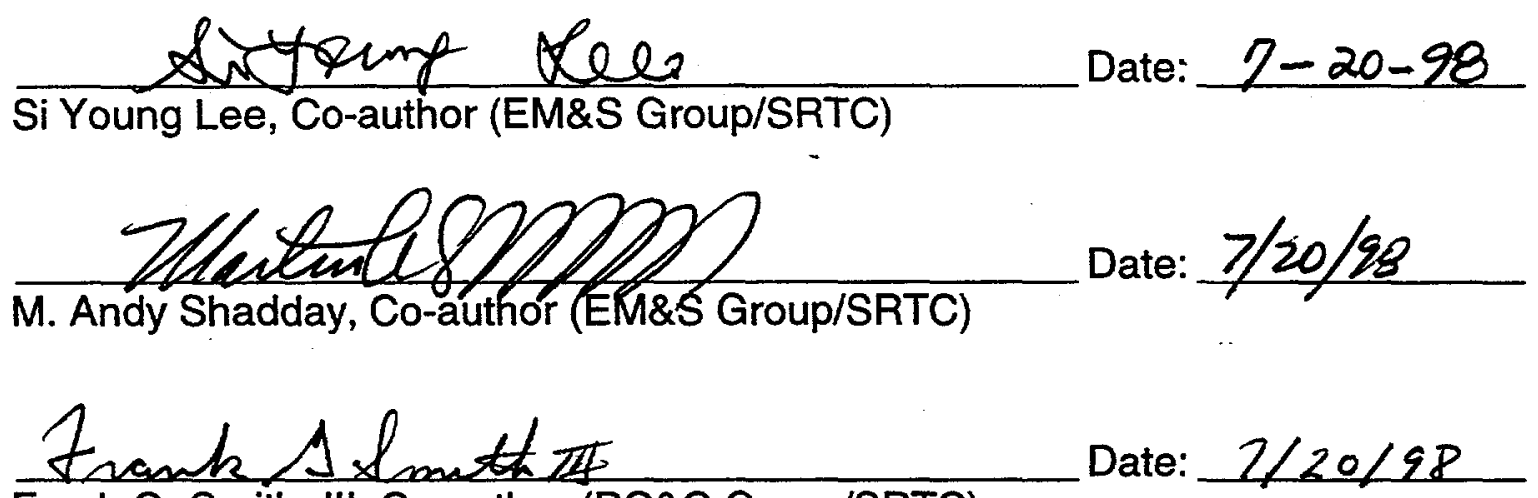

Frank G. Smith, III, Co-author (PC\&C Group/SRTC)

Date: $2 / 20 / 98$
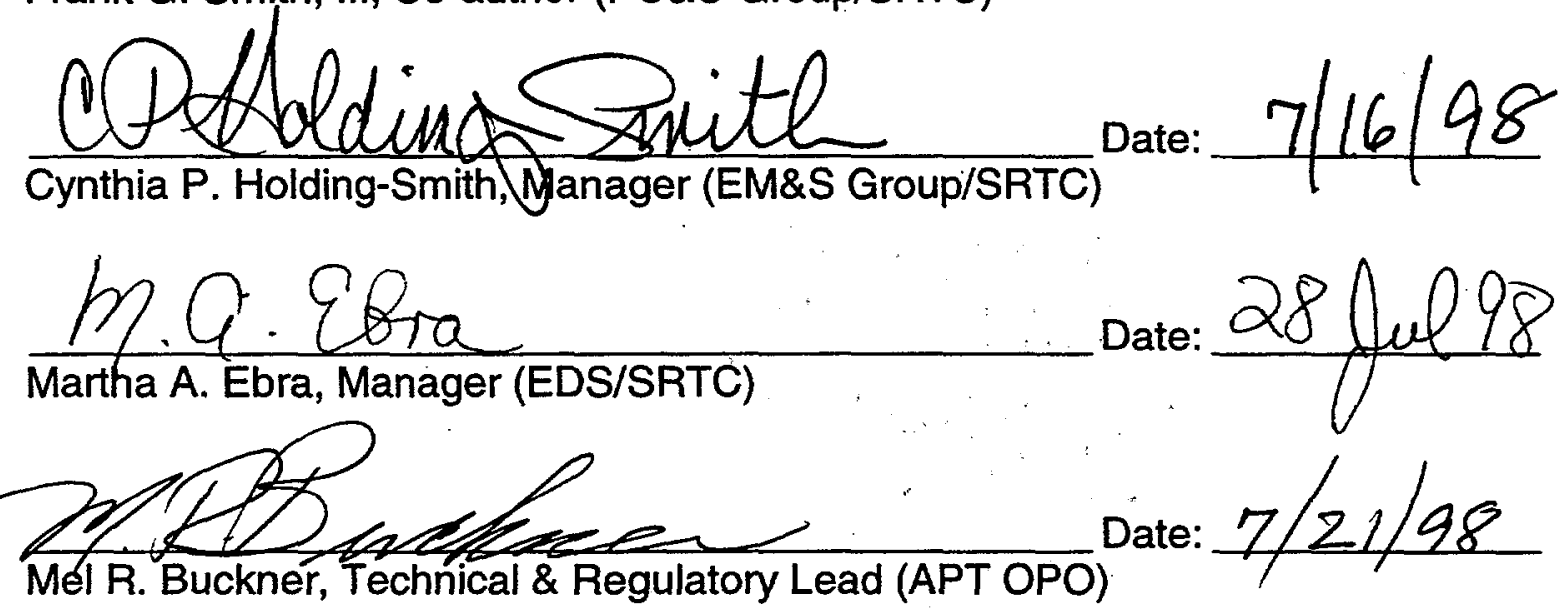

The internal technical review function is being performed at the APT project level and is coordinated through LANL.

-ii- 


\section{Table of Contents}

1 Introduction $\quad 1$

2 TRAC 1-D System Model 2

2.1 Scenario Description...................................................................................... 3

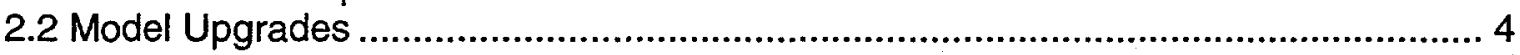

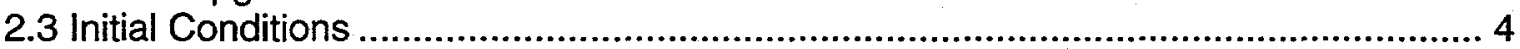

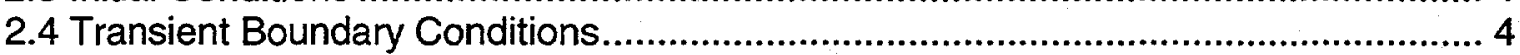

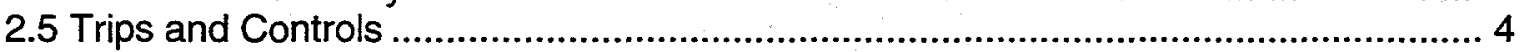

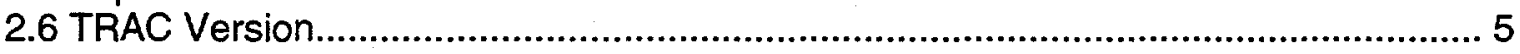

3 TRAC System Model Results 9

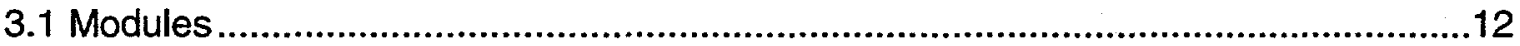

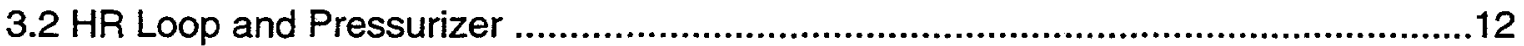

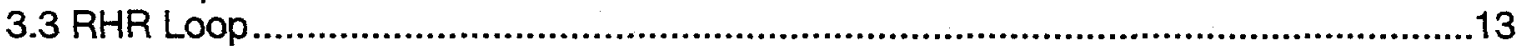

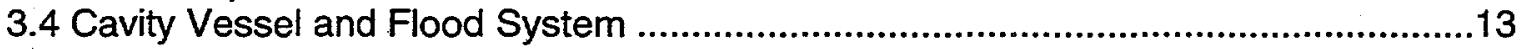

4 Evaluation Model 13

5 Evaluation Model Results 16

6 Conclusions $\quad 18$

6.1 Comparison to Thermal/Hydraulic Design Criteria ...............................................19

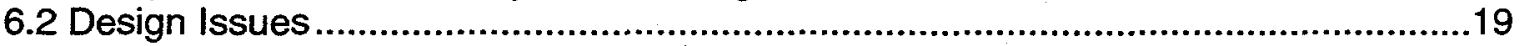

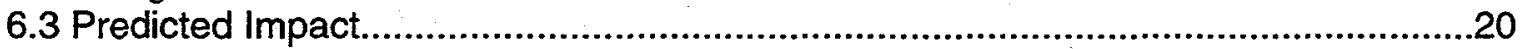

$\begin{array}{ll}7 \text { References } & 20\end{array}$

Appendix A: TRAC Model Component Nomenclature

Appendix B: LOFA (Case 2) TRAC Results

Appendix C: TRAC Standard Input File for LOFA Case 2 (with Beam Shutdown Only)

Appendix D: TRAC Graphics Input File for LOFA Case 2 (with Beam Shutdown Only) 


\section{List of Figures}

Figure 1-1 Decay heat power fractions of full power for various types of blanket modules.

Figure 2-1 Top cross-sectional face map of 6 lumped blanket system modules

Figure 3-1

Primary HR mass flowrate for LOFA with a beam shutdown.

Fixed inlet/outlet header fluid temperatures for LOFA with a beam shutdown.

Figure 3-3

Fixed inlet/outlet header saturation temperatures for LOFA with a beam shutdown

Figure 3-4

Individual module inlet mass flowrates for LOFA with a beam shutdown. 10

Figure 4-1 Figure 4-2

Figure 5-1

Deposited power profiles used in 1-D TRAC system model. 14 Integrated Module 1 power profile.......................................................... 14 System temperature based on evaluation model analysis (linear time scale). 16

Figure 5-2 System temperature based on evaluation model analysis (logarithmic time scale).

\section{List of Tables}

Table 2-1 Six lumped blanket module system model used for the present PSAR analysis. 5

Table 2.5-1 Trip signals used in the LOFA Case 2 simulation...................................6

Table 5-1

Heat-up times to reach onset of bulk boiling for four case studies. 16 


\section{Introduction}

This report is one of a series of reports that document normal operation and accident simulations for the Accelerator Production of Tritium (APT) blanket heat removal system, [1-8]. These simulations were performed for the Preliminary Safety Analysis Report. This report documents the results of simulations of a Loss-of-Flow Accident (LOFA) where power is lost to all of the pumps that circulate water in the blanket region, the accelerator beam is shut off and neither the residual heat removal nor cavity flood systems operate. The accident simulations were performed, using TRAC to model transient behavior of the entire system and an evaluation model to model long term transient behavior in a blanket module. The evaluation model consisted of calculations to estimate the time it would take the APT blanket module to heat to boiling under adiabatic heat up conditions. The masses of lead, aluminum and water in the entire blanket module and the water mass in portions of the primary heat removal loop were estimated using data from the TRAC system model files. A nominal deposited power profile was used to estimate the power added to the system over time.

After the APT beam system shutdown, decay power drops rapidly. Figure 1-1 shows transient decay power after shutdown as a fraction of steady-state power for the 1700 MeV APT design with 13 tungsten ladders [9]. Results from a single long term TRAC system calculation were used to analyze the loss-of-flow accident and to provide starting conditions for the evaluation model. The system calculation provided a transient for total coolant flow having approximately $5 \%$ of the pre-incident flow 60 seconds after initiation of the loss-of-flow-accident.

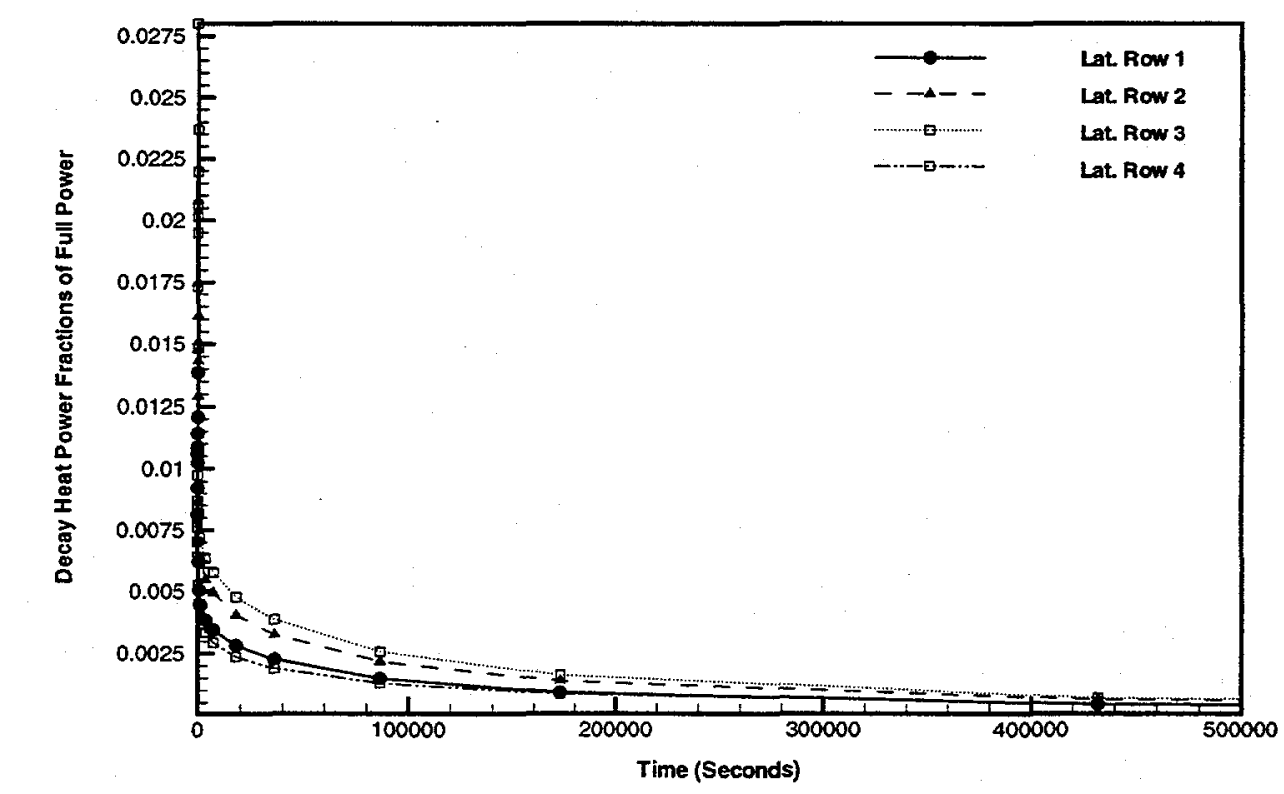

Figure 1-1 Decay heat power fractions of full power for various types of blanket modules. 


\section{TRAC 1-D System Model}

Current blanket system consists of 16 unique blanket modules based on the existing cruciform-type design components (the necessary design specifications required to develop a plate-type set of modules is currently not available but will be used in future revisions to these calculations). Each module is separately connected to the two fixed coolant headers. A lumping strategy was developed based on module similarity, deposited power levels, and locations that resulted in a total of six separate lumped modules and reduced computational effort requirements. The six lumped modules are, respectively: the first-row lateral modules; the second-row lateral modules; the decoupler / Row 1 downstream module; the Row 1 / Row 2 downstream module; the Row 2 / Row 2 downstream module; and the remaining low-power modules, which consist of the upstream module, the four bottom modules, and the two top modules. Figure 2-1 shows cross-sectional face map for the six module blanket system. Table 21 summarizes module description, thermal deposited power, and connection pipe size of each of the six blanket modules as modeled in the one-dimensional lumped approach. Figure A-1 shows the locations of all the six modules and the internal piping connections as included in the one-dimensional TRAC system model. The TRAC components and piping connections for the heat removal (HR), pressurizer, residual heat removal (RHR) blanket coolant systems, and cavity vessel flood system are also shown in Figs. A-2 to A-6. Table A-1 lists all the blanket system components, number of cells for the components, and the component descriptions for the present one-dimensional lumped blanket system model. The present six lumped module TRAC blanket system model includes 170 components and 152 junctions with 10 trip control signals using for the transient loss-of-flow accident (LOFA) simulation. Detailed TRAC system model descriptions are provided in Refs. $[10,11]$.

\subsection{Scenario Description}

Current blanket coolant system has one primary heat removal (HR), one secondary HR, two $100 \%$ primary residual heat removal (RHR), and two $100 \%$ secondary RHR. Both the HR and RHR loops are connected to the large fixed headers (20.5 inch diameter) internal to the target/blanket cavity vessel. Under steady-state normal operating conditions, the blanket module system is connected to a single main primary loop, with three $50 \%$ pumps in parallel. Two pumps are normally operating and the remaining pump is available for immediate startup in the event of failure of a running pump. The coolant loop has two $50 \%$ heat exchangers in parallel. The two RHR primary loops are both sized to accommodate $100 \%$ of the decay heat removal requirements. Currently, the RHR components are sized for approximately $4 \%$ of the full power flow, 1569 $\mathrm{kg} / \mathrm{sec}$, under any design basis accident conditions. Each of the RHR primary loops has one heat exchanger and one pump. The current baseline design has the RHR systems shutdown in standby mode during normal operation to enhance the system's response to some design basis accident scenarios such as loss-of-flow accident (LOFA) and lossof-coolant accident (LOCA). Normal operating conditions for the key blanket system parameters are shown in Appendix A.

For this scenario, it is assumed that the trip signal to shutdown the beam is initiated by a $5 \%$ reduction in pump pressure drop on either of the primary HR pumps. Signal detection occurs within tenths of a second following the initiating event. The trip signal 
is activated approximately 0.2 seconds after the initiating event occurs. A conservative 1 second time delay to account for signal processing is assumed (i.e., best estimate values range within 0.1 to 0.2 second delays). The actual beam shutdown begins to occur at approximately 1.2 seconds after the initiating event occurs. Blanket deposited power levels rapidly decrease to approximately 1 to $3 \%$ of the pre-shutdown levels within 1 second of beam shutdown. The primary RHR pumps and the cavity flood system are assumed to be inoperable. That is, after beam shutdown, no other available accident mitigation options are activated. This scenario was simulated using the integrated 1-D TRAC system model described in Ref. [10] augmented by a simple evaluation model calculation.

As one of the design basis accidents, TRAC analysis was performed for a loss of coolant flow accident due to the loss of power in the primary and secondary HR pumps. This was simulated by restarting a transient calculation from steady-state normal operation results obtained with the one-dimensional six integrated module blanket system model. For initiation of the LOFA simulation, the two primary and secondary HR pumps are tripped off without time delay at time zero. For this accident scenario, it was further assumed that the primary and secondary RHR pumps are not started even though the primary and secondary RHR pumps are supplied with on-site backup diesel power as well as a dc backup power supply. Detailed control signals for the key component operations are provided in Section 2.6.

\subsection{Model Upgrades}

Component action tables for the break component and check valves were updated to activate the action signals for hardware components such as check valves, pumps, heat structures in the six blanket modules, and fill boundaries to simulate the LOFA scenario. Normal steady-state operation conditions can be obtained by using either transient mode or constrained steady-state mode with definition of the monitoring parameters of specific components. For the present accident analyses the constrained steady-state (CSS) capabilities were added to the TRAC normal operation system model. Signal variables and trip signals of the system model were also updated by using the control procedure for the LOFA scenario as described in Ref. [10].

\subsection{Initial Conditions}

Before simulating the accident condition, steady-state results under normal operating (NO) conditions are required to provide the restart input to the transient simulation model of the LOFA. The steady-state NO conditions of the APT blanket system were obtained by specifying maximum pump rotational speeds of the two HR pumps with desired total liquid flowrate using as a monitoring parameter under the constrained steady-state (CSS) controller option. Initial temperatures for the pressurizer and the RHR system components were $40 \mathrm{C}$. Steady-state values under normal operating conditions for the key system parameters of the APT blanket system are listed in Appendix A with additional details provided in Ref. [1]. 


\subsection{Transient Boundary Conditions}

The TRAC system model for the steady state NO calculations is documented in Refs. $[10,11]$. The steady-state NO TRAC run was restarted in a transient mode to initiate the LOFA simulation. To establish an appropriate fly-wheel inertia for the primary heat removal pumps a parametric study was performed (i.e., varying the TRAC pump parameters) using the TRAC system model with the integrated six modules under the LOFA conditions. The inertia terms were set such that a $5 \%$ of pre-incident flowrate is achieved at $60 \mathrm{sec}$ after pump deactivation occurs. System operation conditions of the secondary systems were simulated by using fill boundary condition with transient mass flowrate table at the inlet of the secondary sides of the two HR heat exchanger components.

\subsection{Trips and Controls}

Power to the two primary and secondary HR pumps was tripped off immediately to initiate the LOFA scenario, and the beam power was tripped off with 1.0 seconds time delay after the pressure difference between the suction side and the discharge side of each primary HR pump was reduced to $0.70788 \mathrm{MPa}$ (102.7 psia) corresponding to $95 \%$ of the total pressure difference across the HR pump. The beam trip was simulated by changing the steady-state NO power in the heat structure of each blanket module to the time dependent decay power curve. Figure 1-1 shows transient decay power curves for the blanket heat structures. The beam power trips actually occurred about 1.21 seconds after the initiation of the transient accident so that the time to reduce $5 \%$ of the pressure difference across the HR pump is about 0.21 second. The RHR pumping power signal was not actuated. Check valves on the discharge sides of the HR pumps were actuated to avoid flow reversal immediately after the initiation of the LOFA accident. If flow reversal occurs during the accident condition, the HR and RHR check valves were set to be closed immediately. Table 2.5-1 lists all the trip signals and component controls used for the LOFA simulation.

\subsection{TRAC Version}

This transient model was run using TRAC-PF1/MOD2 version 5.4.28a [12]. A modified version of TRAC to generate graphics files was employed [11]. 
Table 2-1 Six lumped blanket module system model used for the present PSAR analysis.

\begin{tabular}{|c|c|c|c|}
\hline $\begin{array}{l}\text { Six } \\
\text { Lumped } \\
\text { Modules }\end{array}$ & $\begin{array}{c}\text { Prototypic } 16 \text { Full Blanket } \\
\text { Modules }\end{array}$ & $\begin{array}{c}\text { Thermal Deposited } \\
\text { Power } \\
\text { Downflow / Upflow / } \\
\text { Total Power }\end{array}$ & $\begin{array}{l}\text { Pipe } \\
\text { Size } \\
\text { (inch) }\end{array}$ \\
\hline Module 1 & $\begin{array}{c}\text { Front } 1^{\text {st }} \text { Lateral Dec. / Row } 1 \\
\text { Module } \\
\text { Back } 1^{\text {st }} \text { Lateral Dec. / Row } 1 \\
\text { Module }\end{array}$ & $\begin{array}{c}.222 \mathrm{MW} / \\
15.768 \mathrm{MW} / \\
23.990 \mathrm{MW}\end{array}$ & 7.500 \\
\hline Module 2 & $\begin{array}{l}\text { Front } 2^{\text {nd }} \text { Lateral Row } 2 / \text { Row } 3 \\
\text { Modules } \\
\text { Back } 2^{\text {nd }} \text { Lateral Row } 2 / \text { Row } 3 \\
\text { Modules }\end{array}$ & $\begin{array}{l}3.060 \mathrm{MW} / \\
7.660 \mathrm{MW} / \\
10.720 \mathrm{MW}\end{array}$ & 4.750 \\
\hline Module 3 & $\begin{array}{l}1^{\text {st }} \text { Downstream Dec. / Row } 1 \\
\text { Module } \\
\end{array}$ & $\begin{array}{c}0.744 \mathrm{MW} / 2.812 \mathrm{MW} / \\
3.556 \mathrm{MW} \\
\end{array}$ & 3.750 \\
\hline Module 4 & $\begin{array}{l}2^{\text {nd }} \text { Downstream Row } 1 / \text { Row } 2 \\
\text { Module }\end{array}$ & $\begin{array}{c}3.924 \mathrm{MW} / 5.412 \mathrm{MW} / \\
9.336 \mathrm{MW}\end{array}$ & 5.375 \\
\hline Module 5 & $\begin{array}{c}3^{\text {rd }} \text { Downstream Row 2/ Row } 2 \\
\text { Module }\end{array}$ & $\begin{array}{c}1.355 \mathrm{MW} / 1.811 \mathrm{MW} / \\
3.167 \mathrm{MW} \\
\end{array}$ & 6.000 \\
\hline Module 6 & $\begin{array}{c}\text { Low Power Modules } \\
\text { Blanket Upstream Dec. / Row } 2 \\
\text { Module } \\
\text { Lower Front Dec. / Row } 2 \text { Module } \\
\text { Lower Front Row } 2 \text { / Row } 2 \\
\text { Module } \\
\text { Lower Back Dec. / Row } 2 \text { Module } \\
\text { Lower Back Row } 2 \text { / Row } 2 \\
\text { Module } \\
\text { Upper Front Row } 2 \text { / Row } 2 \\
\text { Module } \\
\text { Upper Back Row } 2 \text { / Row } 2 \\
\text { Module } \\
\end{array}$ & $\begin{array}{c}\text { (Horizontal Flow) } \\
0 \mathrm{MW} / \\
5.712 \mathrm{MW} / \\
5.712 \mathrm{MW}\end{array}$ & 3.875 \\
\hline $\begin{array}{l}\text { Total } \\
\text { Deposited } \\
\text { Power }\end{array}$ & & $\begin{array}{c}17.305 \mathrm{MW} / 39.175 \\
\mathrm{MW} / 56.480 \mathrm{MW}\end{array}$ & \\
\hline
\end{tabular}


Table 2.5-1 Trip signals used in the LOFA Case 2 simulation.

\begin{tabular}{|c|c|c|c|}
\hline $\begin{array}{c}\text { Trip } \\
\text { Signal } \\
\text { ID }\end{array}$ & $\begin{array}{c}\text { Control } \\
\text { Component } \\
\end{array}$ & $\begin{array}{l}\text { Signal Variables } \\
\text { ID Number } \\
\text { (Control Variable) }\end{array}$ & Signal Values \\
\hline 101 & $\begin{array}{l}\text { Fill boundary for } \\
\text { secondary heat } \\
\text { exchanger side }\end{array}$ & 1 (time) & $1.0 \times 10^{-6} \mathrm{sec}$ \\
\hline 102 & $\begin{array}{l}\text { Cavity flood } \\
\text { system valve }\end{array}$ & $\begin{array}{c}10 \text { (cavity vessel } \\
\text { pressure) }\end{array}$ & valve closed \\
\hline 103 & RHR check valve & $\begin{array}{c}1 \text { (time) and action } \\
\text { table (S-shaped forcing } \\
\text { function) }\end{array}$ & $1.0 \times 10^{-6} \mathrm{sec}$ \\
\hline 104 & Heat structure & $\begin{array}{l}4 \text { (the pressure } \\
\text { difference between the } \\
\text { suction and discharge } \\
\text { sides of the primary HR } \\
\text { pump) and time delay }\end{array}$ & $\begin{array}{l}1.0 \text { sec time delay after } 5 \% \\
\text { reduction of the pressure } \\
\text { difference across the } \\
\text { primary HR pump }\end{array}$ \\
\hline 105 & RHR pump & not actuated & \\
\hline 106 & Primary HR pump & no time delay & $1.0 \times 10^{-6} \mathrm{sec}$ \\
\hline 107 & $\begin{array}{c}\text { Primary HR check } \\
\text { valve }\end{array}$ & $\begin{array}{l}1 \text { (time) and action } \\
\text { table (S-shaped forcing } \\
\text { function) }\end{array}$ & $1.0 \times 10^{-6} \mathrm{sec}$ \\
\hline 108 & $\begin{array}{l}\text { Cavity vessel } \\
\text { check valve }\end{array}$ & 1 (time) & valve closed \\
\hline 109 & $\begin{array}{c}\text { Cavity vessel } \\
\text { check valve on } \\
\text { the HR side } \\
\end{array}$ & 1 (time) & valve closed \\
\hline 110 & $\begin{array}{l}\text { Cavity vessel vent } \\
\text { valve } \\
\end{array}$ & $\begin{array}{l}7 \text { (pressurizer } \\
\text { pressure) }\end{array}$ & valve closed \\
\hline
\end{tabular}




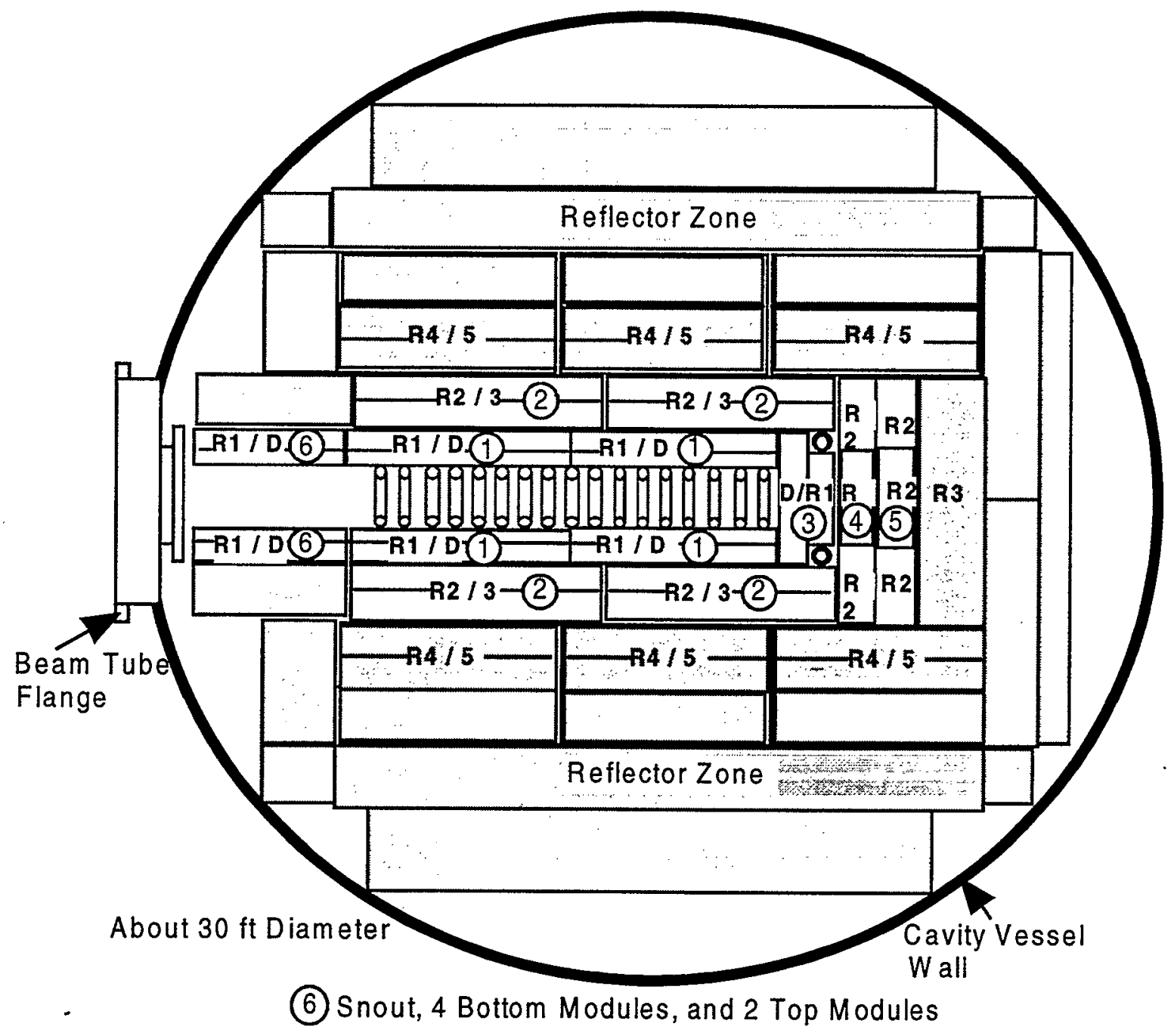

Figure 2-1 Top cross-sectional face map of 6 lumped blanket system modules 


\section{TRAC System Model Results}

The LOFA model to simulate the loss of power for the primary and secondary HR pumps was run for 5600 seconds after the initiation of the accident. The TRAC calculations set the flowrate on the secondary side of the HR system such that a flow decay similar to the primary HR flow decay occurs for times up to approximately 100 seconds, while beyond 100 seconds its flowrate is set to zero. However, credit was taken for the thermal sink capacity of the light water trapped on the shell side of the primary HR heat exchangers. The heat capacity of water residing within the shell side of the primary heat exchangers represents a sizable portion of the total available heat capacity of the composite system (i.e., blanket module metal, module water, HR primary water, shell side water). Figures 3-1 through 3-4 show selected output from the TRAC results. Based on these figures the following brief summary can be seen:

- The initial primary HR loop mass flowrate of $1569 \mathrm{~kg} / \mathrm{s}$ drops to a natural circulation value of approximately $12.8 \mathrm{~kg} / \mathrm{s}$ after 2000 seconds as shown in Fig. 3-1. This flowrate gradually decreases (e.g., by 5600 seconds it is $12.0 \mathrm{~kg} / \mathrm{s}$ ) as the blanket cools and the driving force for the circulation diminishes.

- The fluid temperature difference between fixed headers is related to the overall thermal driving forces available to sustain natural circulation within the primary HR loop as shown in Fig. 3-2. Due to the presence of a check valve within the RHR primary loop, RHR flow remains stagnant. The temperature difference is $4.0 \mathrm{C}$ at 2000 seconds and $3.5 \mathrm{C}$ by 5600 seconds with an overall system heat-up rate of approximately $2 \mathrm{C}$ per hour.

- Based on the fluid saturation temperatures presented in Fig. 3-3 and assuming the quasi-steady state behavior persists (i.e., constant heat-up rate), saturated boiling conditions are estimated to be reached in less than 60 hours. Sixty hours is an upper limit since the heat-up rate will continue to climb as the natural circulation rate diminishes. Figure 3-3 provides the fluid saturation temperatures at the fixed headers, due to their hydrostatic pressure increase saturation temperatures are approximately $170 \mathrm{C}$ near the heated surfaces within the blanket bins.

- At the individual blanket module level, mass flowrates remain positive (i.e., no flow reversals are observed) as shown in Fig. 3-4. At these very low decay power levels metal temperatures remain only a few degrees above the loçal free stream coolant temperatures.

- As mentioned above, TRAC predicts a diminishing natural circulation pattern with a very slow heat-up of the coolant.

More complete results from the TRAC system calculation for the entire 5600 seconds of the transient are shown in Appendix $B$ and are discussed in the following sections. 


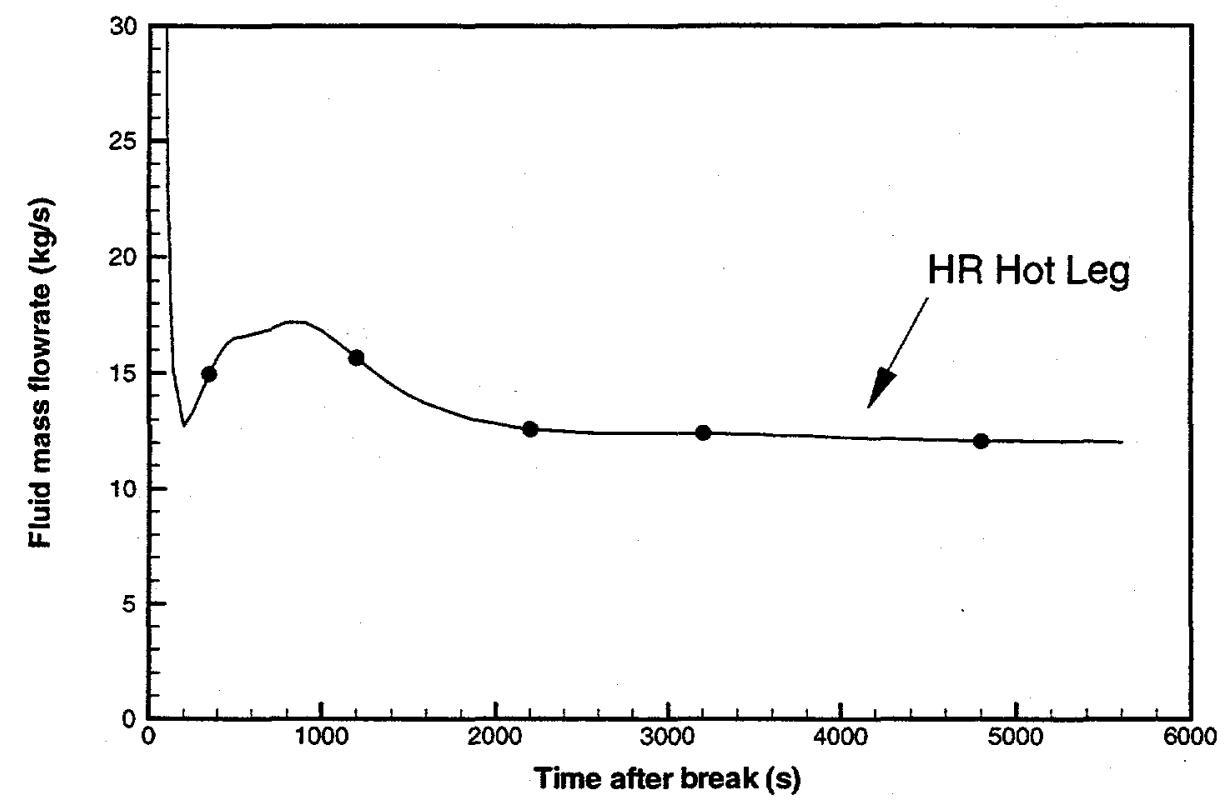

Figure 3-1 Primary HR mass flowrate for LOFA with a beam shutdown.

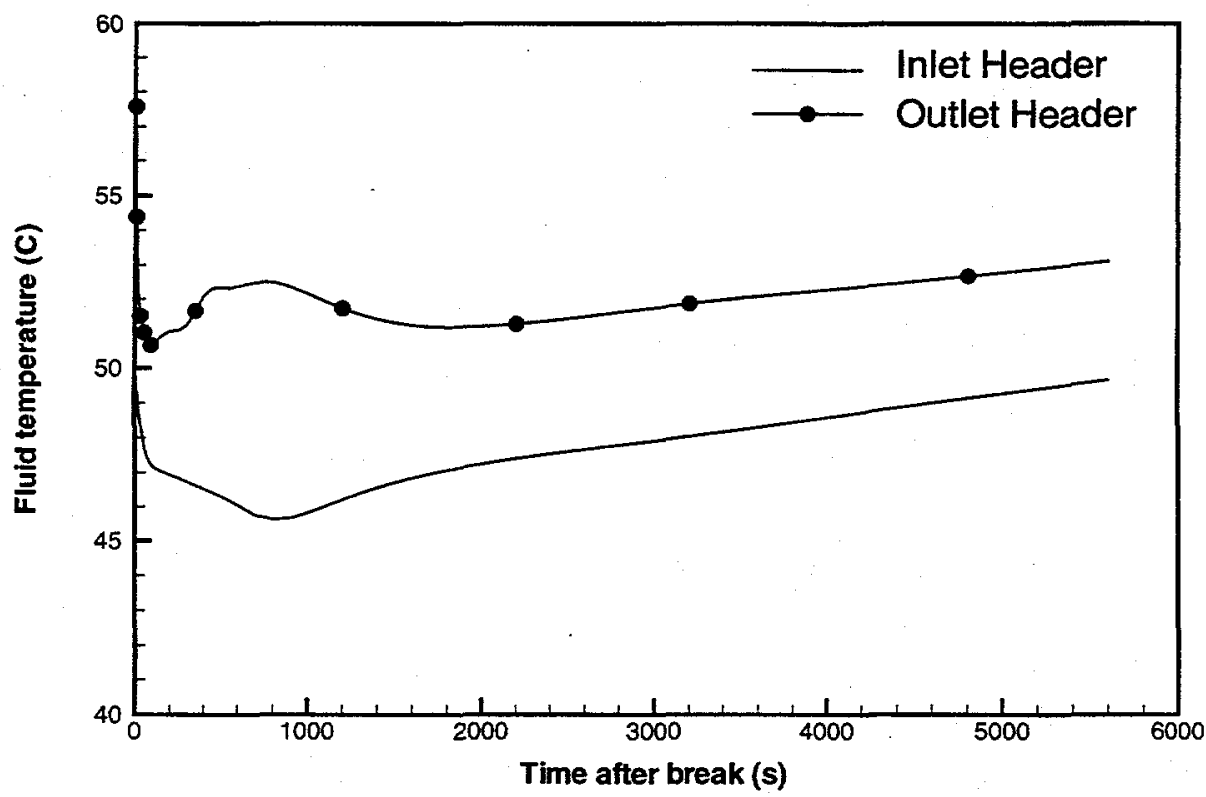

Figure 3-2 Fixed inlet/outlet header fluid temperatures for LOFA with a beam shutdown. 


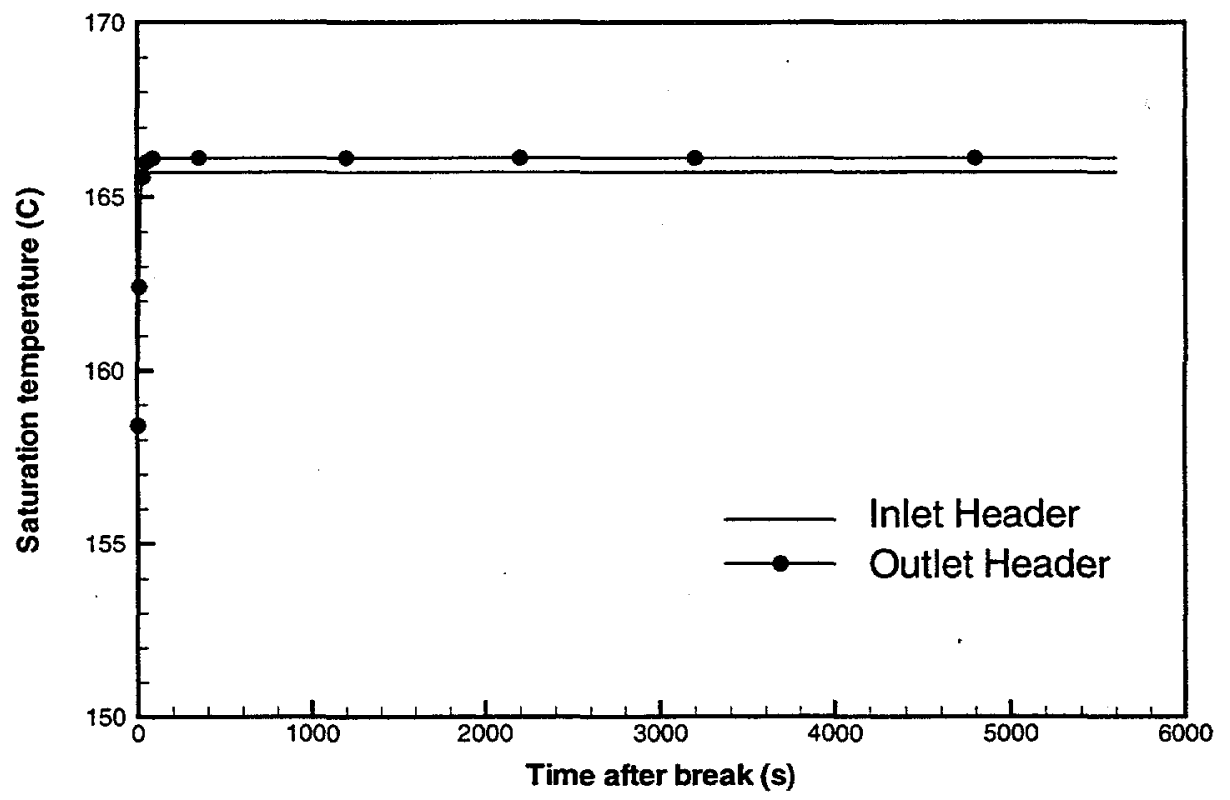

Figure 3-3 Fixed inlet/outlet header saturation temperatures for LOFA with a beam shutdown.

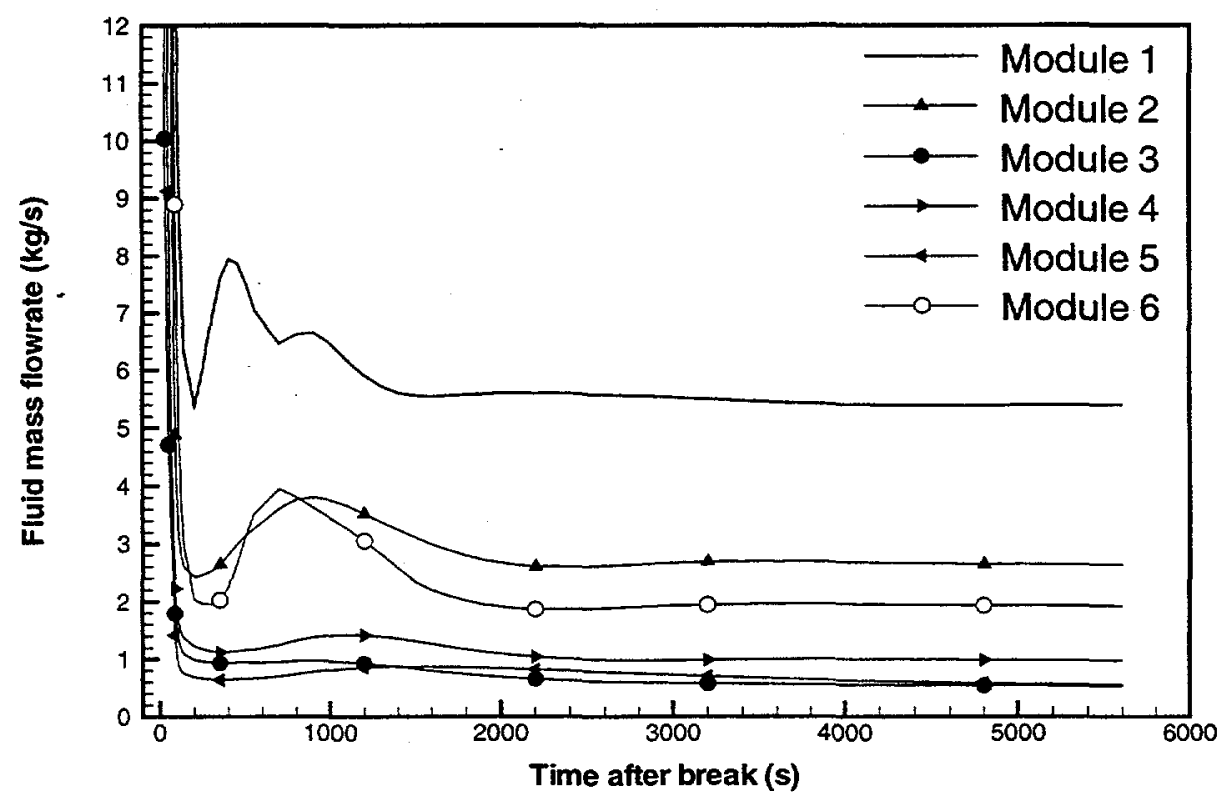

Figure 3-4 Individual module inlet mass flowrates for LOFA with a beam shutdown. 


\subsection{Modules}

Figure A-1 shows the component layout of the internal blanket module system used in the TRAC system model. All of the modules are connected to the fixed headers. Primary coolant water is supplied to the hot blanket modules through the inlet fixed header and returned to the outlet fixed header. These two fixed headers are located inside the cavity vessel. Figures B-2a to B-7d show the transient results for pressures, fluid temperatures, liquid subcoolings, and void fractions for the three plenums (inlet, middle, and exit plenums) of each blanket module. None of the module channels have any void fraction within the liquid coolant through the transient accident period. The graphical results show a rapid transient response in the fluid pressure in the flow channels of all six blanket modules within the first few seconds of the accident. Fluid pressure increases at the module plenums following initiation of the LOFA as flow decays and the fluid reaches hydrostatic conditions. Initially, the fluid temperature in the modules rapidly decreases as $40 \mathrm{C}$ water from the pressurizer enters the modules. Over the next several minutes, the fluid temperature at the module inlet plenums slowly decreases while fluid temperatures at the outlet plenumis increase 1 to $4 \mathrm{C}$ from decay heat generated in the modules. After 5 to 20 minutes depending on the module, the fluid temperatures at the module outlets decrease and begin to follow the decay heat curves.

Figs. B-26 through B-43 show detailed graphical results for the.solid structures of the six blanket modules. Maximum lead temperature was $152 \mathrm{C}$ during normal operation condition near the mid-plane of the first lateral module. Generally, solid temperatures were decreased quickly during the first few seconds after initiation of the loss of power, and then increase about 2 to $5 \mathrm{C}$ over the next 5 to 20 minutes. The solid temperatures slowly approached steady-state equilibrium values following the trend of the decay heat curve shown in Fig. 1-1. Maximum aluminum cladding surface temperature was $93.5 \mathrm{C}$ during normal operation condition at the mid-plane of the blanket module 1 and rapidly dropped to the minimum value (about $50 \mathrm{C}$ ) near the exit of the module 1 channel at the transient time of 50 seconds. Trends in the metal temperatures follow those in the cooling water with a rapid initial decrease followed by a slight increase over the next several minutes and a final slow decrease throughout the rest of the accident transient.

\subsection{HR Loop and Pressurizer}

Figure A-2 shows the HR system component layout used for the one-dimensional TRAC system model. Transient behaviors for key thermal-hydraulic parameters of the two internal fixed headers are graphically shown in Figs. B-1a to B-1d. As the primary HR liquid flowrate decreases quickly with the loss of pumping power, the hot leg pressure increased rapidly to 107 psia at about 60 seconds after the loss of power. The hot-leg fixed header pressure is slightly higher than the cold-leg fixed header pressure by the elevation height difference. Cold-leg fixed header temperature decreases by $2.5 \mathrm{C}$ during first 35 seconds after the accident due to the incoming pressurizer cold water (40 C) and the rapid decay of in primary coolant water flowrate. Both of the fixed headers had zero voidage during the entire transient simulation period.

Transient behavior for important thermal-hydraulic parameters of most external balance of plant (BOP) components are shown in Figs. B-8a to B-25e. The results show that 
liquid flowrates for the two primary HR pumps are reduced to about $5 \%$ of the normal full flowrates through the primary HR loop at about 60 seconds after the loss of pumping power. Initially, the fluid temperature at the pump suction side decreases rapidly as shown in Fig. B-8b as cold water from the pressurizer $(40 \mathrm{C})$ enters the loop. The temperature increases about $1.5 \mathrm{C}$ between 10 and 20 minutes into the accident as water heated in the modules circulates to the pumps. At this time, coolant liquid flowrate of the primary $\mathrm{HR}$ system is only about $13 \mathrm{~kg} / \mathrm{s}$ from natural convection. Figs. B-9a to $\mathrm{B}-10 \mathrm{e}$ show the transient behaviors of the two primary HR pumps during the LOFA simulation time. The two HR pumps show near-symmetric behavior with no cavitation during this accident.

Figure A-3 shows the component layout for the pressurizer system connected to the inlet fixed header external to the cavity vessel. The initial fluid temperature of the pressurizer was assumed to $40 \mathrm{C}$. Figs. B-15a to B-15e show the transient behavior of the key thermal-hydraulic parameters for the pressurizer and surge line during the loss of the pumping power accident. From the results, the liquid in the pressurizer was not drained completely during the accident so that gas inside the pressurizer is not entrained into the heat removal system loop. Void fraction in the surge line of the pressurizer was zero during the transient accident to satisfy the design requirement for the pressurizer component. No void was entrained into the primary HR loop through the surge line of the pressurizer during the entire transient time of the LOFA accident.

\subsection{RHR Loop}

Figure A-4 shows the TRAC layout for the RHR system. The initial temperature for the RHR system was $40 \mathrm{C}$. The RHR system has check valve on the RHR pump discharge side to prevent flow reversal during the LOFA scenario. During the LOFA Case 2 accident, the RHR system remains stagnant at the initial temperature.

\subsection{Cavity Vessel and Flood System}

Figure A-5 shows the TRAC component layout that shows the heat transfer connections between the blanket module heat structures and the cavity vessel. Figure A-6 shows the TRAC component layout for the cavity vessel and flood system. During the LOFA Case 2 accident, the cavity flood system pool is stagnant with an ambient temperature of $40 \mathrm{C}$. The cavity vessel has no liquid phase with ambient temperature saturated at about 5 psia during the LOFA accident scenario.

\section{Evaluation Model}

The transient behavior of the blanket system was predicted using the integrated system model out to approximately 5600 seconds into the LOFA (i.e., slightly over 1.5 hours). By this point in time a quasi-steady state behavior had been achieved. Based on these system model results and a supporting simplified conservative evaluation model (EM), the transient behavior was extended out to 25 days beyond the initiating event for a variety of case studies. This solution strategy was chosen based on the belief that simulation times on the order of days were unattainable using the integrated system model and that the predictive capability of TRAC to accurately model the natural circulation patterns diminishes as the temperature driving forces diminish. The EM 
approach uses the TRAC results at the early times where the solution is still considered valid and extends it to long times through conservative modeling assumptions.

In the 1-D TRAC system model, all the heat sources and sinks along the length of the coolant loops are not modeled in detail. Consequently, for safety analyses, natural circulation behavior predicted by this model should not be relied on when thermal driving forces become small. Therefore, the TRAC analyses beyond $t=5600$ seconds into the transient are not used. At this time, the flow is assumed to have stagnated and lumped energy balance calculations are performed to estimate the time to saturation. Various adiabatic cases were studied by varying the amount of coolant participating in the heatup process.

To perform this portion of the analysis, deposited power decay curves were generated and integrated over time to determine the total amount of heat released as a function of time. Figure 4-1 summarizes the decay curves used for the six composite lumped modules in the TRAC system model. For the purposes of this calculation, the deposited power curve for Module 1 was used to estimate the average deposited power. As shown in Fig. 4-1, this decay curve falls approximately in the middle of the possible values and represents close to the average power decay. This curve was integrated over time to obtain the total power deposited in the system. Figure 4-2 shows the integrated Module 1 decay curve starting at 5400 seconds. The total power was then distributed to the system mass and the temperature increase calculated. For these calculations, $6.46 \times 10^{4} \mathrm{~kg}$ of lead and $3.64 \times 10^{3} \mathrm{~kg}$ of aluminum were determined to be present in the APT blanket region.

Starting with a uniform system temperature of $50 \mathrm{C}$, sensible heat-up calculations were performed assuming that increasing amounts of available coolant participate in the heatup process.

Four cases were investigated:

1. Power deposition in the blanket metal structures and the water in the module flow channels;

2. Power deposition in the metal and flow channel water plus the water within the pjping from the fixed headers to the blanket modules;

3. Power deposited in the metal, blanket water and piping water plus the water in the primary heat removal loop;

4. Power deposited in the metal, blanket water, piping water and primary heat removal loop water plus the water in the secondary side of the primary loop heat exchangers.

In all four cases, it was assumed that the homogenized system of metal and water could instantaneously reach equilibrium with the deposited power. As would be expected, these four cases are in the order of decreasing severity. Assuming that more water is available to absorb some of the deposited energy decreases the rate of temperature rise in the system. For each case, calculations were made until fluid saturation was reached. From the hydrostatic pressure in the module channels, the saturation temperature was estimated to be $170 \mathrm{C}$. The calculations assume that adiabatic heating starts at 5400 seconds. 


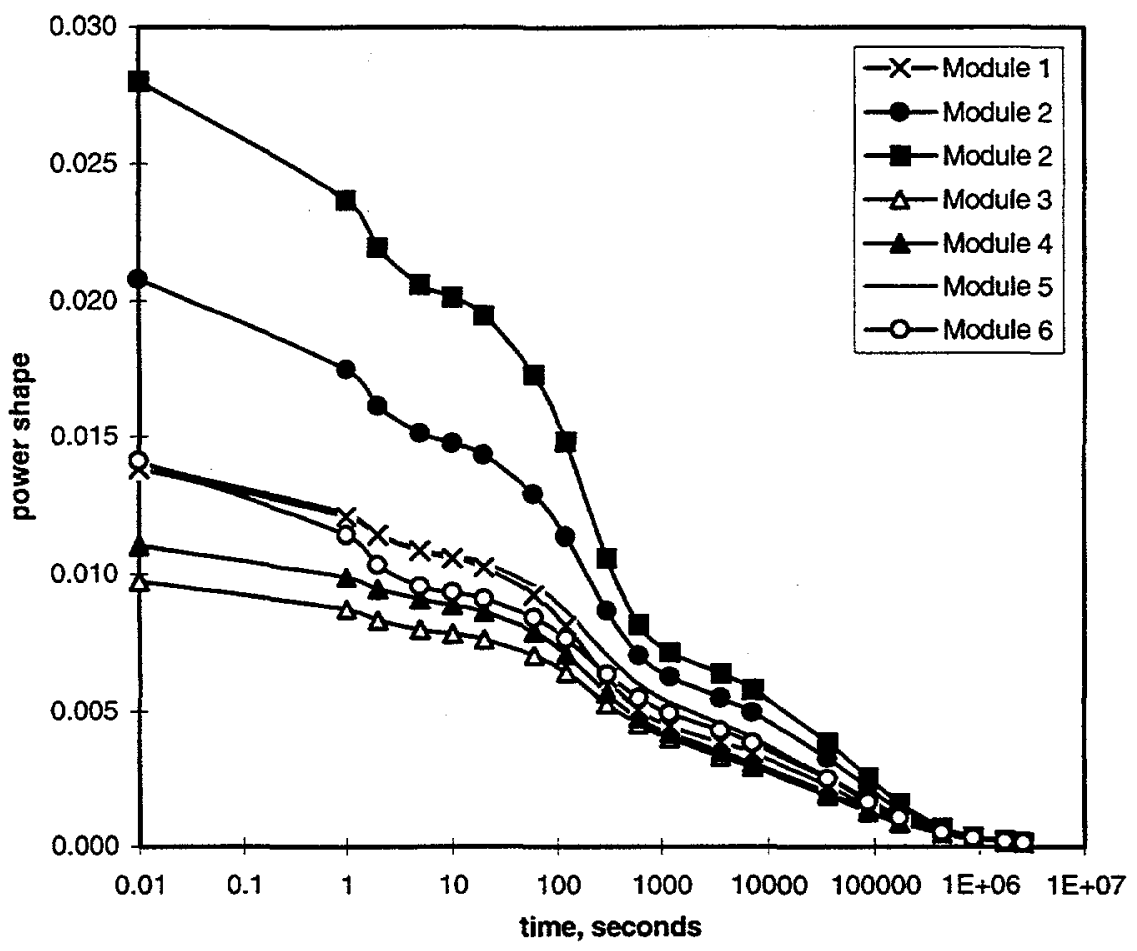

Figure 4-1 Deposited power profiles used in 1-D TRAC system model.

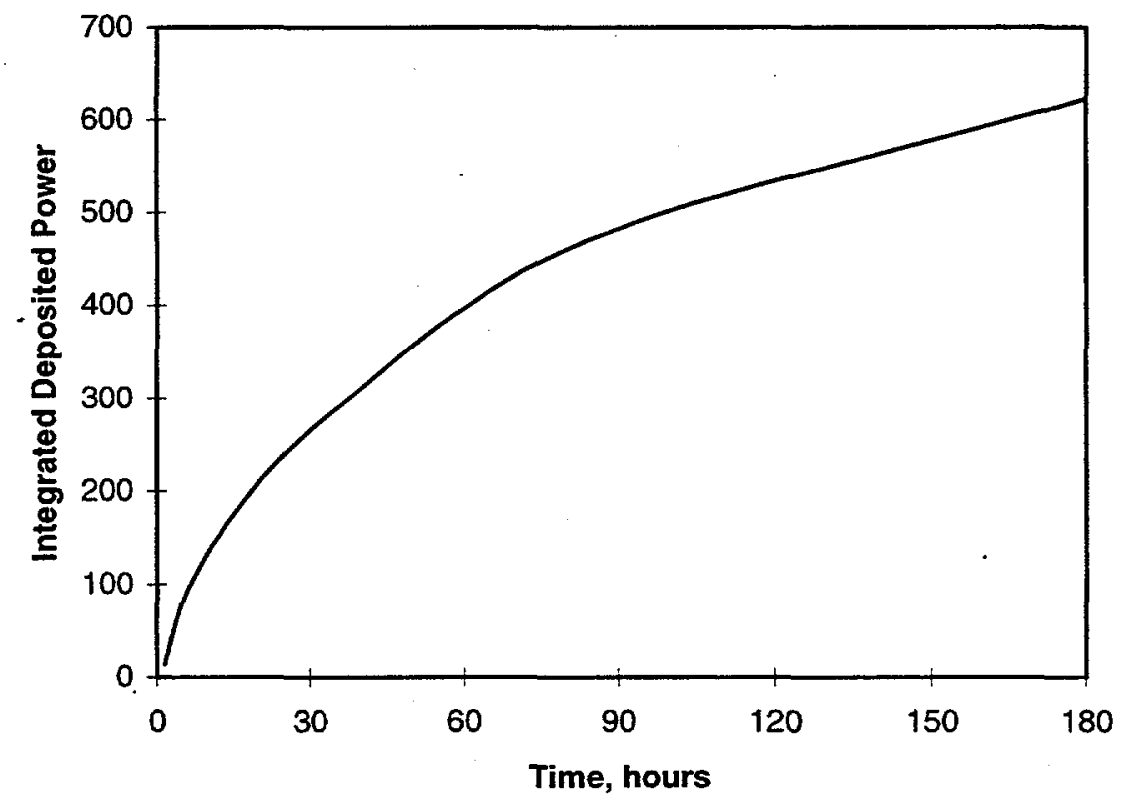

Figure 4-2 Integrated Module 1 power profile. 


\section{$5 \quad$ Evaluation Model Results}

The times to reach saturation conditions are tabulated in Table 5-1 and the transient responses are plotted in Figs. 5-1 and 5-2. Figure 5-2 plots the data using a logarithmic scale for the time to better separate the two cases where the system quickly heats up. The amount of water used in each of the case calculations is listed in Table 5-1.

For an extreme case that assumes all of the power is deposited entirely in the metal and the water present in the module cooling channels, the temperature reaches $170 \mathrm{C}$ within about 6 hours. At the other extreme, taking credit for all of the water in the blanket modules, in the primary heat removal system and in the secondary side of the primary heat exchangers, the heating time extends to greater than 25 days. The actual situation clearly lies between these two extremes. In the early part of the LOFA accident, there is still significant water circulation as the pumps coast down. Therefore, an analysis using all of the available coolant is appropriate (case 4). However, later in the accident, as the forced circulation stops, deposited heat is primarily absorbed by the blanket metal and the water in the blanket modules (case 1). As the blanket modules become hotter than the rest of the primary coolant circulation loop a natural convection flow around the loop is established. Therefore, we expect all of the coolant inventory to participate to some extent in the heat transfer process. Assuming that the actual behavior is bounded by the two intermediate cases analyzed (cases 2 and 3 ), we would estimate that it will take on the order of several days for the blanket module to heat to boiling when flow is lost in the primary cooling system.

Results from this simple analysis then support the belief that one or more days are available to take corrective actions prior to reaching saturation conditions. At the very low decay power levels one plus days after beam shutdown (i.e., approximately $0.2 \%$ or less), boil-off rates will significantly extend the corrective action period prior to experiencing the onset of temperature excursions within the blanket module materials.

Without taking any corrective measures, the above results indicate that peak metal temperatures for lead and aluminum within the bins of the blanket modules remain below their local fluid saturation temperatures for one or more days (i.e., approximately $170 \mathrm{C})$. Current thermal/hydraulic design criteria impose transient metal temperature limits on lead and aluminum of $327.5 \mathrm{C}$ and $150 \mathrm{C}$, respectively, based on a limit for no more than a $10 \mathrm{k}$ hour exposure.

In the above calculations, credit was taken only for the safety class beam shutdown system. The above conservative calculations indicate that no margin exists to prevent the loss of coolable geometry unless some sort of corrective measures are taken within the first one or two days. This duration of time is very long (60 hours to just reach the onset of bulk boiling) and it is unrealistic to assume that the accident will be allowed to progress this long without additional administrative measures, such as:

- restoring $A C$ power to the facility;

- bringing in temporary power supplies to operate the RHR or cavity flood systems;

- replenishing primary HR coolant that is boiled-off through purification lines; or

- reducing system pressure using controls to the pressurizer gas supply system. Reducing system pressure to atmospheric would allow the onset of bulk boiling to occur at approximately $120 \mathrm{C}$; thus, maintaining a coolable blanket geometry with the impact of reducing the available boil-off times that are significant. 
Based purely on the conservative exposure assessment above, the RHR or cavity flood systems would not in-and-of-themselves be required to be designated a safety-class function. However, the potential loss-of-coolable blanket module geometries could result in a significant impact to the neighboring target ladders. To ensure no unwanted side-effects occur, either the RHR system or the cavity flood system should be designated a safety-class function. For this particular event sequence, the choice is somewhat arbitrary. However, based on considerations to be discussed under event sequence \#4, the RHR system becomes the preferred choice for mitigation. The RHR system is design for operation in standard shutdown modes; whereas, the cavity flood system is design as an engineered safety system that would require additional maintenance be performed prior to restarting the facility.

Table 5-1 Heat-up times to reach onset of bulk boiling for four case studies.

\begin{tabular}{|c|c|c|c|c|}
\hline Case & 1 & $\mathbf{2}$ & $\mathbf{3}$ & $\mathbf{4}$ \\
\hline $\begin{array}{c}\text { Material } \\
\text { Considered }\end{array}$ & $\begin{array}{c}\text { Modules } \\
\text { only }\end{array}$ & $\begin{array}{c}\text { plus internal } \\
\text { piping }\end{array}$ & $\begin{array}{c}\text { plus primary } \\
\text { HR piping }\end{array}$ & $\begin{array}{c}\text { plus shell } \\
\text { side of HXs }\end{array}$ \\
\hline Water, kg/10 & 6.97 & 17.88 & 65.99 & 113.23 \\
\hline $\begin{array}{c}\text { Time to reach } \\
\mathbf{1 7 0 ~ C}\end{array}$ & 6 hours & 17 hours & 178 hours & $>25$ days \\
\hline
\end{tabular}

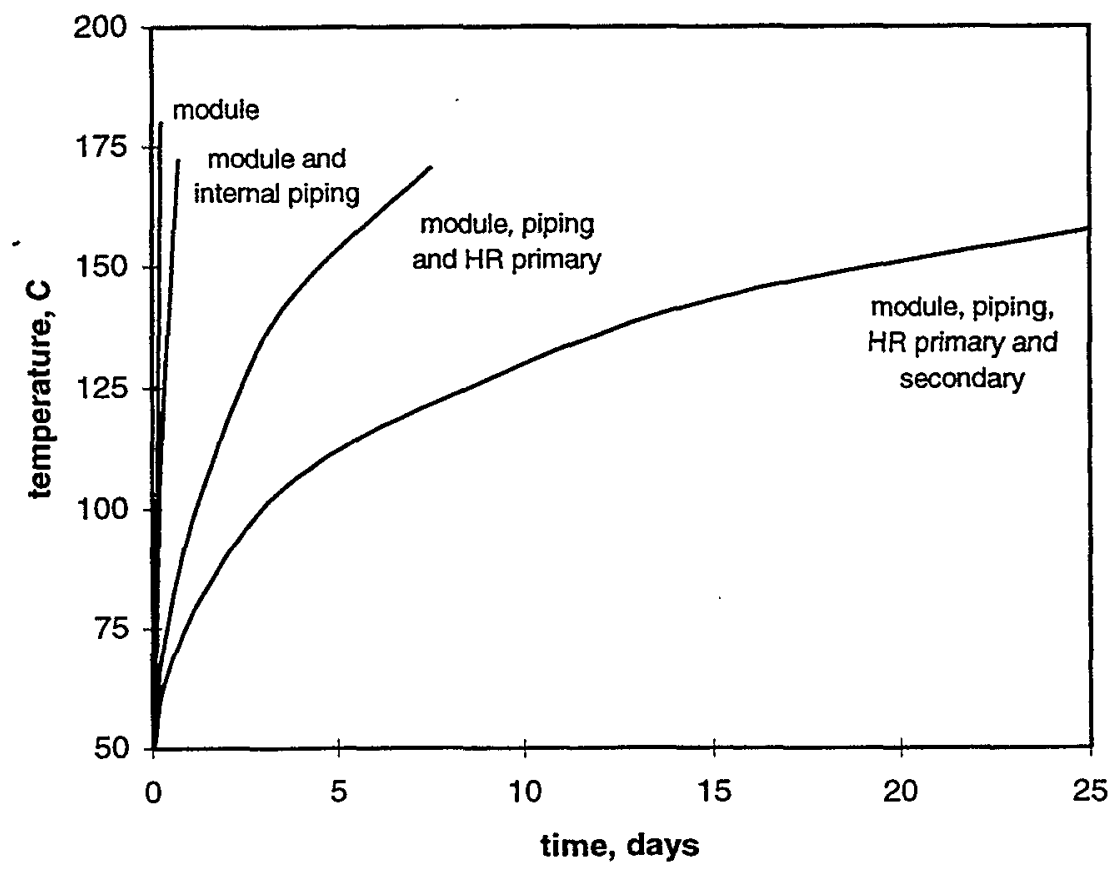

Figure 5-1 System temperature based on evaluation model analysis (linear time scale). 


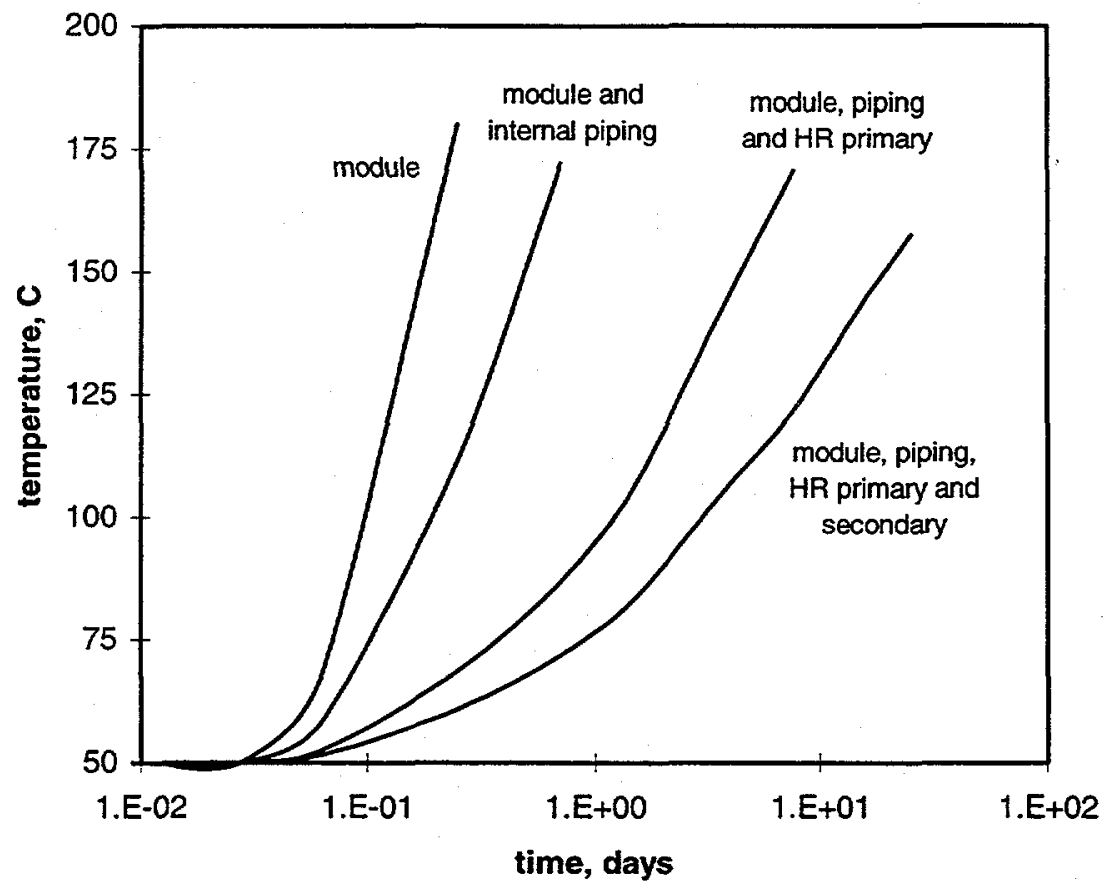

Figure 5-2 System temperature based on evaluation model analysis (logarithmic time scale).

\section{Conclusions}

Results are presented for an accident analyses of a LOFA initiated by loss-of-power with beam shut down but without RHR or cavity flood. Prevention of the release of radioactive material to the environment is associated with maintaining a coolable blanket geometry throughout the event sequence. BDBA event sequences, those without either an active intact RHR or cavity flood system, result in the loss of a coolable blanket geometry. The frequencies of all such event sequences are estimated to be in the beyond extremely unlikely range.

For the LOFA Case 2 analysis, the following SSC is credited:

- beam shutdown is determined to serve a safety class function.

The following technical safety requirements (TSRs) are identified during the LOFA analyses:

- The beam must be shut down when the flow in the blanket primary HR coolant loop is $\mathrm{XX} \%$ of the nominal flow. This is the theoretical limit and the actual limit must be set accounting for the instrument errors and instrument delays. It is conceivable that further delay can be accommodated while preventing the loss in coolable blanket geometry. However, additional analyses are needed to justify further delays. The beam shutdown based on the flow rate reduction is a safety class TSR.

In the LOFA Case 2 analyses, all the consequence calculations are performed conservatively. In the quantification of the control points, in general, best-estimate analyses (TRAC) are used. 
The following are some of the planned future analyses to supplement the results presented in this appendix:

- Assessment of the TRAC lumping strategies by additional component analyses driven by the boundary and initial conditions obtained from systems analyses. Note that the LOFA is a slow transient and the lumping strategy based on quasi-steady calculations is probably adequate. Nonetheless, this must be demonstrated by a few transient component and sub-system analyses.

- Verification of TRAC constitutive packages for low flow conditions using representative separate effects data.

- Sensitivity analyses to support quantification of safety margins and uncertainties.

\subsection{Comparison to Thermal/Hydraulic Design Criteria}

Simulations performed using the TRAC system model and the FLOWTRAN-TF detailed bin model show that the APT blanket modules maintain a coolable geometry during the LOFA scenario. The thermal/hydraulic $(T / H)$ design criteria, along with the basis for their development, is discussed in Refs. [13]. For LOFA the T/H onset criteria are based on meeting very strict phenomenological limits with a high degree of confidence, as follows:

- for local heated surfaces within the module components, the onset-of-significantvoids [OSV]) at a three sigma confidence level; and

- for the remaining unheated piping sections of the blanket system, the onset-of-bulkboiling $[O B B]$ ) at a three sigma confidence level.

Additional (steady-state derived) material design criteria are imposed on the maximum lead and aluminum (Series 6061 - Type T6) metal temperatures acceptable for the module components. The limiting values for these parameters are $327.5 \mathrm{C}$ and $115 \mathrm{C}$ for lead and aluminum, respectively. These material design criteria ensure that a coolable geometry can be maintained throughout the expected lifetime of each module unit. Less strict exposure dependent temperature limits can also be applied. Material limits for the plate-type structures have been tentatively set to: (1) $115 \mathrm{C}$ for steady-state normal operation or indefinite times of exposure; and (2) $170 \mathrm{C}$ for exposures less than 10,000 hours.

Confidence bounds are required to establish the acceptable level of probability of exceeding these criteria. The results presented in this report represent primarily best estimate values (however, some parameters were set to their estimated upper bounds, such as power density). Quantification of overall uncertainties and then their corresponding confidence levels (i.e., operating and modeling uncertainties) have not yet been performed. Future efforts to perform a response surface analysis are planned. At that time quantification of safety margins will be determined.

\subsection{Design Issues}

Adequate safety margin is provided by the reference 1 plate-type design to allow the APT blanket section to withstand the LOFA scenarios analyzed for a time period of 
several days. In particular, the maximum aluminum temperature remained below $170 \mathrm{C}$ over this time period. The maximum aluminum temperature exceeded $170 \mathrm{C}$ if the accident was allowed to proceed beyond this time frame. Since it is reasonable to assume that additional action can be taken to further cool the blanket region during this time period, the current APT design provides adequate protection against this accident event.

\subsection{Predicted Impact}

Anticipated blanket conditions during LOFA Case 2 fall within all specified thermal/hydraulic design criteria for time periods of several days. During this time no on-site or off-site impact to people or the environment would occur from conditions within the blanket region of the APT as a result of this LOFA. Beyond several days, metal temperatures within the blanket module can exceed the limits imposed to ensure structural integrity. If this is allowed to occur slumping of the blanket plates can damage the helium tubes and target ladders leading to the release of hazardous and radioactive materials that would impact the environment. However, the analysis presented in this report shows that several days are available in which to take additional action to mitigate the accident event and prevent undesirable consequences.

\section{References}

1. L. L. Hamm, S. Y. Lee, M. A. Shadday, and F. G. Smith, III, "Normal Operation (NO) of APT Blanket System and its Components, Based on Initial Conceptual Design," Westinghouse Savannah River Company, WSRC-TR-98-0057 (July 1998).

2. L. L. Hamm, S. Y. Lee, M. A. Shadday, and F. G. Smith, III, "APT Blanket System Loss-of-Flow Accident (LOFA) Analyses Based on Initial Conceptual Design Case 1: with Beam Shutdown and RHR," Westinghouse Savannah River Company, WSRC-TR-98-0058 (July 1998).

3. L. L. Hamm, S. Y. Lee, M. A. Shadday, and F. G. Smith, III, "APT Blanket System Loss-of-Coolant Accident (LOCA) Analysis Based on Initial Conceptual Design - Case 1: External HR Break Near Inlet Header," Westinghouse Savannah River Company, WSRC-TR-98-0059 (July 1998).

4. L. L. Hamm, S. Y. Lee, M. A. Shadday, and F. G. Smith, III, "APT Blanket System Loss-of-Coolant Accident (LOCA) Analysis Based on Initial Conceptual Design Case 2: External HR Break at Pump Outlet with Pump Trip," Westinghouse Savannah River Company, WSRC-TR-98-0060 (July 1998).

5. L. L. Hamm, S. Y. Lee, M. A. Shadday, and F. G. Smith, III, "APT Blanket System Loss-of-Coolant Accident (LOCA) Analysis Based on Initial Conceptual Design Case 3: External HR Break at Pump Outlet without Pump Trip," Westinghouse Savannah River Company, WSRC-TR-98-0061 (July 1998).

6. L. L. Hamm, S. Y. Lee, M. A. Shadday, and F. G. Smith, III, "APT Blanket System Loss-of-Coolant Accident (LOCA) Analysis Based on Initial Conceptual Design Case 4: External Pressurizer Surge Line Break Near Inlet Header," Westinghouse Savannah River Company, WSRC-TR-98-0062 (July 1998).

7. L. L. Hamm, S. Y. Lee, M. A. Shadday, and F. G. Smith, III, "APT Blanket System Loss-of-Coolant Accident (LOCA) Analyses Based on Initial Conceptual Design Case 5: External RHR Break Near Inlet Header," Westinghouse Savannah River Company, WSRC-TR-98-0063 (July 1998). 
WESTINGHOUSE SAVANNAH RIVER COMPANY

BLANKET SAFETY ANALYSIS FOR LOFA

(CASE 2: WITH BEAM SHUTDOWN ONLY)
Report: • WSRC-TR-98-0085

Section:

Date:

Page:
1

$07 / 15 / 98$

20 of 20

8. L. L. Hamm, S. Y. Lee, M. A. Shadday, and F. G. Smith, III, "APT Blanket System Internally Dry Flooded Cavity Accident (IDFCA) Based on Initial Plate-Type Design - Demonstration of Bin Heat Conduction Capability," Westinghouse Savannah River Company, WSRC-TR-98-0064 (July 1998).

9. G. Willcutt, "Decay Power Fractions for $1700 \mathrm{MeV}$ Design," e-mail memo from Los Alamo National Laboratory, March 20, 1997.

10. L. L. Hamm, S. Y. Lee, M. A. Shadday, and F. G. Smith, III, "APT Blanket System Model Based On Initial Conceptual Design - Integrated 1D TRAC System Model," Westinghouse Savannah River Company, WSRC-TR-98-0053 (July 1998).

11. L. L. Hamm, S. Y. Lee, M. A. Shadday, and F. G. Smith, III, "TRAC Code Modifications made for APT Blanket Safety Analyses," Westinghouse Savannah River Company, WSRC-TR-98-0054 (July 1998).

12. Safety Code Development Group, "TRAC-PF1/MOD2: An Advanced Best Estimate Computer Program for Pressurized Water Reactor Thermal-Hydraulic Analysis," Los Alamos National Laboratory report LA-12031-M, Vol. 1 (NUREG/CR-5673), (July 21, 1993).

13. L. L. Hamm, S. Y. Lee, M. A. Shadday, and F. G. Smith, III, "APT Blanket System Safety Analysis Methodology," Westinghouse Savannah River Company WSRCTR-98-0052 (May 1998). 


\section{Appendix A: TRAC Model Component Nomenclature}

Table A-1 Blanket System Component Descriptions in TRAC Model.

\begin{tabular}{|c|c|c|c|c|}
\hline System & Component Type & $\begin{array}{c}\text { Comp } \\
\#\end{array}$ & $\begin{array}{l}\text { No of } \\
\text { Cells }\end{array}$ & Descriptions \\
\hline \multirow[t]{42}{*}{ HR } & Fixed Header (FH) & 380 & 1 & coolant Supply FH \\
\hline & & 340 & 1 & coolant Return FH \\
\hline & Pressurizer (Pzr) & 760 & 1 & Pzr surge line 1 connected to Supply FH 380 \\
\hline & & 761 & 2 & Pzr surge line 2 \\
\hline & & 762 & 1 & Pzr surge line 3 \\
\hline & & 763 & 1 & Pzr surge line 4 \\
\hline & & 764 & 1 & Pzr surge line 5 \\
\hline & & 765 & 13 & Pzr surge line 6 \\
\hline & & 766 & 9 & primary Pzr \\
\hline & Hot Leg Loop & 20 & 1 & pipe connected to Return FH340 \\
\hline & & 21 & 1 & plenum for potential break loc. \\
\hline & & 22 & 7 & pipe connection to external loop \\
\hline & & 23 & 1 & pipe connect. for potential break \\
\hline & & 24 & 13 & connection pipe \\
\hline & & 25 & 1 & connection pipe \\
\hline & & 26 & 2 & pipe connected to two pumps \\
\hline & & 27 & 1 & plenum for two pump connection \\
\hline & & 28 & 2 & pump\#1 suction pipe \\
\hline & & 29 & 7 & pump\#2 suction pipe \\
\hline & & 30 & 2 & pump located at cell face 2 \\
\hline & & 31 & 2 & pump located at cell face 2 \\
\hline & & 32 & 3 & check valve located at pump\#1 discharge \\
\hline & & 33 & 3 & check valve located at pump\#2 discharge \\
\hline & & 34 & 1 & pump outlet plenum \\
\hline & & 36 & 1 & connect. pipe between pump and pipe \\
\hline & & 37 & 1 & HX connect. pipe for potential break \\
\hline & & 38 & 1 & pipe connect. to two HX's inlet plenum \\
\hline & & 40 & 1 & plenum \\
\hline & $H X$ & 48 & 3 & HX\#1 inlet pipe \\
\hline & & 50 & 4 & $H X \# 11^{\text {st }}$ pass \\
\hline & & 52 & 3 & $\mathrm{HX} \# 1$ middle header \\
\hline & & 54 & 4 & $H X \# 12^{\text {nd }}$ pass \\
\hline & & 49 & 3 & HX \#2 inlet pipe \\
\hline & & 51 & 4 & $\mathrm{HX} \# 21^{\text {st }}$ pass \\
\hline & & 53 & 3 & HX \#2 middle header \\
\hline & & 55 & 4 & $H X \# 22^{\text {nd }}$ pass \\
\hline & & 710 & 1 & $\mathrm{HX} \# 1$ secondary side fill \\
\hline & & 711 & 4 & $H X \# 12^{\text {nd }}$ pass secondary side \\
\hline & & 712 & 3 & HX \#1 middle header secondary side \\
\hline & & 713 & 4 & $\mathrm{HX} \# 11^{\mathrm{st}}$ pass secondary side \\
\hline & & 714 & 1 & HX \#1 secondary side break $B C$ \\
\hline & & 730 & 1 & $\mathrm{HX} \# 2$ secondary side fill $\mathrm{BC}$ \\
\hline
\end{tabular}


Report:

Section:

Date:

Page:
WSRC-TR-98-0085 Appendix A $07 / 14 / 98$ 2 of 12

BLANKET SAFETY ANALYSES FOR
(CASE 2: WITH BEAM SHUTDOWN ONLY)

Table A-1 Blanket System Component Descriptions in TRAC Model (continued).

\begin{tabular}{|c|c|c|c|c|}
\hline System & Component Type & Comp & $\begin{array}{l}\text { No } \\
\text { of } \\
\text { Cells }\end{array}$ & $\begin{array}{ll} & \text { Descriptions } \\
\end{array}$ \\
\hline & & 731 & 4 & $H X \# 22^{\text {nd }}$ pass secondary side \\
\hline & & 732 & 3 & HX \#2 middle header secondary side \\
\hline & & 733 & 4 & $H X \# 21^{\text {st }}$ pass secondary side \\
\hline & & 734 & 1 & $\mathrm{HX} \# 2$ secondary side break $\mathrm{BC}$ \\
\hline \multirow[t]{12}{*}{ HR } & Cold Leg Loop & 56 & 3 & HX\#1 outlet pipe \\
\hline & & 57 & 6 & HX \#2 outlet pipe \\
\hline & & 60 & 3 & HX outlet plenum merged after two HX's \\
\hline & & 62 & 1 & cold leg pipe \\
\hline & & 63 & 1 & cold leg pipe \\
\hline & & 64 & 13 & cold leg pipe located outside cavity wall \\
\hline & & 65 & 1 & pipe for cold leg pipe break \\
\hline & & 66 & 1 & horizontal cold leg pipe penetration \\
\hline & & 67 & 1 & plenum for internal break on HR loop \\
\hline & & 854 & 2 & HR isolation valve for internal break \\
\hline & & 69 & 1 & plenum for internal LOCA simulation \\
\hline & & 68 & 5 & pipe connect. to FH 340 inside cavity \\
\hline \multirow[t]{9}{*}{$\begin{array}{l}\text { Cavity } \\
\text { Vessel }\end{array}$} & Cold Leg Loop & 850 & 2 & valve located bet. cavity vessel and HR \\
\hline & & 852 & 2 & valve located bet. cavity vessel and HR \\
\hline & & & 1 & plenum for cavity vessel connection \\
\hline & & 828 & 3 & cavity vent valve \\
\hline & & 802 & 1 & break component for cavity vent pressure $B C$ \\
\hline & & 823 & 11 & pipe for cavity lower section simulation \\
\hline & & 824 & 1 & plenum for cavity connection \\
\hline & & 840 & 2 & valve to connect cavity line to Module 1 \\
\hline & & 825 & 4 & pipe for cavity middle section simulation \\
\hline \multirow[t]{8}{*}{$\begin{array}{l}\text { Cavity } \\
\text { Pool }\end{array}$} & Cavity Flood Line & 820 & 13 & $\begin{array}{c}\text { pipe for cavity pool connection to cavity } \\
\text { vessel }\end{array}$ \\
\hline & & 821 & 2 & cavity flood line valve \\
\hline & & 822 & 1 & flood line pipe inside cavity vessel \\
\hline & Cavity Flood Pool & 801 & 1 & break component for cavity pool BC \\
\hline & & 810 & 10 & pipe for top cavity pool section \\
\hline & & 811 & 1 & plenum for middle cavity pool section \\
\hline & & 812 & 7 & pipe for lower cavity pool section \\
\hline & & 813 & 1 & plenum for cavity pool bottom \\
\hline \multirow[t]{10}{*}{ RHR } & RHR Loop & 621 & 1 & pipe located to return $\mathrm{FH}$ \\
\hline & & 623 & 10 & pipe located inside the cavity vessel \\
\hline & & 624 & 1 & pipe located outside the cavity vessel \\
\hline & & 625 & 18 & pipe bet. RHR pump and pipe comp. \#624 \\
\hline & & 630 & 2 & RHR pump located at face 2 \\
\hline & & 640 & 3 & check valve located at pump discharge \\
\hline & & 652 & 4 & HX tubes \\
\hline & & 660 & 16 & pipe at the cold leg side \\
\hline & & 661 & 1 & pipe located before cavity vessel \\
\hline & & 662 & 8 & cold leg pipe inside cavity vessel \\
\hline
\end{tabular}


WESTINGHOUSE SAVANNAH RIVER COMPANY

BLANKET SAFETY ANALYSES FOR LOFA

(CASE 2: WITH BEAM SHUTDOWN ONLY)
Report:

Section:

Date:

Page:
WSRC-TR-98-0085 Appendix A

$07 / 14 / 98$

3 of 12

Table A-1 Blanket System Component Descriptions in TRAC Model (continued).

\begin{tabular}{|c|c|c|c|c|}
\hline $\begin{array}{l}\text { System } \\
\end{array}$ & Component Type & Comp & $\begin{array}{l}\text { No } \\
\text { of } \\
\text { Cells }\end{array}$ & Descriptions \\
\hline & & 663 & 1 & cold leg pipe connected to supply FH \\
\hline & & 672 & 1 & fill for $H X$ secondary side $B C$ \\
\hline & & 671 & 4 & HX secondary shell side \\
\hline & & 673 & 1 & break comp. for $\mathrm{HX}$ secondary side $\mathrm{BC}$ \\
\hline \multirow[t]{18}{*}{ Module } & Module 1 Flow & 454 & 7 & pipe connected to supply FH \\
\hline & & 80 & 1 & $\begin{array}{l}\text { plenum for potential internal break simulation } \\
\text { at Module } 1\end{array}$ \\
\hline & & 375 & 5 & $\begin{array}{c}\text { pipe connection bet. Suuply FH and Module } \\
1 \text { upper plenum }\end{array}$ \\
\hline & & 370 & 1 & upper plenum for Module 1 downcomer \\
\hline & & 360 & 5 & Module 1 downflow region \\
\hline & & 350 & 1 & $\begin{array}{c}\text { middle plenum bet. Module } 1 \text { downflow and } \\
\text { upflow regions }\end{array}$ \\
\hline & & 300 & 5 & Module 1 upflow region \\
\hline & & 330 & 1 & upper plenum for module 1 upflow region \\
\hline & & 335 & 5 & $\begin{array}{c}\text { connection pipe after Module } 1 \text { upper } \\
\text { plenum }\end{array}$ \\
\hline & & 429 & 4 & pipe connected to return $\mathrm{FH}$ \\
\hline & Module 2 Flow & 173 & 7 & pipe coonected to supply FH \\
\hline & & 81 & 1 & $\begin{array}{l}\text { plenum for potential internal break simulation } \\
\text { at Module } 2\end{array}$ \\
\hline & & 82 & 3 & pipe connection \\
\hline & & 172 & 1 & upper plenum for Module 2 downcomer \\
\hline & & 158 & 6 & Module 2 downflow region \\
\hline & & 147 & 1 & $\begin{array}{l}\text { middle plenum bet. Module } 2 \text { downflow and } \\
\text { upflow regions }\end{array}$ \\
\hline & & 102 & 6 & Module 2 upflow region \\
\hline & & 133 & 1 & upper plenum for module 2 upflow region \\
\hline \multirow[t]{14}{*}{ - } & & 136 & 7 & pipe connected to return FH \\
\hline & Module 3 Flow & 415 & 7 & pipe connected to supply FH \\
\hline & & 85 & 1 & $\begin{array}{l}\text { plenum for potential internal break simulation } \\
\text { at Module } 3\end{array}$ \\
\hline & & 86 & 3 & pipe connection \\
\hline & & 479 & 1 & upper plenum for Module 3 downcomer \\
\hline & & 478 & 5 & Module 3 downflow region \\
\hline & & 418 & 1 & $\begin{array}{c}\text { middle plenum bet. Module } 3 \text { downflow and } \\
\text { upflow regions }\end{array}$ \\
\hline & & 409 & 5 & Module 3 upflow region \\
\hline & & 423 & 1 & upper plenum for module 3 upflow region \\
\hline & & 417 & 7 & pipe connected to return FH \\
\hline & Module 4 Flow & 485 & 7 & pipe connected to supply FH \\
\hline & & 87 & 1 & $\begin{array}{l}\text { plenum for potential internal break simulation } \\
\text { at Module } 4\end{array}$ \\
\hline & & 88 & 3 & pipe connection \\
\hline & & 489 & 1 & upper plenum for Module 4 downcomer \\
\hline
\end{tabular}


Table A-1 Blanket System Component Descriptions in TRAC Model (continued).

\begin{tabular}{|c|c|c|c|c|}
\hline System & Component Type & Comp & $\begin{array}{l}\text { No of } \\
\text { Cells }\end{array}$ & Descriptions \\
\hline & & 480 & 6 & Module 4 downflow region \\
\hline & & 419 & 1 & $\begin{array}{c}\text { middle plenum bet. Module } 4 \text { downflow and } \\
\text { upflow regions }\end{array}$ \\
\hline & & 412 & 6 & Module 4 upflow region \\
\hline & & 483 & 1 & upper plenum for module 4 upflow region \\
\hline & & 484 & 7 & pipe connected to return $\mathrm{FH}$ \\
\hline \multirow[t]{31}{*}{ Module } & Module 5 Flow & 513 & 7 & pipe connected to supply FH \\
\hline & & 89 & $\overline{1}$ & $\begin{array}{c}\text { plenum for potential internal break } \\
\text { simulation at Module } 5\end{array}$ \\
\hline & & 90 & 3 & pipe connection \\
\hline & & 510 & 1 & upper plenum for Module 5 downcomer \\
\hline & & 507 & 6 & Module 5 downflow region \\
\hline & & 503 & 1 & $\begin{array}{l}\text { middle plenum bet. Module } 4 \text { downflow and } \\
\text { upflow regions }\end{array}$ \\
\hline & & 500 & 6 & Module 5 upflow region \\
\hline & & 508 & 1 & upper plenum for Module 5 upflow region \\
\hline & & 511 & 7 & pipe connected to return $\mathrm{FH}$ \\
\hline & Module 6 Flow & 541 & 7 & pipe connected to supply FH \\
\hline & & 83 & 1 & $\begin{array}{c}\text { plenum for potential internal break } \\
\text { simulation at Module } 6\end{array}$ \\
\hline & & 84 & 1 & pipe connection \\
\hline & & 538 & 1 & upper plenum for Module 6 decoupler \\
\hline & - & 535 & 5 & Module 6 downcomer region \\
\hline & & 531 & 1 & $\begin{array}{l}\text { middle plenum bet. Module } 6 \text { decoupler and } \\
\text { main heated regions }\end{array}$ \\
\hline & & 528 & 5 & Module 6 main heated region \\
\hline & & 536 & 1 & $\begin{array}{c}\begin{array}{c}\text { upper plenum for module } 6 \text { main heated } \\
\text { region }\end{array} \\
\end{array}$ \\
\hline & & 539 & 12 & pipe connected to return $\mathrm{FH}$ \\
\hline & $\begin{array}{l}\text { Module } 1 \text { Heater } \\
\text { Structure } \\
\end{array}$ & 901 & 5 & Al tube structure in Row 1 \\
\hline & & 951 & 5 & Lead zone with Al cladding in Row 1 \\
\hline & & 984 & 5 & Al tube structure in decoupler \\
\hline & $\begin{array}{l}\text { Module } 2 \text { Heater } \\
\text { Structure }\end{array}$ & 905 & 6 & Al tube structure in Row 2 \\
\hline & & 955 & 6 & Lead zone with Al cladding in Row 2 \\
\hline & & 916 & 6 & Al tube structure in Row 3 \\
\hline & & 966 & 6 & Lead zone with Al cladding in Row 3 \\
\hline & $\begin{array}{c}\text { Module } 3 \text { Heater } \\
\text { Structure }\end{array}$ & 911 & 5 & Al tube structure in Row 1 \\
\hline & & 961 & 5 & Lead zone with Al cladding in Row 1 \\
\hline & & 988 & 5 & Al tube structure in decoupler \\
\hline & $\begin{array}{l}\text { Module } 4 \text { Heater } \\
\text { Structure } \\
\end{array}$ & 912 & 6 & Al tube structure in Row 1 \\
\hline & & 962 & 6 & Lead zone with Al cladding in Row 1 \\
\hline & & 931 & 6 & Al tube structure in Row 2 \\
\hline
\end{tabular}


Table A-1 Blanket System Component Descriptions in TRAC Model (continued).

\begin{tabular}{|c|c|c|c|c|}
\hline System & Component Type & $C_{\#}^{C o m p}$ & $\begin{array}{l}\text { No } \\
\text { of } \\
\text { Cells }\end{array}$ & Descriptions \\
\hline & & 978 & 6 & Lead zone with Al cladding in Row 2 \\
\hline & $\begin{array}{l}\text { Module } 5 \text { Heater } \\
\text { Structure }\end{array}$ & 913 & 6 & Al tube structure in Row 2 \\
\hline & & 963 & 6 & Lead zone with Al cladding in Row 2 \\
\hline & & 932 & 6 & Al tube structure in Row 2 \\
\hline & & 979 & 6 & Lead zone with Al cladding in Row 2 \\
\hline & $\begin{array}{c}\text { Module } 6 \text { Heater } \\
\text { Structure }\end{array}$ & 915 & 5 & Al tube structure in Row 2 \\
\hline & & 965 & 5 & Lead zone with Al cladding in Row 2 \\
\hline
\end{tabular}

Table A-2 Steady State Conditions.

\begin{tabular}{|c|c|c|}
\hline Parameter & Units & $\begin{array}{c}\text { Calculated } \\
\text { Values }\end{array}$ \\
\hline Total power deposited in blanket modules & $\mathrm{MW}$ & 56.5 \\
\hline Total flow rate & $\mathrm{kg} / \mathrm{sec}$ & 1569 \\
& $\mathrm{gpm}$ & 25252 \\
\hline Pressure in cold-leg fixed header & $\mathrm{MPa}$ & 0.7325 \\
& $\mathrm{psia}$ & 106.24 \\
\hline Pressure in hot-leg fixed header & $\mathrm{MPa}$ & 0.4563 \\
& $\mathrm{psia}$ & 66.180 \\
\hline Pressurizer (cell \#1) pressure & $\mathrm{MPa}$ & 0.7311 \\
& $\mathrm{psia}$ & 106.03 \\
\hline Pump \#1 suction pressure & $\mathrm{MPa}$ & 0.2751 \\
& $\mathrm{psia}$ & 39.90 \\
\hline Pump \#1 discharge pressure & $\mathrm{MPa}$ & 1.0356 \\
& $\mathrm{psia}$ & 150.20 \\
\hline Pump \#2 suction pressure & $\mathrm{MPa}$ & 0.2958 \\
& $\mathrm{psia}$ & 42.91 \\
\hline Pump \#2 discharge pressure & $\mathrm{MPa}$ & 1.0409 \\
& $\mathrm{psia}$ & 150.97 \\
\hline Temperature in cold-leg fixed header & $\mathrm{C}$ & 49.43 \\
& $\mathrm{~F}$ & 121.0 \\
\hline Temperature in hot-leg fixed header & $\mathrm{C}$ & 58.03 \\
& $\mathrm{~F}$ & 136.5 \\
\hline Max. fluid temperature of the hottest & $\mathrm{C}$ & 71.95 \\
& $\mathrm{~F}$ & 161.5 \\
\hline
\end{tabular}




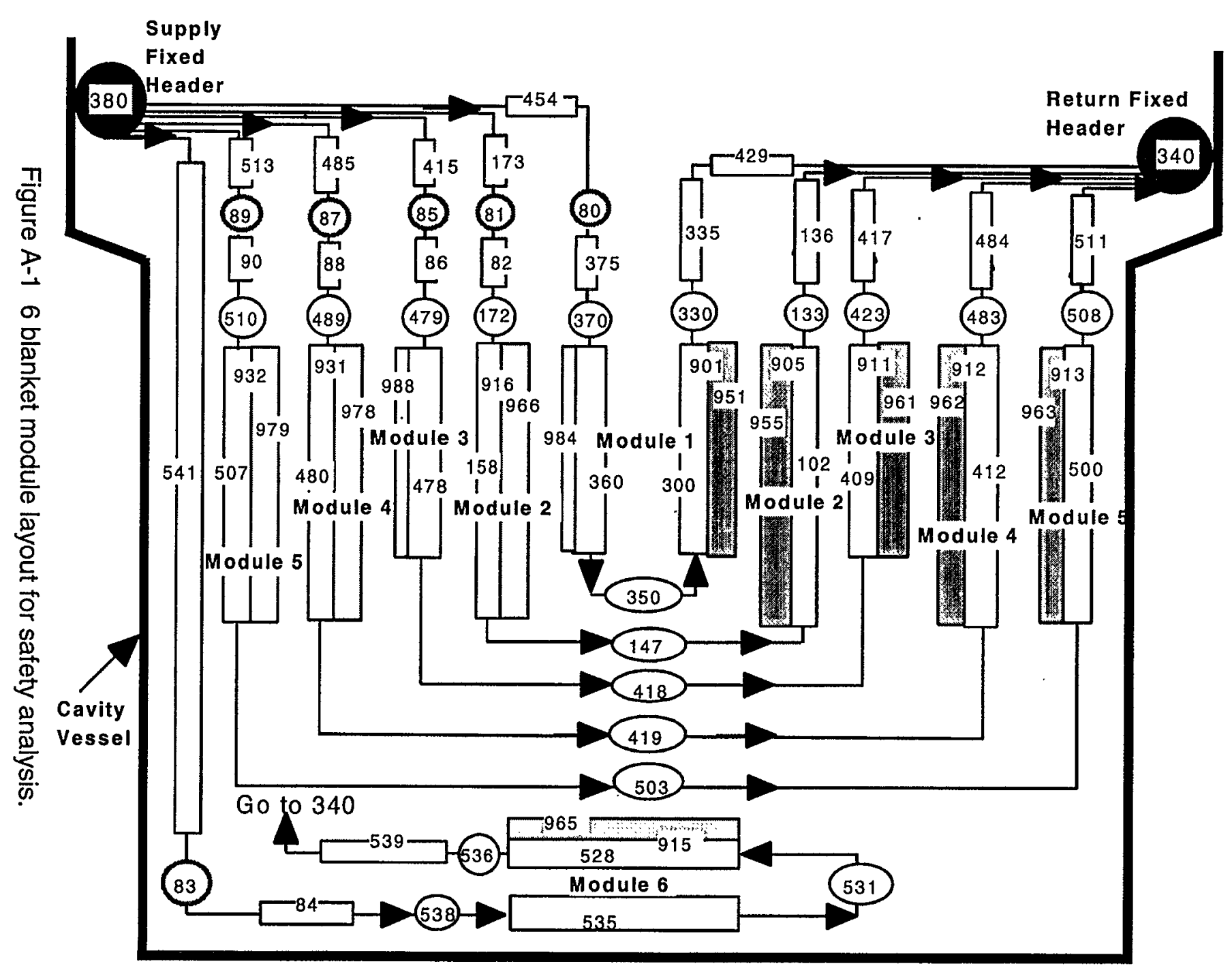

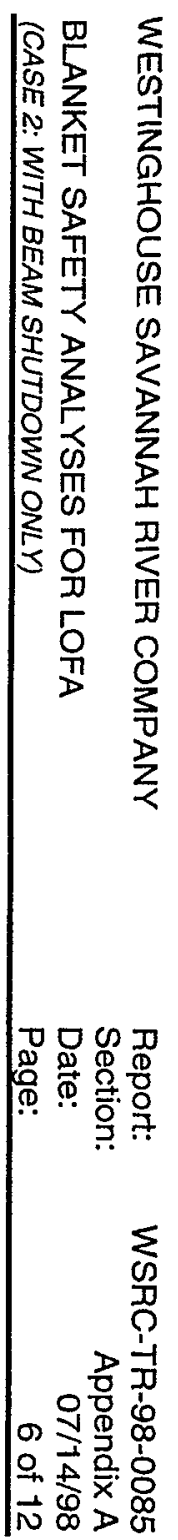




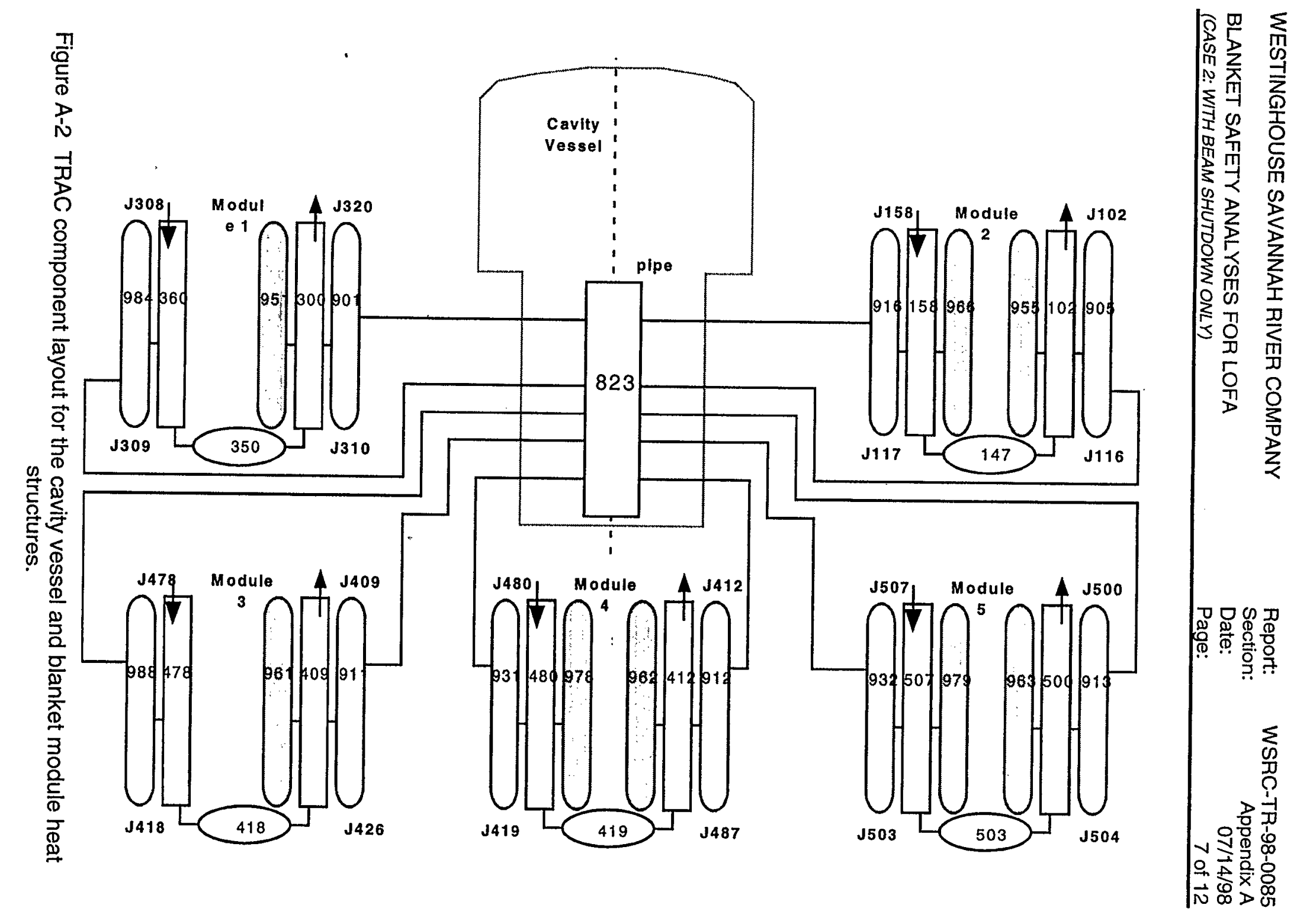




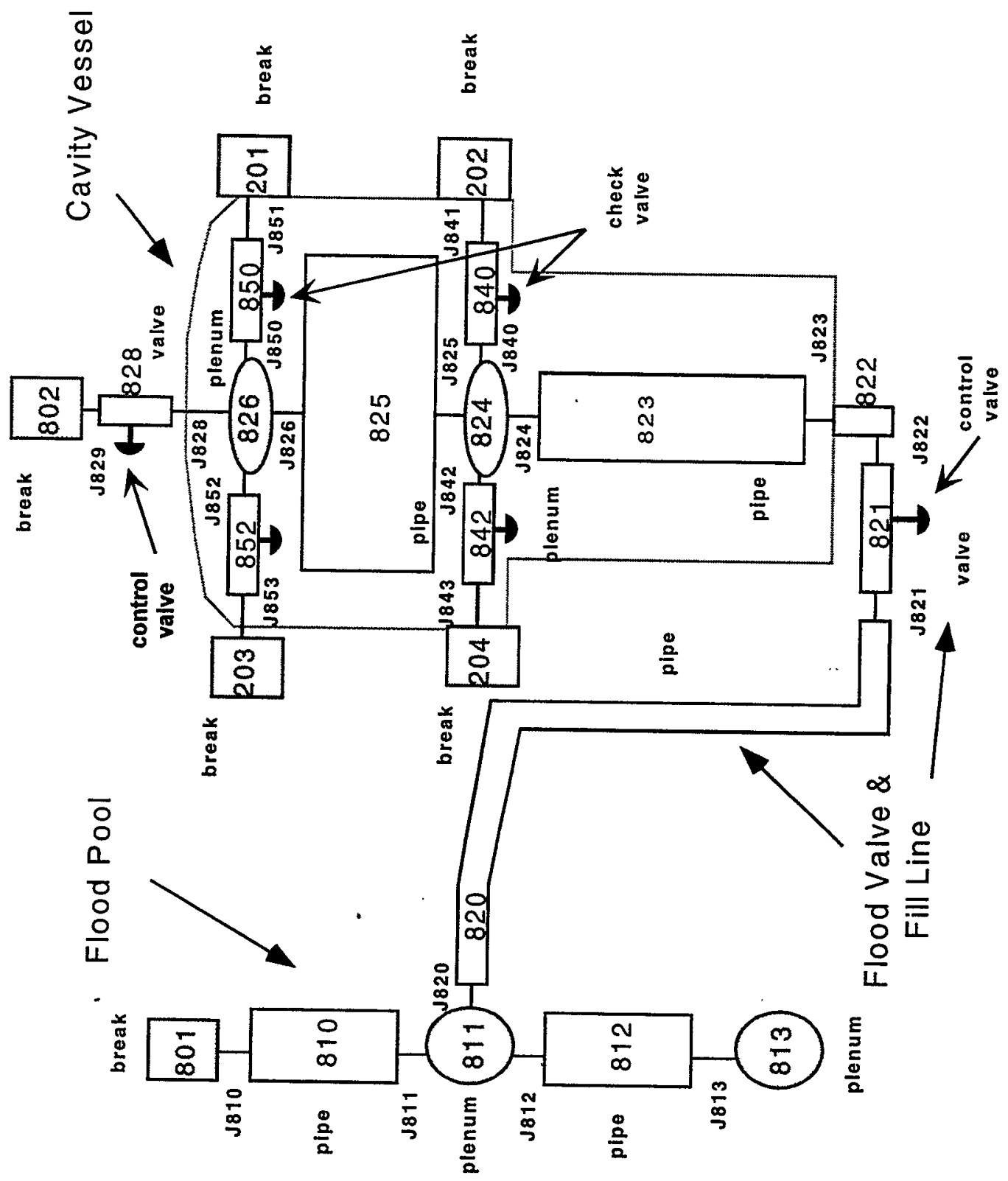

Figure A-3 TRAC component layout for the cavity vessel and cavity flood system. 

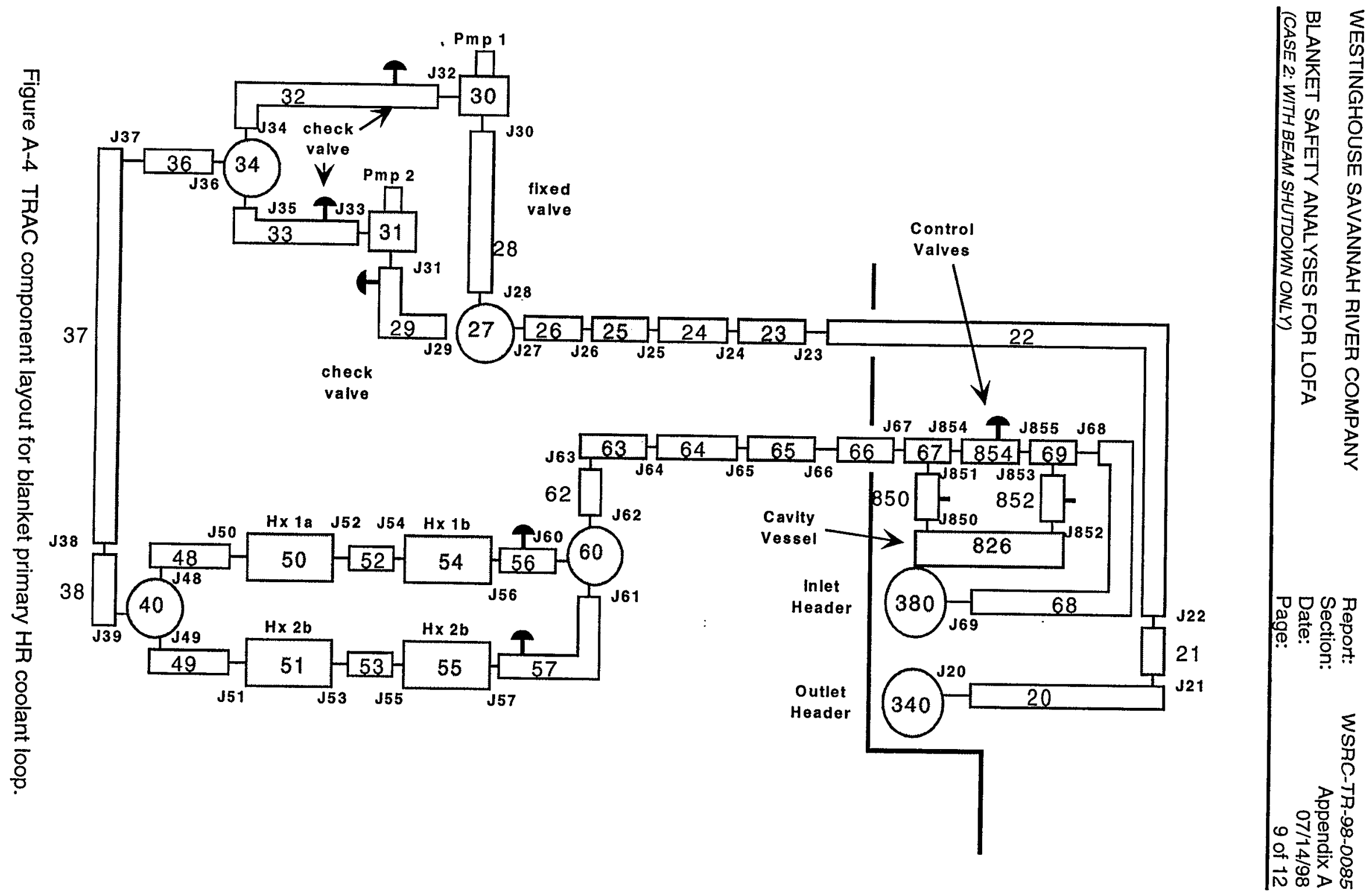


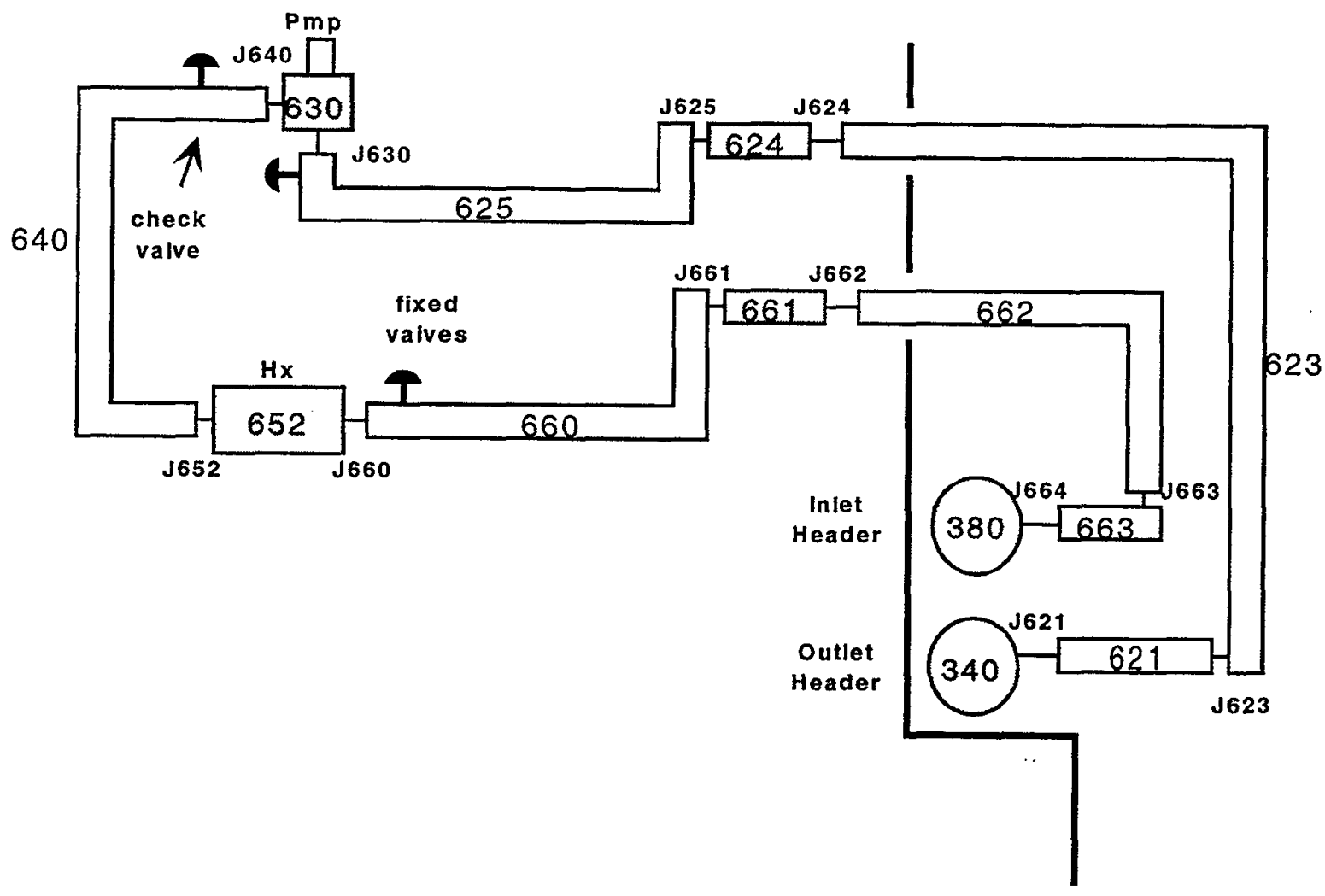

Figure A-5 TRAC component layout for blanket primary RHR coolant loop. 
Report:

Section:

Date:

Page:
WSRC-TR-98-0085

Appendix A

07/14/98 11 of 12
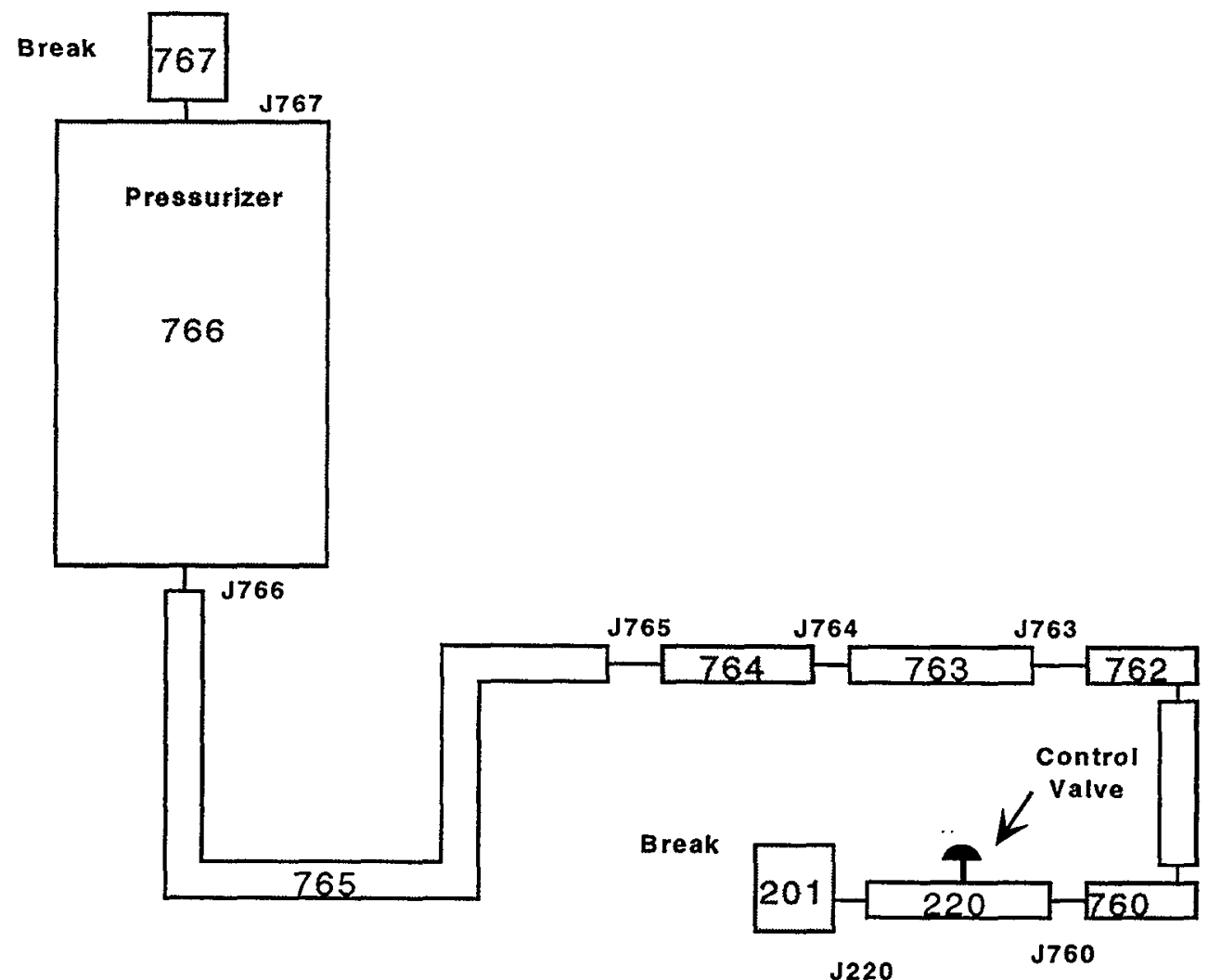

J762

761

J761

Figure A-6 TRAC component layout for blanket primary pressurizer and surge line. 


\section{Appendix B: LOFA (Case 2) TRAC Results}

\section{Appendix B1 LOFA (Case 2) TRAC Plenum Component Figures}

The following figures are from a TRAC simulation for Case 2 of a LOFA (with beam shutdown only):

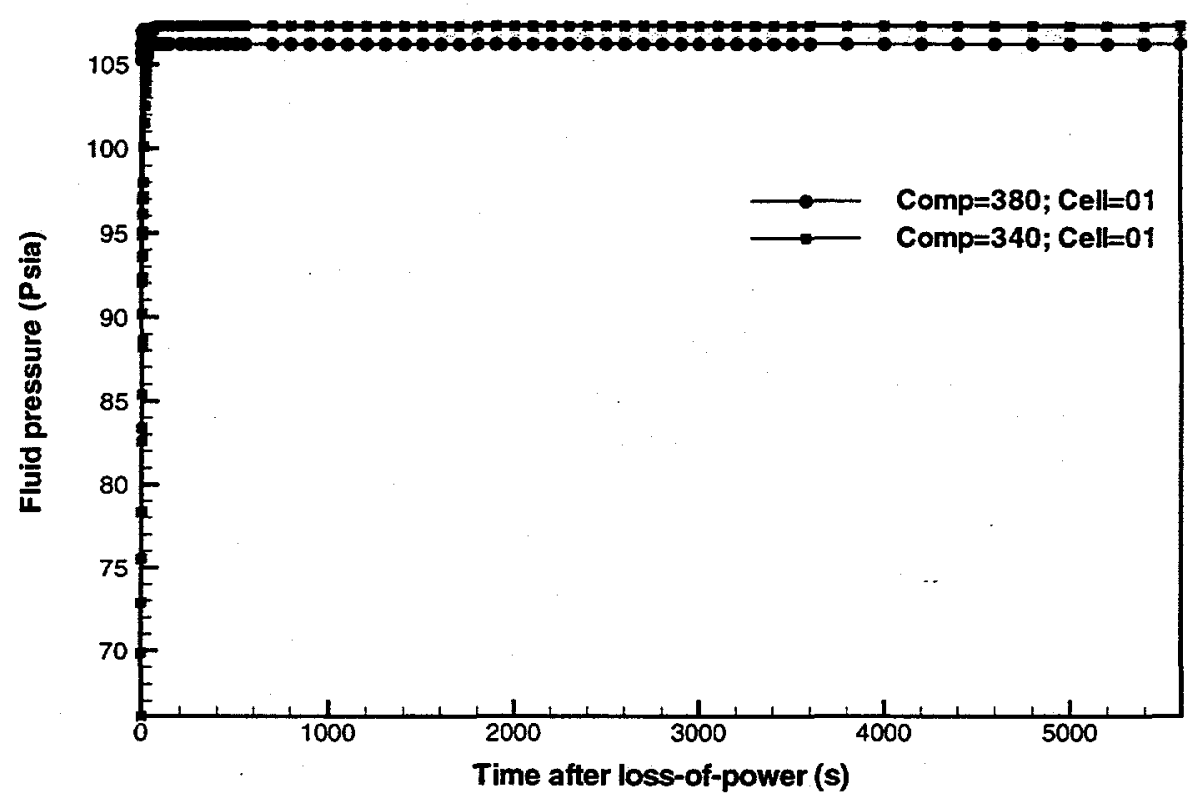

Figure B-1a Fixed header fluid pressures for a LOFA (Case 2: with beam shutdown only). 
Report:

Section:

BLANKET SAFETY ANALYSIS FOR LOFA

(CASE 2: WITH BEAM SHUTDOWN ONLY)
Date:

Page:
WSRC-TR-98-0085

Appendix B

$07 / 14 / 98$

2 of 72

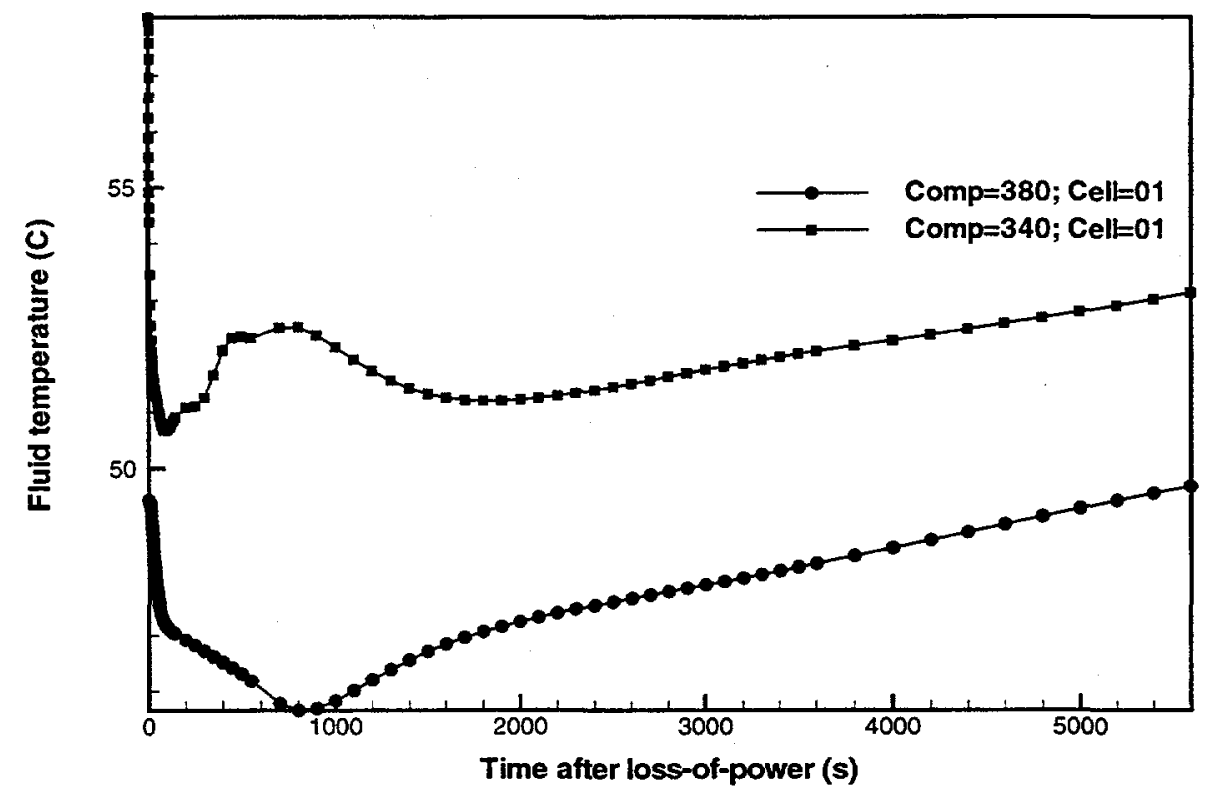

Figure B-1b Fixed header fluid temperatures for a LOFA (Case 2: with beam shutdown only).

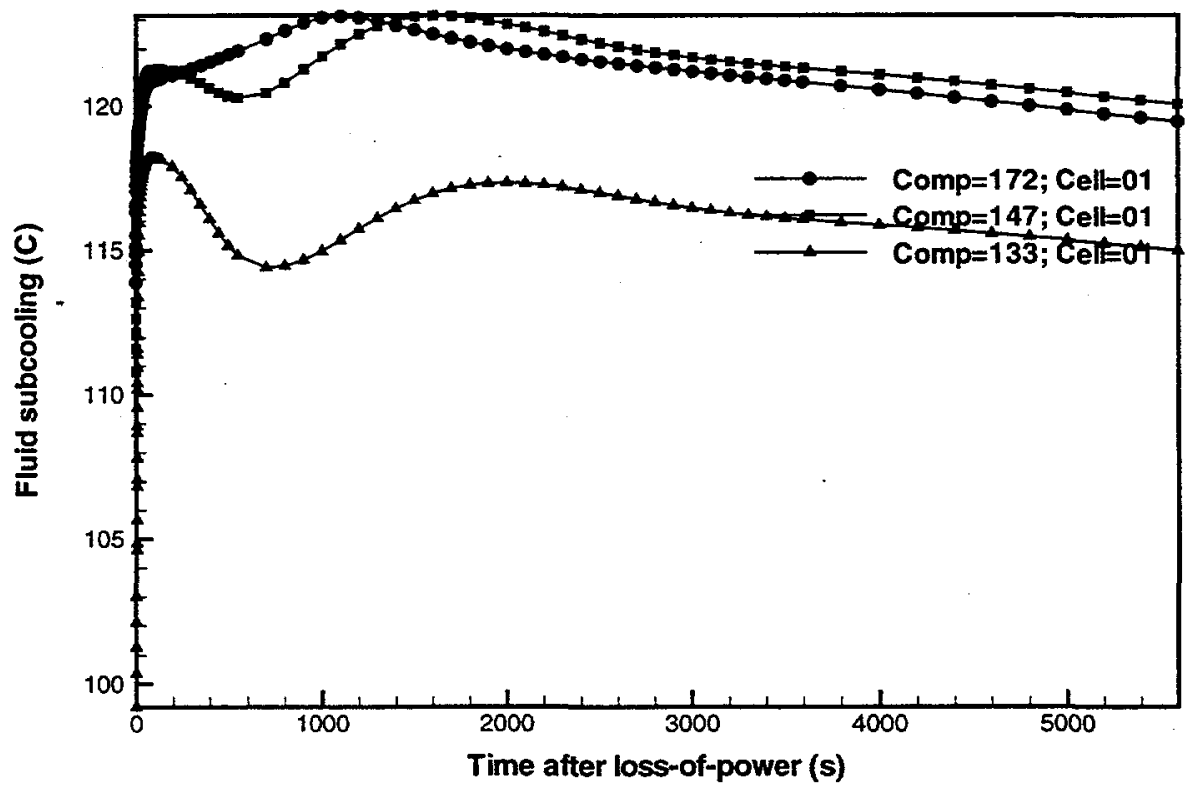

Figure B-1c Fixed header fluid subcoolings for a LOFA (Case 2: with beam shutdown only). 


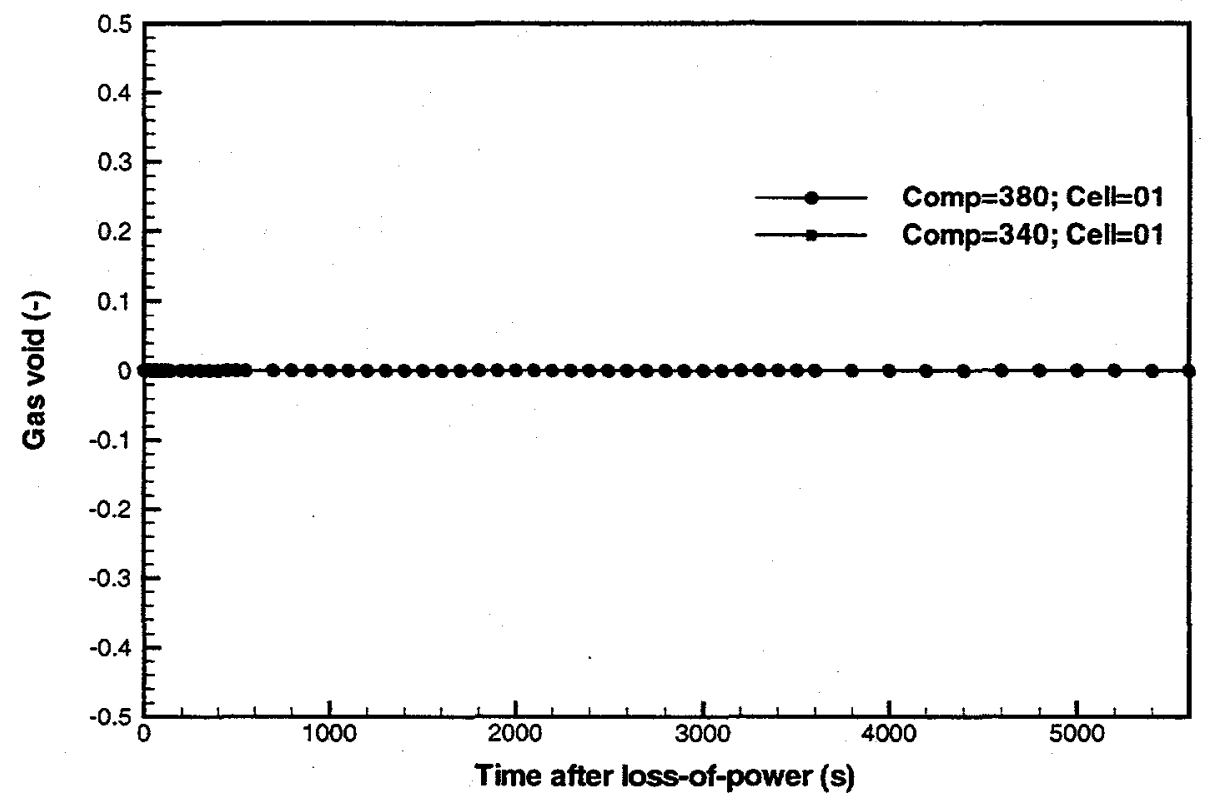

Figure B-1d Fixed header void fractions for a LOFA (Case 2: with beam shutdown only).

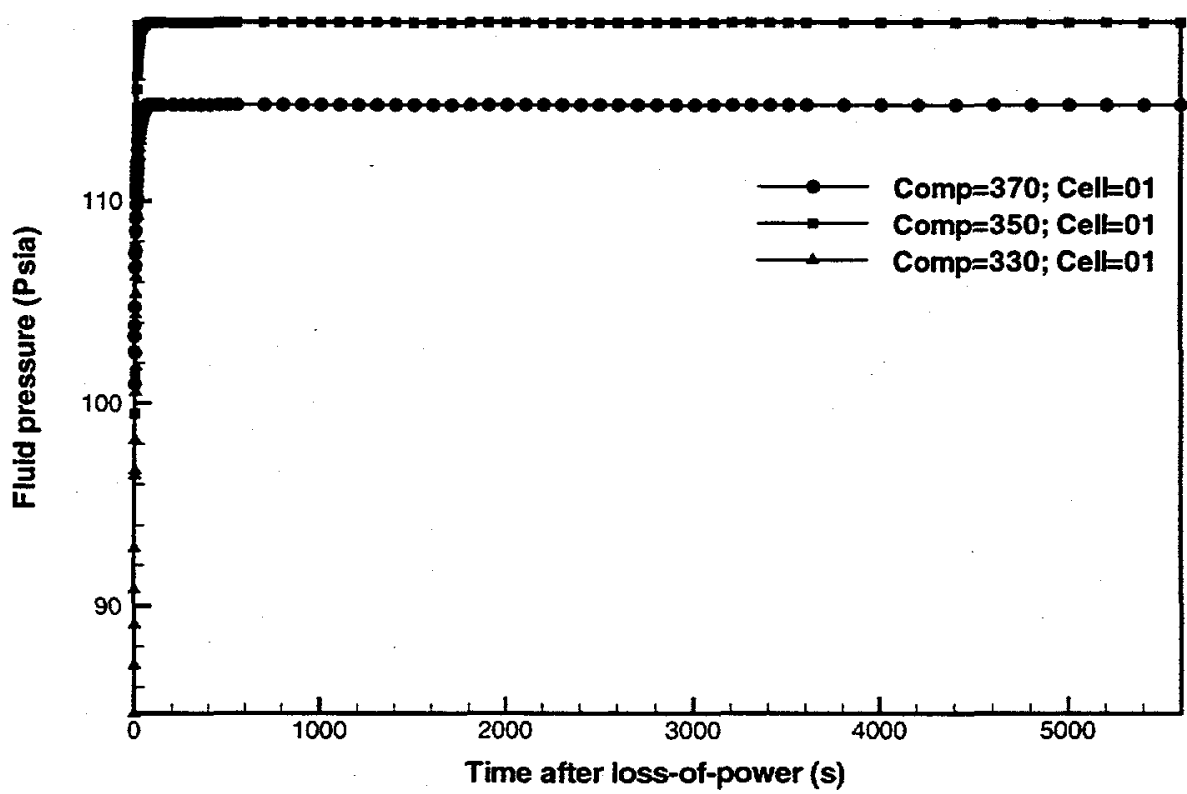

Figure B-2a Module 1 plenum fluid pressures for a LOFA (Case 2: with beam shutdown only). 


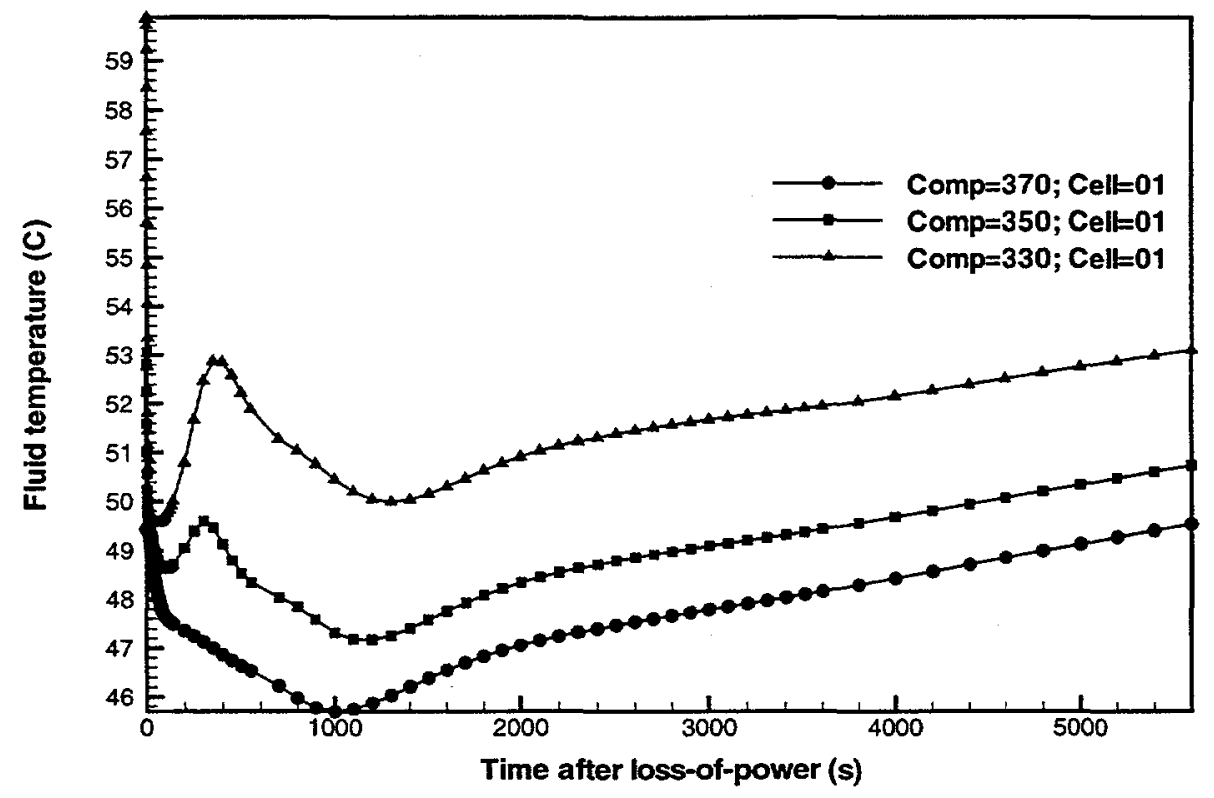

Figure B-2b Module 1 plenum fluid temperatures for a LOFA (Case 2: with beam shutdown only).

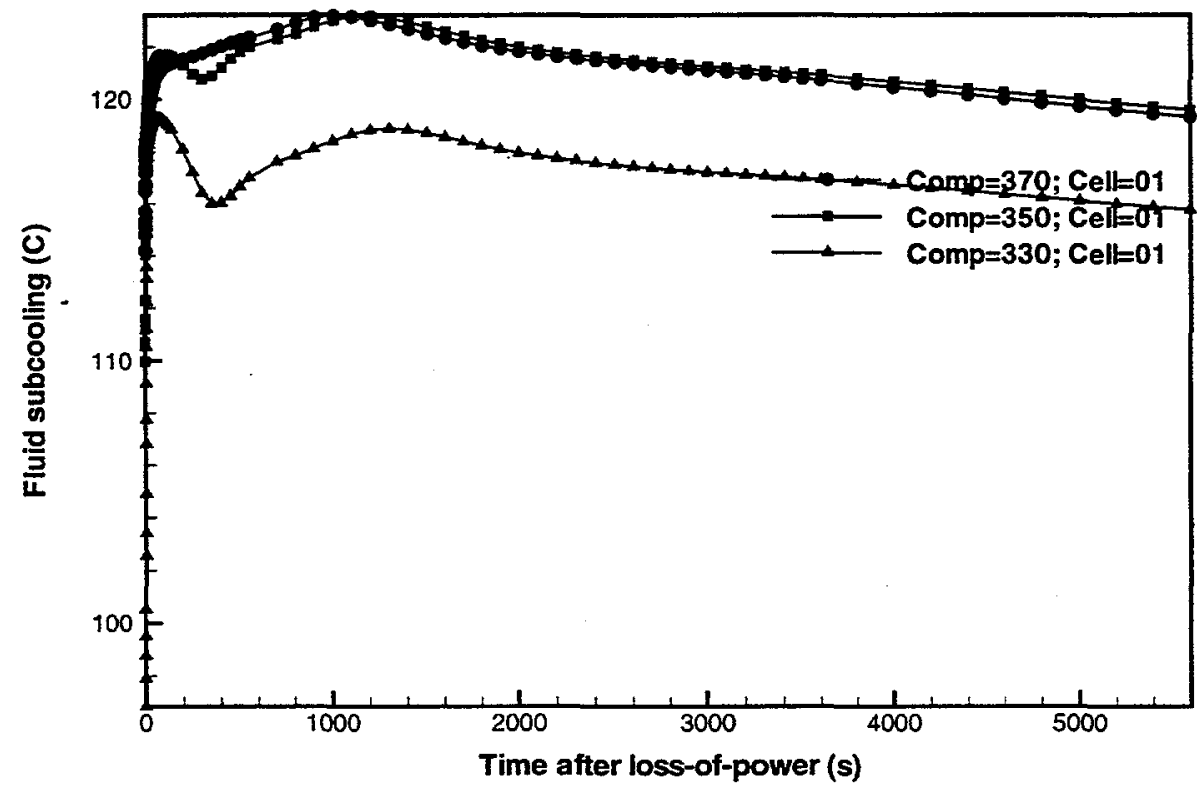

Figure B-2c Module 1 plenum fluid subcoolings for a LOFA (Case 2: with beam shutdown only). 


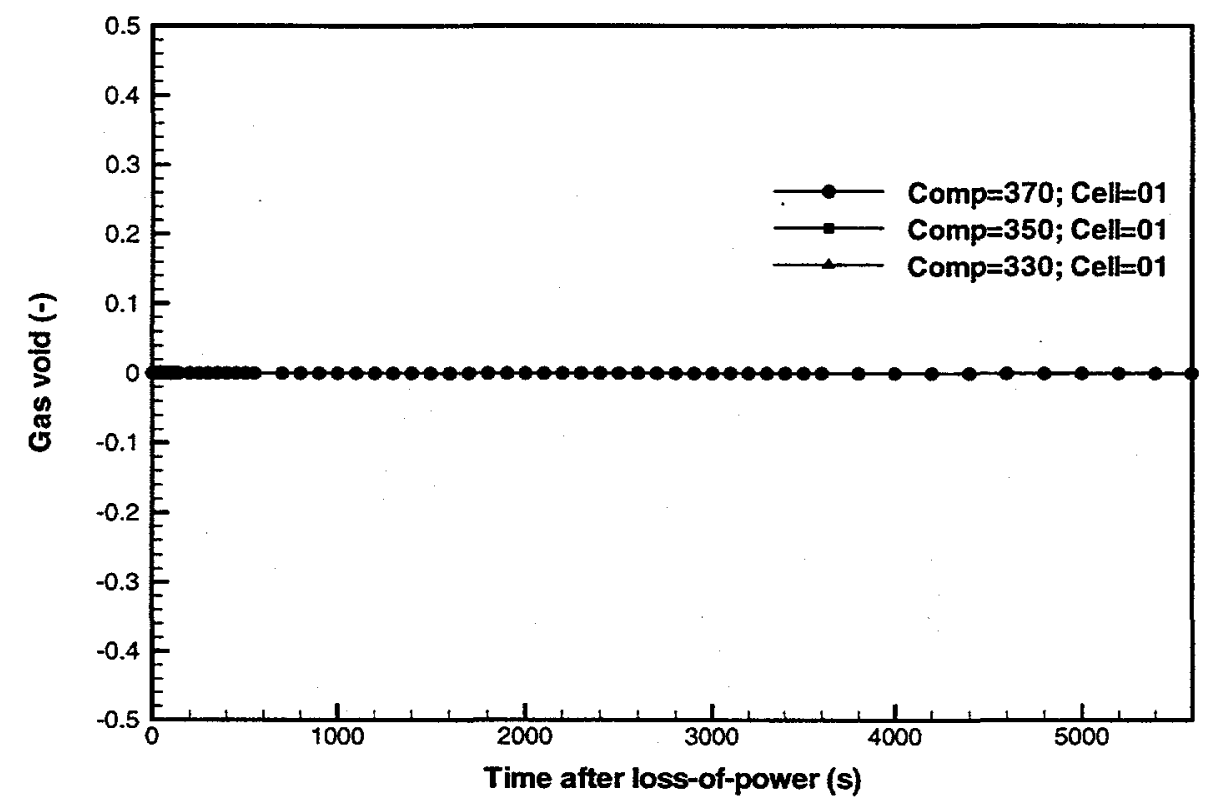

Figure B-2d Module 1 plenum void fractions for a LOFA (Case 2: with beam shutdown only).

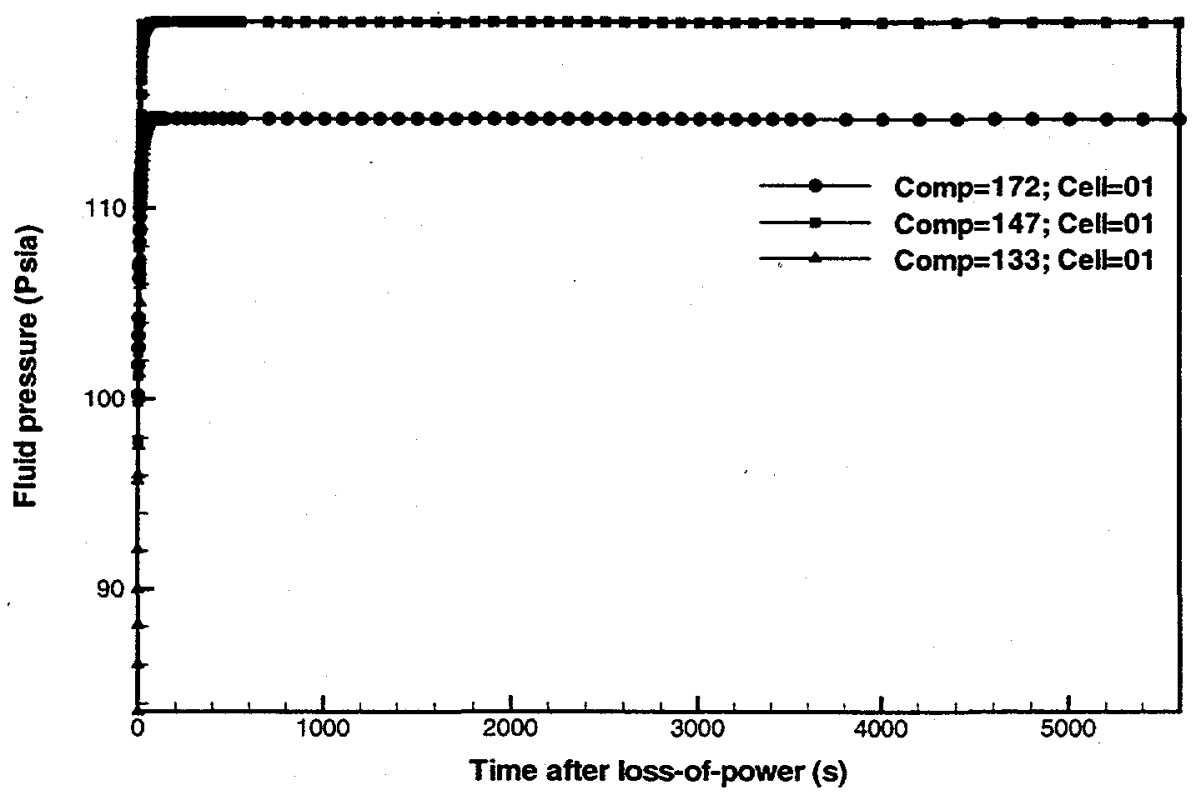

Figure B-3a Module 2 plenum fluid pressures for a LOFA (Case 2: with beam shutdown only). 


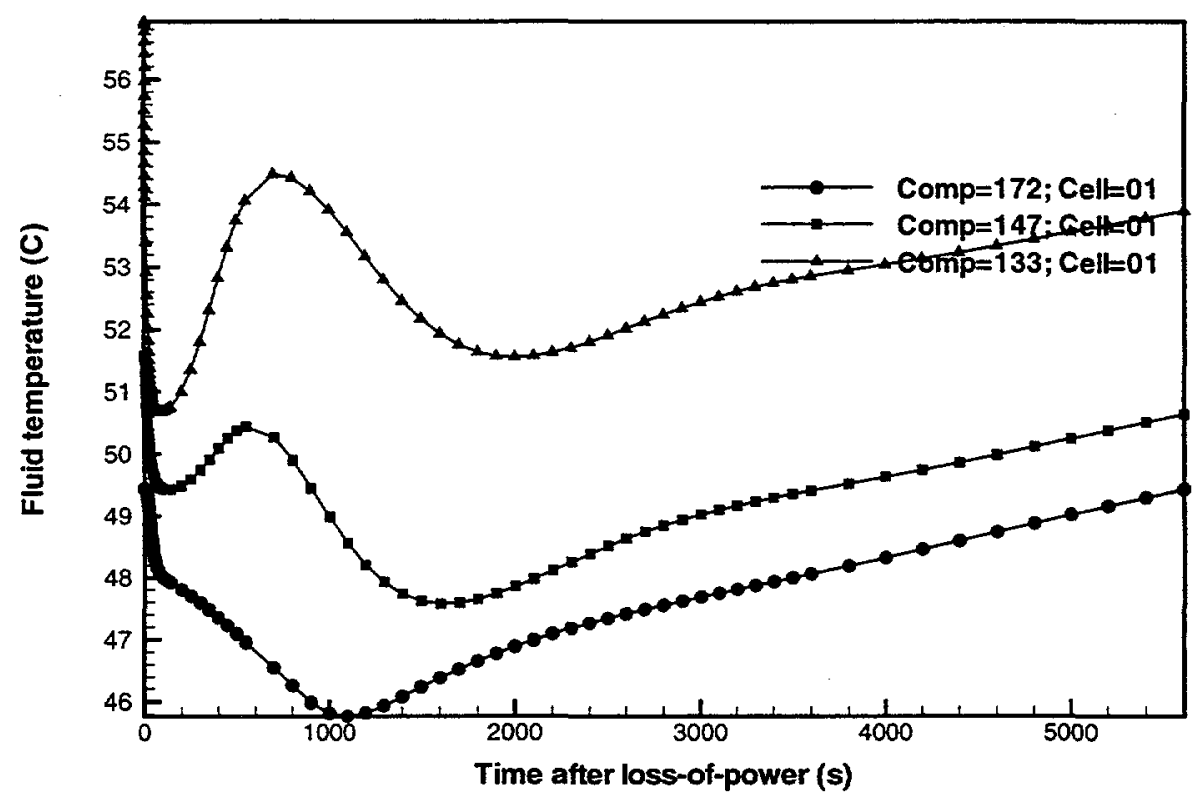

Figure B-3b Module 2 plenum fluid temperatures for a LOFA (Case 2: with beam shutdown only).

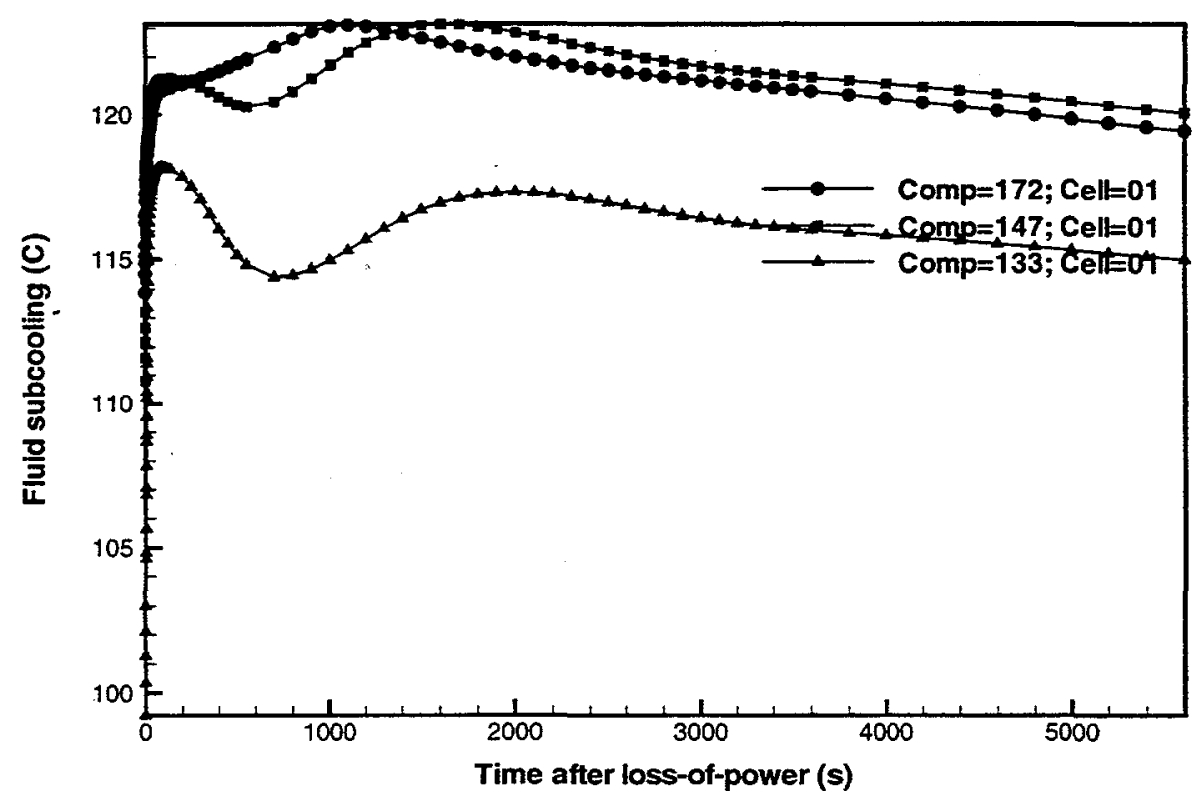

Figure B-3c Module 2 plenum fluid subcoolings for a LOFA (Case 2: with beam shutdown only). 


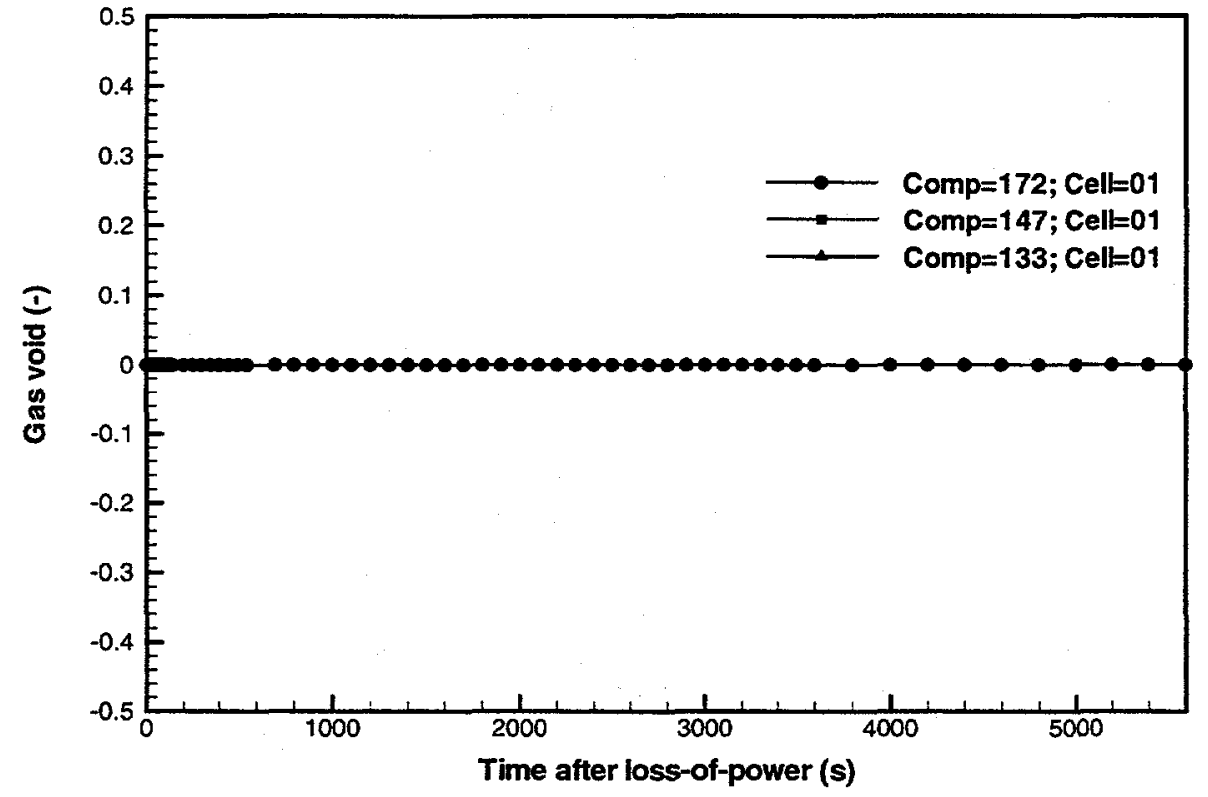

Figure B-3d Module 2 plenum void fractions for a LOFA (Case 2: with beam shutdown only).

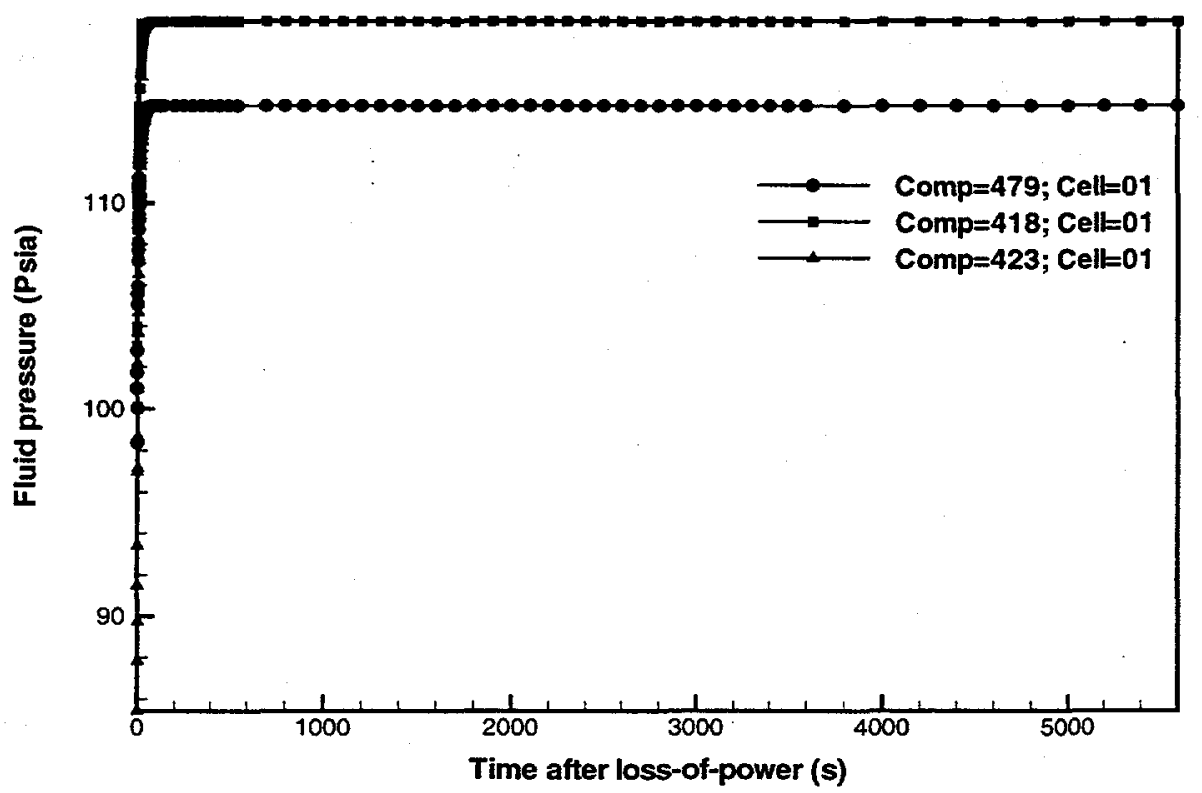

Figure B-4a Module 3 plenum fluid pressures for a LOFA (Case 2: with beam shutdown only). 


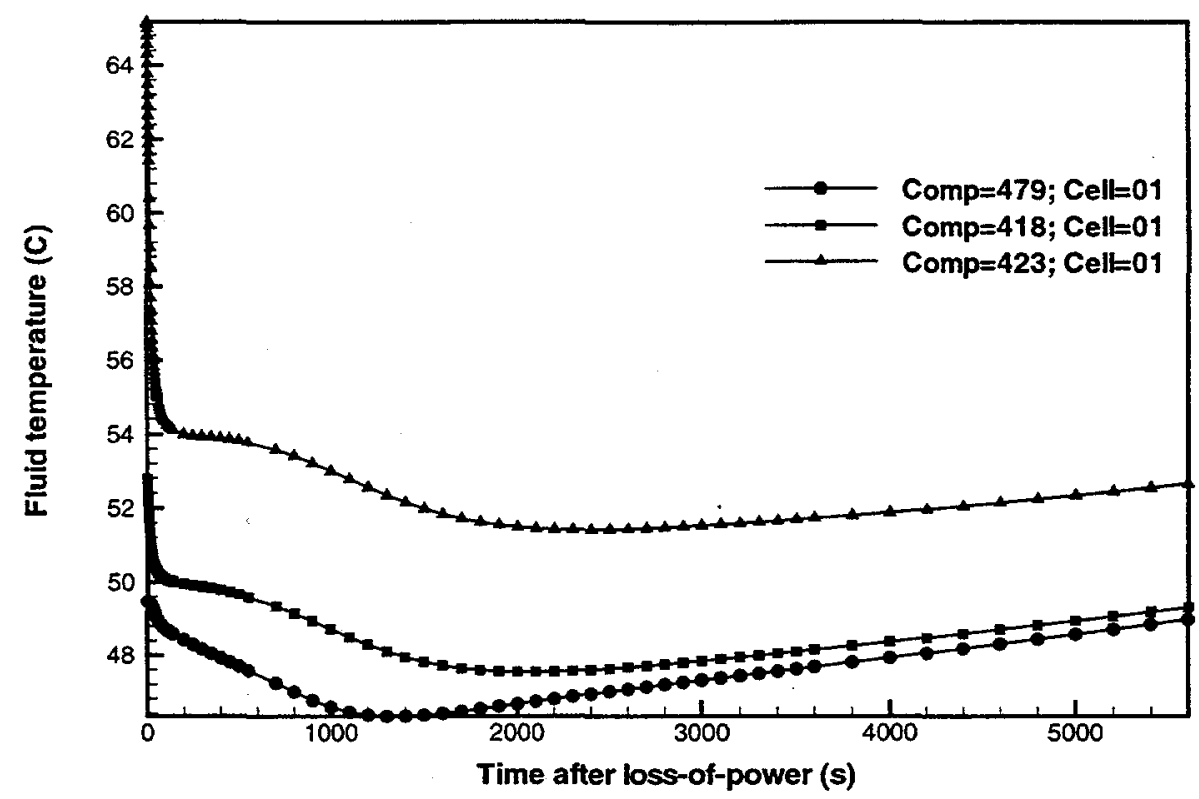

Figure B-4b Module 3 plenum fluid temperatures for a LOFA (Case 2: with beam shutdown only).

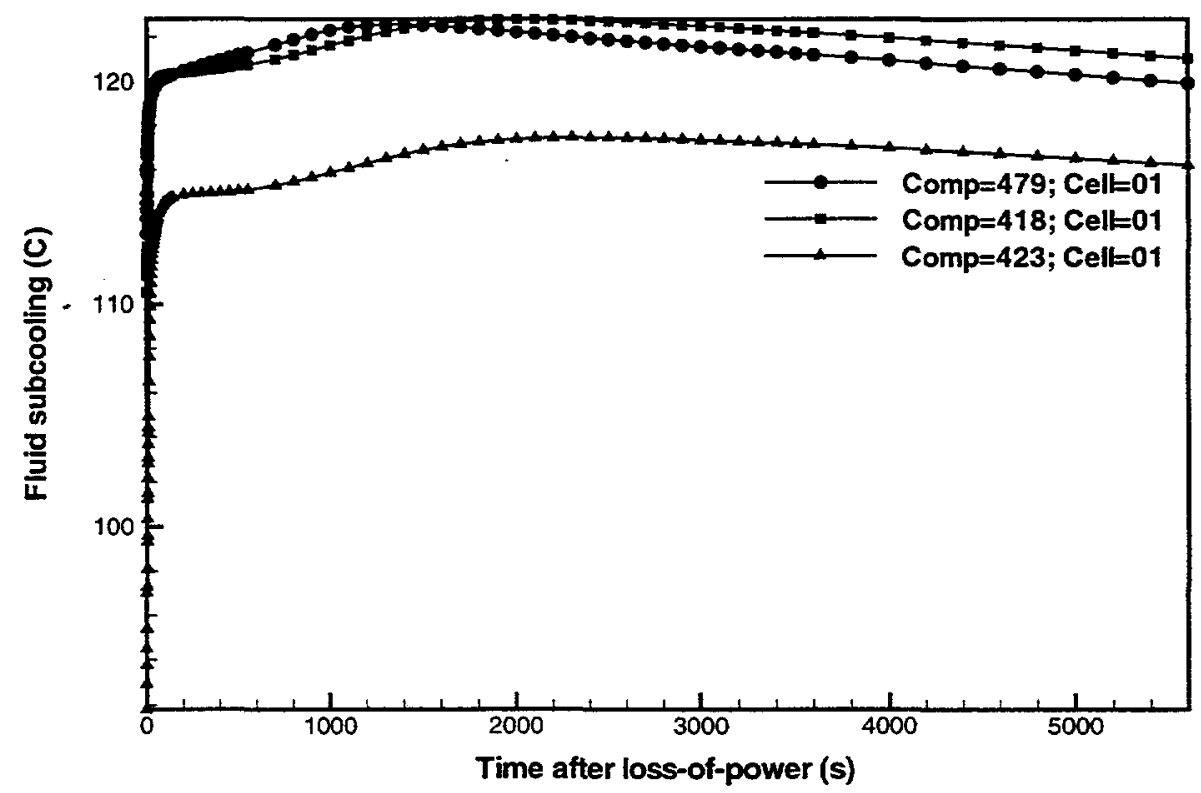

Figure B-4c Module 3 plenum fluid subcoolings for a LOFA (Case 2: with beam shutdown only). 


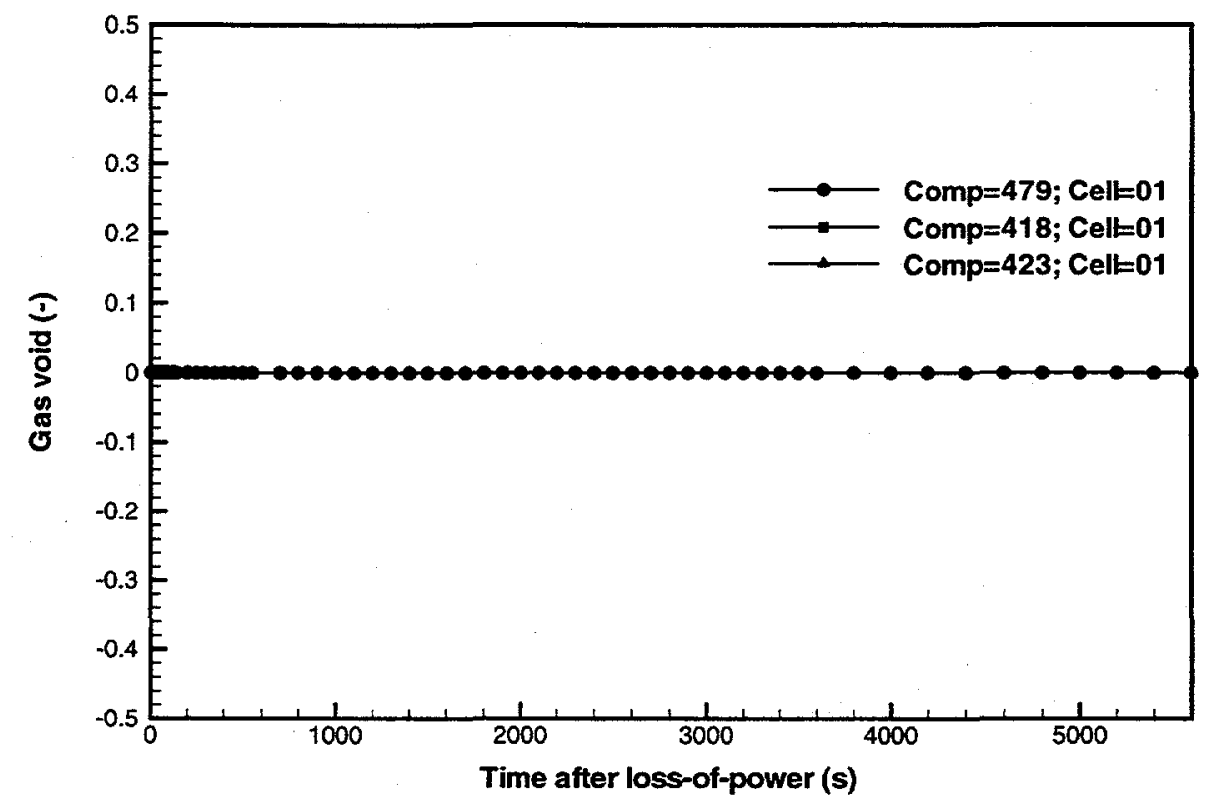

Figure B-4d Module 3 plenum void fractions for a LOFA (Case 2: with beam shutdown only).

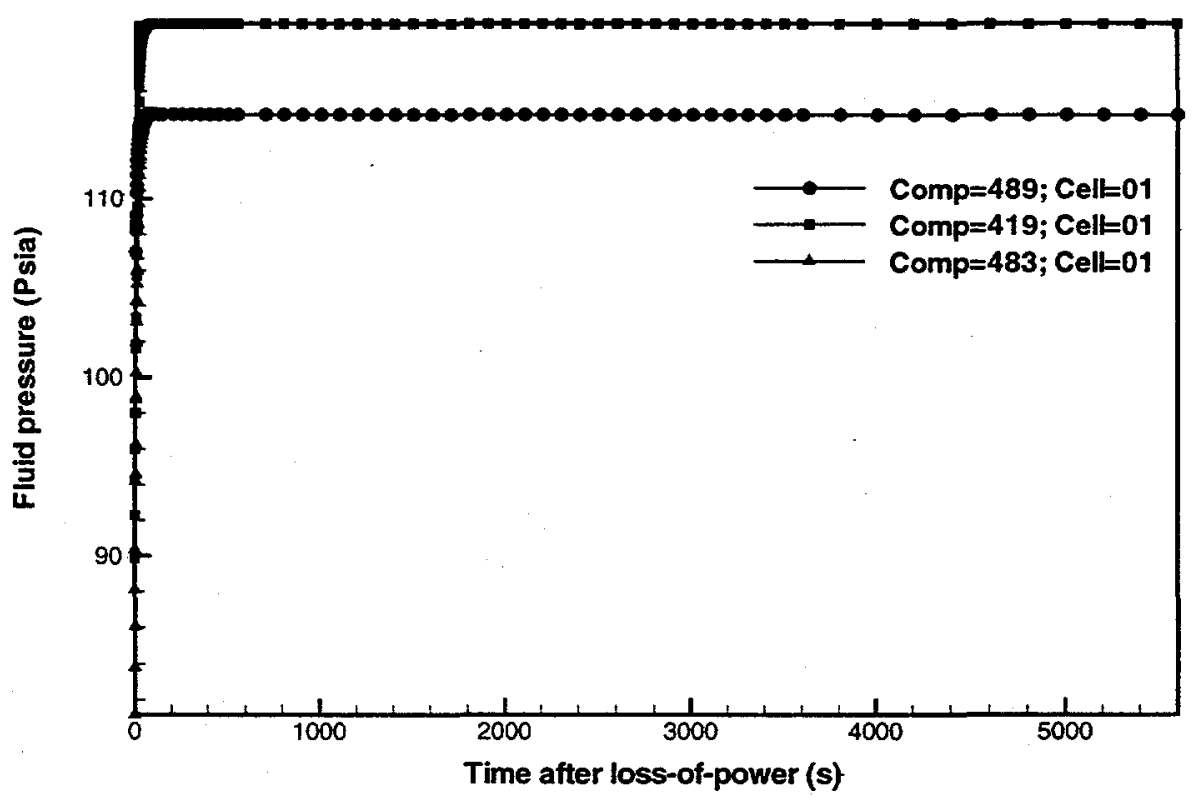

Figure B-5a Module 4 plenum fluid pressures for a LOFA (Case 2: with beam shutdown only). 


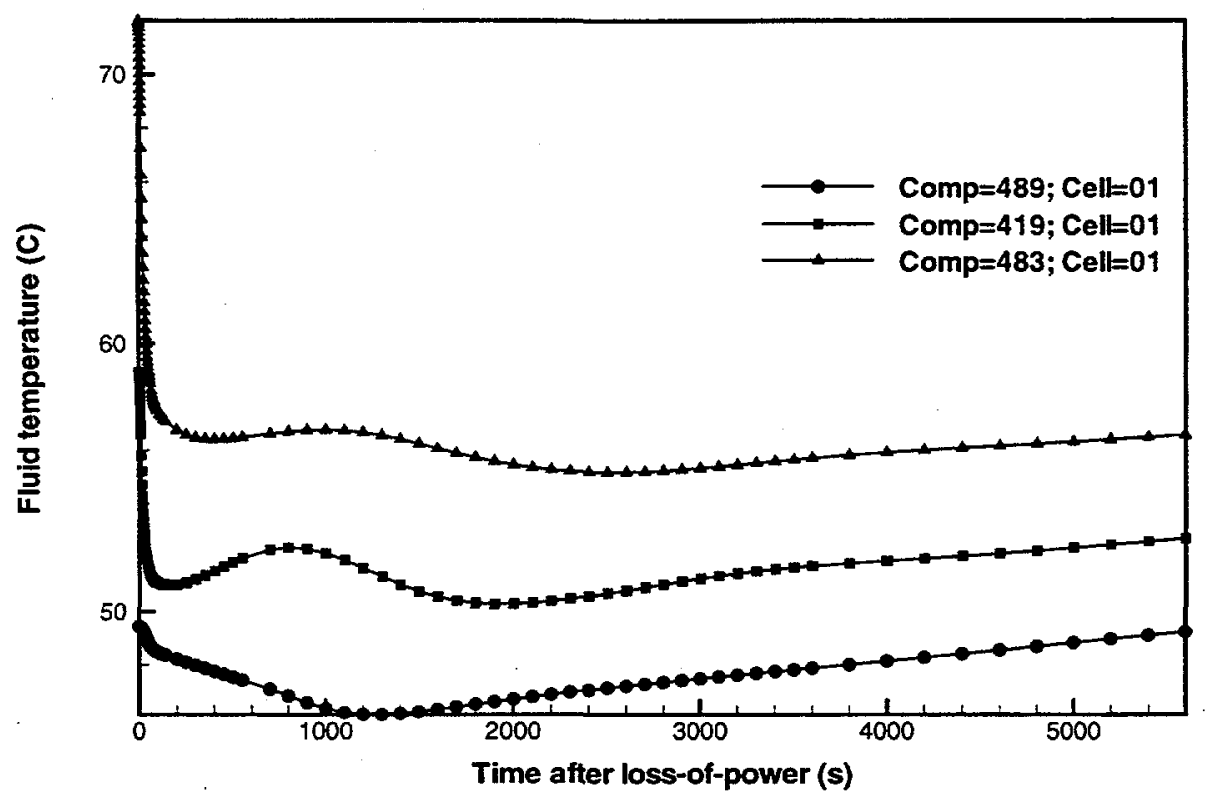

Figure B-5b Module 4 plenum fluid temperatures for a LOFA (Case 2: with beam shutdown only).

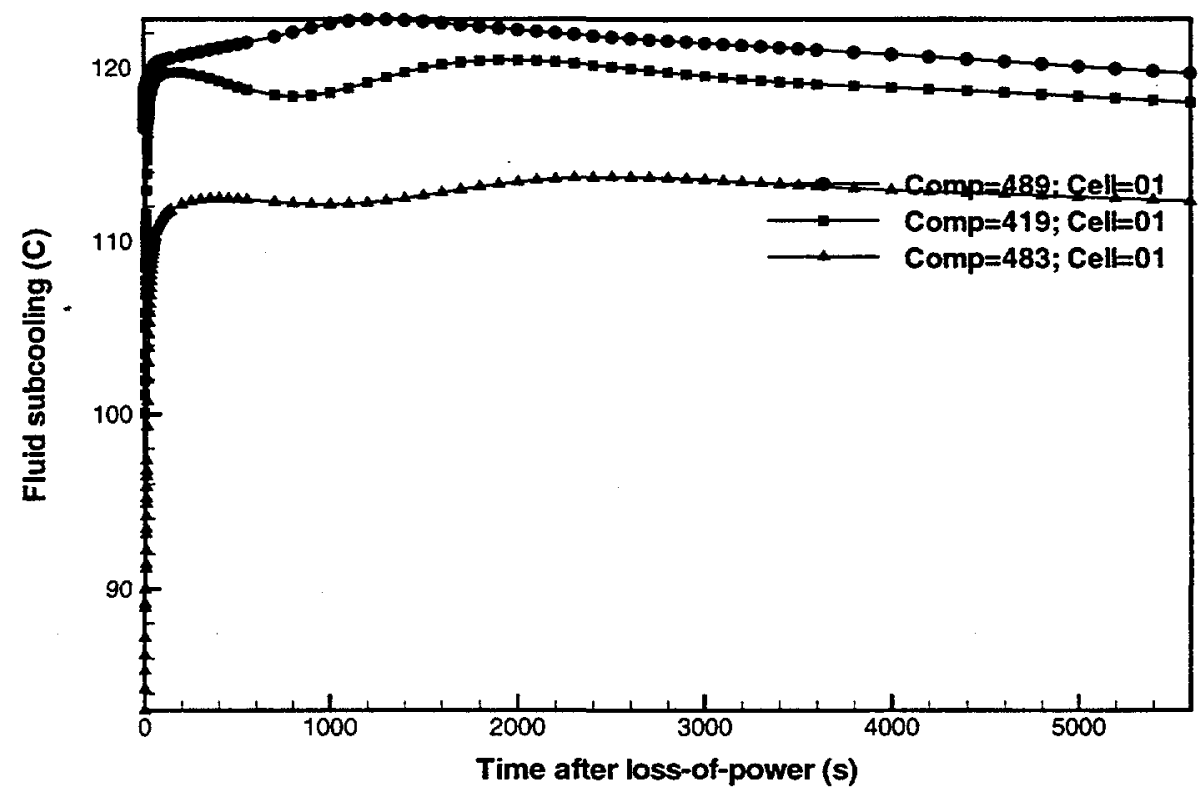

Figure B-5c Module 4 plenum fluid subcoolings for a LOFA (Case 2: with beam shutdown only). 


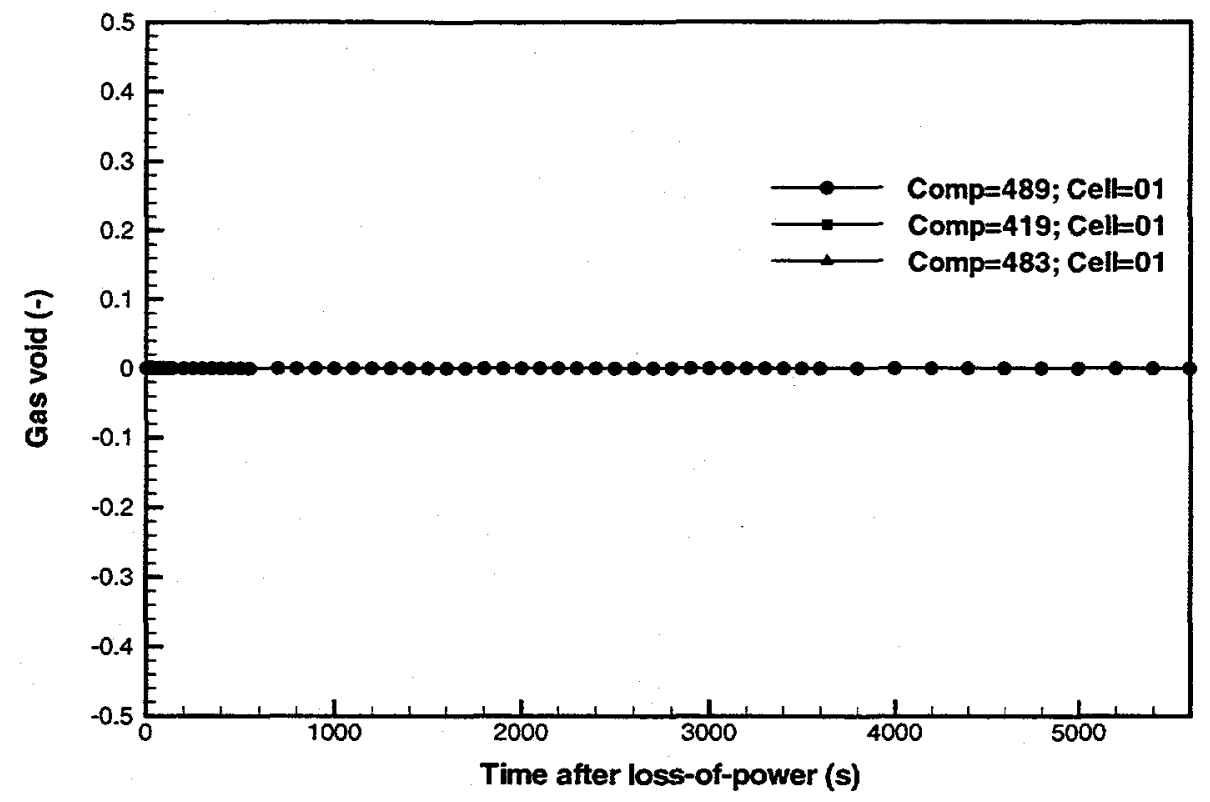

Figure B-5d Module 4 plenum void fractions for a LOFA (Case 2: with beam shutdown only).

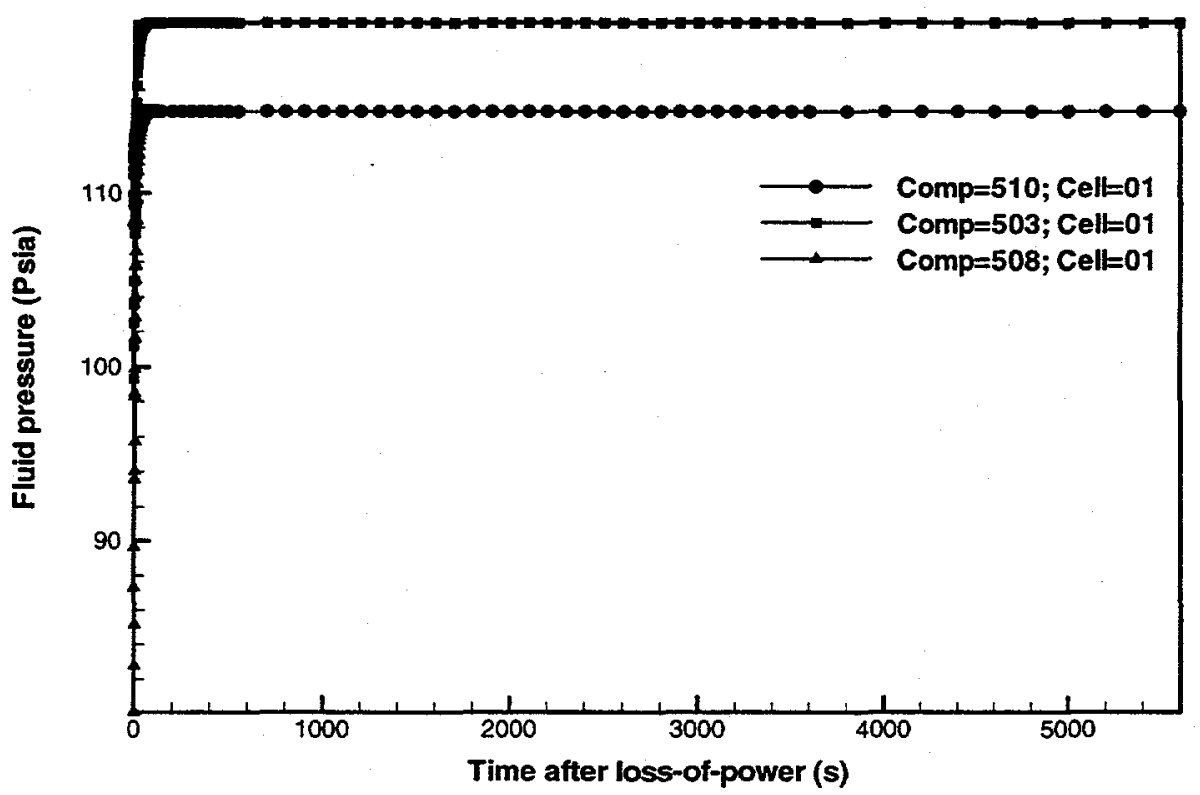

Figure B-6a Module 5 plenum fluid pressures for a LOFA (Case 2: with beam shutdown only). 


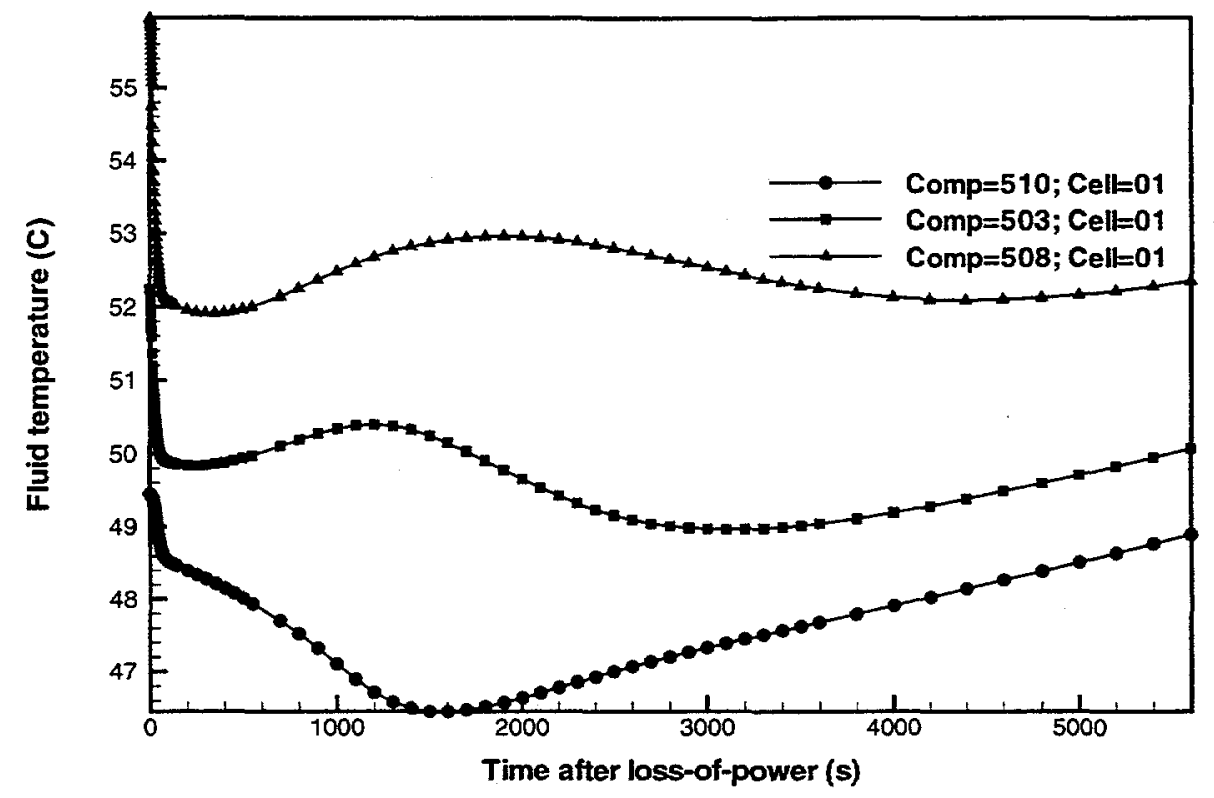

Figure B-6b Module 5 plenum fluid temperatures for a LOFA (Case 2: with beam shutdown only).

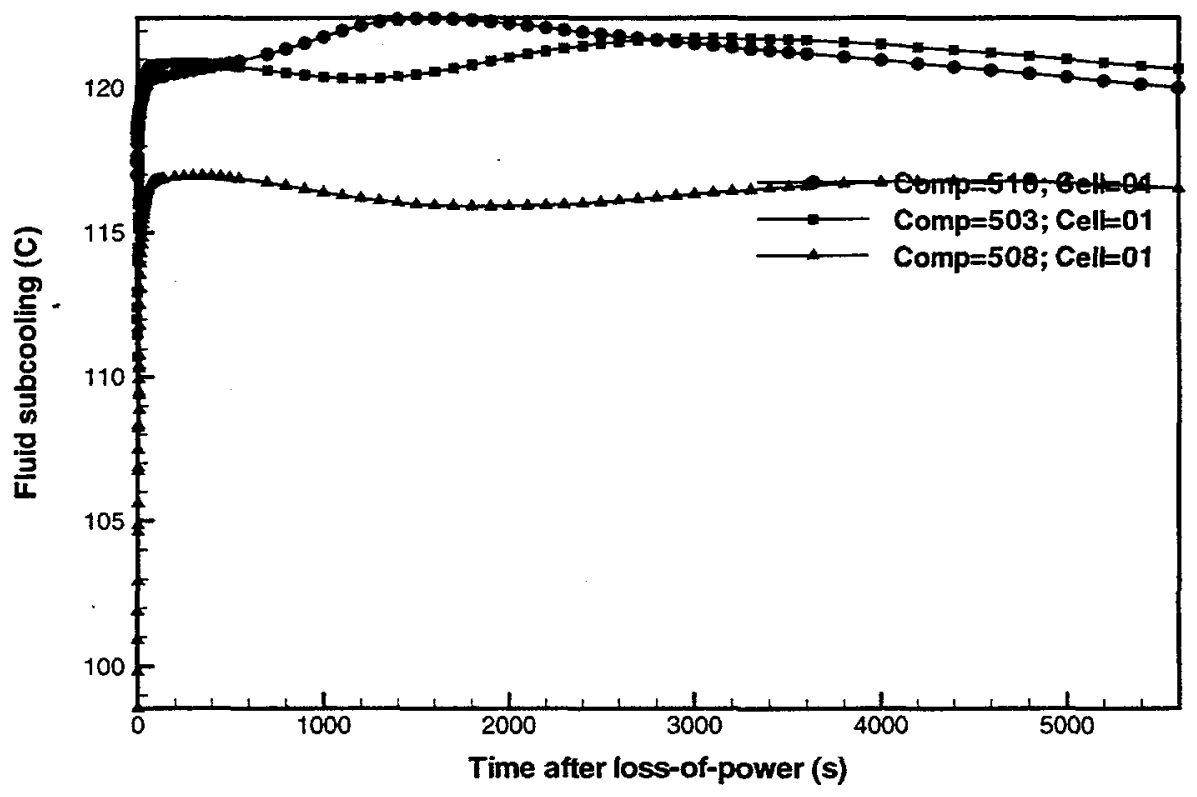

Figure B-6c Module 5 plenum fluid subcoolings for a LOFA (Case 2: with beam shutdown only). 


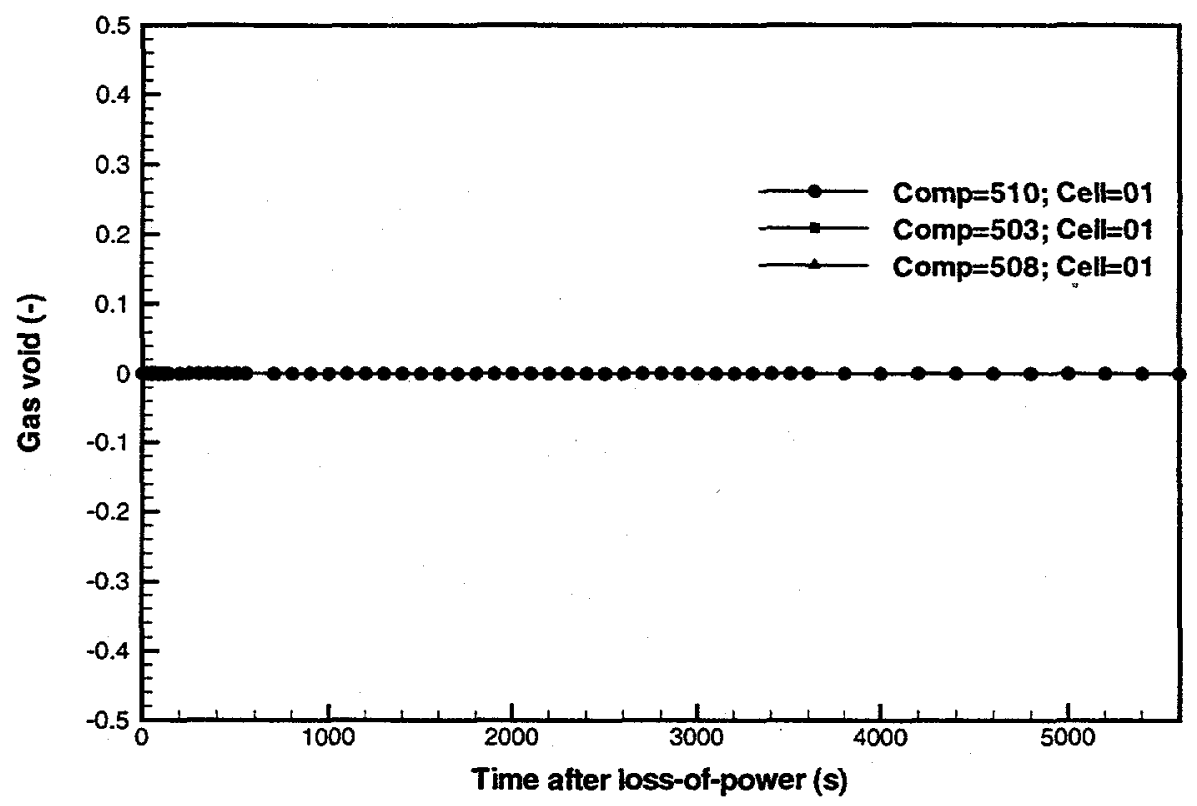

Figure B-6d Module 5 plenum void fractions for a LOFA (Case 2: with beam shutdown only).

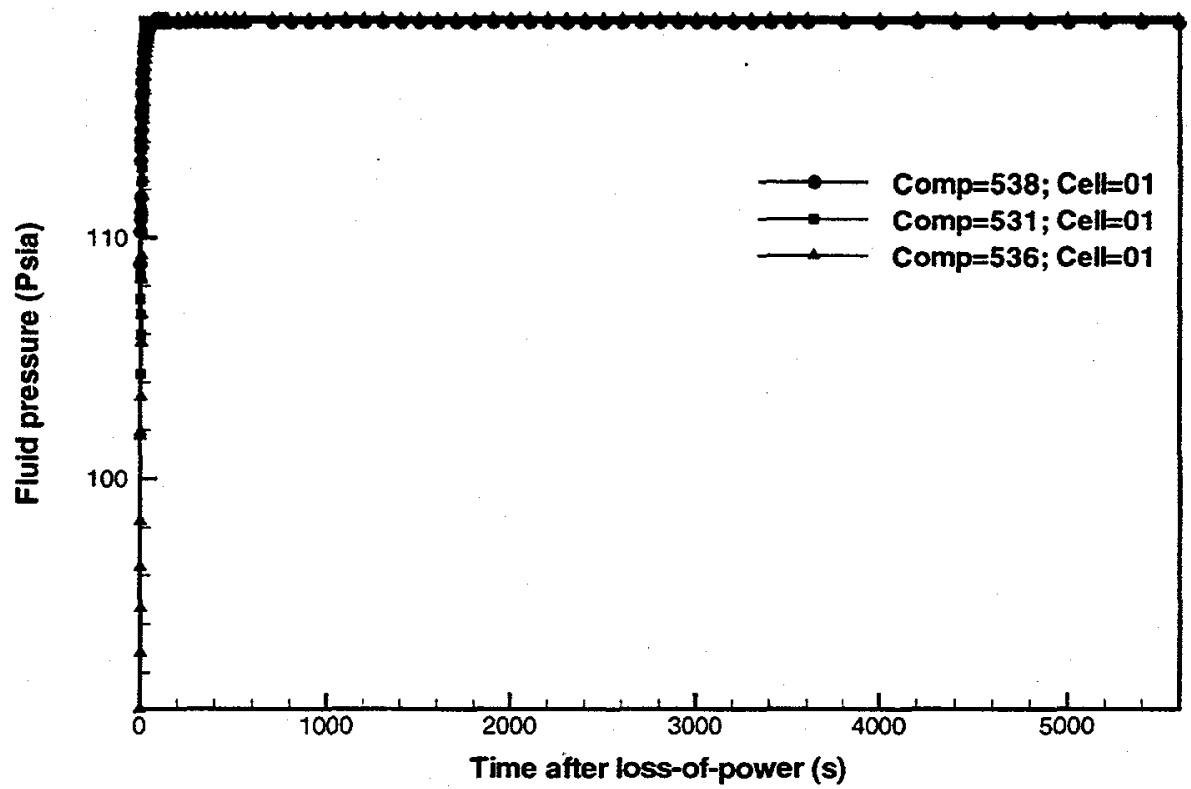

Figure B-7a Module 6 plenum fluid pressures for a LOFA (Case 2: with beam shutdown only). 


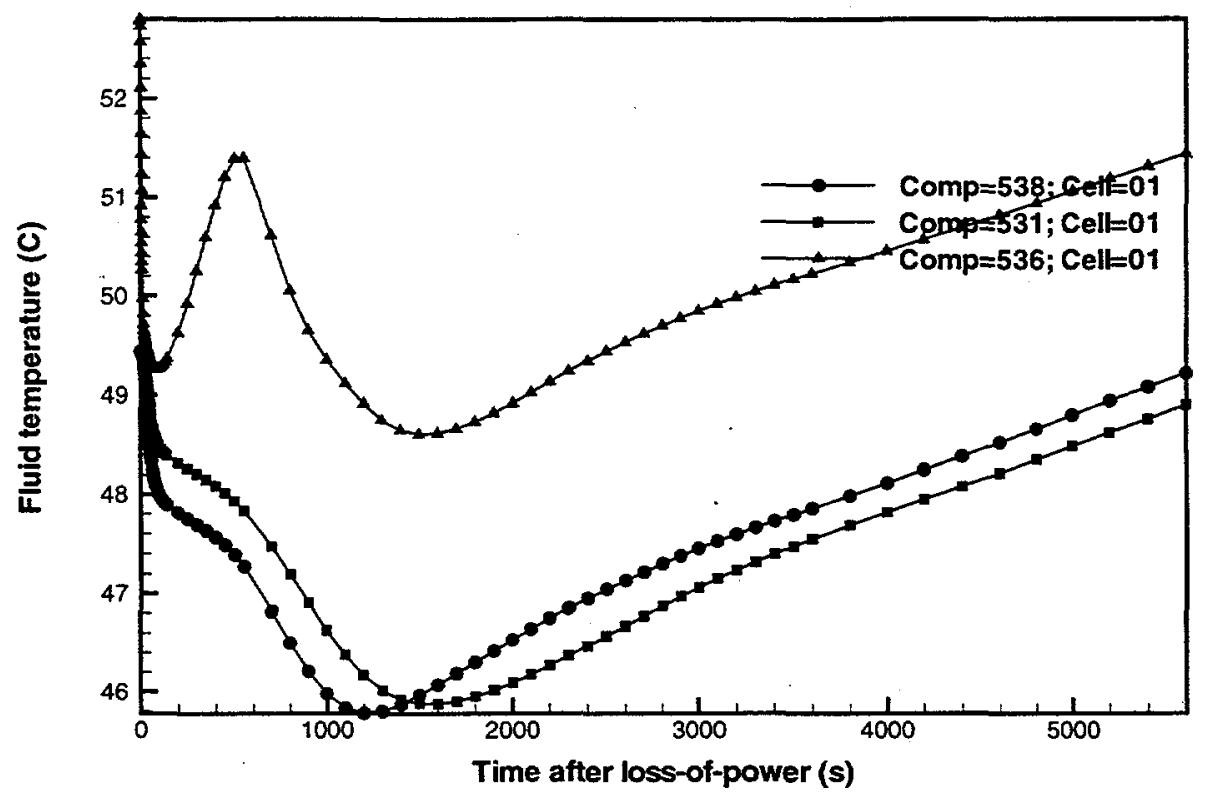

Figure B-7b Module 6 plenum fluid temperatures for a LOFA (Case 2 : with beam shutdown only).

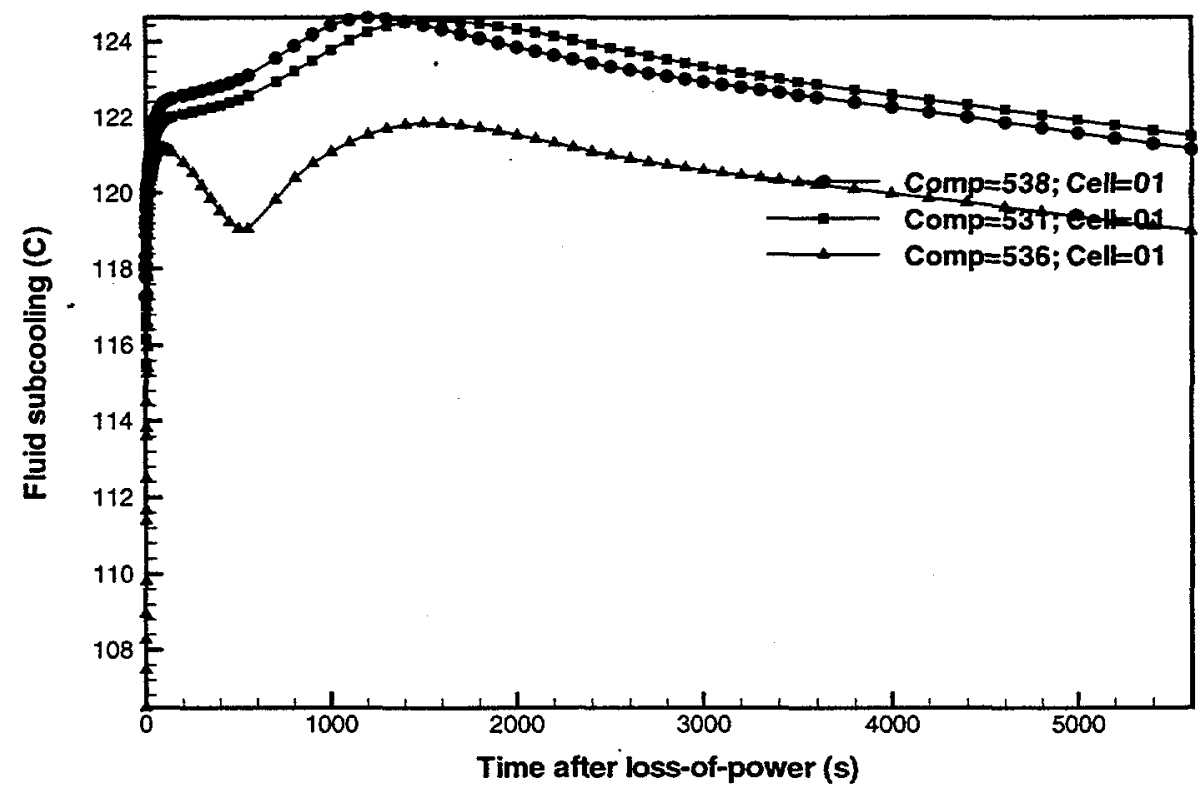

Figure B-7c Module 6 plenum fluid subcoolings for a LOFA (Case 2: with beam shutdown only). 


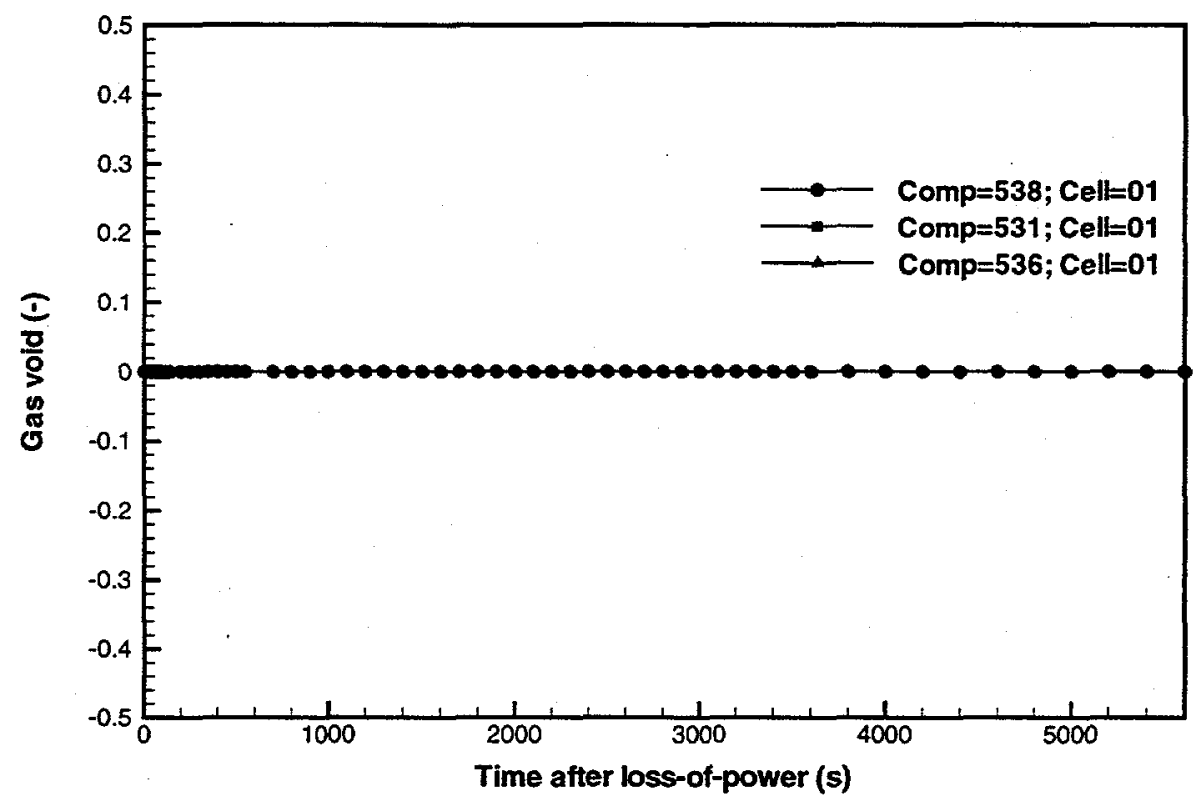

Figure B-7d Module 6 plenum void fractions for a LOFA (Case 2: with beam shutdown only). 


\section{Appendix B2 LOFA (Case 2) TRAC Pipe, Pump, and Valve Component} Figures

The following figures are from a TRAC simulation for Case 2 of a LOFA (with beam shutdown only):

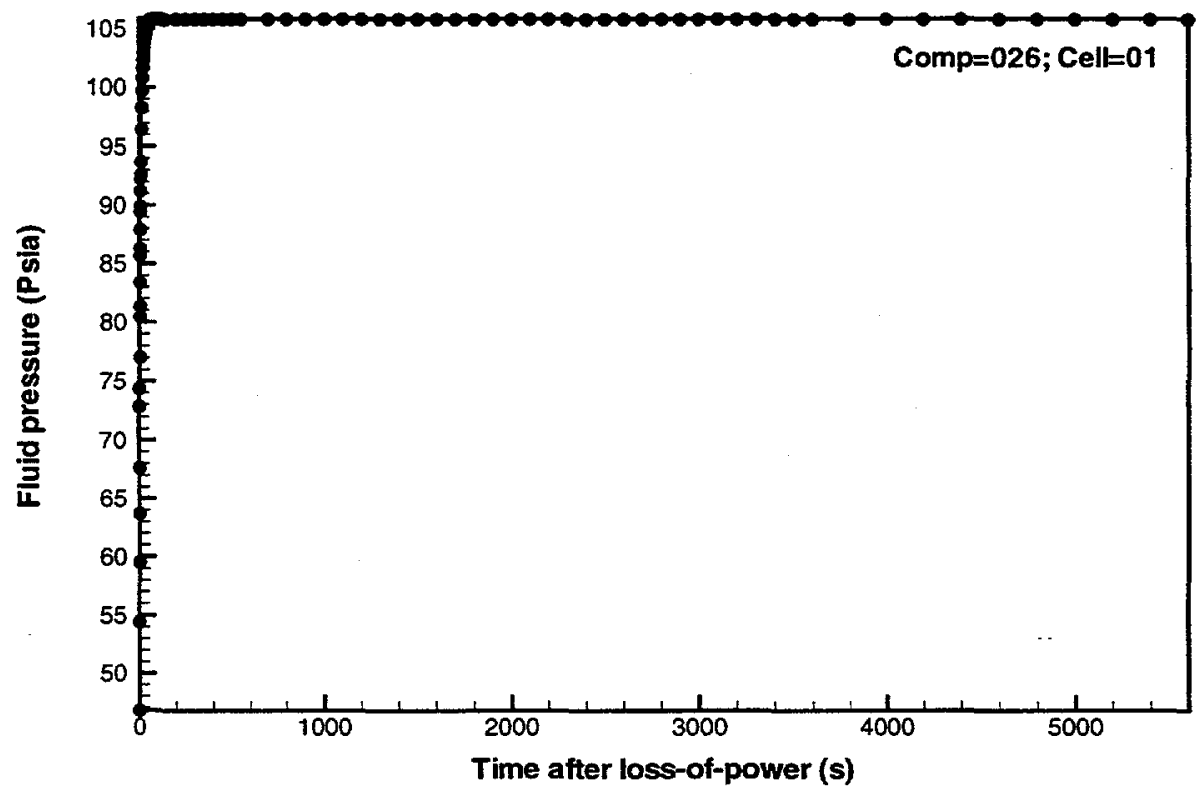

Figure B-8a Primary HR hot-leg piping fluid pressures for a LOFA (Case 2: with beam shutdown only). 


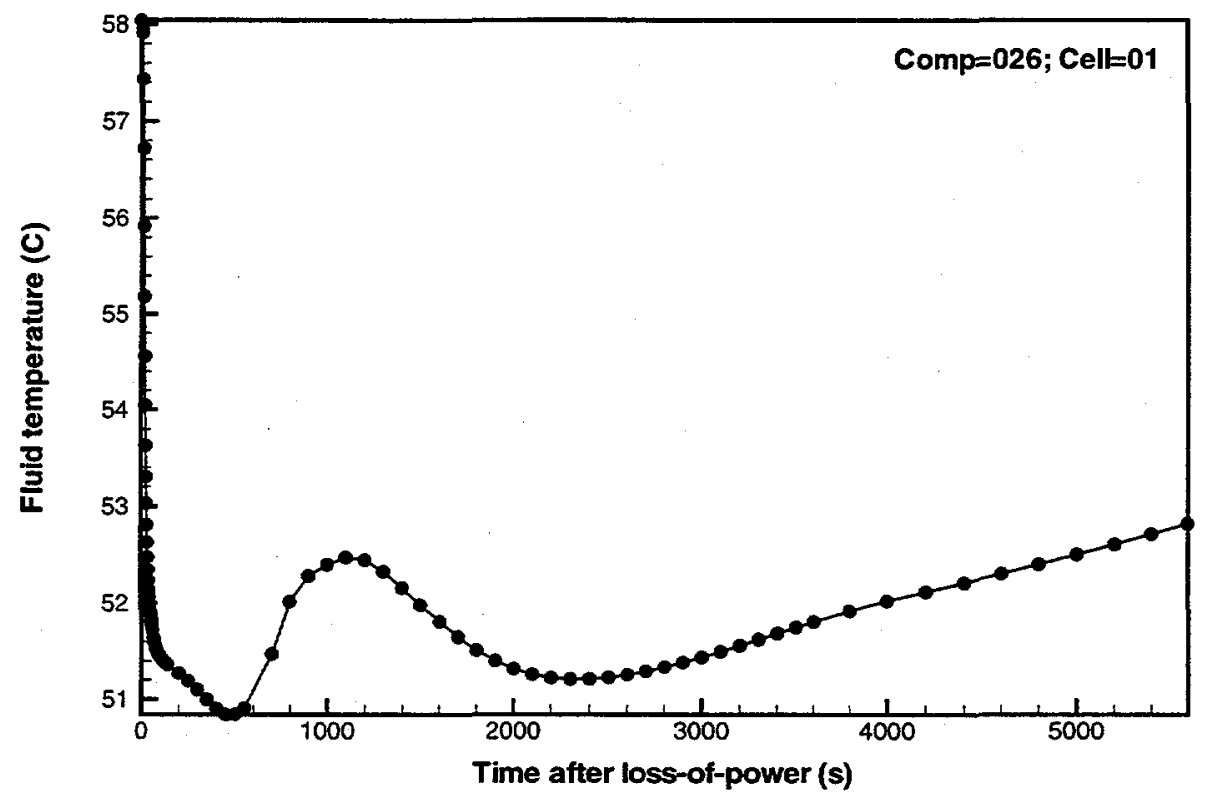

Figure B-8b Primary HR hot-leg piping fluid temperatures for a LOFA (Case 2: with beam shutdown only).

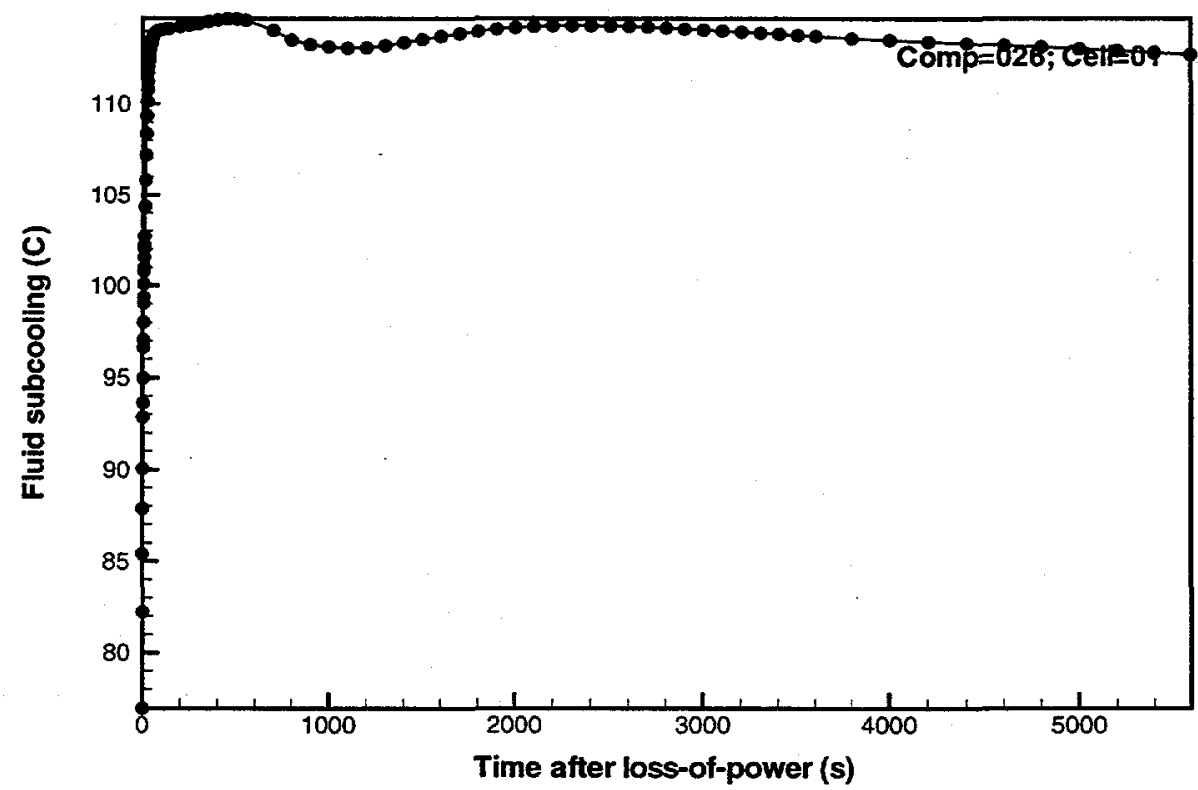

Figure B-8c Primary HR hot-leg piping fluid subcoolings for a LOFA (Case 2: with beam shutdown only). 


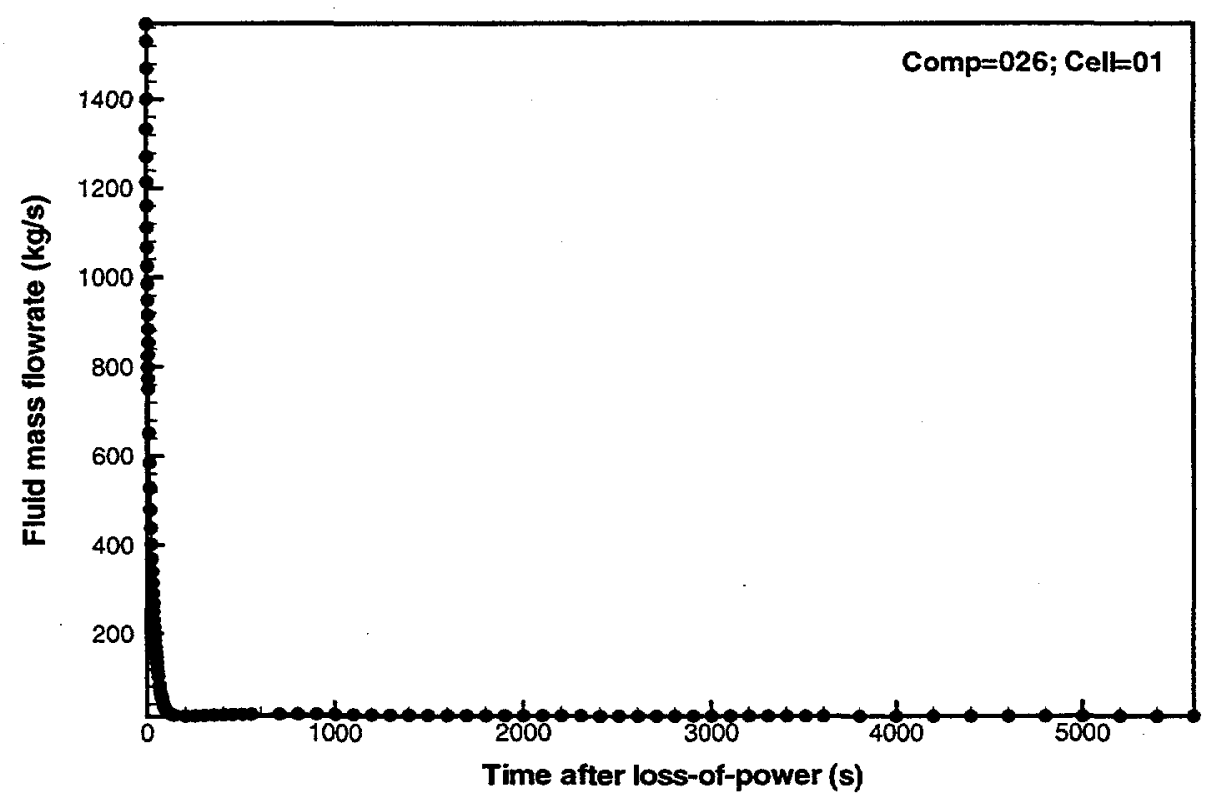

Figure B-8d Primary HR hot-leg piping liquid mass flowrates for a LOFA (Case 2: with beam shutdown only).

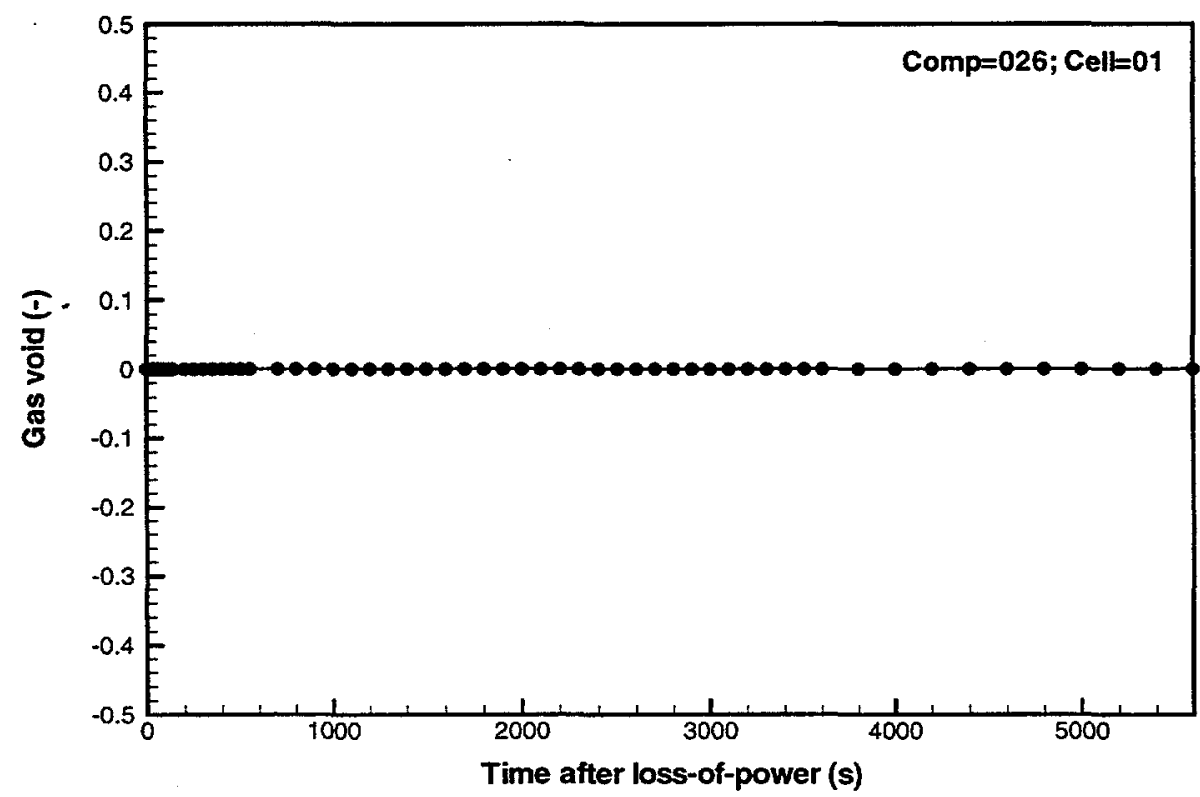

Figure B-8e Primary HR hot-leg piping void fractions for a LOFA (Case 2: with beam shutdown only). 


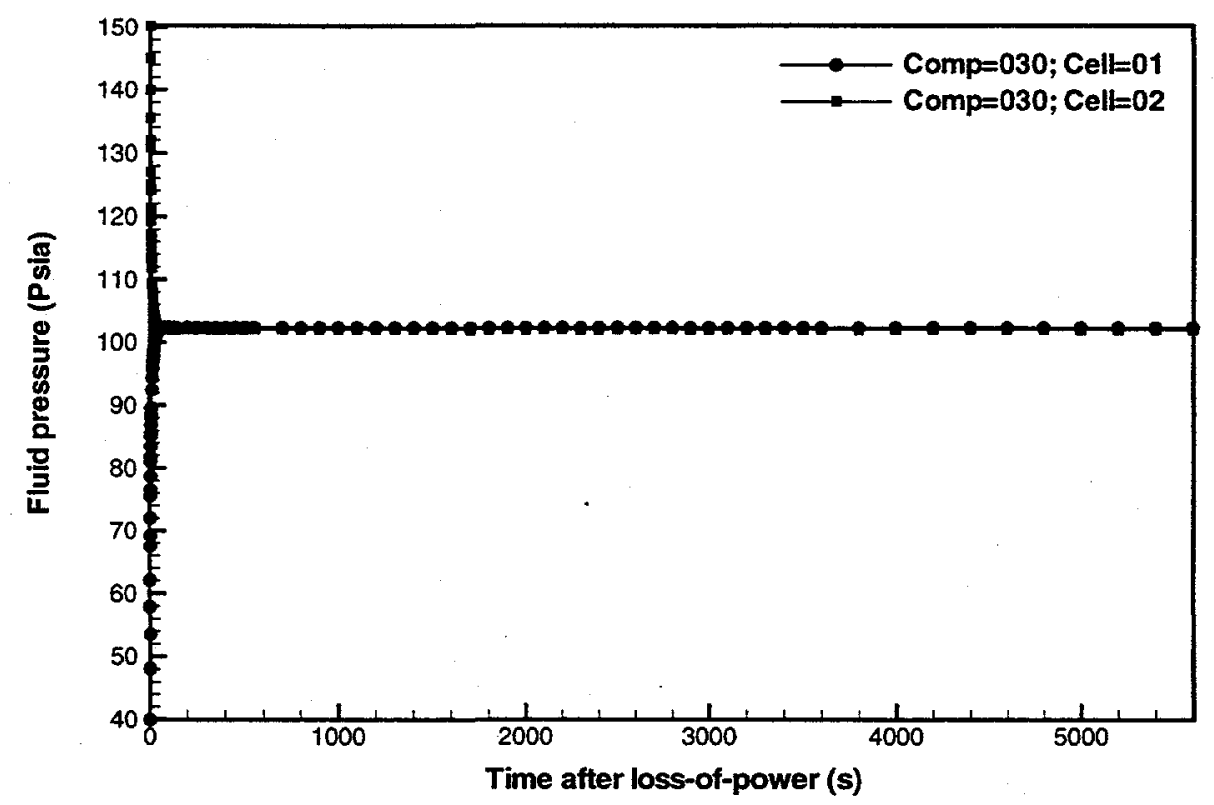

Figure B-9a Primary HR pump 1 fluid pressures for a LOFA (Case 2: with beam shutdown only).

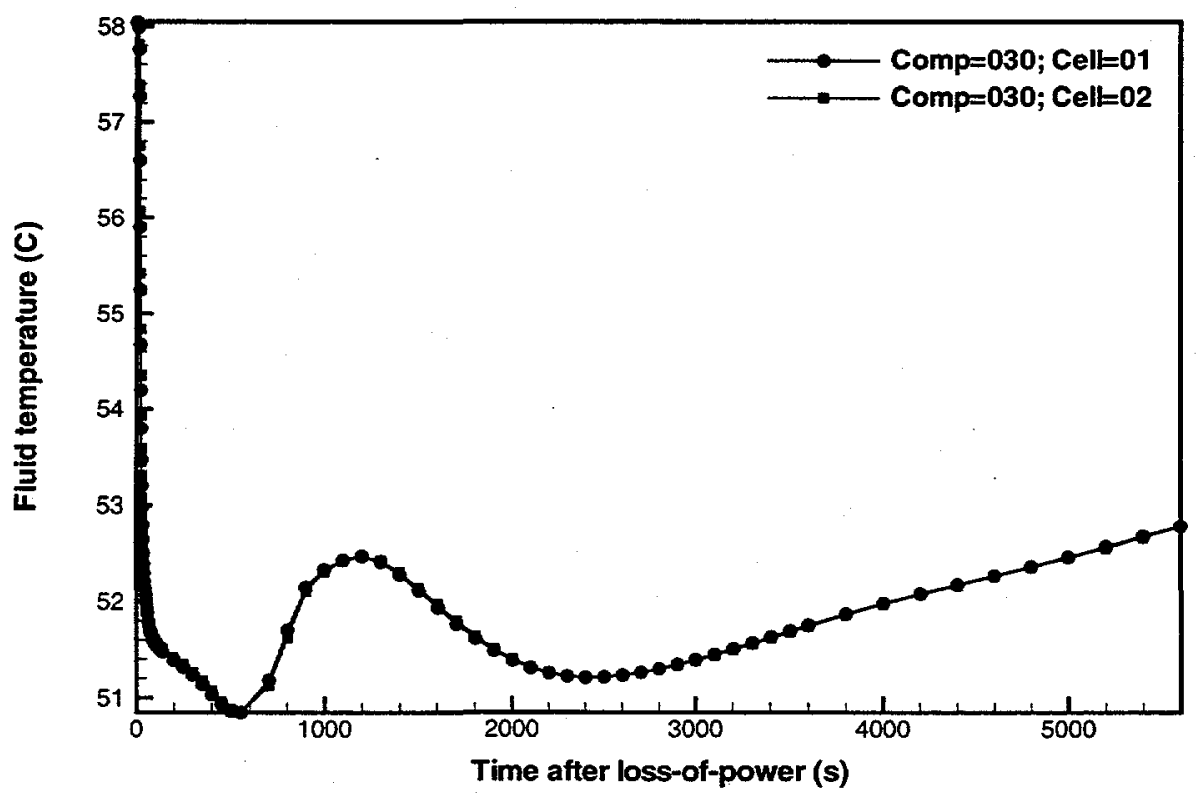

Figure B-9b Primary HR pump 1 fluid temperatures for a LOFA (Case 2: with beam shutdown only). 


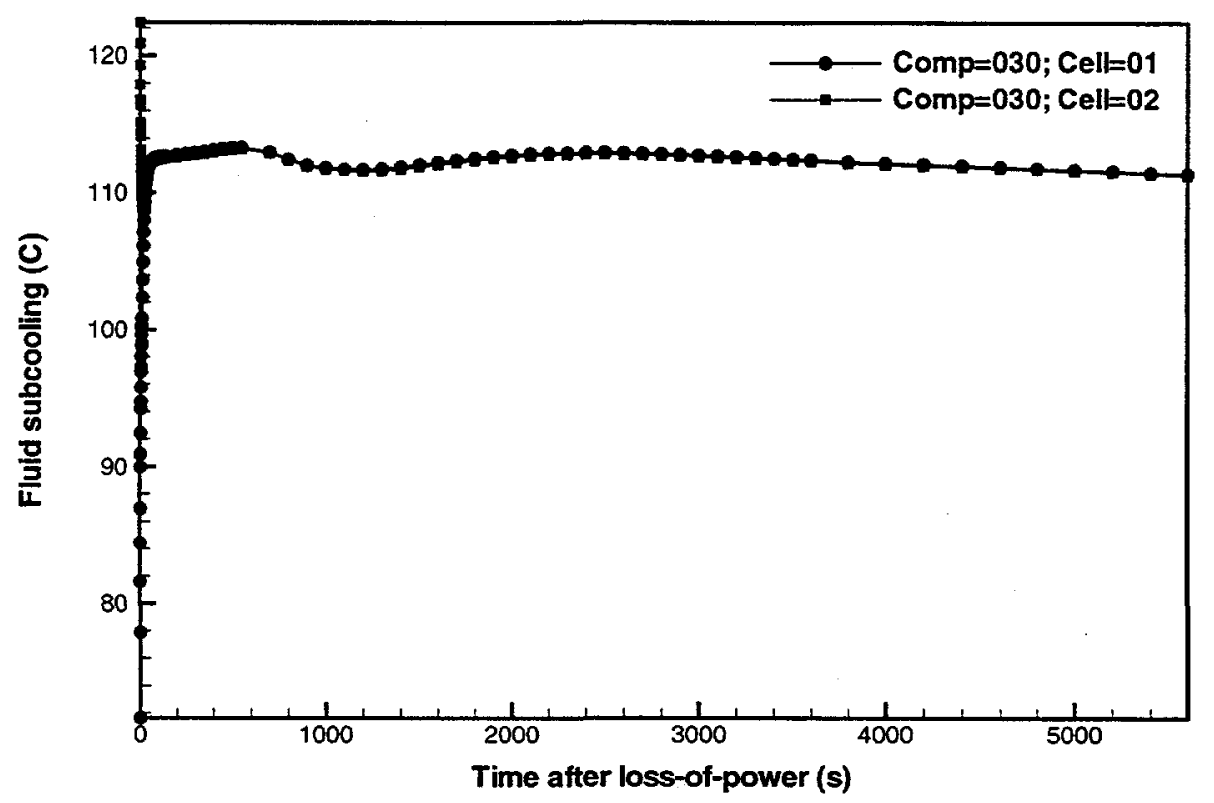

Figure B-9c Primary HR pump 1 fluid subcoolings for a LOFA (Case 2: with beam shutdown only).

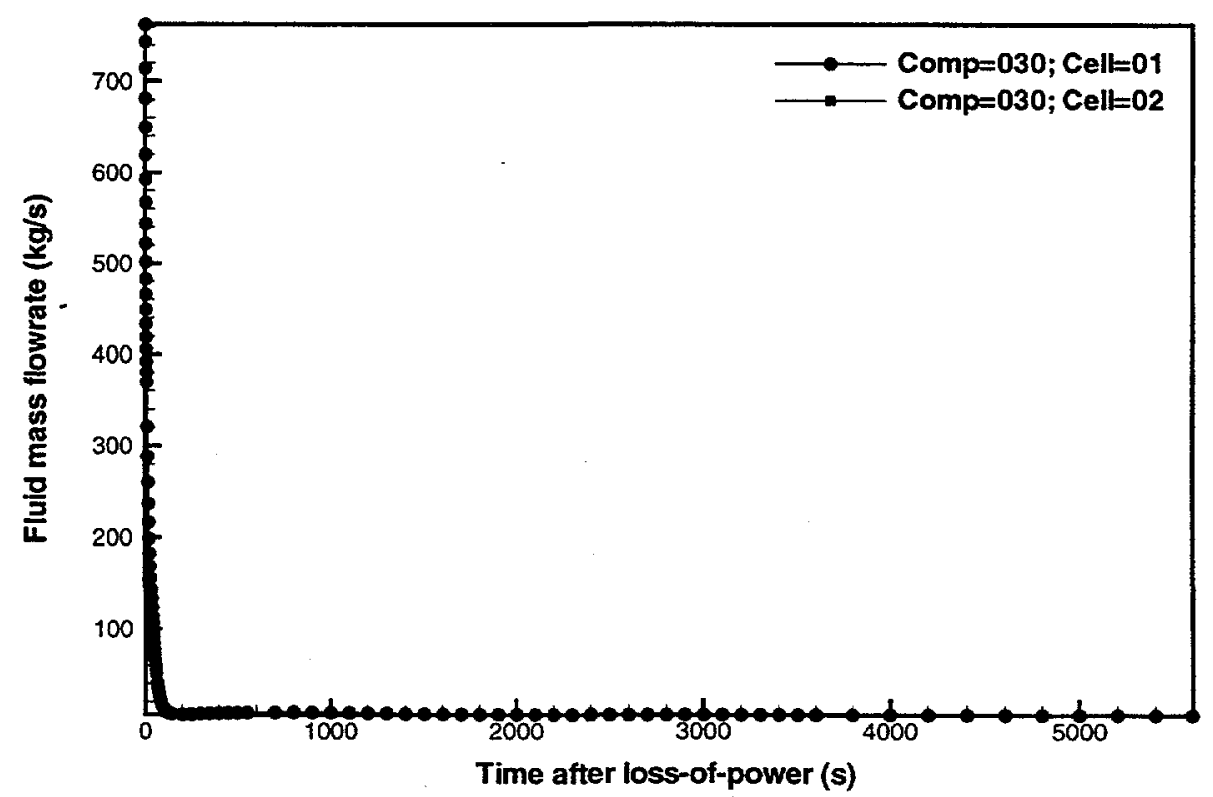

Figure B-9d Primary HR pump 1 liquid mass flowrates for a LOFA (Case 2: with beam shutdown only). 


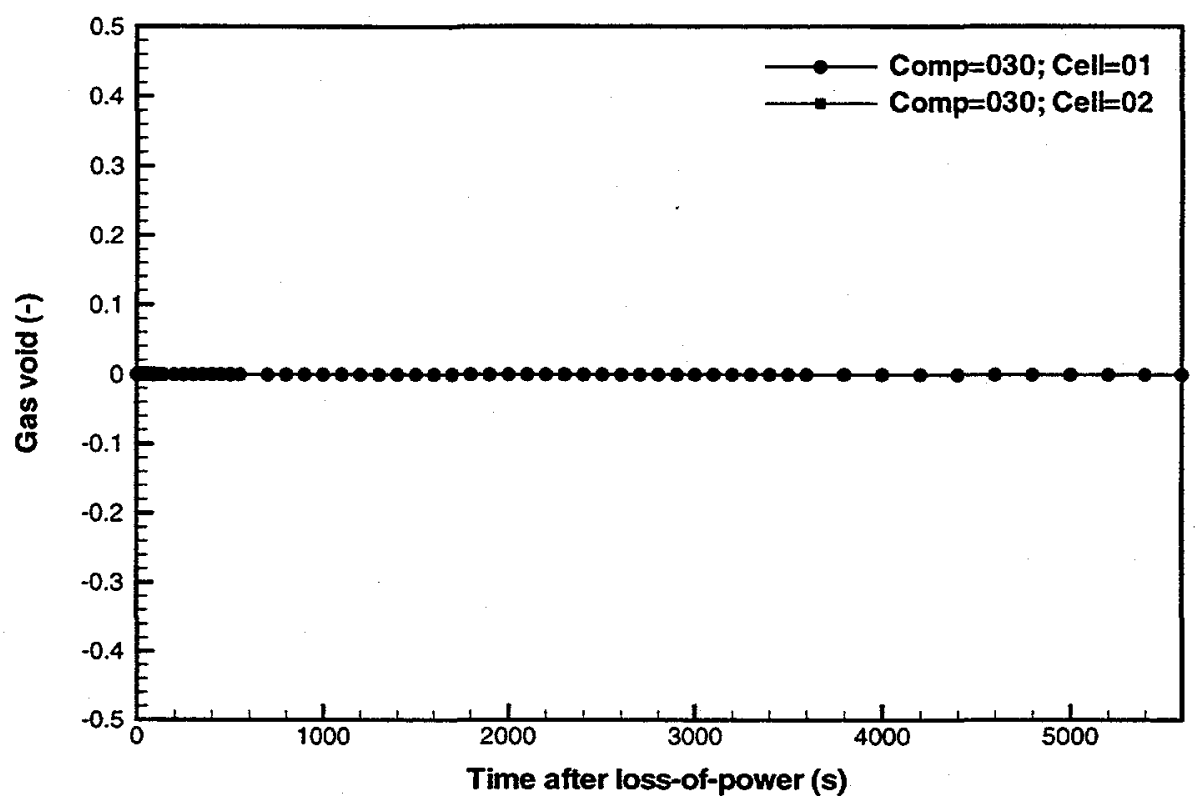

Figure B-9e Primary HR pump 1 void fractions for a LOFA (Case 2: with beam shutdown only).

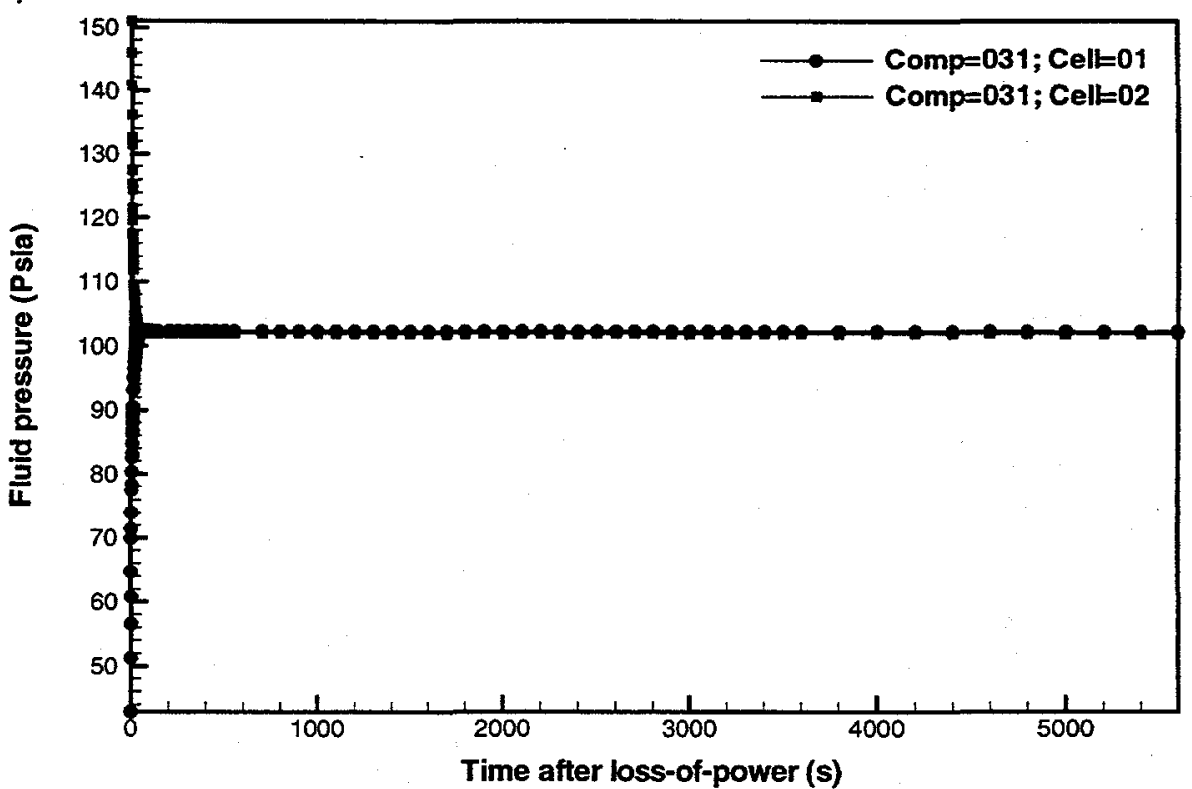

Figure B-10a Primary HR pump 2 fluid pressures for a LOFA (Case 2: with beam shutdown only). 


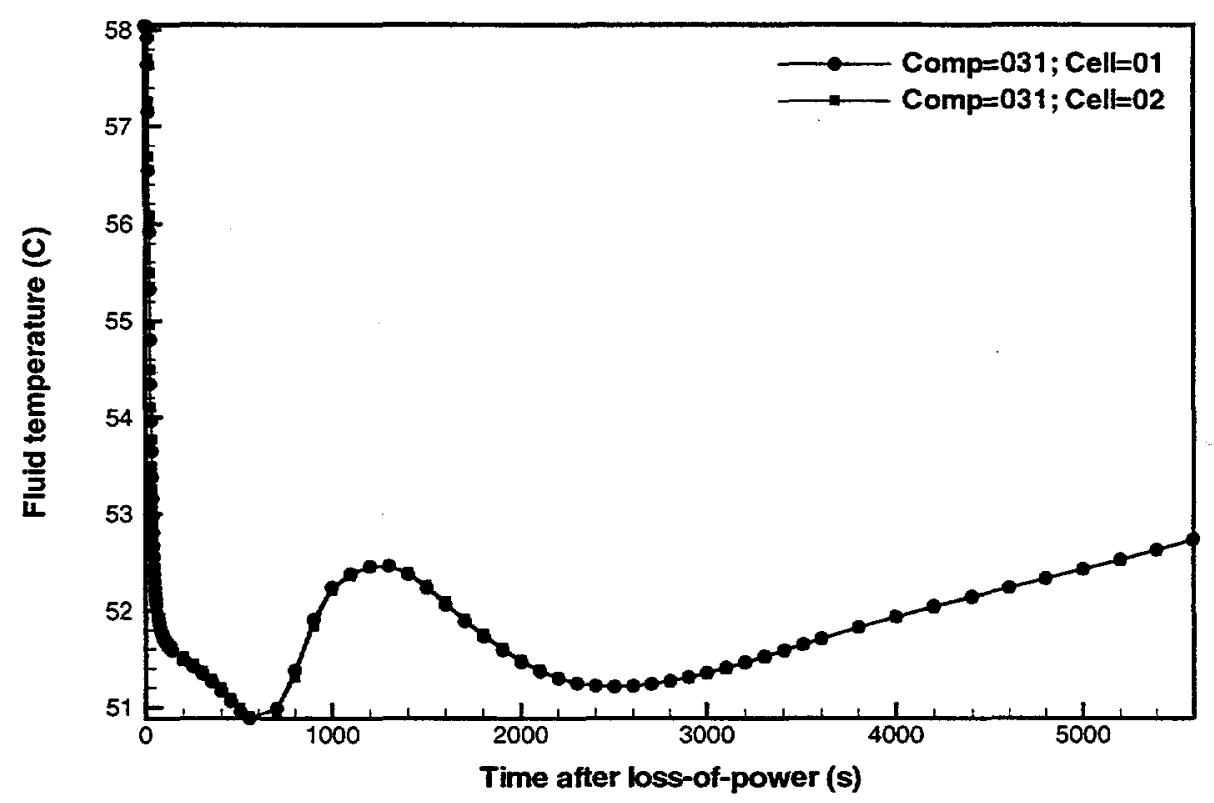

Figure B-10b Primary HR pump 2 fluid temperatures for a LOFA (Case 2: with beam shutdown only).

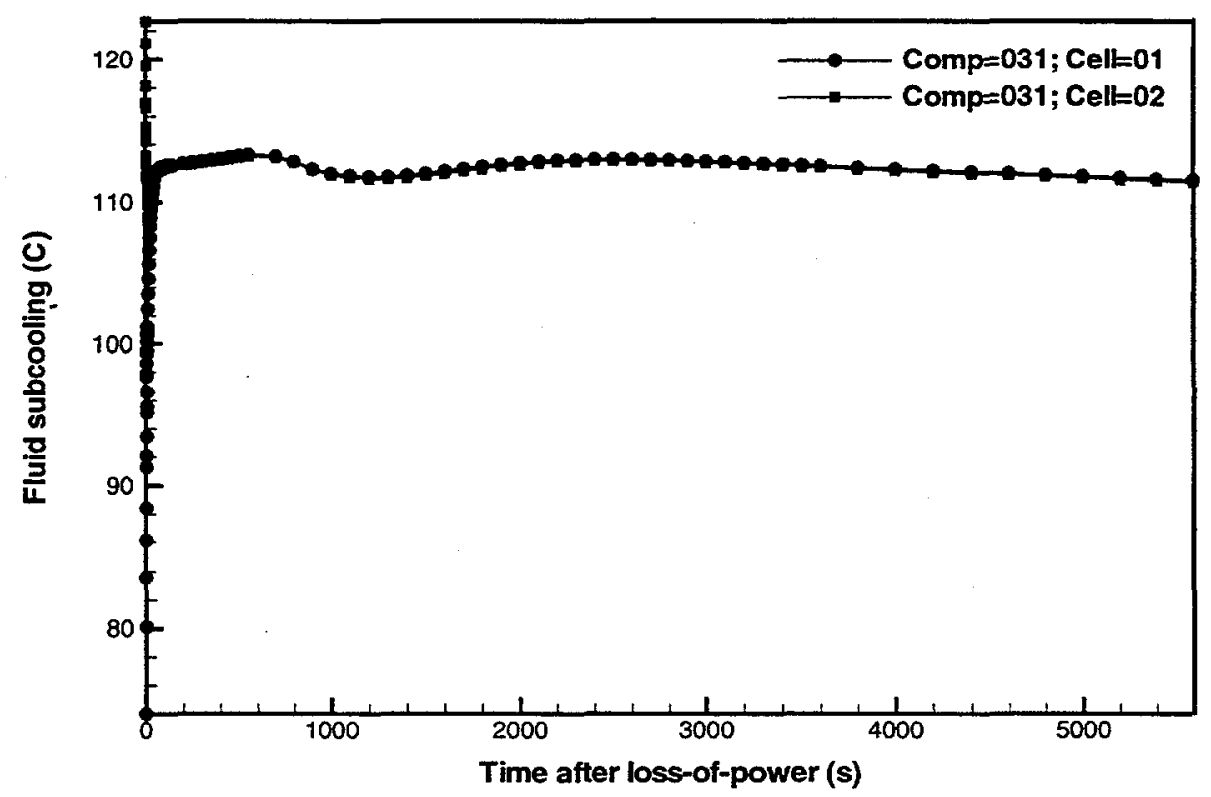

Figure B-10c Primary HR pump 2 fluid subcoolings for a LOFA (Case 2: with beam shutdown only). 


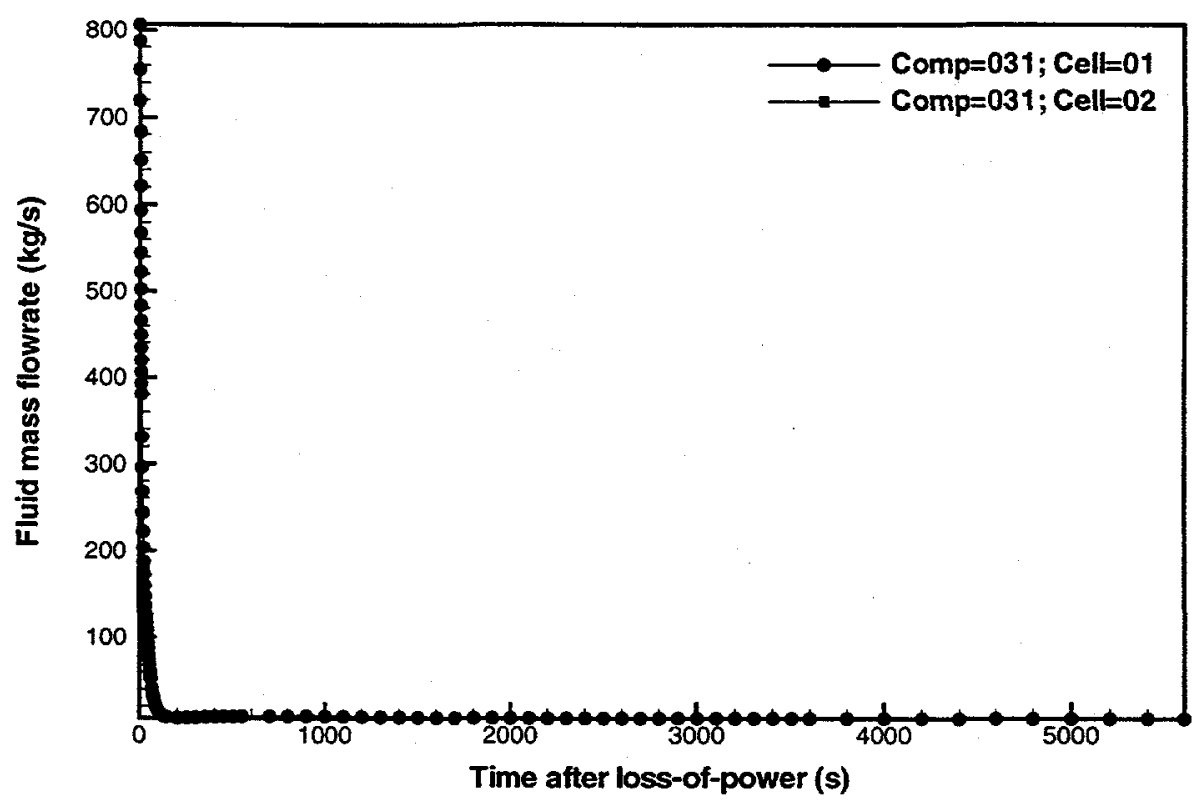

Figure B-10d Primary HR pump 2 liquid mass flowrates for a LOFA (Case 2: with beam shutdown only).

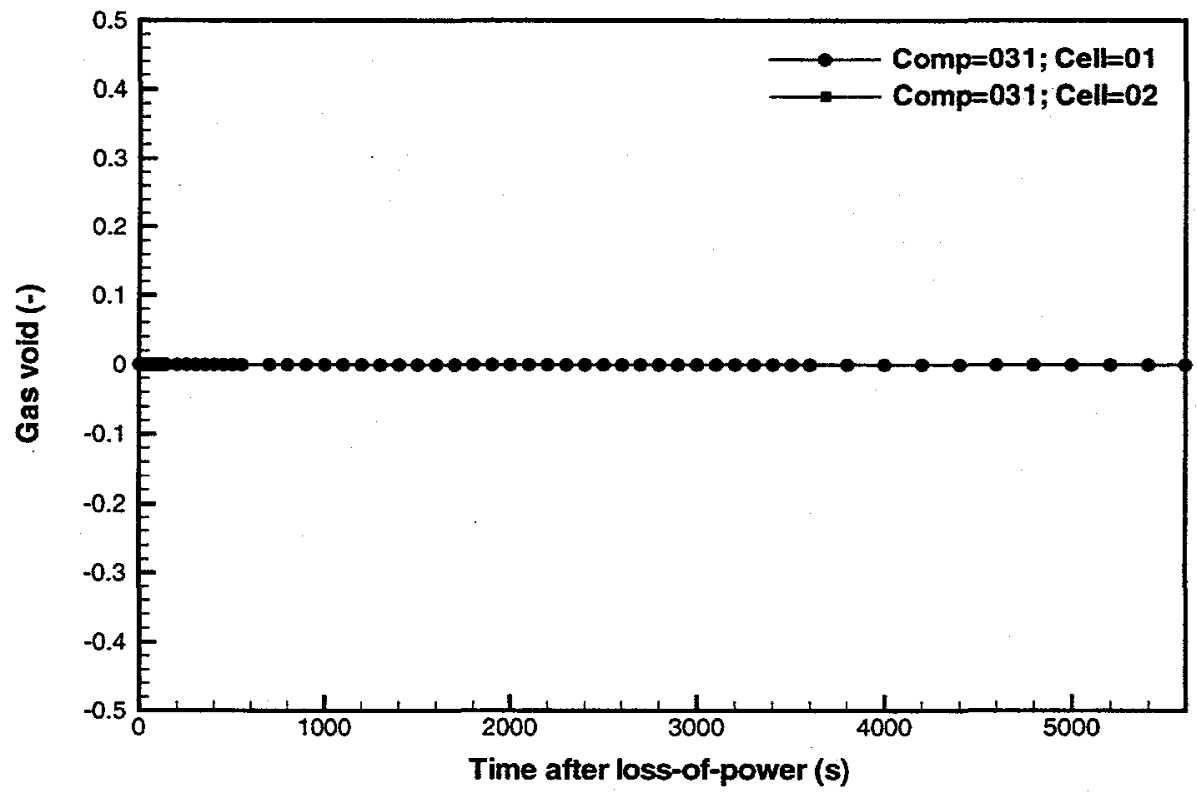

Figure B-10e Primary HR pump 2 void fractions for a LOFA (Case 2: with beam shutdown only). 


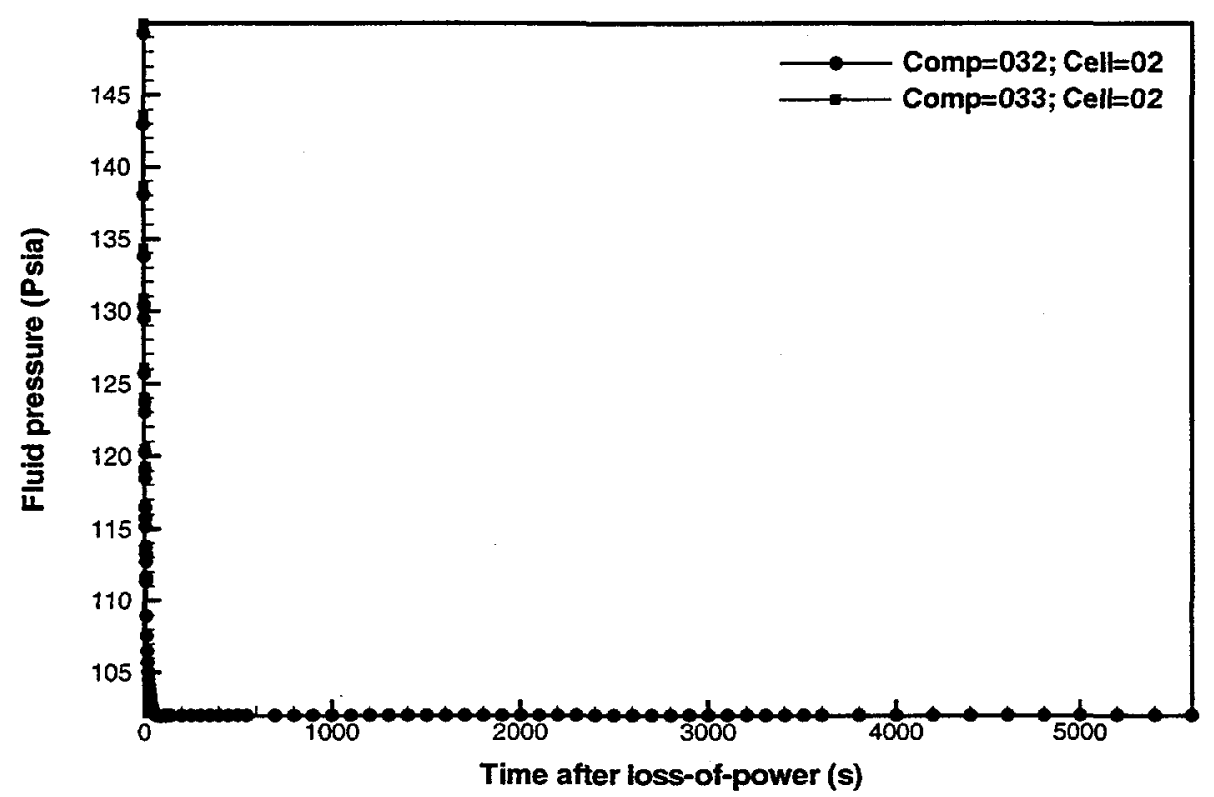

Figure B-11a Primary HR pump discharge piping fluid pressures for a LOFA (Case 2: with beam shutdown only).

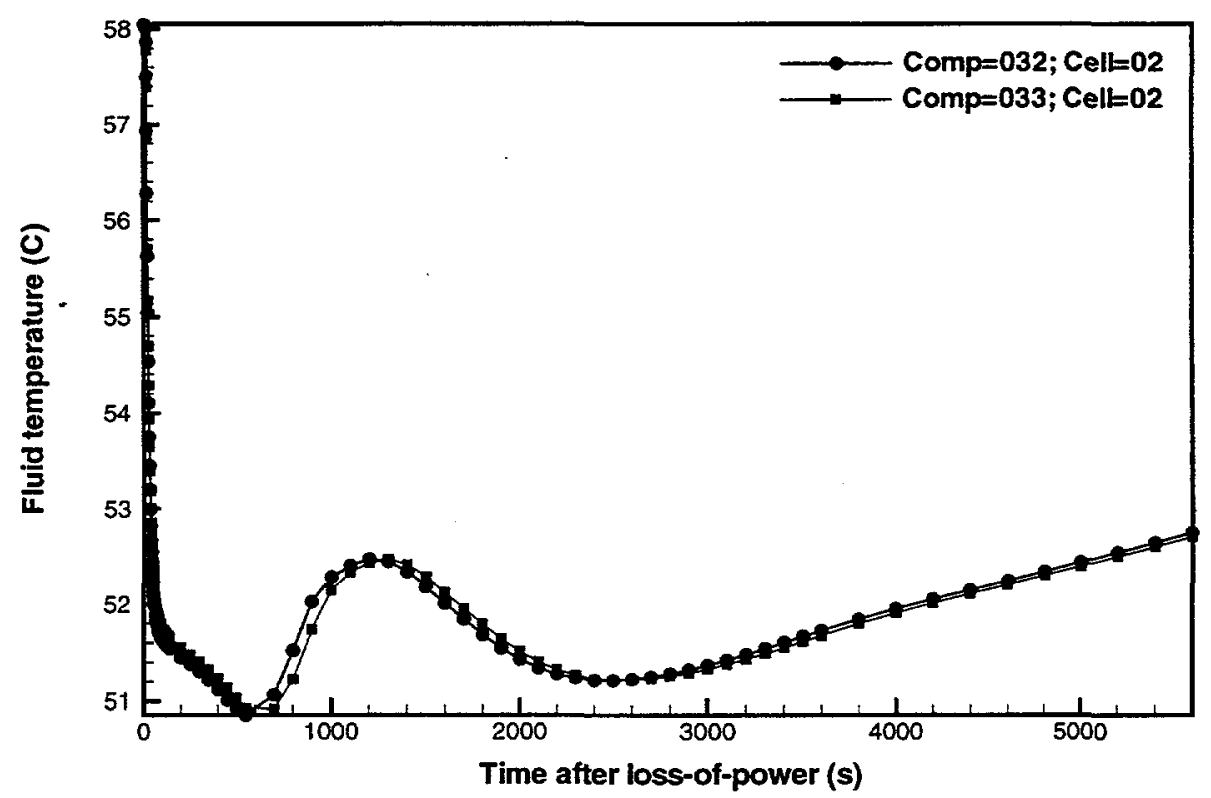

Figure B-11b Primary HR pump discharge piping fluid temperatures for a LOFA (Case 2: with beam shutdown only). 


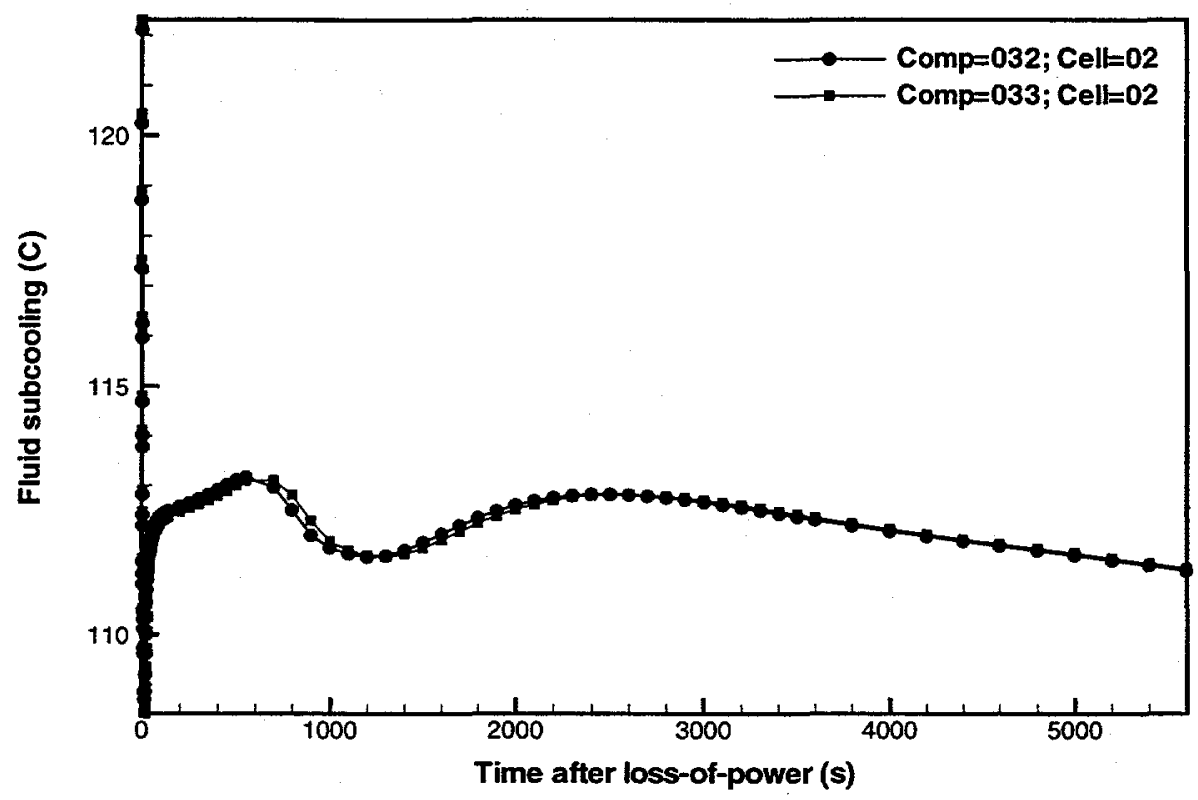

Figure B-11C Primary HR pump discharge piping fluid subcoolings for a LOFA (Case 2: with beam shutdown only).

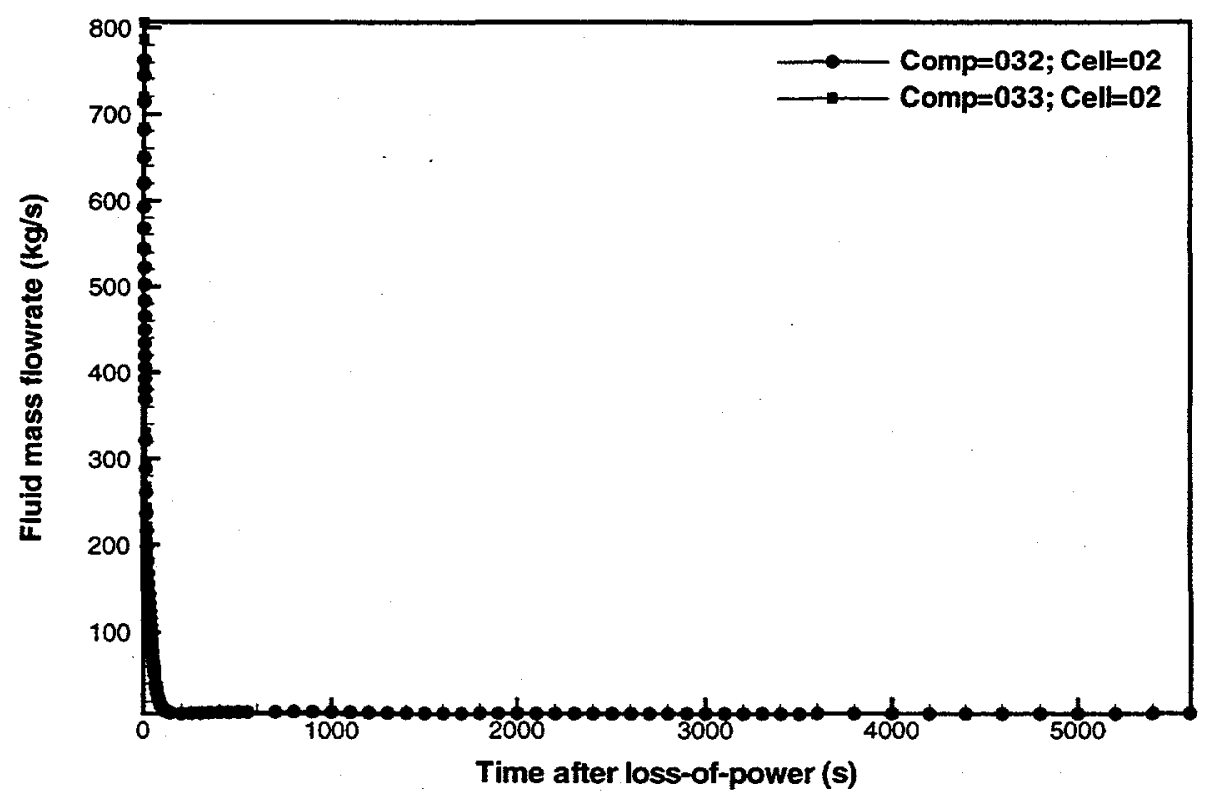

Figure B-11d Primary HR pump discharge piping liquid mass flowrates for a LOFA (Case 2: with beam shutdown only). 


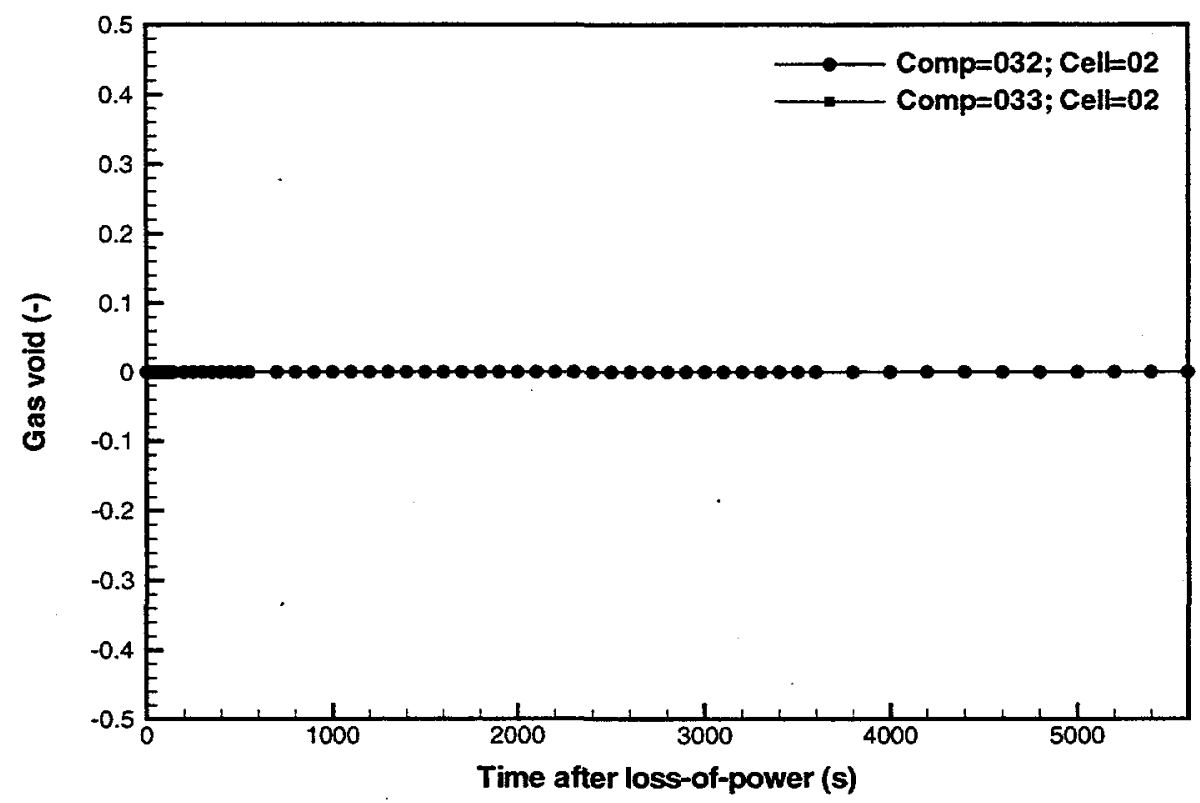

Figure B-11e Primary HR pump discharge piping void fractions for a LOFA (Case 2: with beam shutdown only).

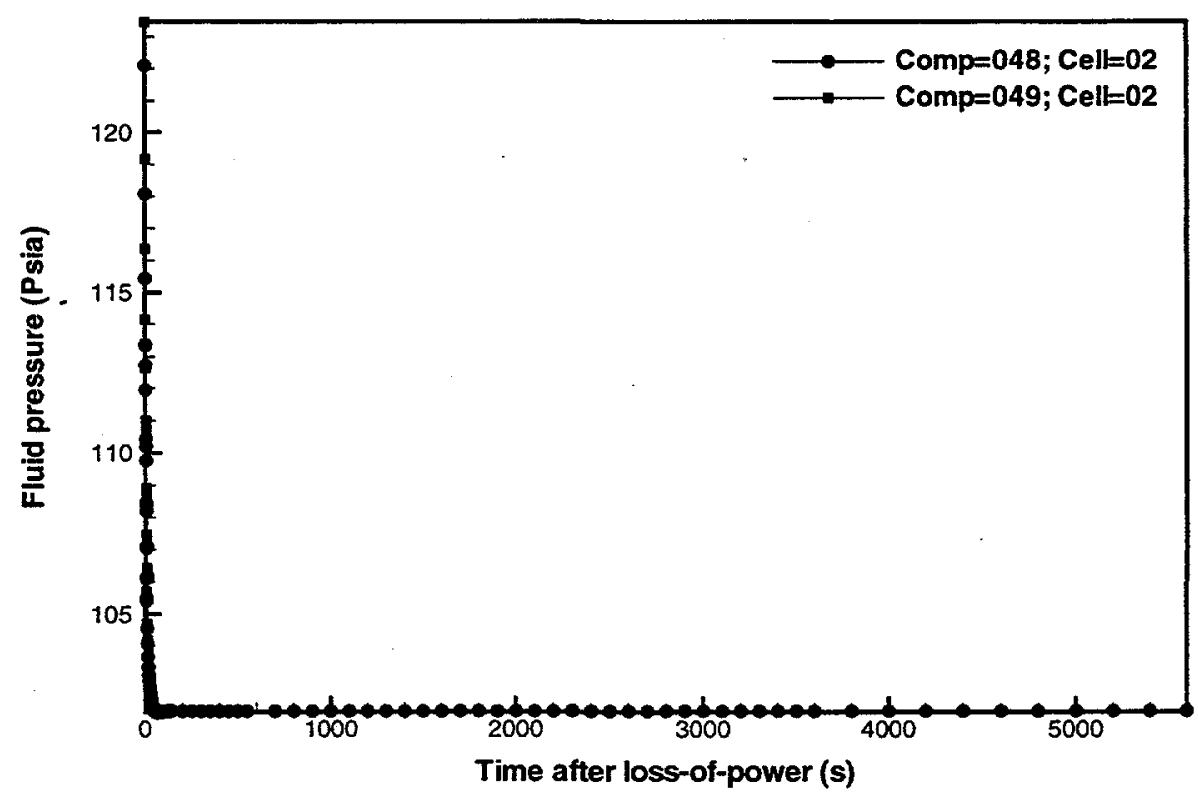

Figure B-12a Primary HR heat exchanger inlet piping fluid pressures for a LOFA (Case 2: with beam shutdown only). 


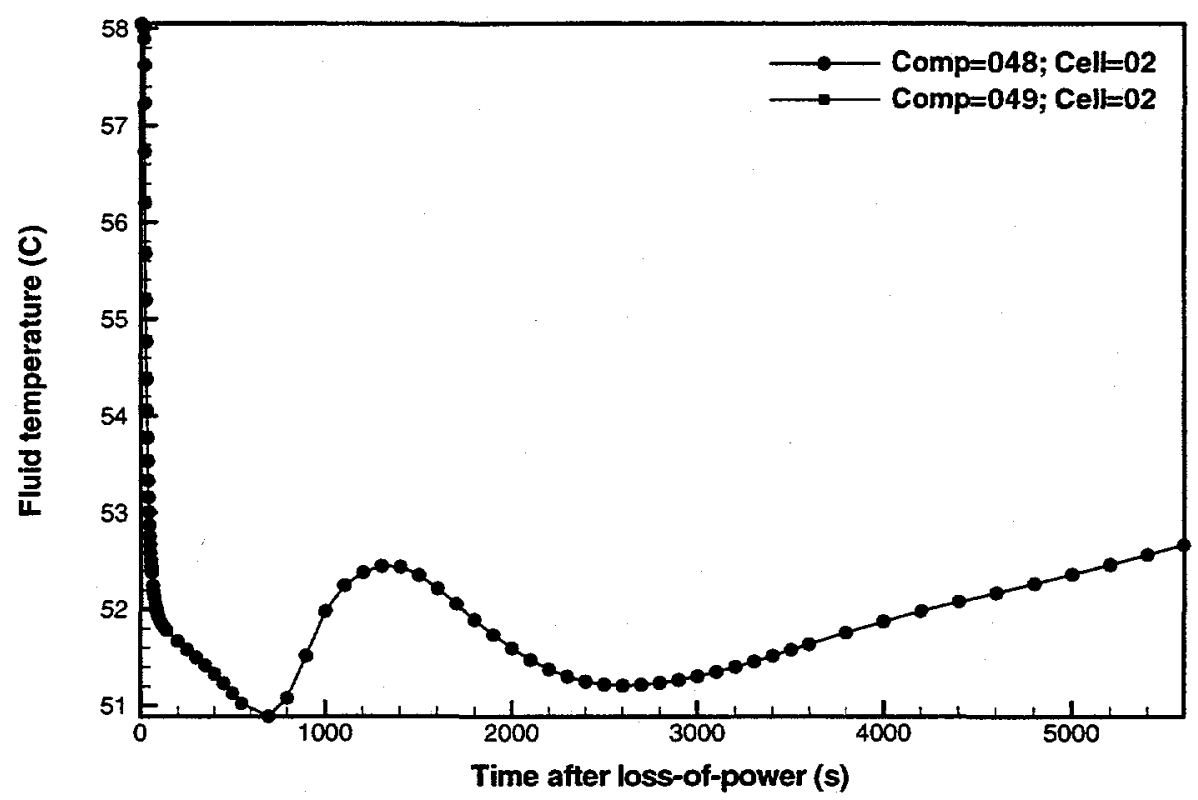

Figure B-12b Primary HR heat exchanger inlet piping fluid temperatures for a LOFA (Case 2: with beam shutdown only).

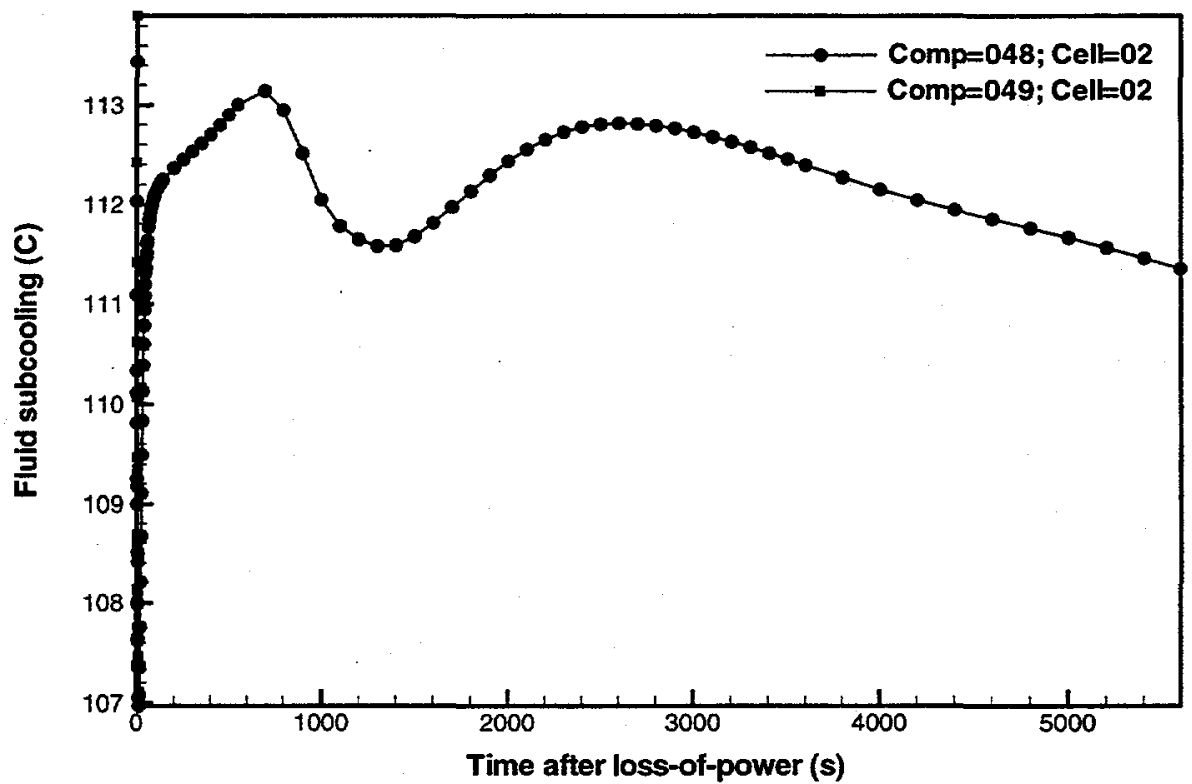

Figure B-12c Primary HR heat exchanger inlet piping fluid subcoolings for a LOFA (Case 2: with beam shutdown only). 


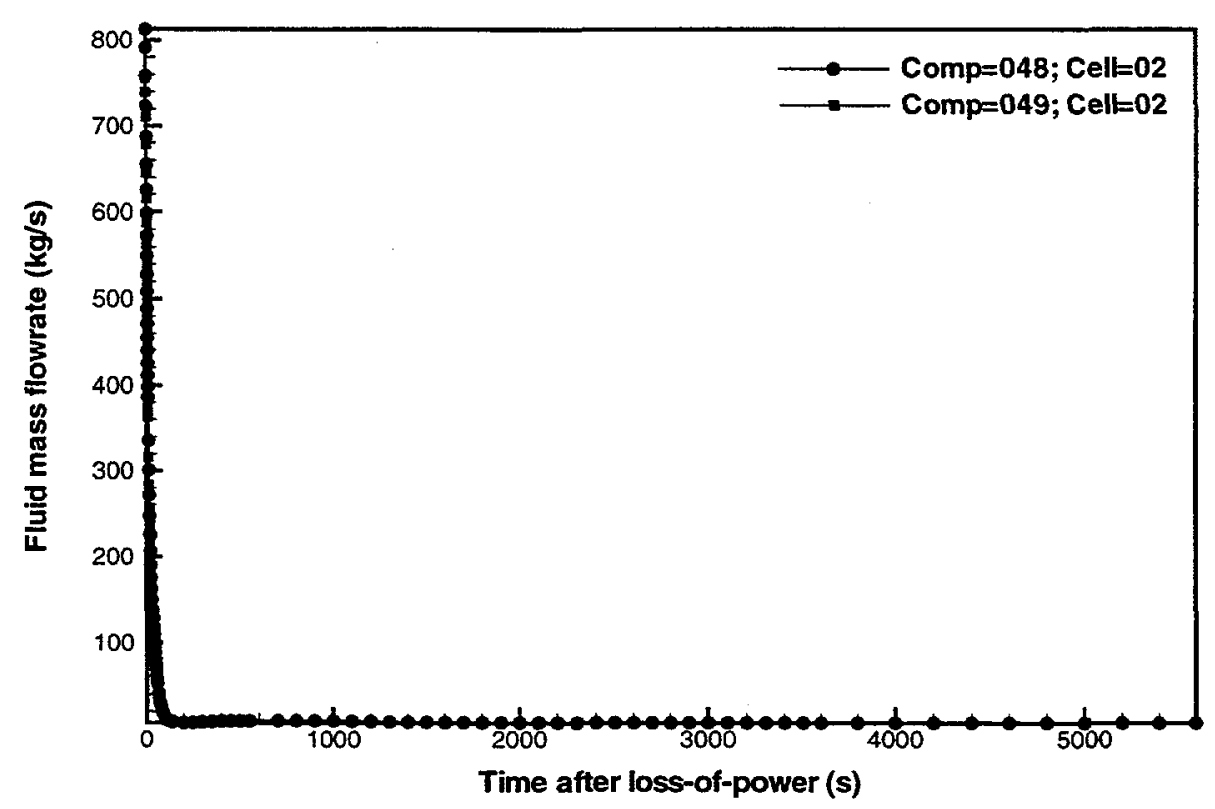

Figure B-12d Primary HR heat exchanger inlet piping liquid mass flowrates for a LOFA (Case 2: with beam shutdown only).

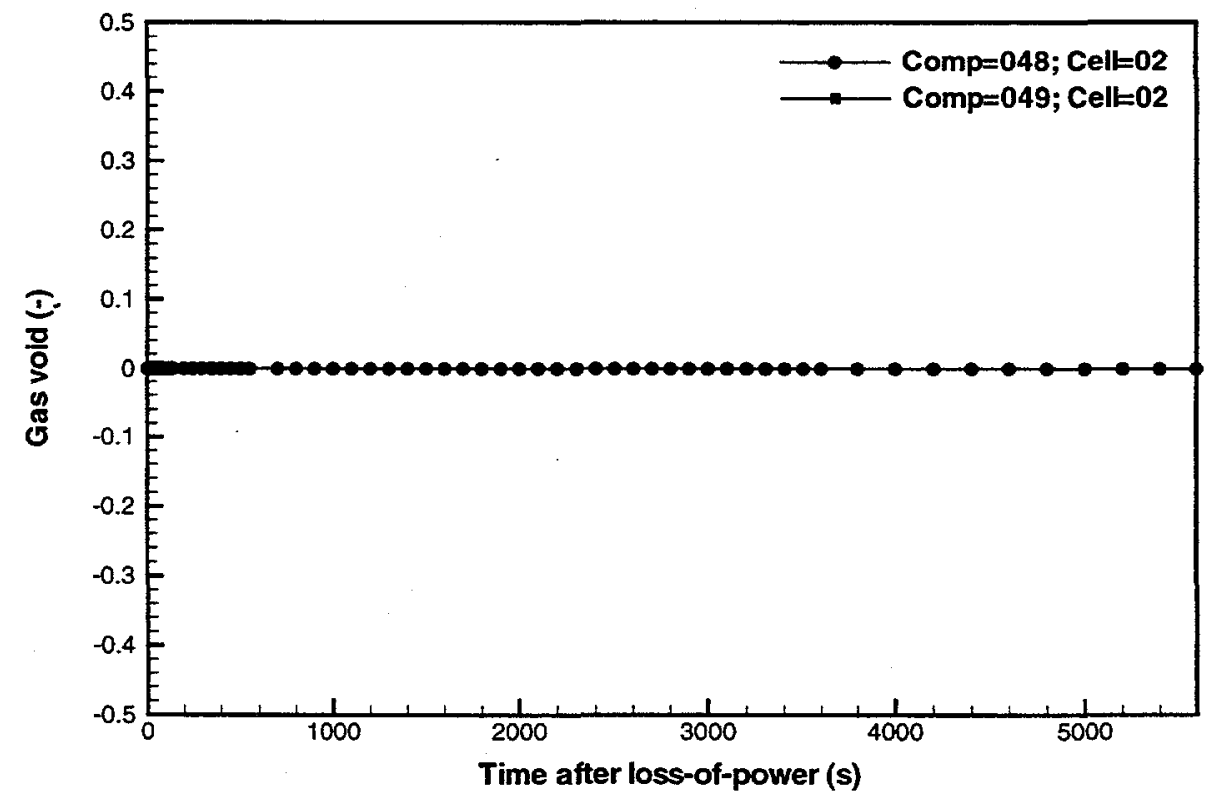

Figure B-12e Primary HR heat exchanger inlet piping void fractions for a LOFA (Case 2: with beam shutdown only). 


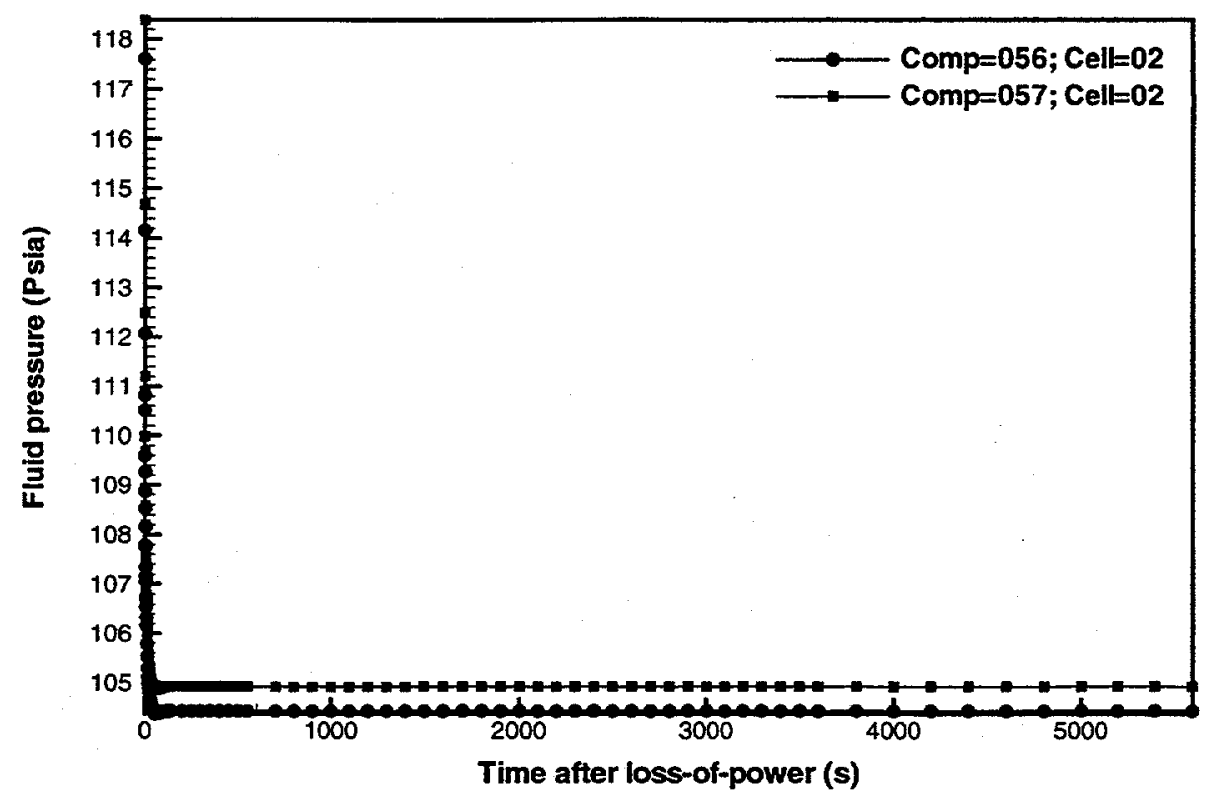

Figure B-13a Primary HR heat exchanger outlet piping fluid pressures for a LOFA (Case 2: with beam shutdown only).

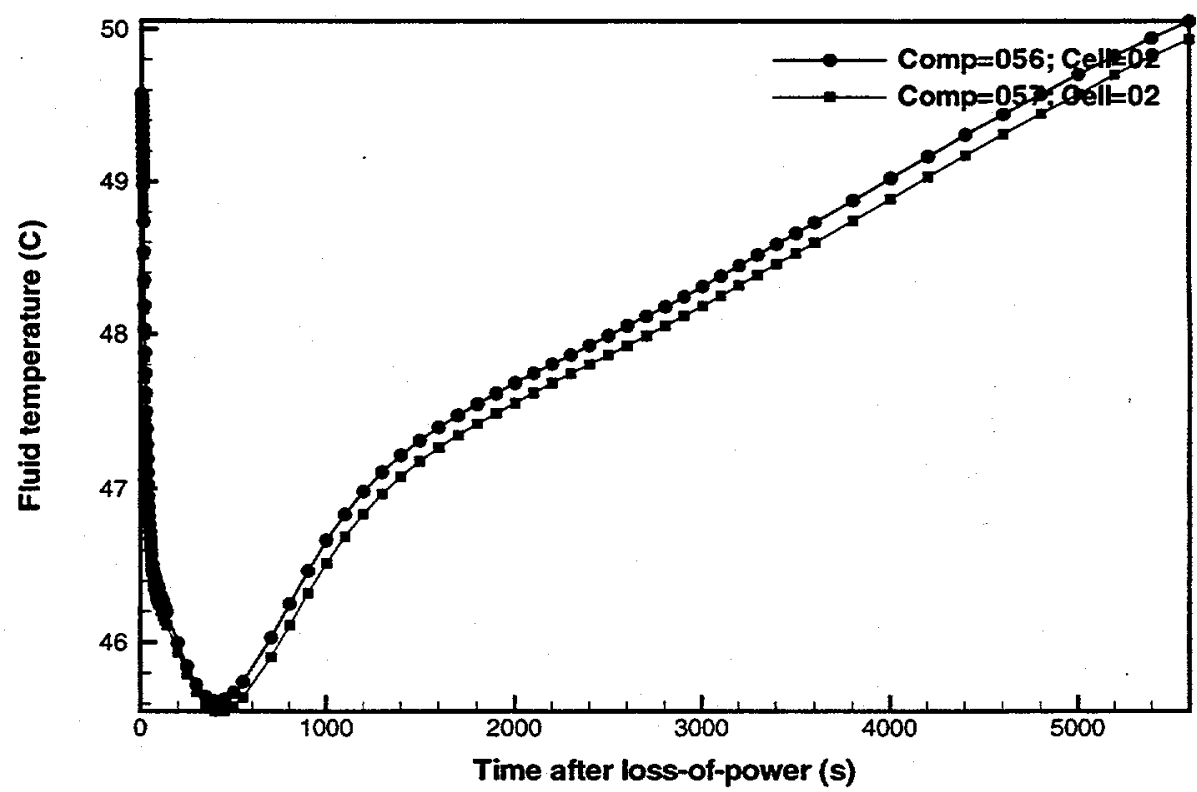

Figure B-13b Primary HR heat exchanger outlet piping fluid temperatures for a LOFA (Case 2: with beam shutdown only). 


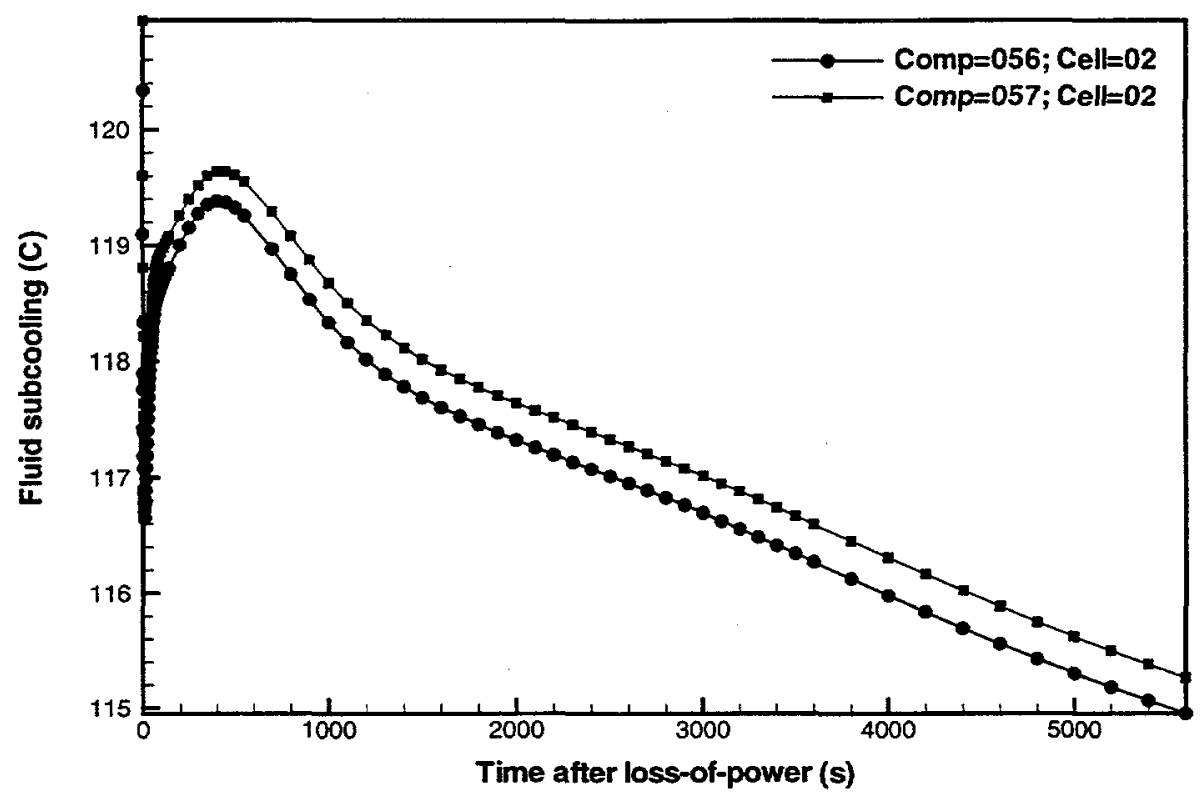

Figure B-13c Primary HR heat exchanger outlet piping fluid subcoolings for a LOFA (Case 2: with beam shutdown only).

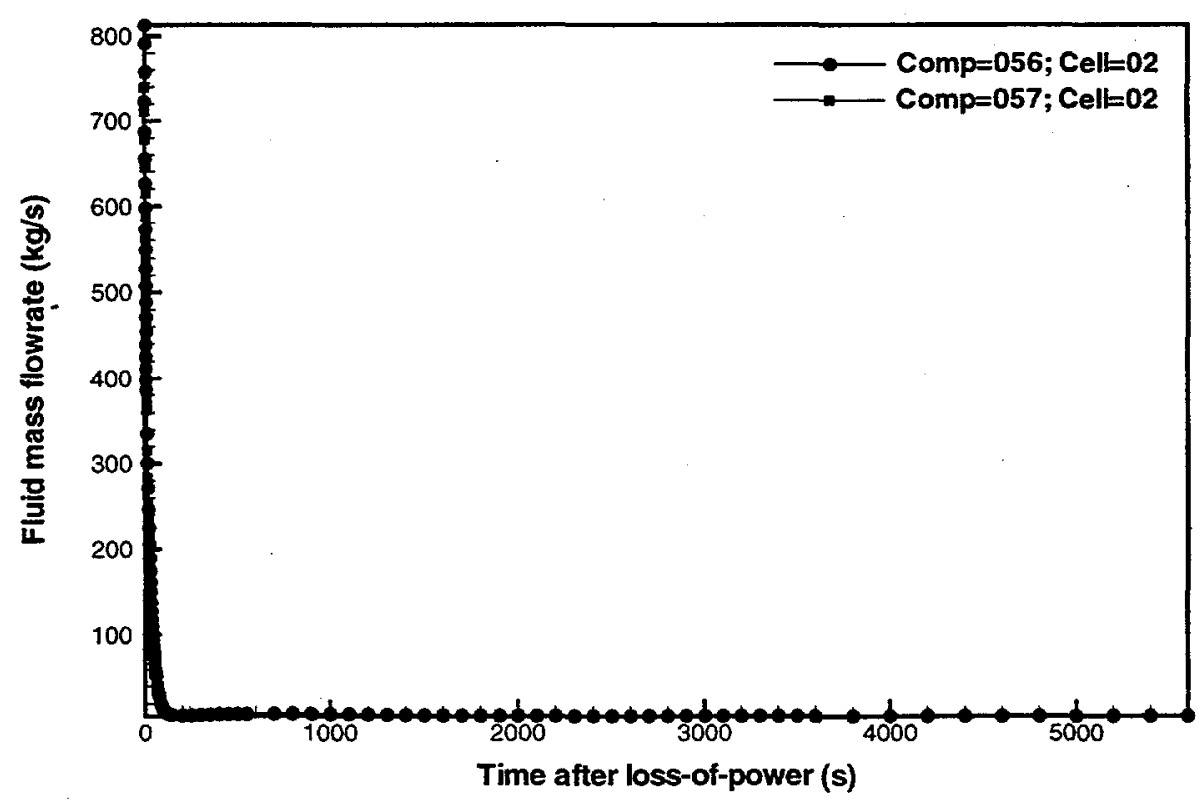

Figure B-13d Primary HR heat exchanger outlet piping liquid mass flowrates for a LOFA (Case 2: with beam shutdown only). 


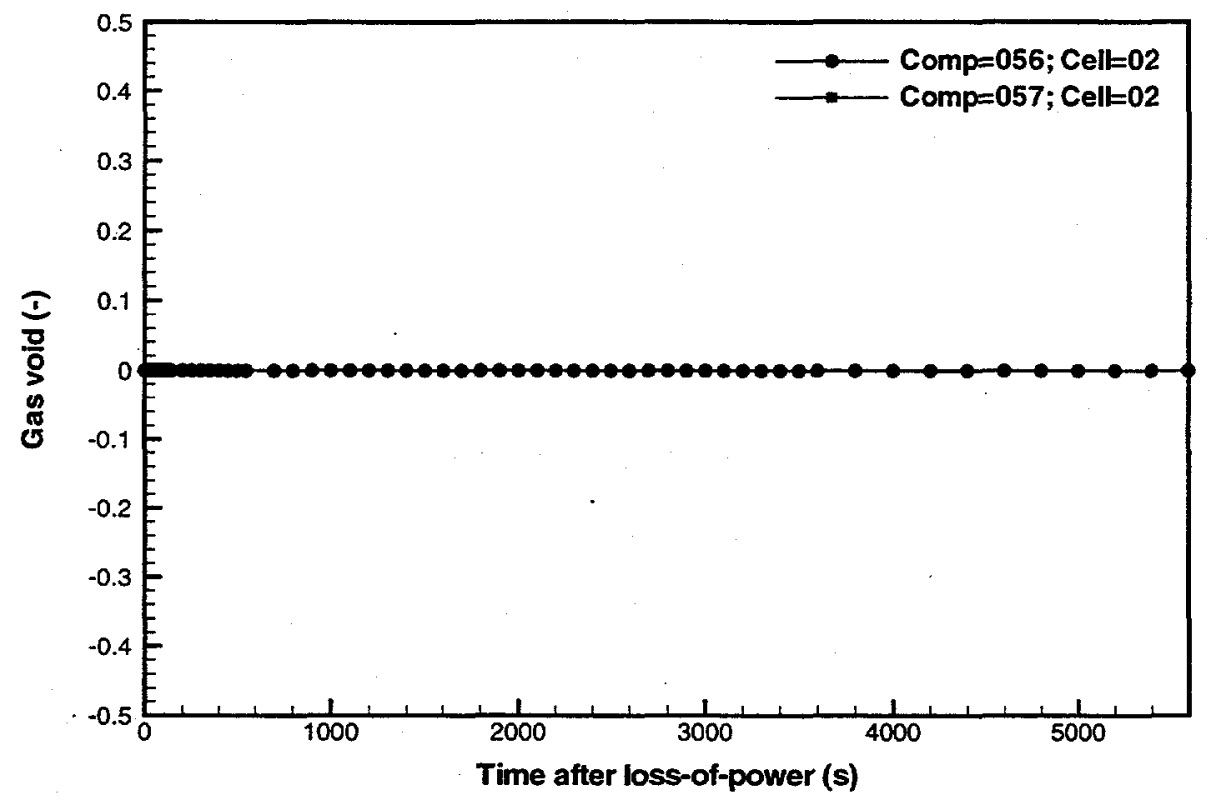

Figure B-13e Primary HR heat exchanger outlet piping void fractions for a LOFA (Case 2: with beam shutdown only).

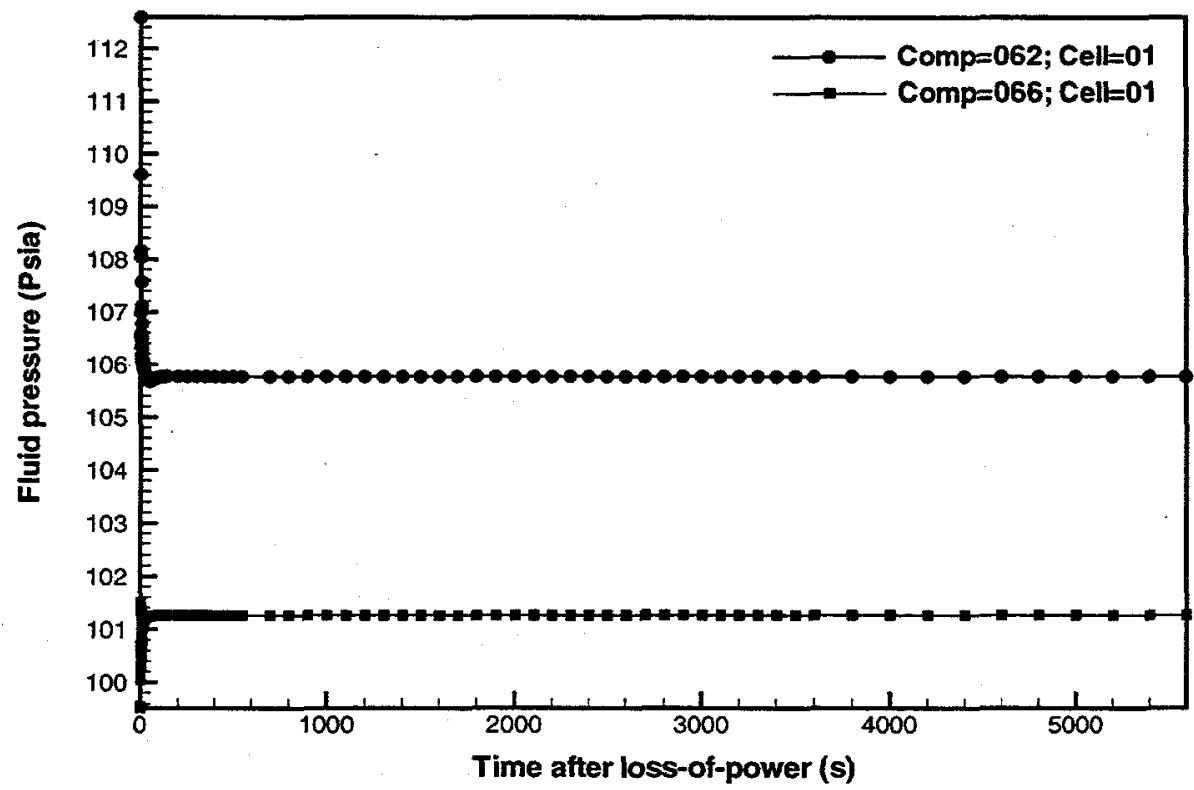

Figure B-14a Primary HR cold-leg piping fluid pressures for a LOFA (Case 2: with beam shutdown only). 


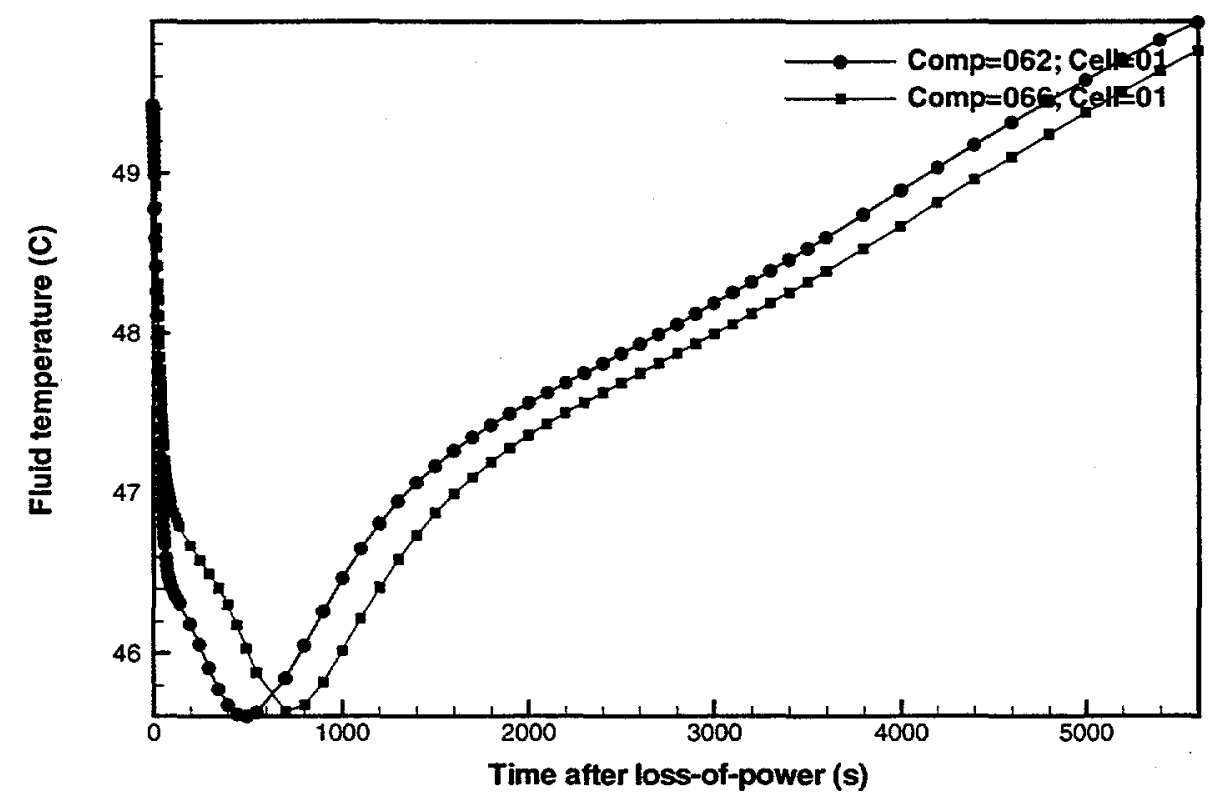

Figure B-14b Primary HR cold-leg piping fluid temperatures for a LOFA (Case 2: with beam shutdown only).

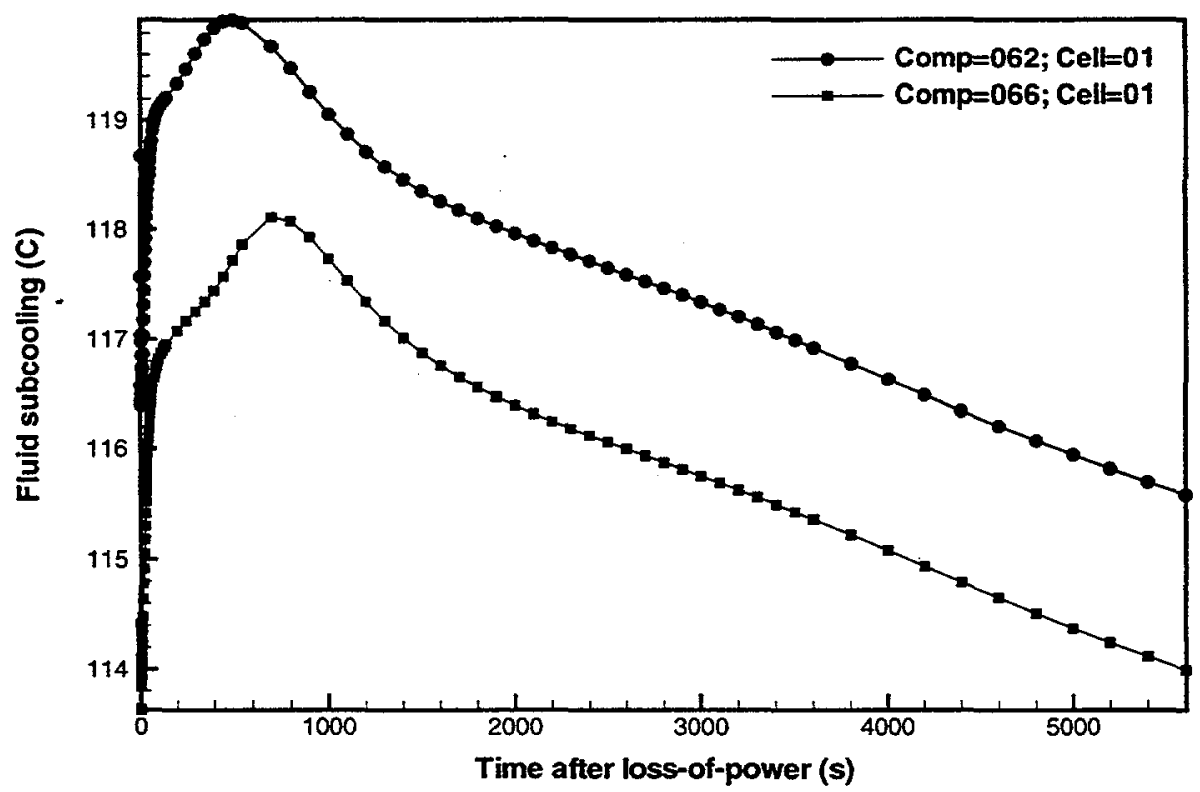

Figure B-14c Primary HR cold-leg piping fluid subcoolings for a LOFA (Case 2: with beam shutdown only). 


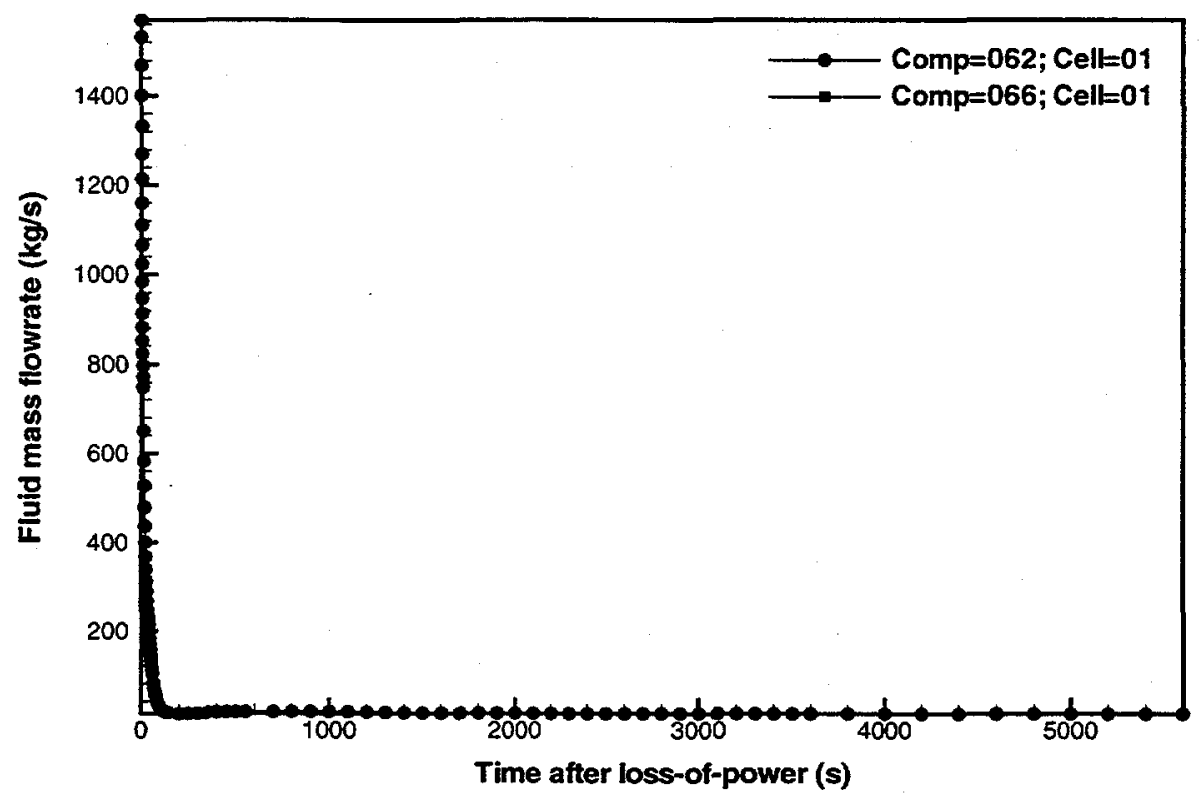

Figure B-14d Primary HR cold-leg piping liquid mass flowrates for a LOFA (Case 2: with beam shutdown only).

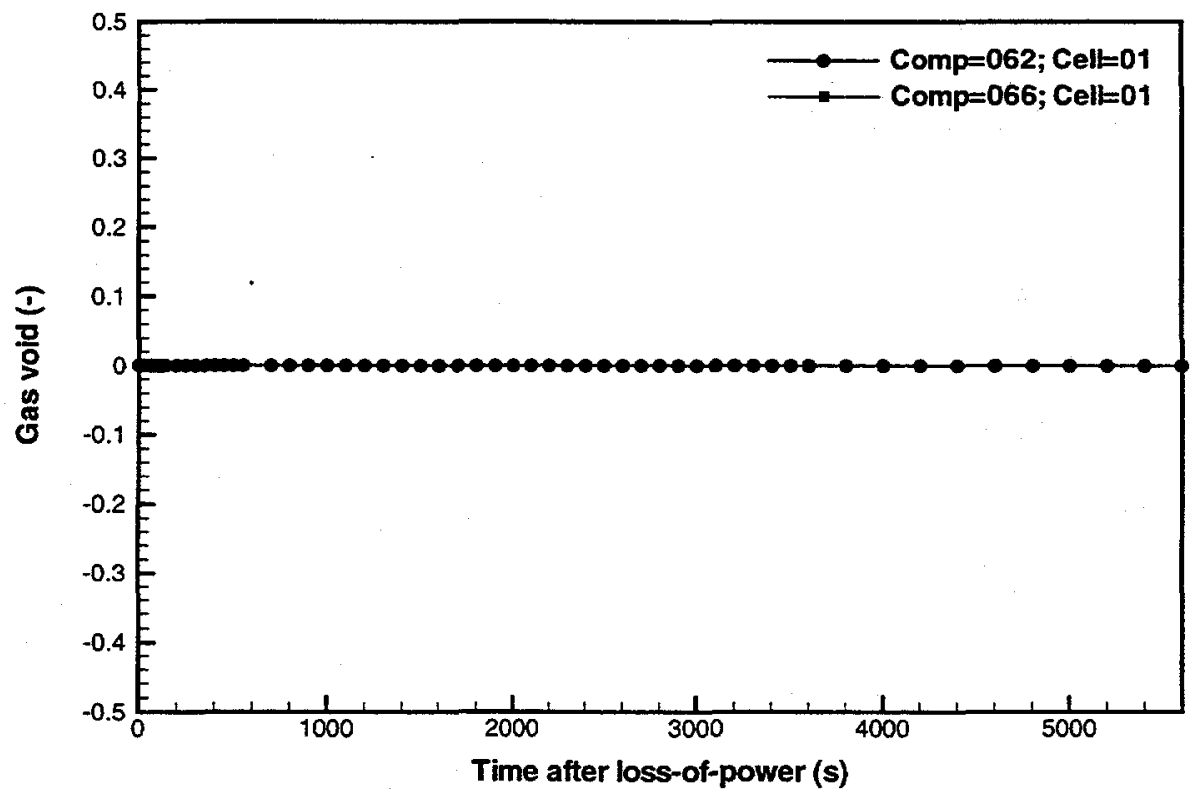

Figure B-14e Primary HR cold-leg piping void fractions for a LOFA (Case 2: with beam shutdown only). 


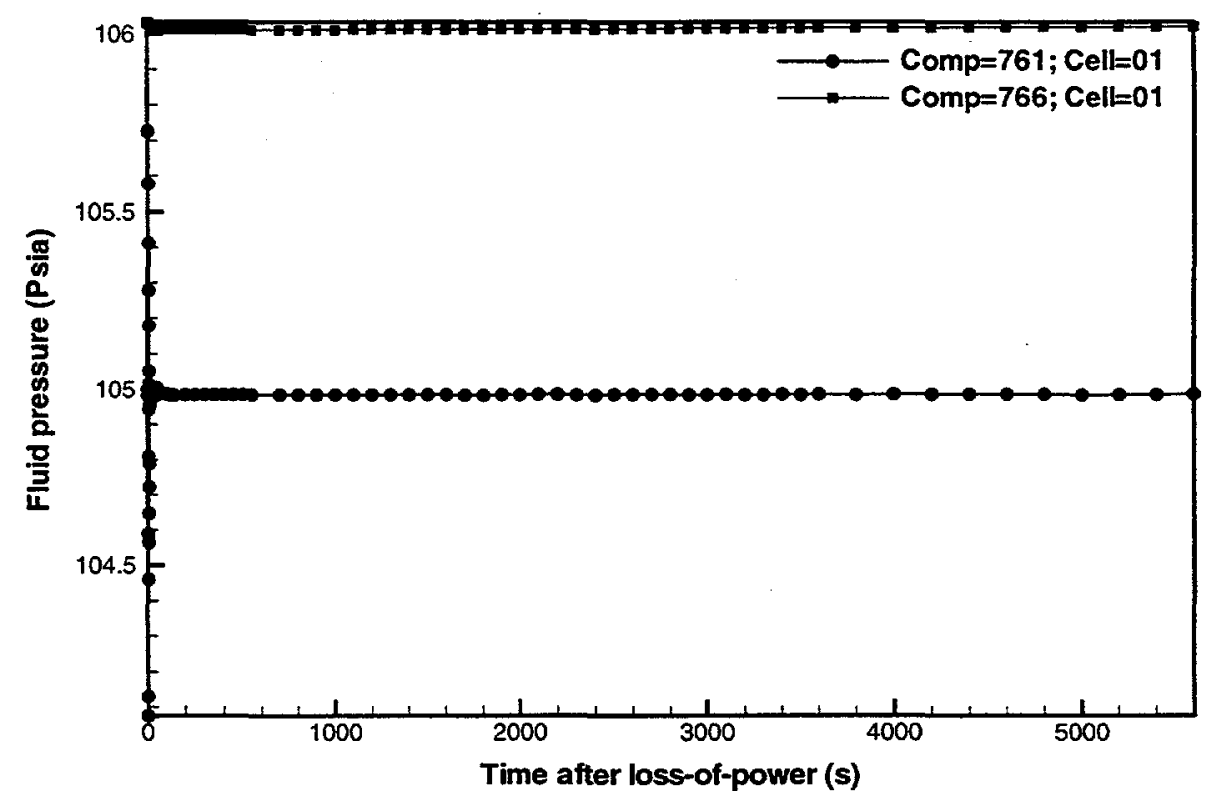

Figure B-15a Primary HR pressurizer and surge line fluid pressures for a LOFA (Case 2: with beam shutdown only).

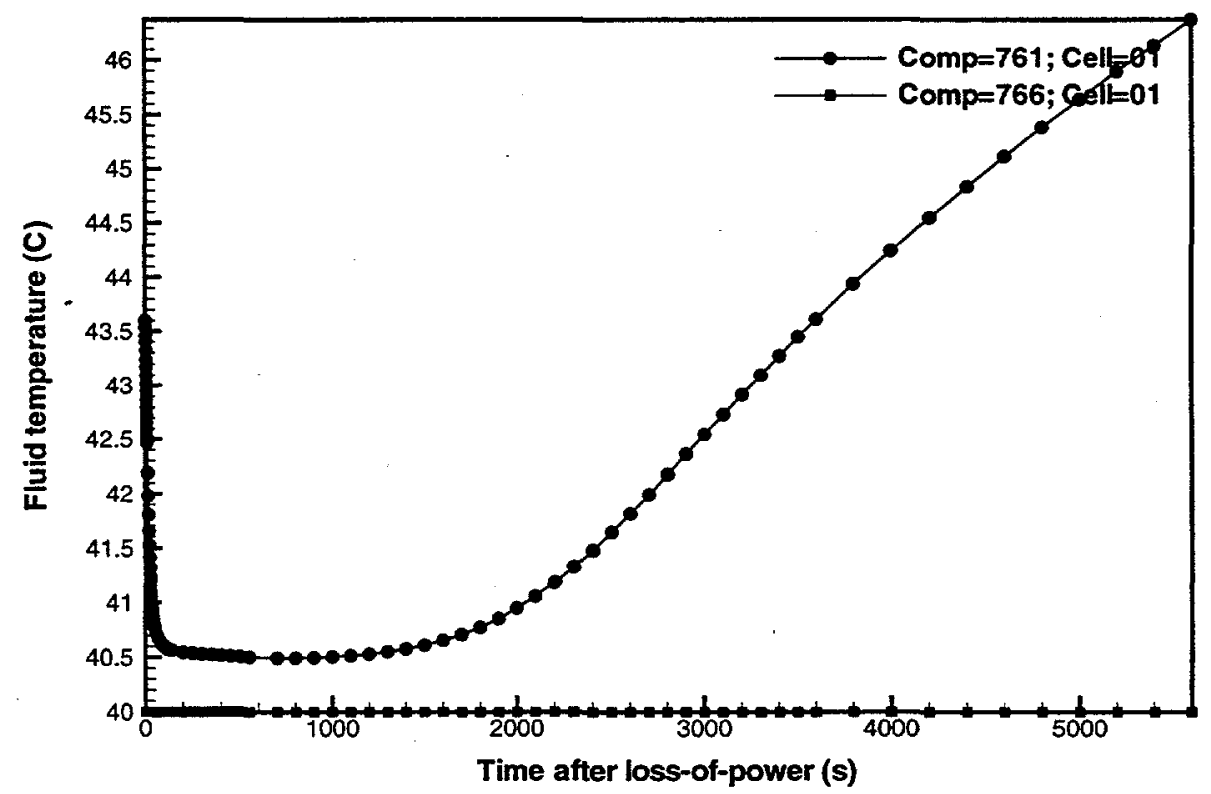

Figure B-15b Primary HR pressurizer and surge line fluid temperatures for a LOFA (Case 2: with beam shutdown only). 


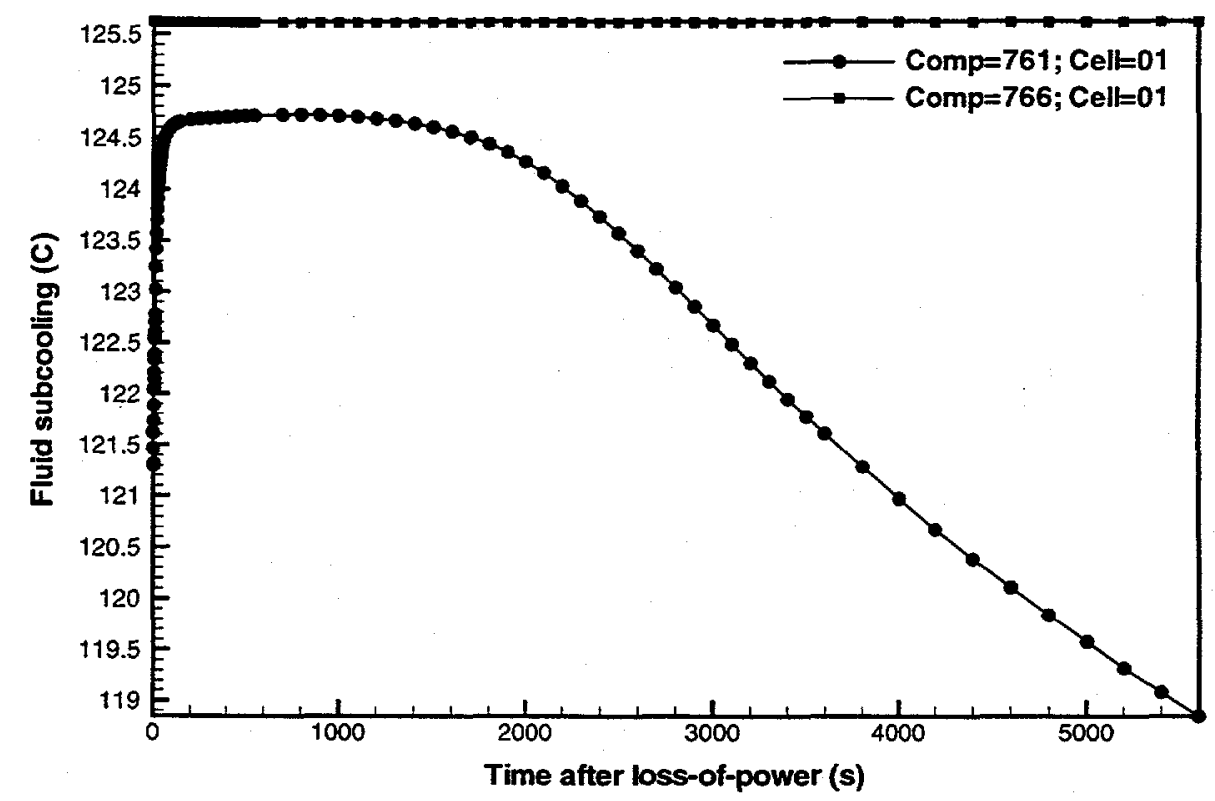

Figure B-15c Primary HR pressurizer and surge line fluid subcoolings for a LOFA (Case 2: with beam shutdown only).

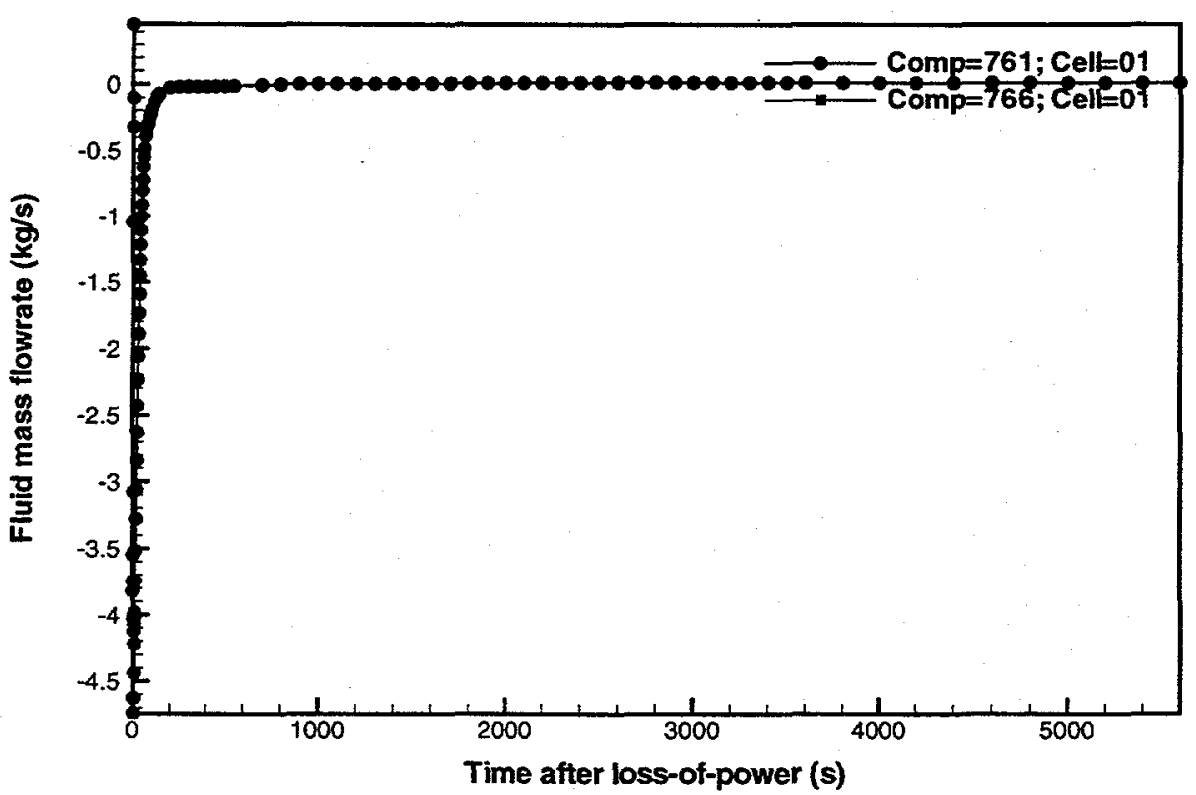

Figure B-15d Primary HR pressurizer and surge line liquid mass flowrates for a LOFA (Case 2: with beam shutdown only). 


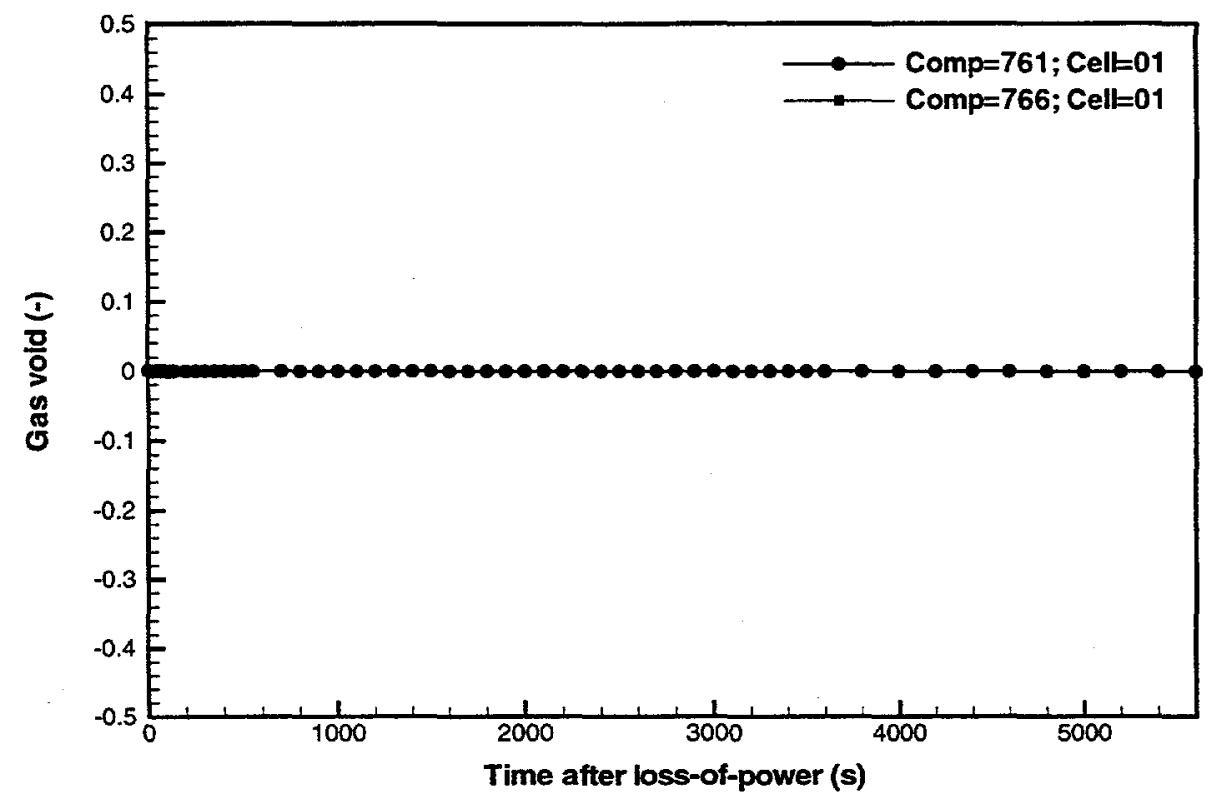

Figure B-15e Primary HR pressurizer and surge line void fractions for a LOFA (Case 2: with beam shutdown only).

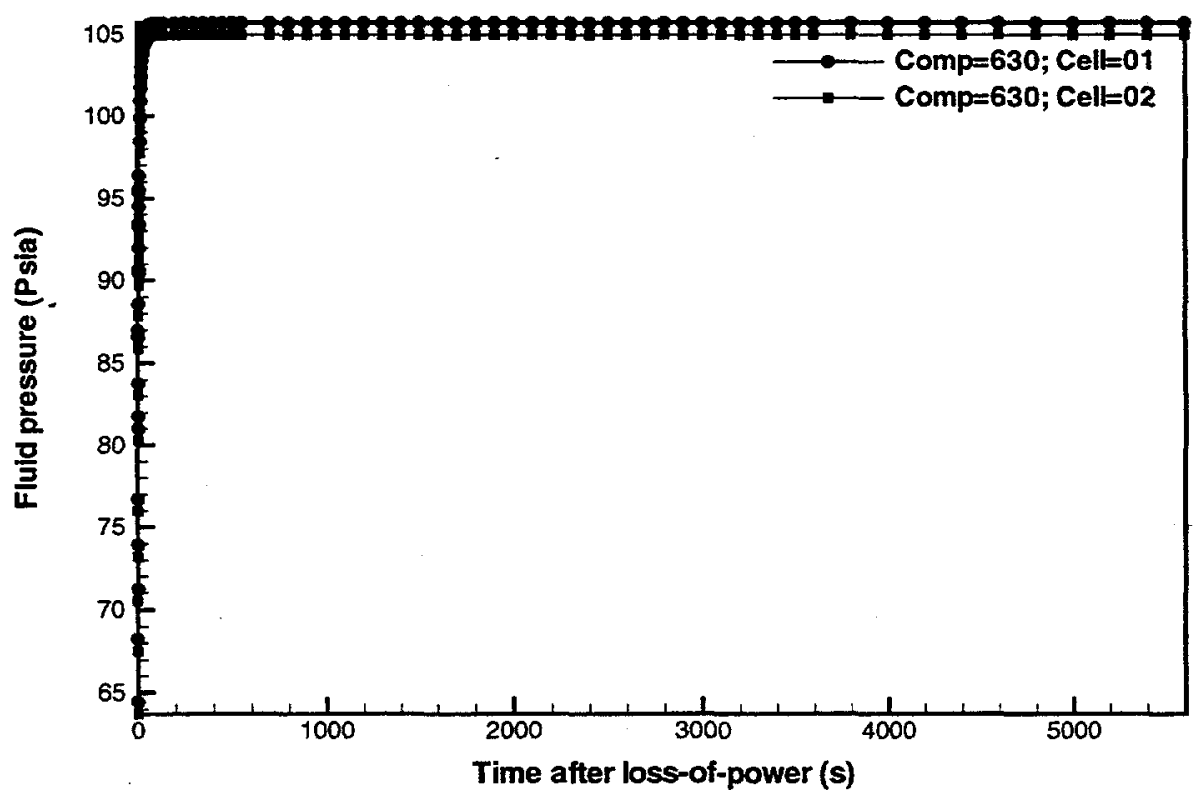

Figure B-16a Primary RHR pump fluid pressures for a LOFA (Case 2: with beam shutdown only). 


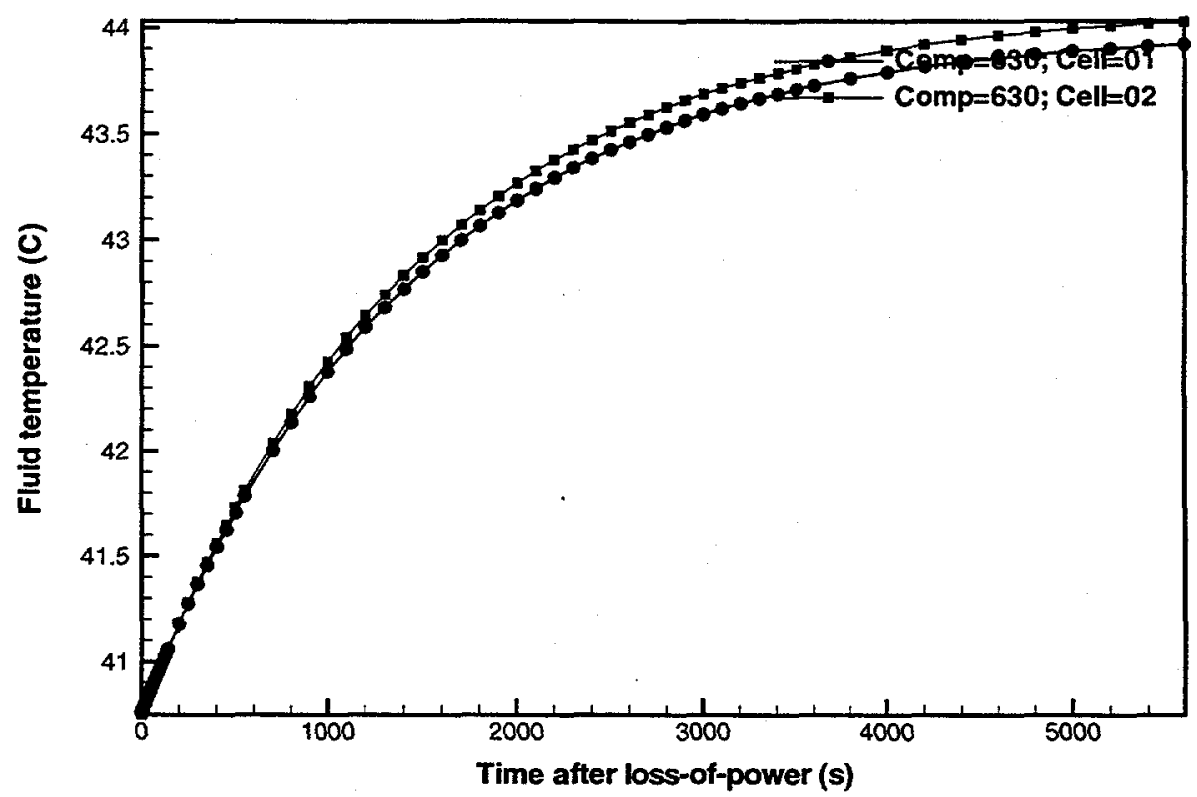

Figure B-16b Primary RHR pump fluid temperatures for a LOFA (Case 2: with beam shutdown only).

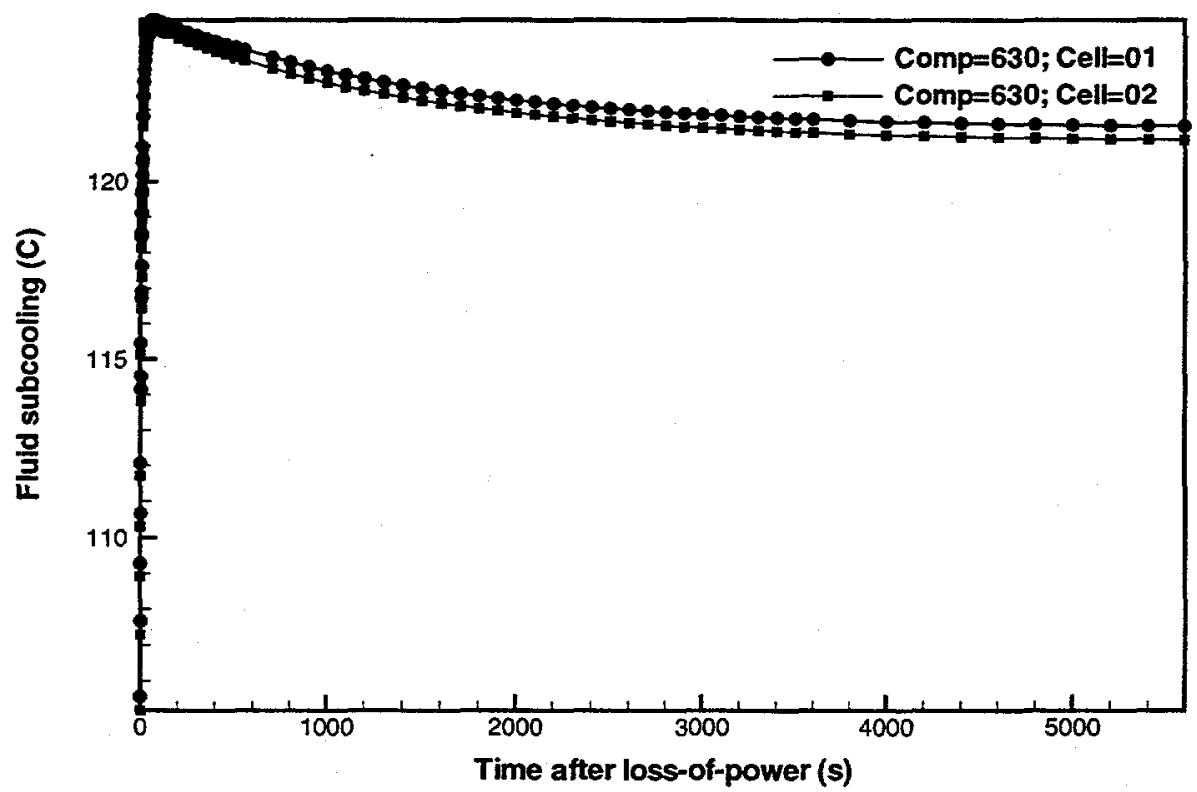

Figure B-16c Primary RHR pump fluid subcoolings for a LOFA (Case 2: with beam shutdown only). 


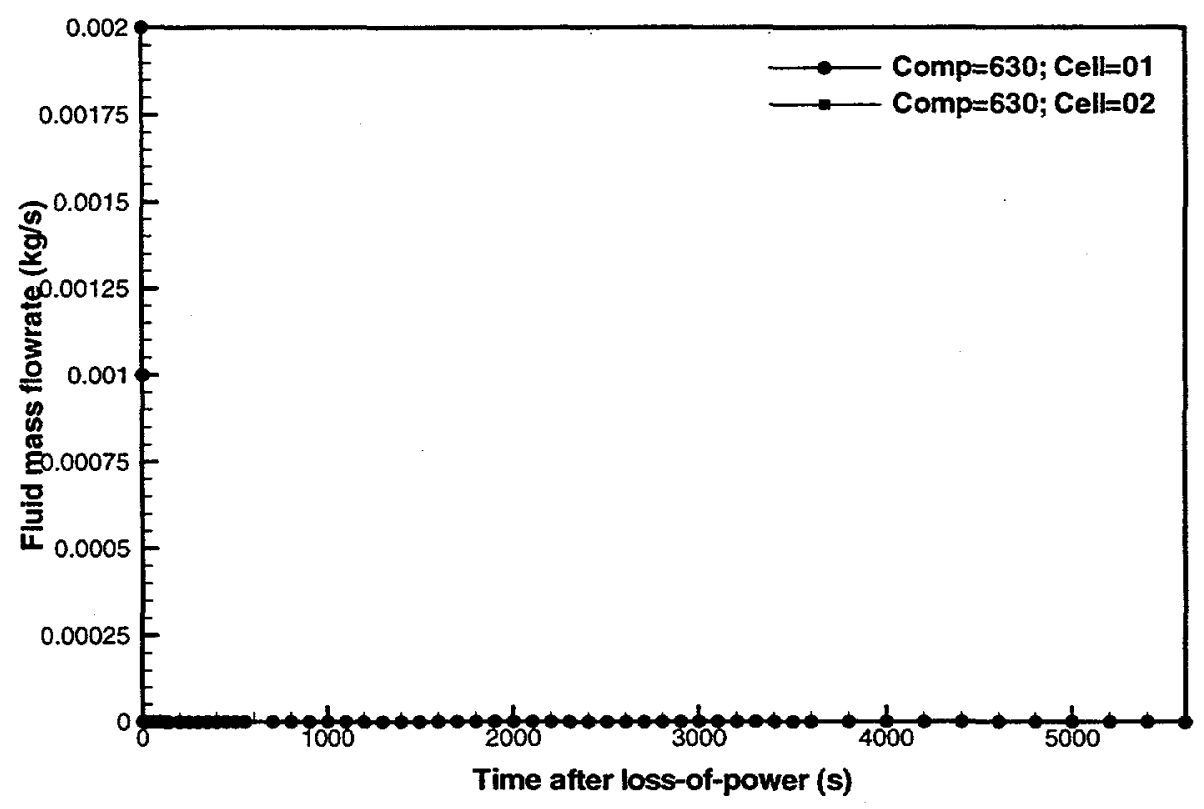

Figure B-16d Primary RHR pump liquid mass flowrates for a LOFA (Case 2: with beam shutdown only).

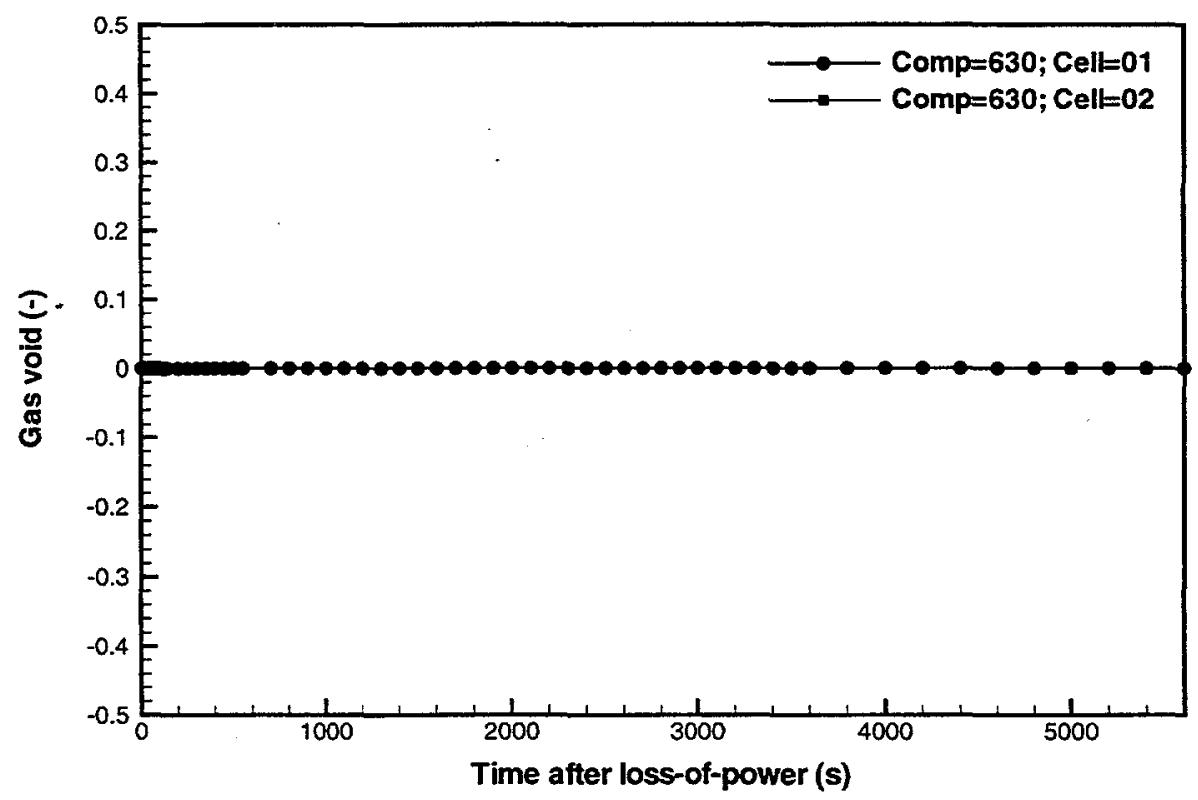

Figure B-16e Primary RHR pump void fractions for a LOFA (Case 2: with beam shutdown only). 


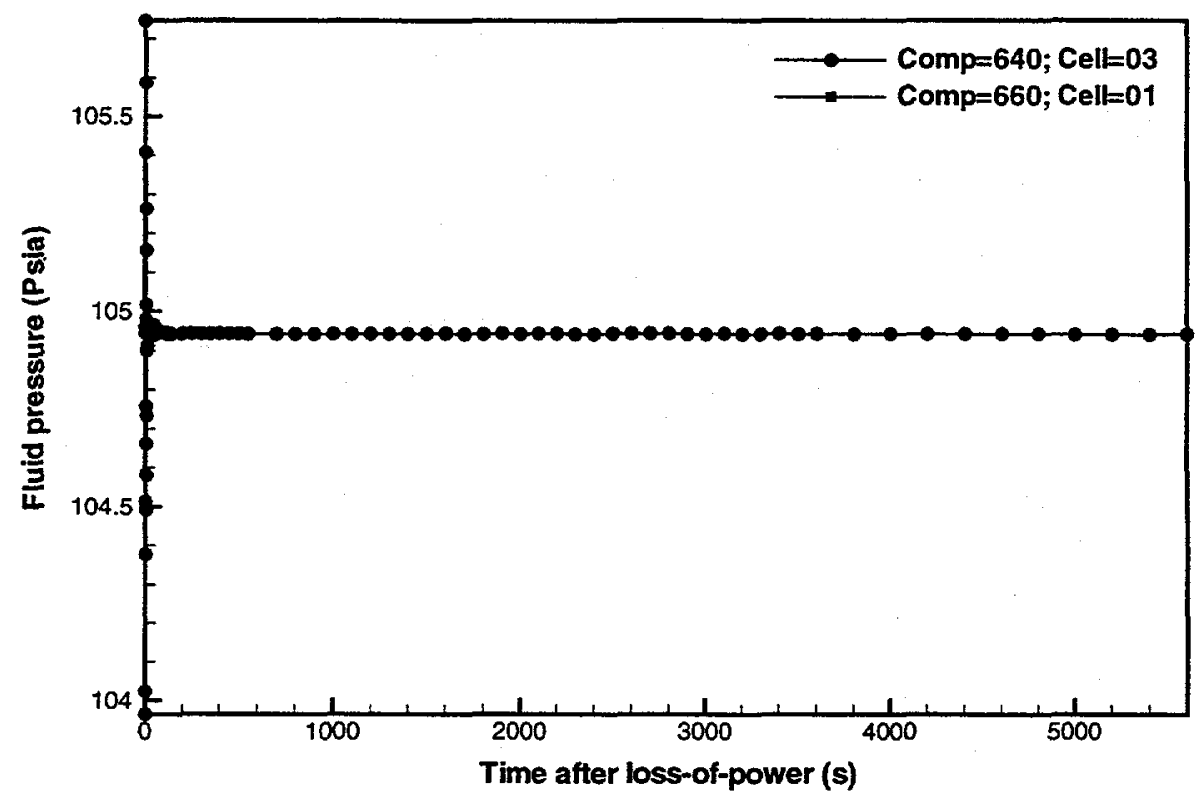

Figure B-17a Primary RHR heat exchanger fluid pressures for a LOFA (Case 2: with beam shutdown only).

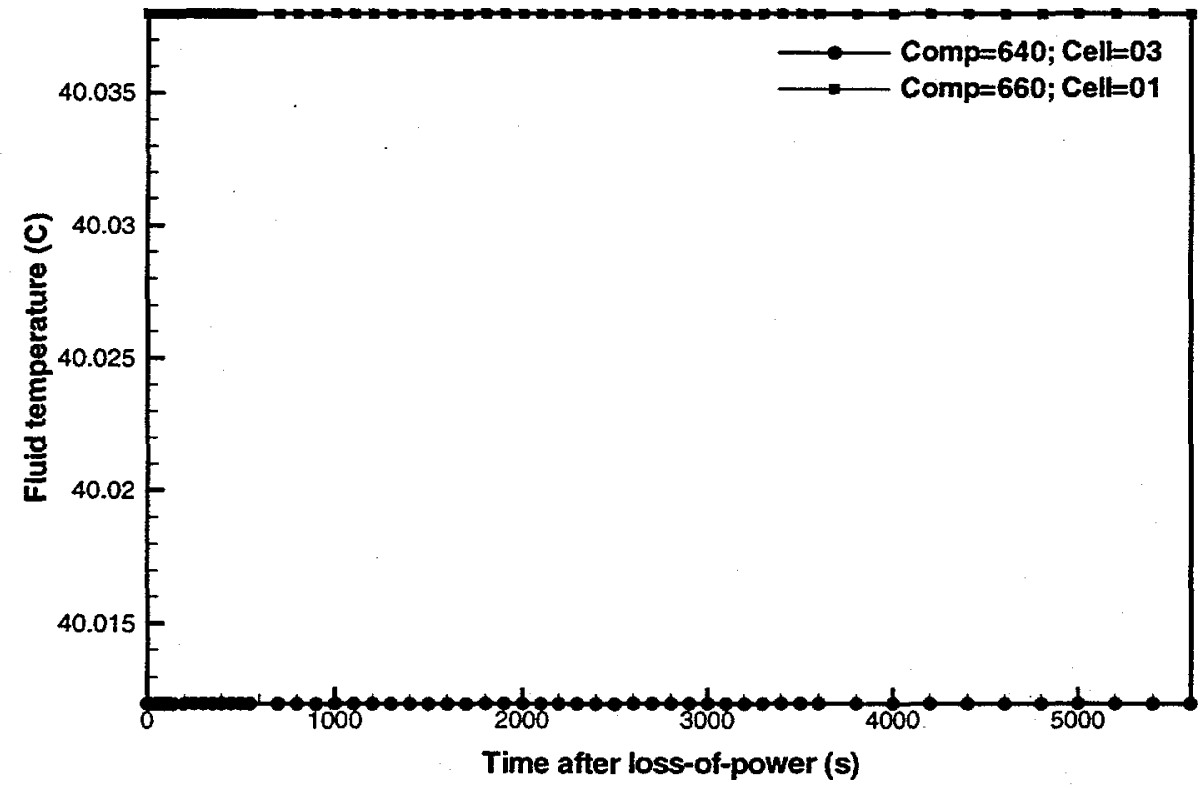

Figure B-17b Primary RHR heat exchanger fluid temperatures for a LOFA (Case 2: with beam shutdown only). 


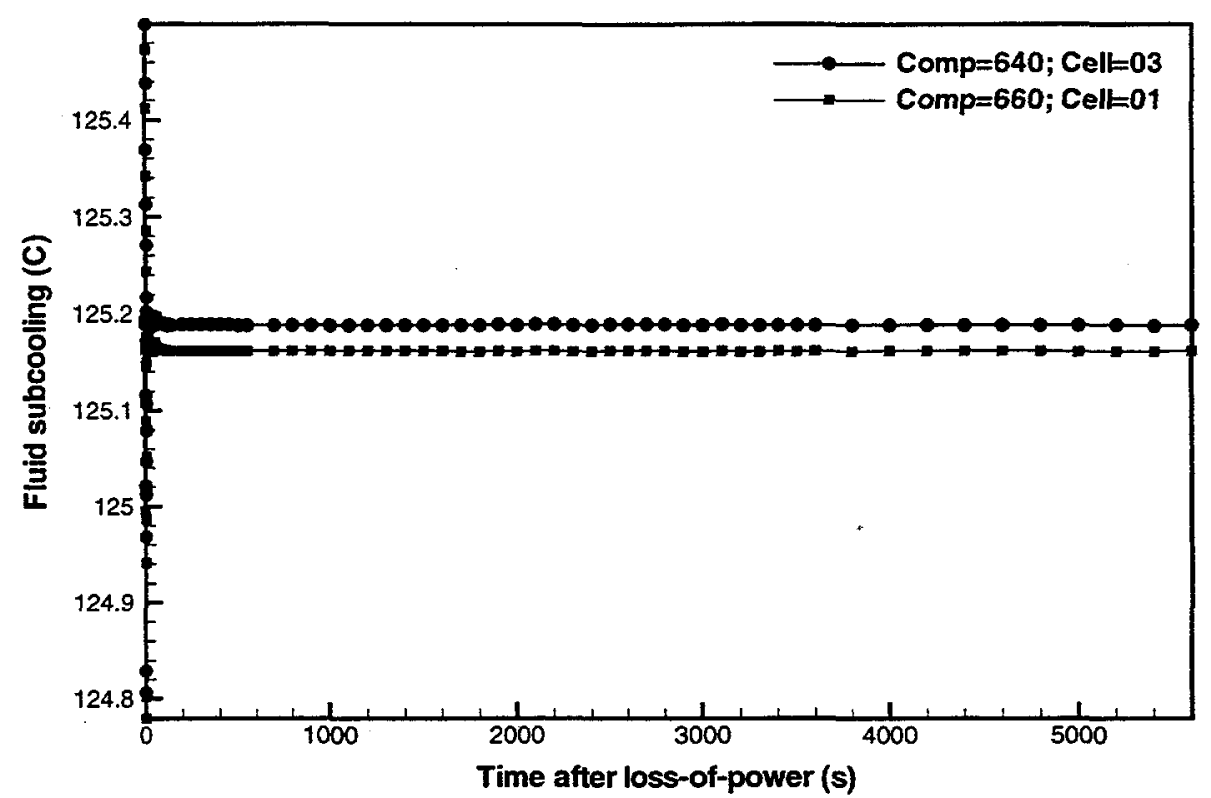

Figure B-17c Primary RHR heat exchanger fluid subcoolings for a LOFA (Case 2: with beam shutdown only).

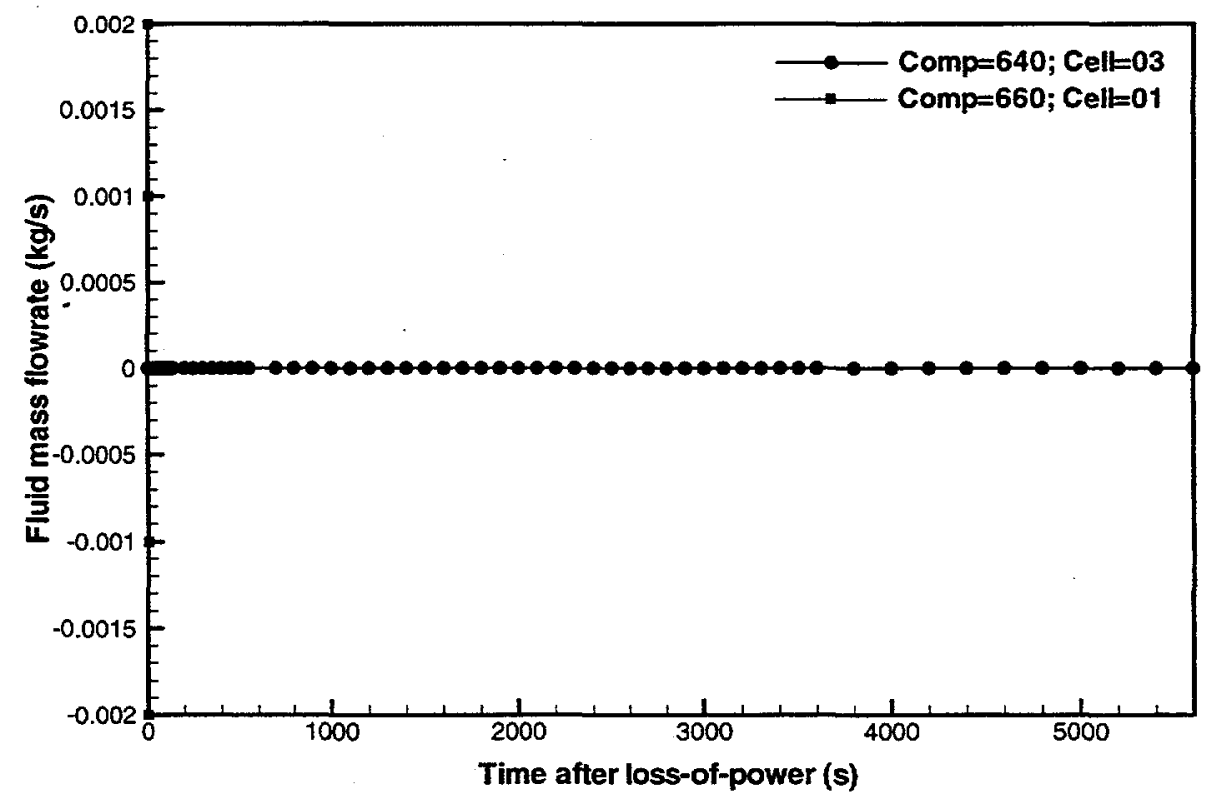

Figure B-17d Primary RHR heat exchanger liquid mass flowrates for a LOFA (Case 2: with beam shutdown only). 


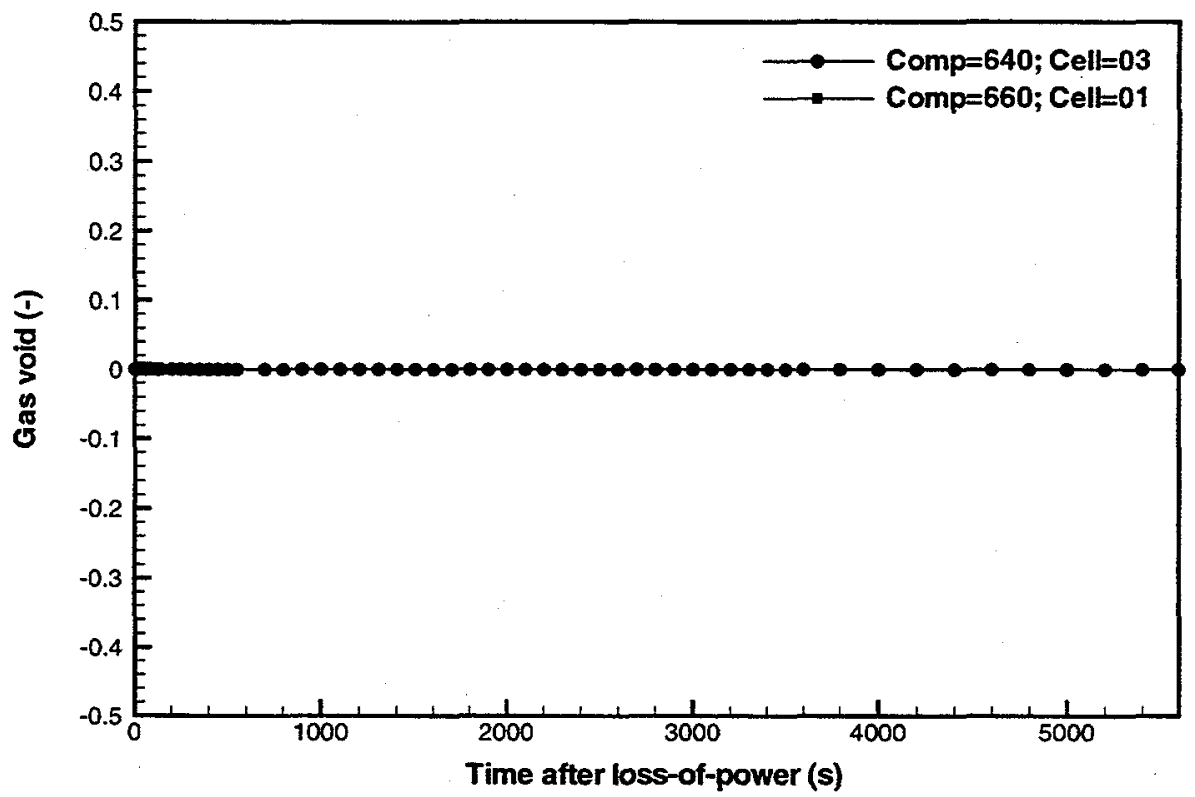

Figure B-17e Primary RHR heat exchanger void fractions for a LOFA (Case 2: with beam shutdown only).

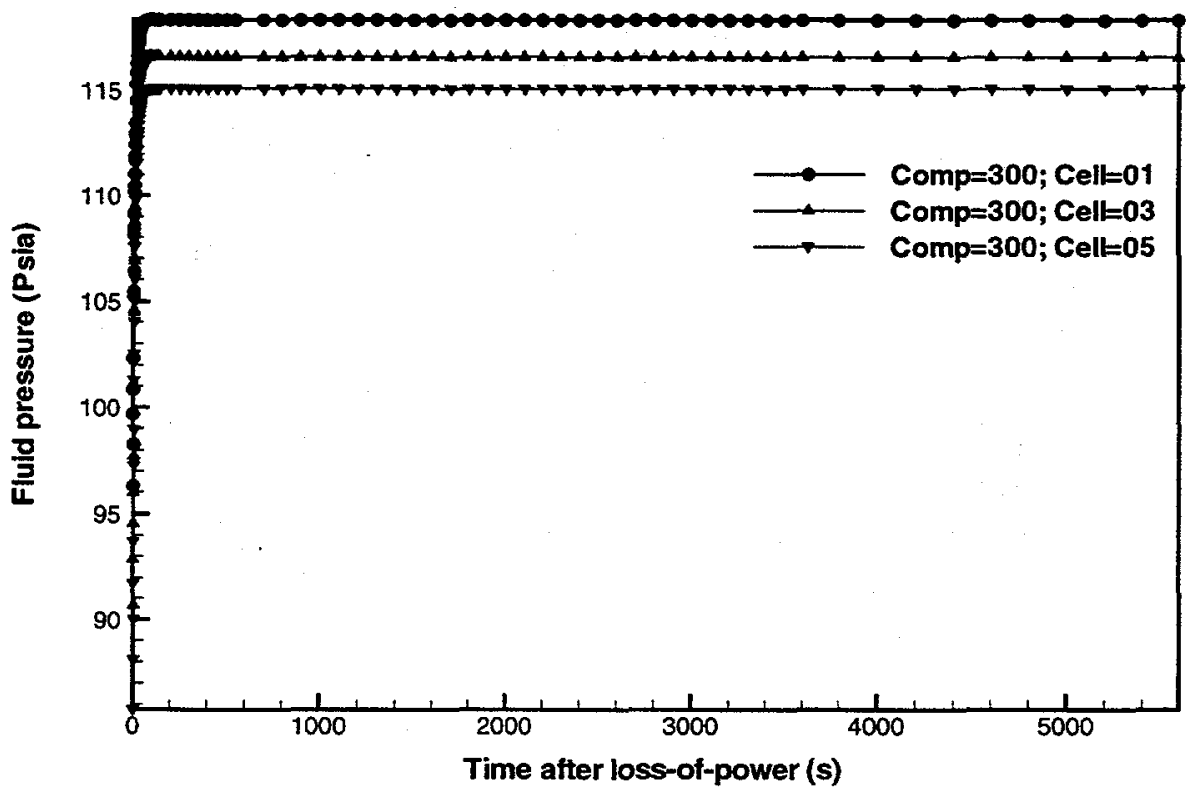

Figure B-18a Module 1 channel fluid pressures for a LOFA (Case 2: with beam shutdown only). 


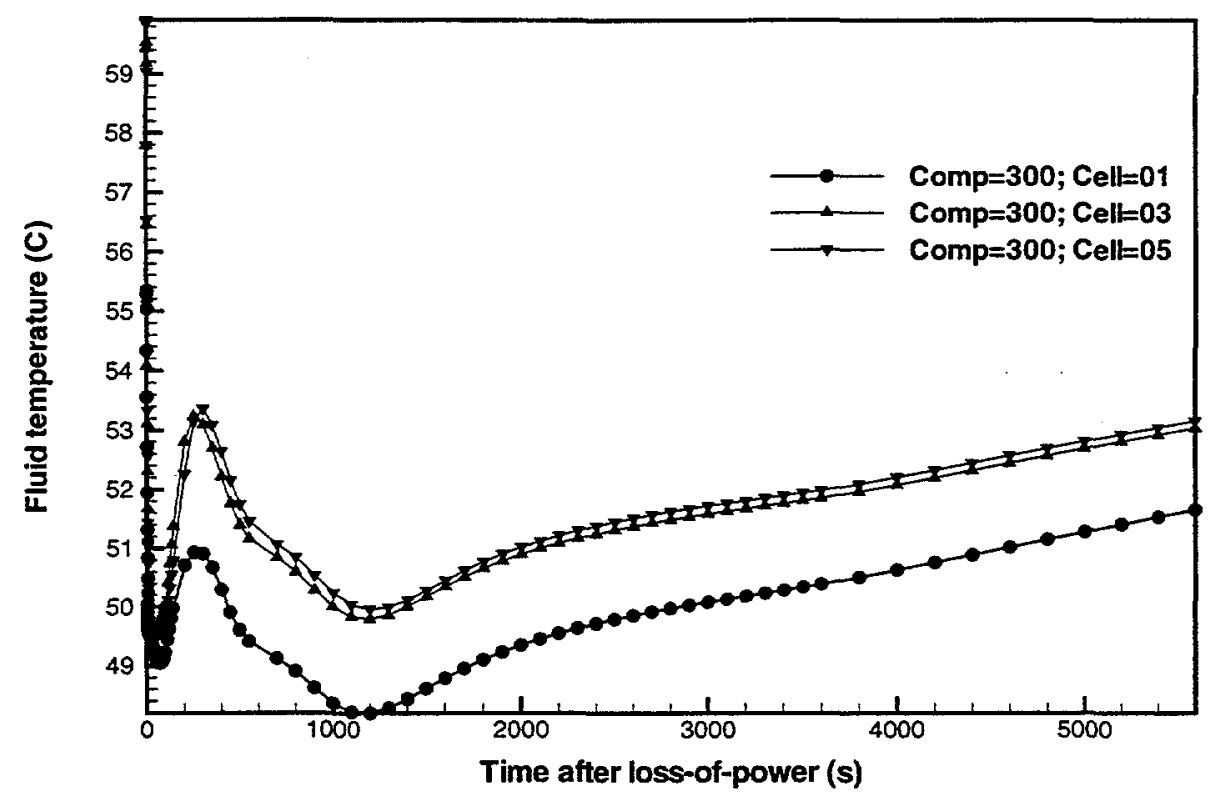

Figure B-18b Module 1 channel fluid temperatures for a LOFA (Case 2: with beam shutdown only).

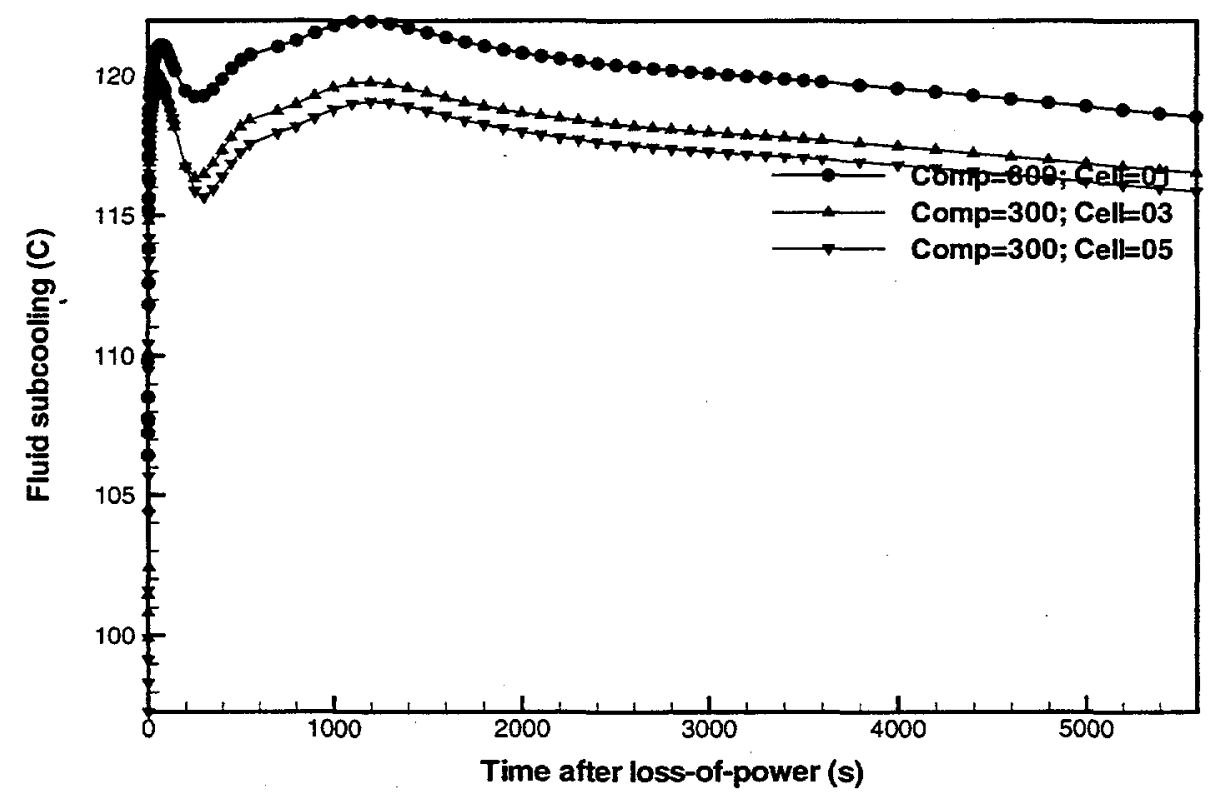

Figure B-18c Module 1 channel fluid subcoolings for a LOFA (Case 2: with beam shutdown only). 


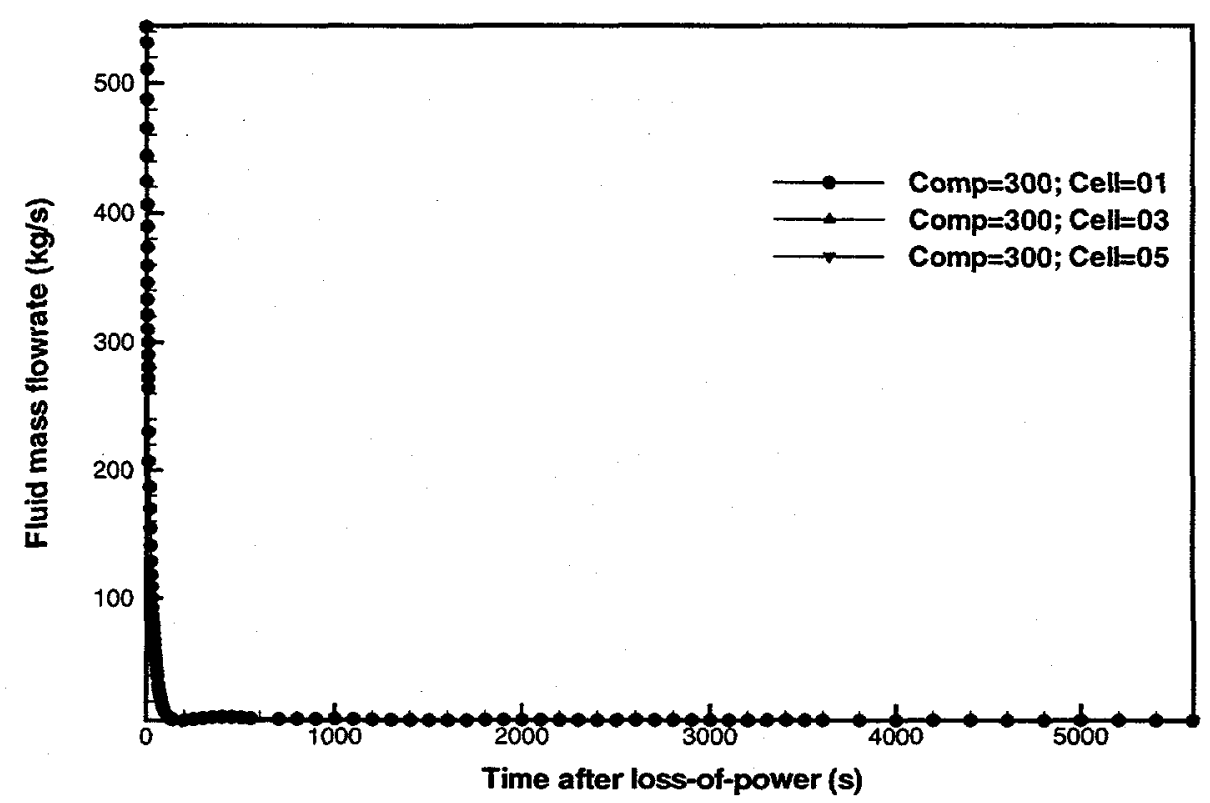

Figure B-18d Module 1 channel liquid mass flowrates for a LOFA (Case 2: with beam shutdown only).

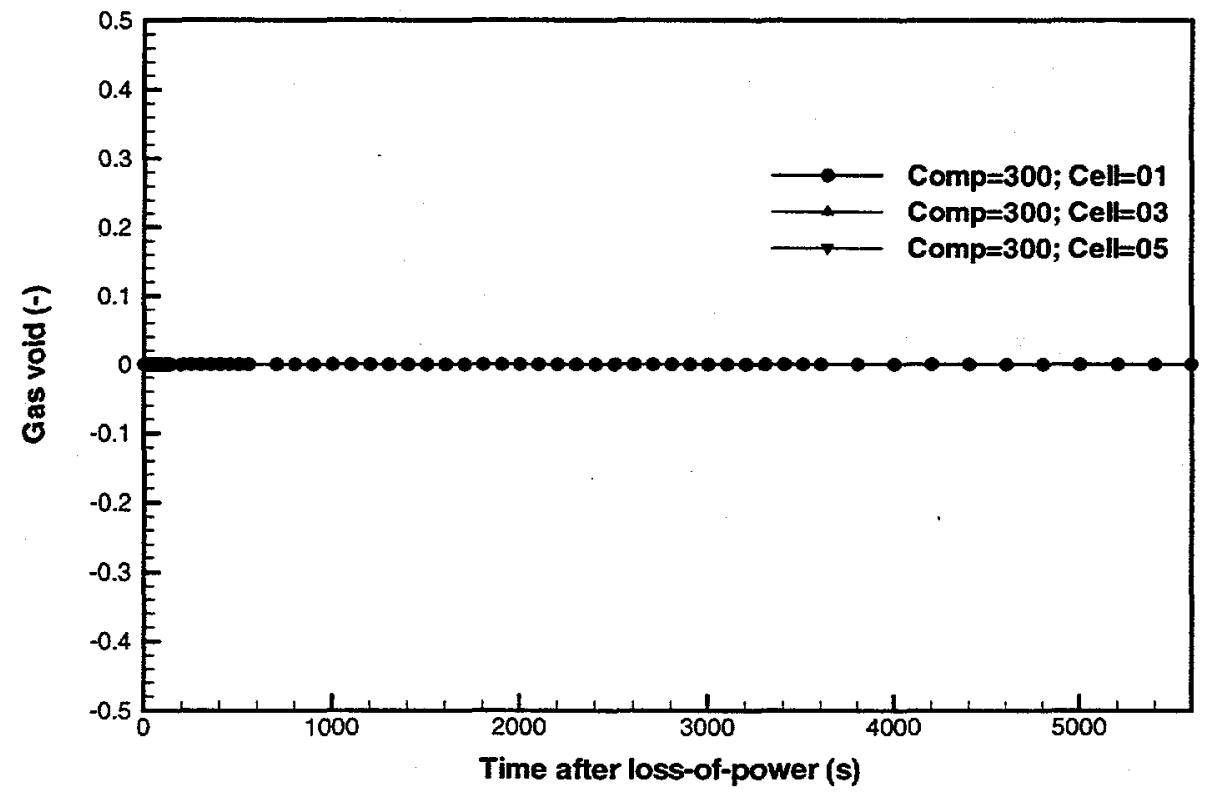

Figure B-8e Module 1 channel void fractions for a LOFA (Case 2: with beam shutdown only). 


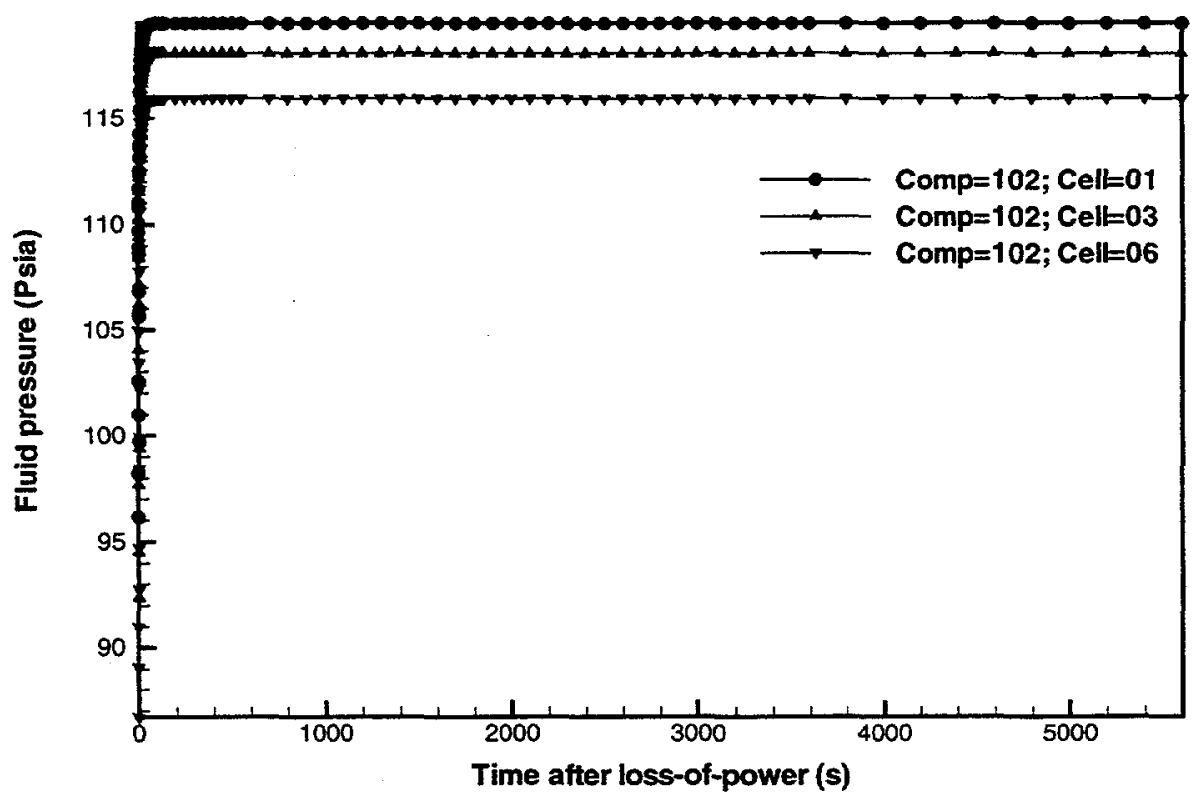

Figure B-19a Module 2 channel fluid pressures for a LOFA (Case 2: with beam shutdown only).

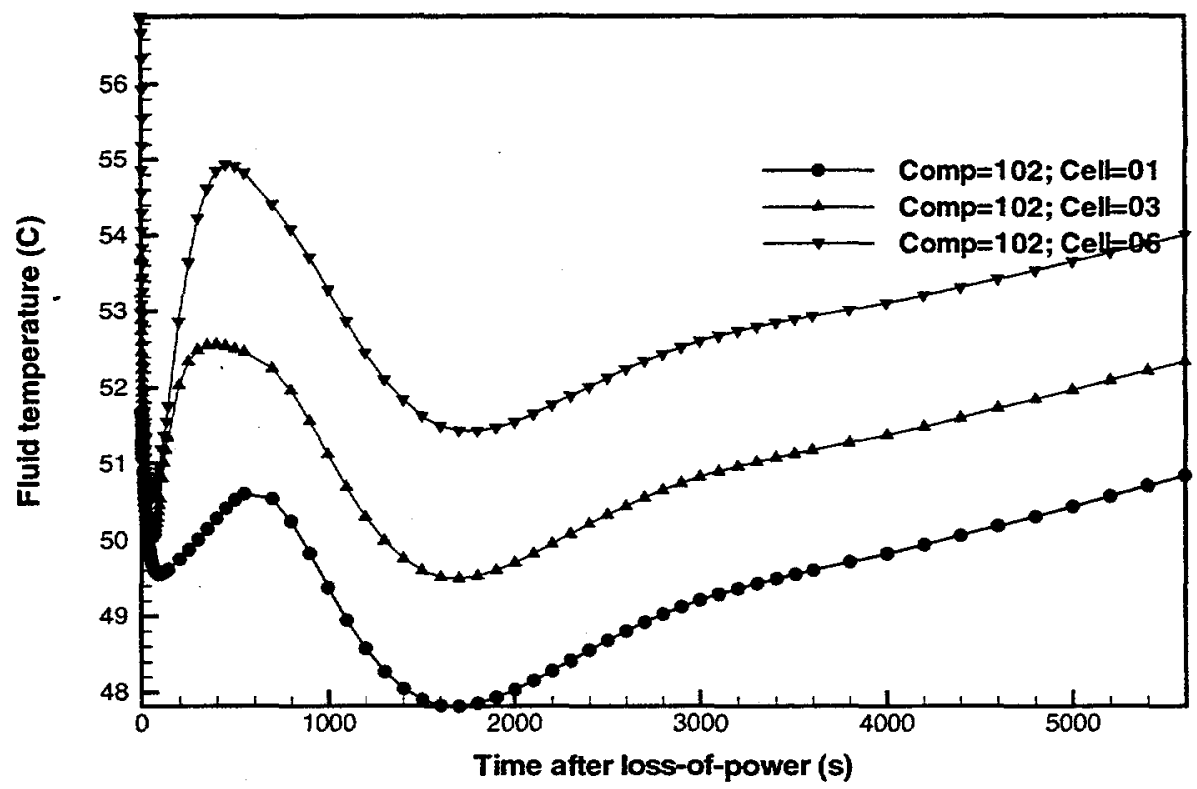

Figure B-19b Module 2 channel fluid temperatures for a LOFA (Case 2: with beam shutdown only). 


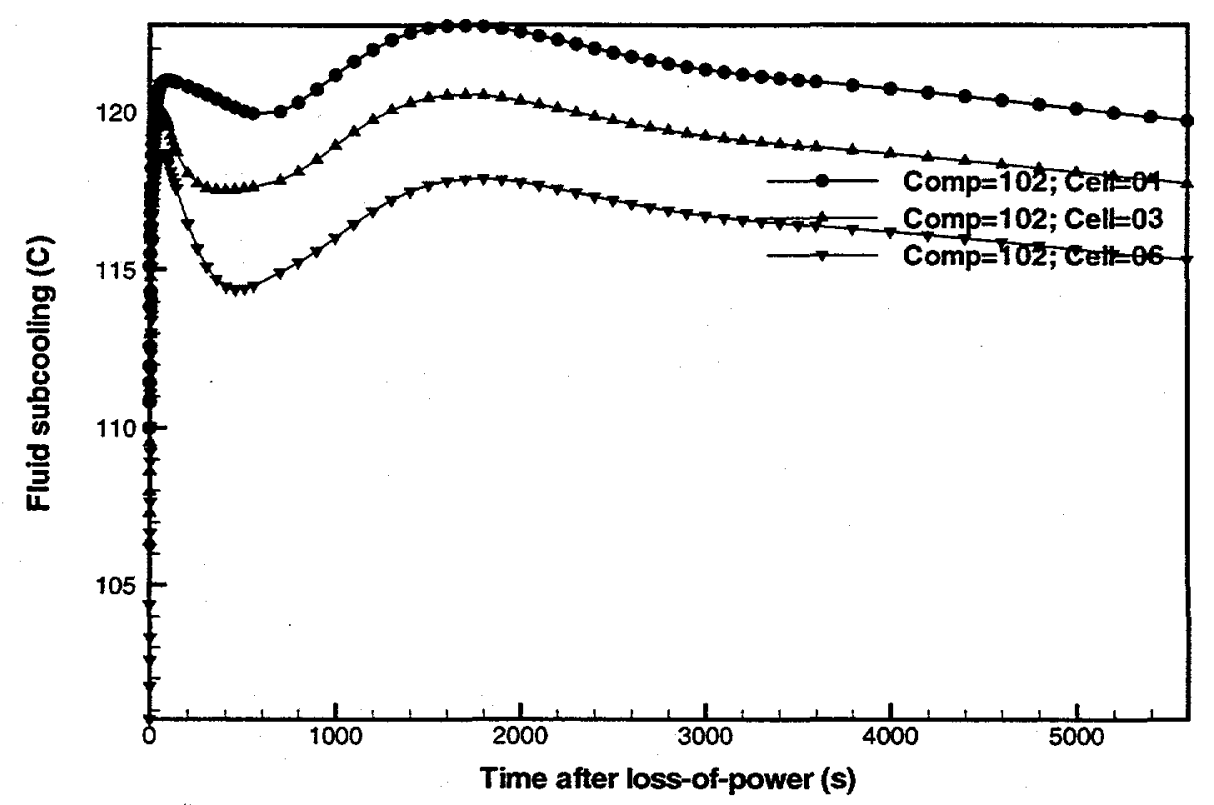

Figure B-19c Module 2 channel fluid subcoolings for a LOFA (Case 2: with beam shutdown only).

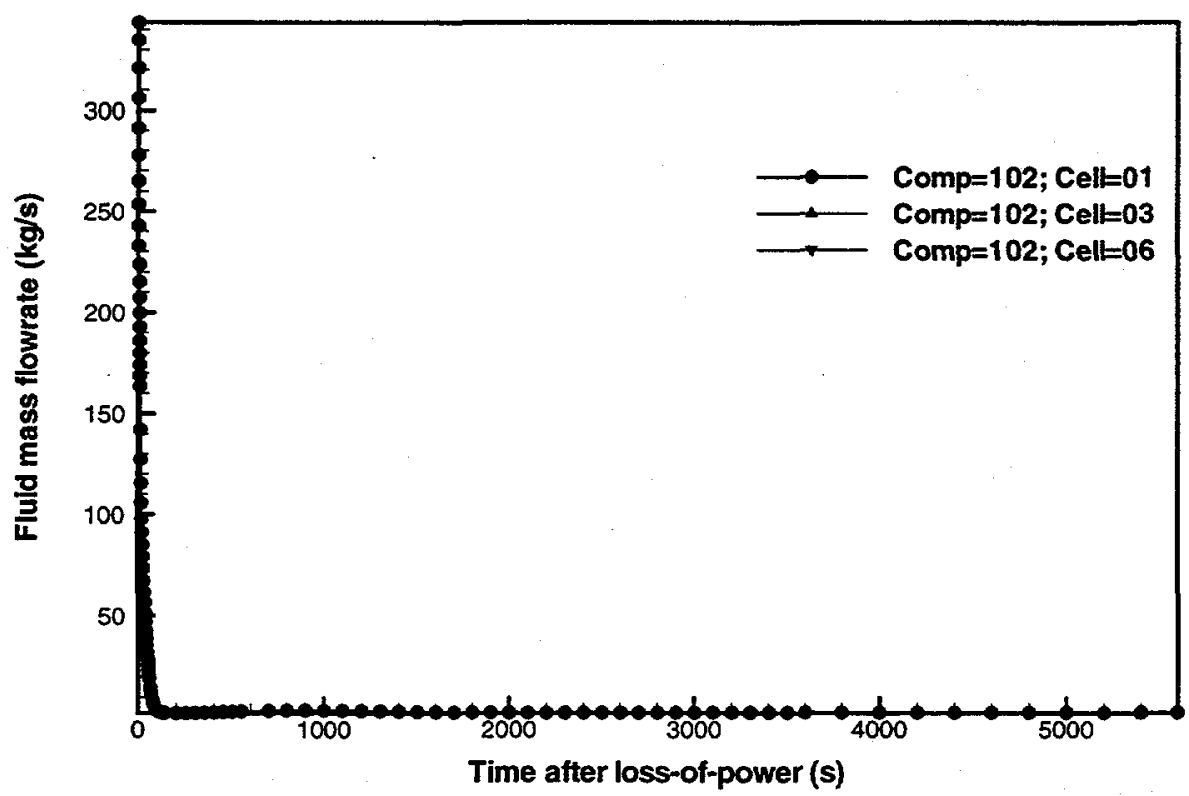

Figure B-19d Module 2 channel liquid mass flowrates for a LOFA (Case 2: with beam shutdown only). 


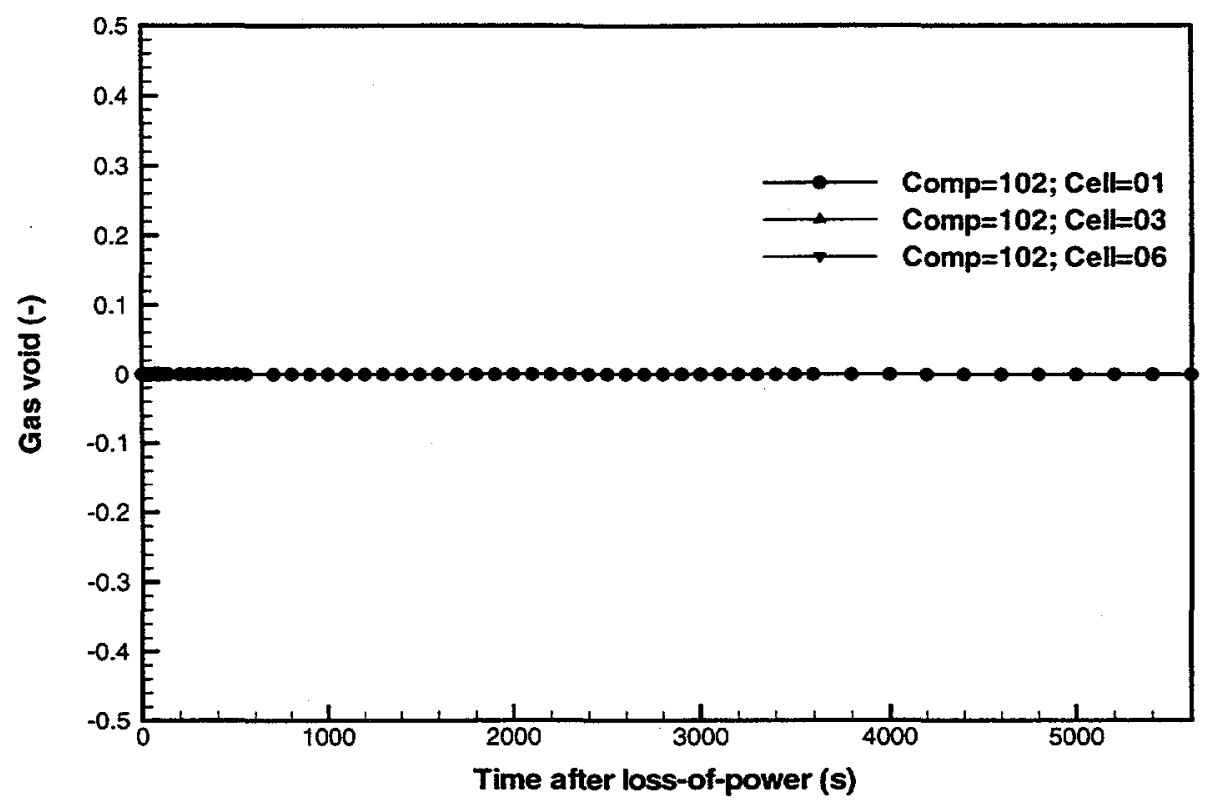

Figure B-19e Module 2 channel Module 2 channel void fractions for a LOFA (Case 2: with beam shutdown only).

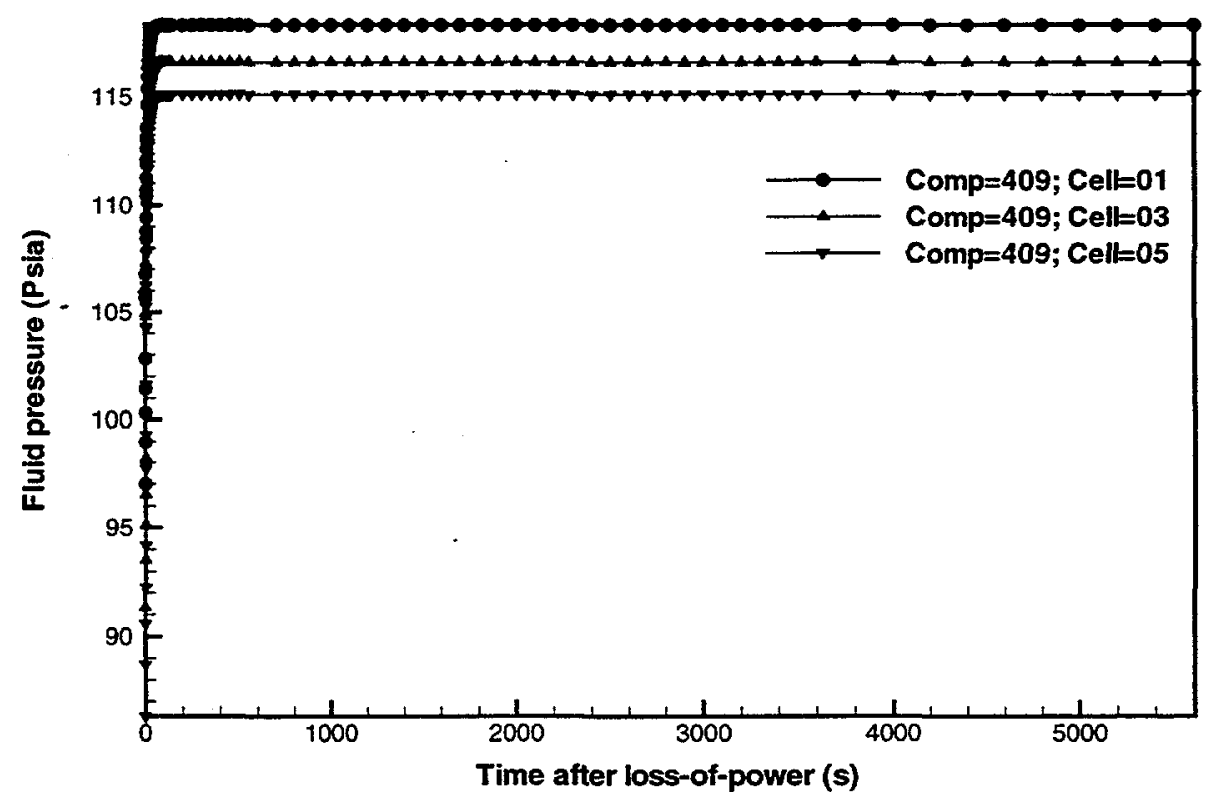

Figure B-20a Module 3 channel fluid pressures for a LOFA (Case 2: with beam shutdown only). 


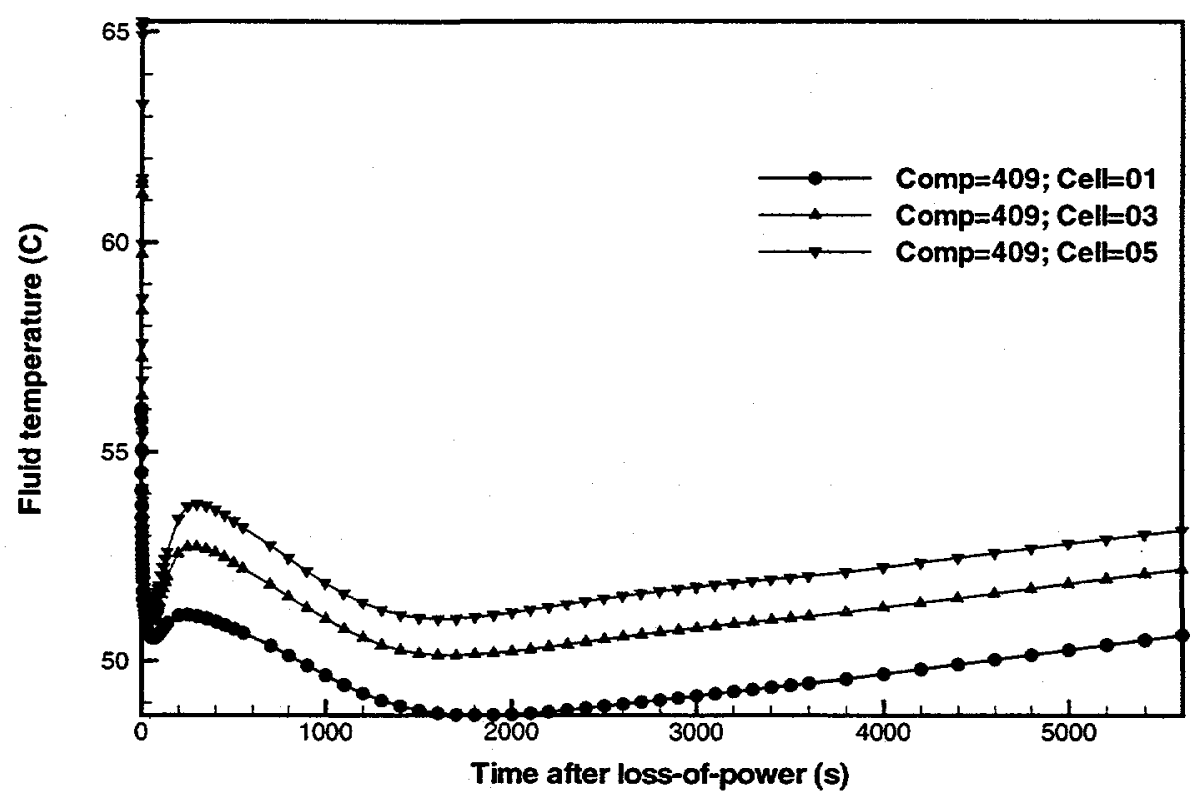

Figure B-20b Module 3 channel Module 3 channel fluid temperatures for a LOFA (Case 2: with beam shutdown only).

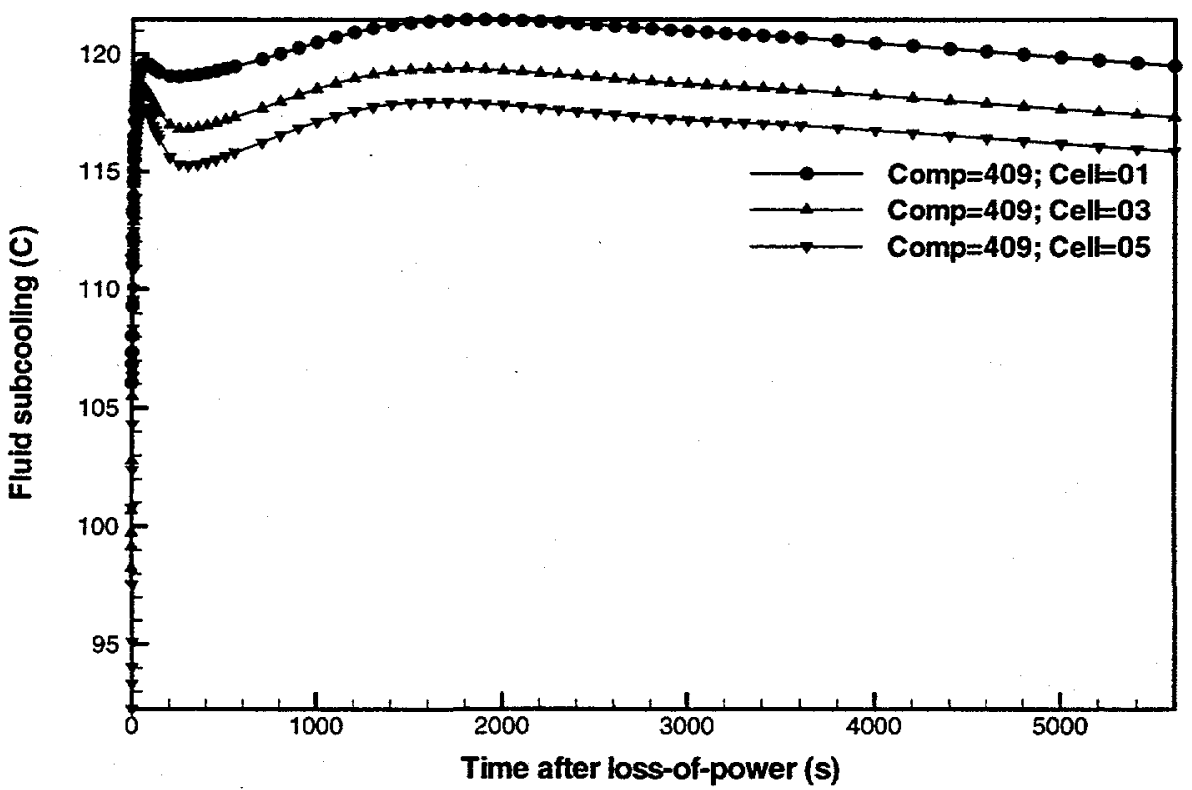

Figure B-20c Module 3 channel fluid subcoolings for a LOFA (Case 2: with beam shutdown only). 


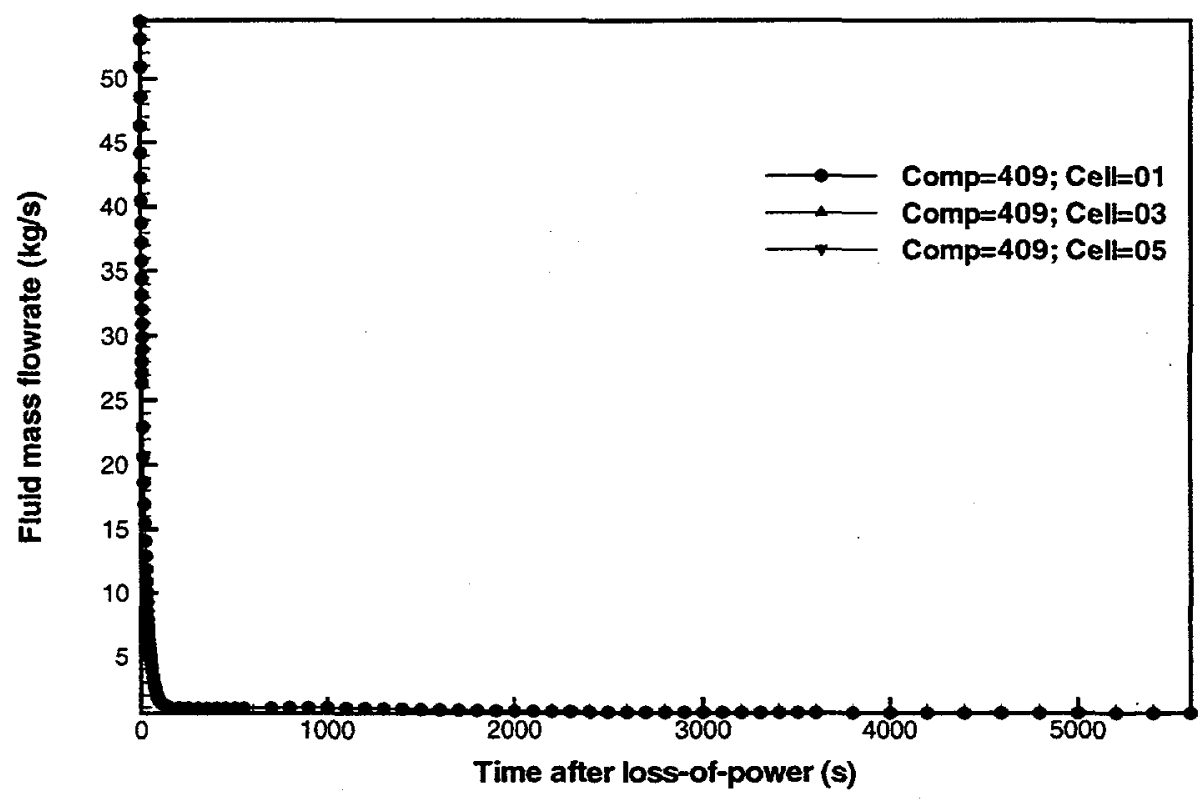

Figure B-20d Module 3 channel liquid mass flowrates for a LOFA (Case 2: with beam shutdown only).

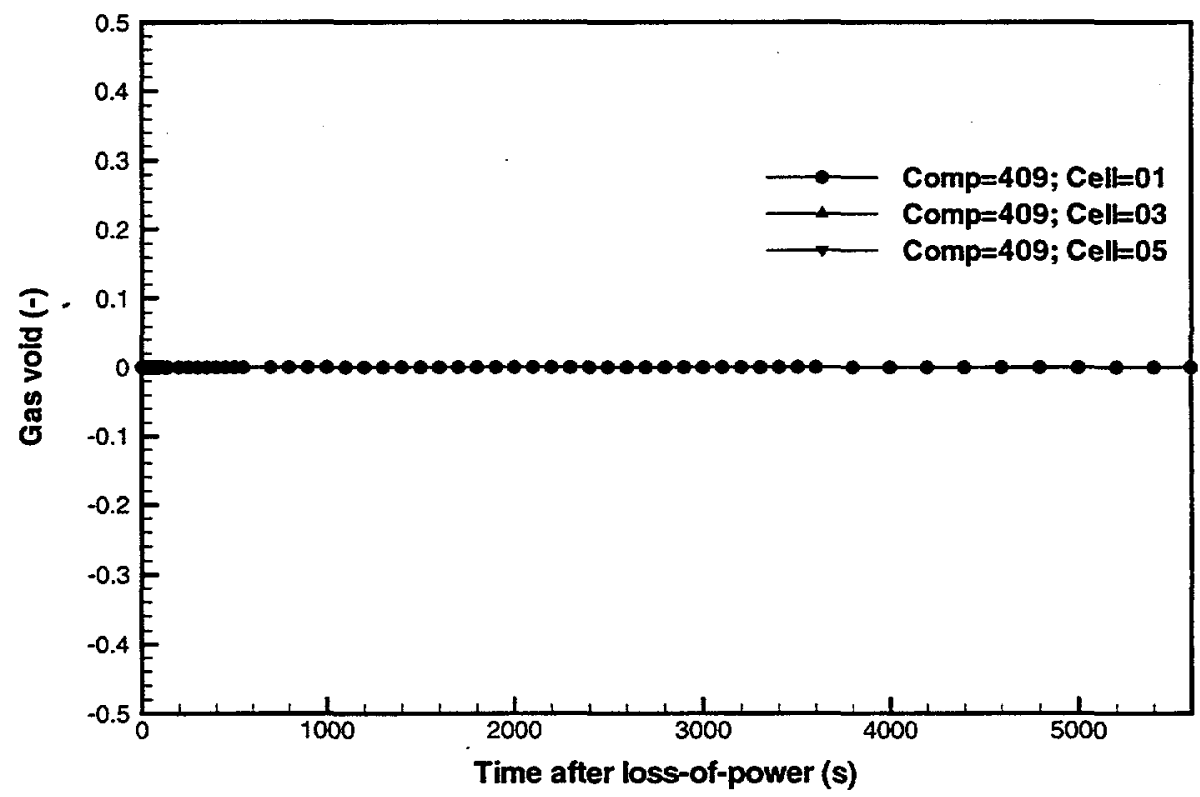

Figure B-20e Module 3 channel void fractions for a LOFA (Case 2: with beam shutdown only). 


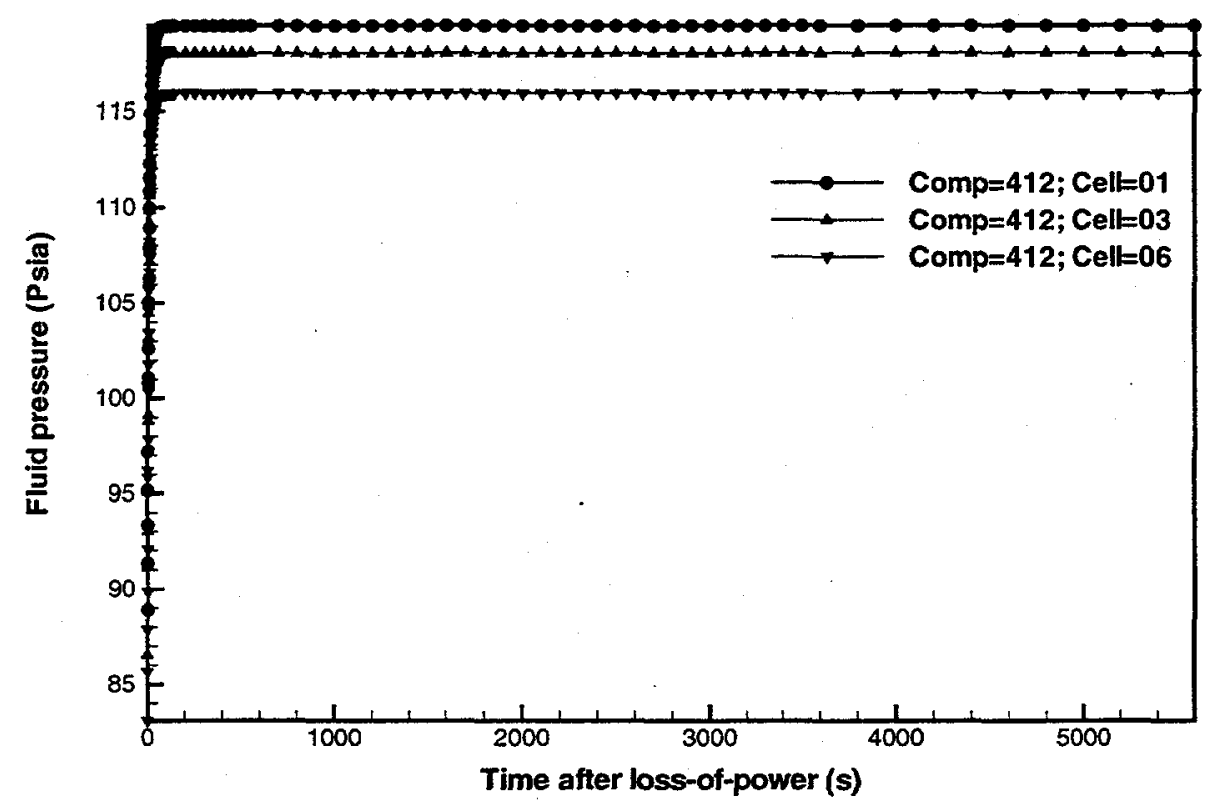

Figure B-21a Module 4 channel fluid pressures for a LOFA (Case 2: with beam shutdown only).

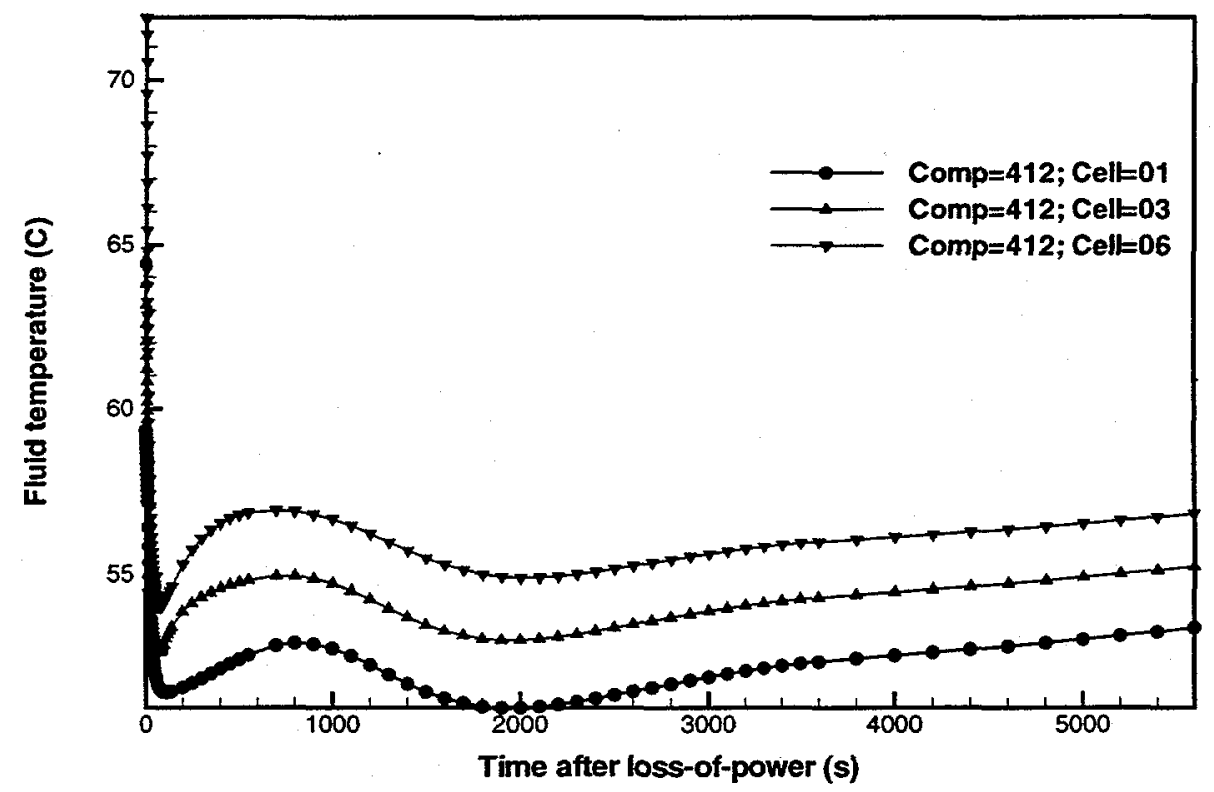

Figure B-21b Module 4 channel fluid temperatures for a LOFA (Case 2: with beam shutdown only). 


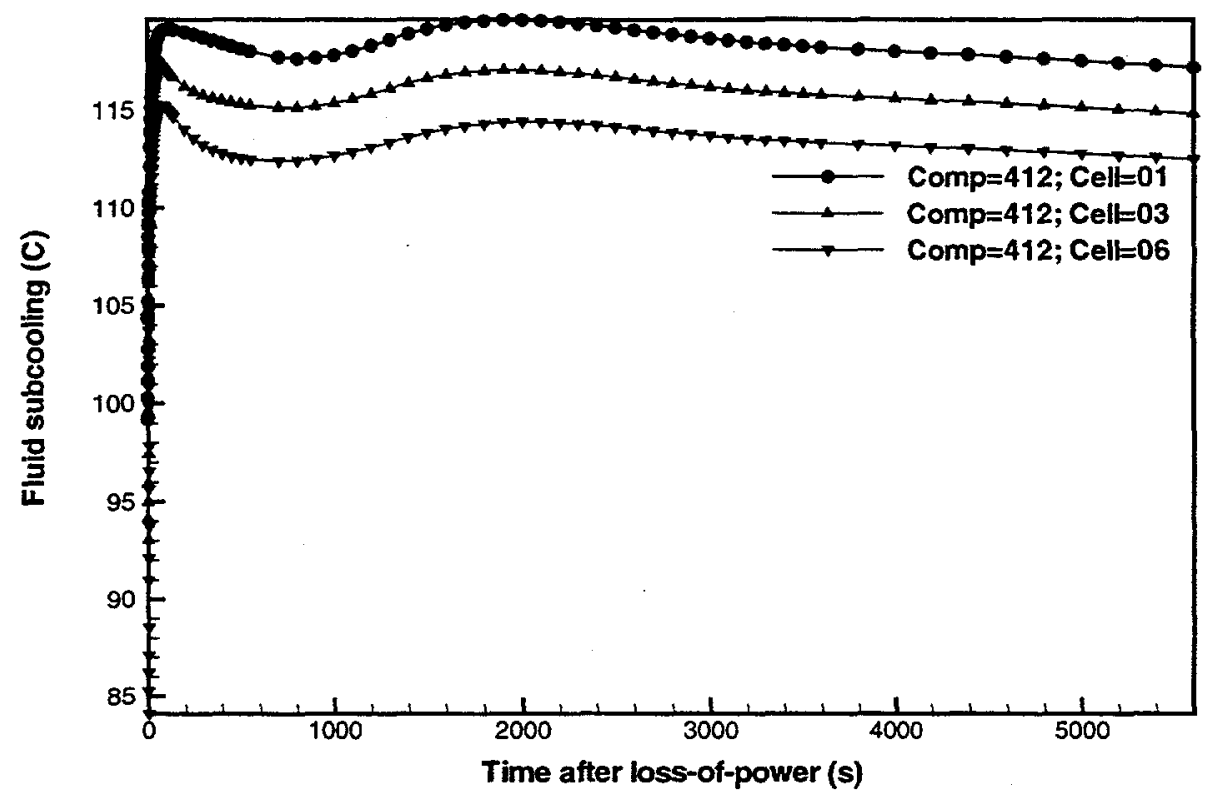

Figure B-21c Module 4 channel fluid subcoolings for a LOFA (Case 2: with beam shutdown only).

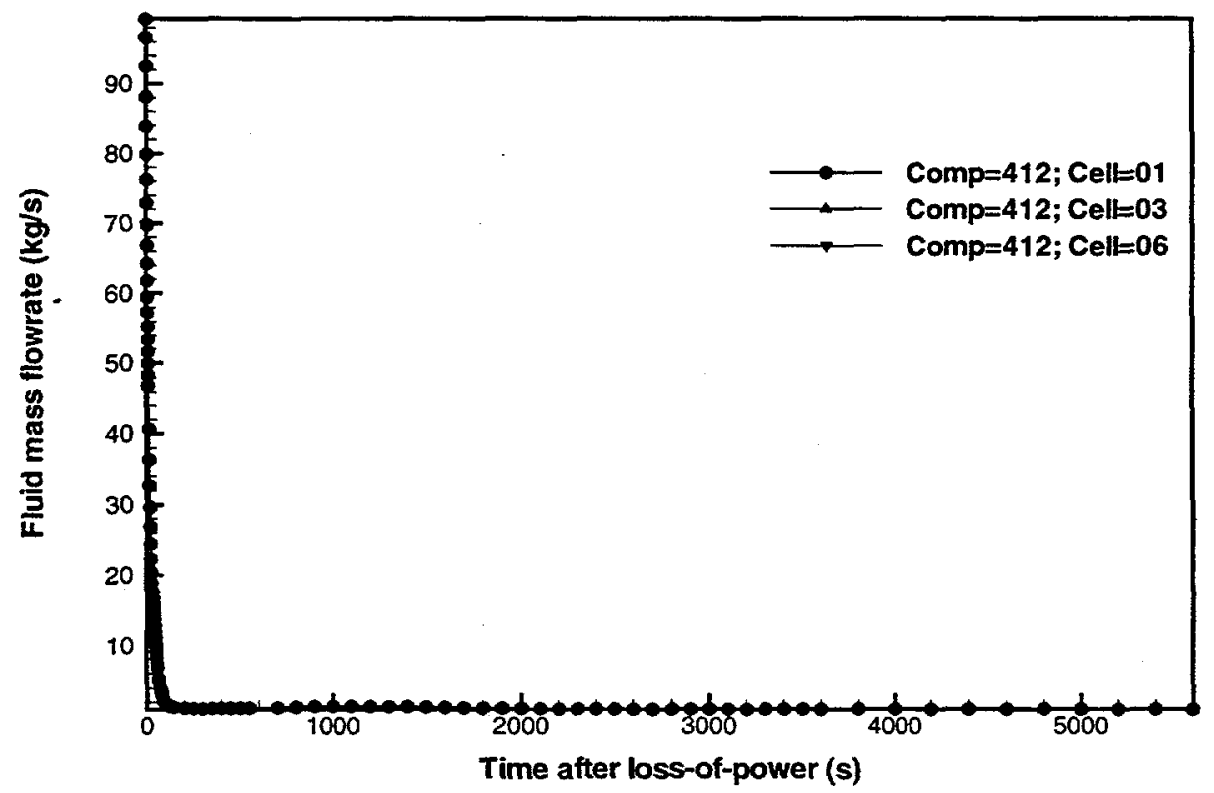

Figure B-21d Module 4 channel liquid mass flowrates for a LOFA (Case 2: with beam shutdown only). 


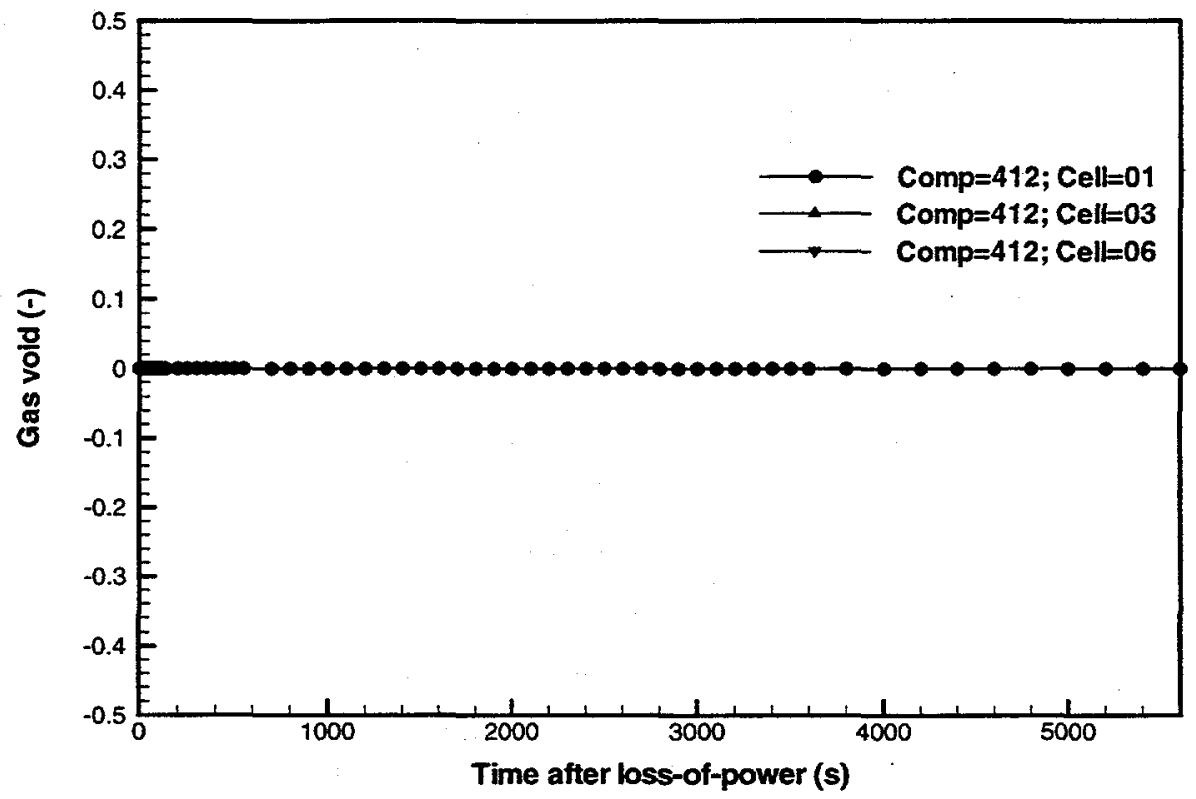

Figure B-21e Module 4 channel void fractions for a LOFA (Case 2: with beam shutdown only).

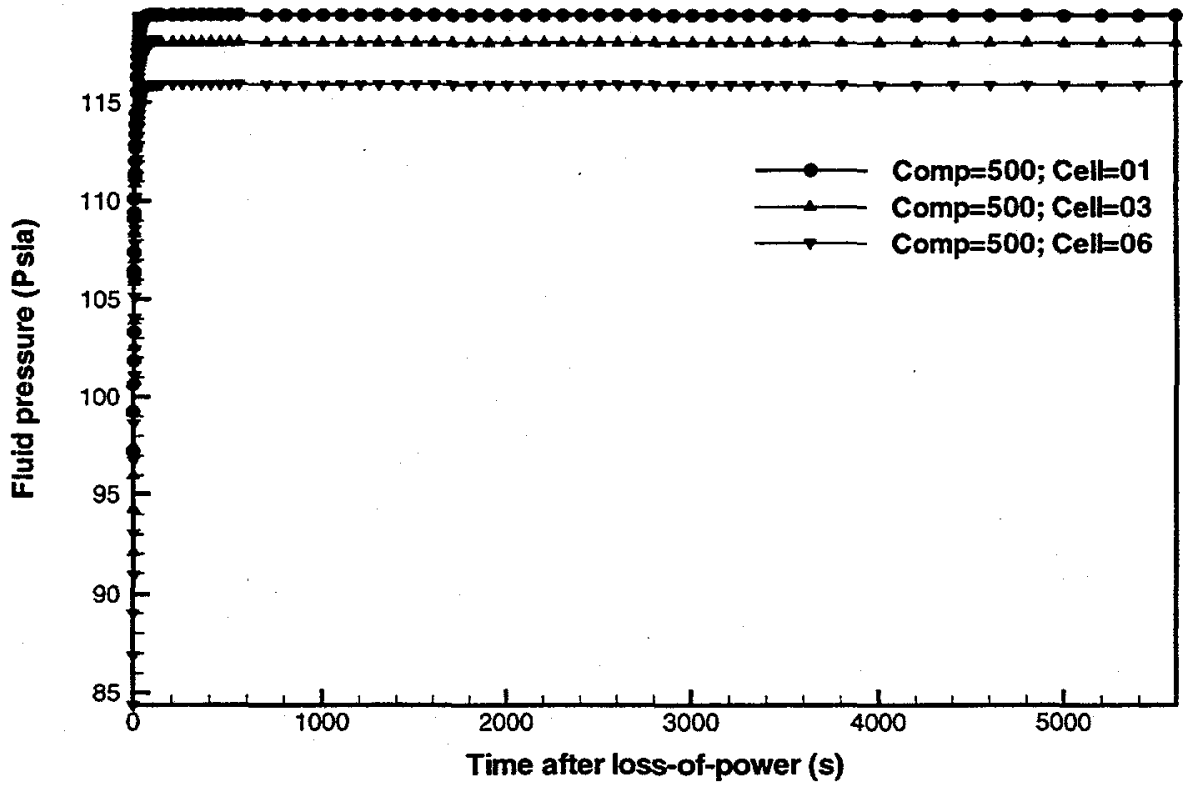

Figure B-22a Module 5 channel fluid pressures for a LOFA (Case 2: with beam shutdown only). 


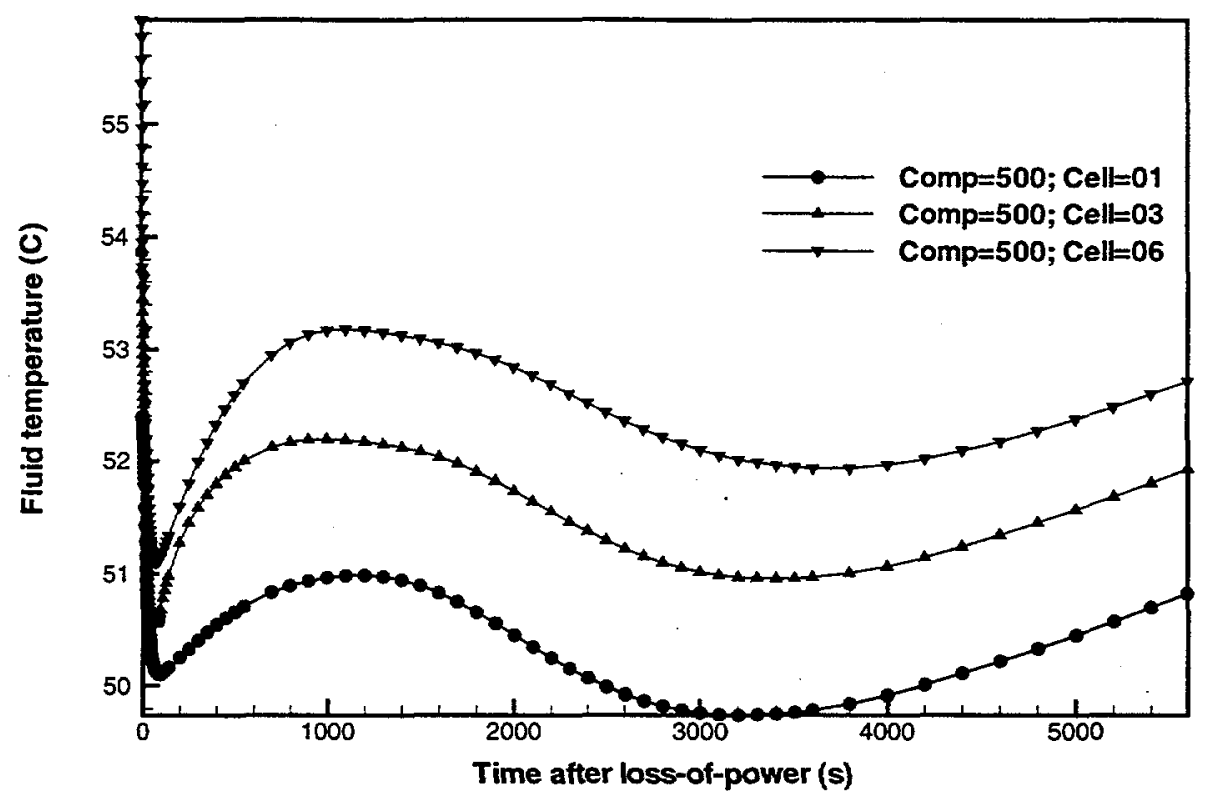

Figure B-22b Module 5 channel fluid temperatures for a LOFA (Case 2: with beam shutdown only).

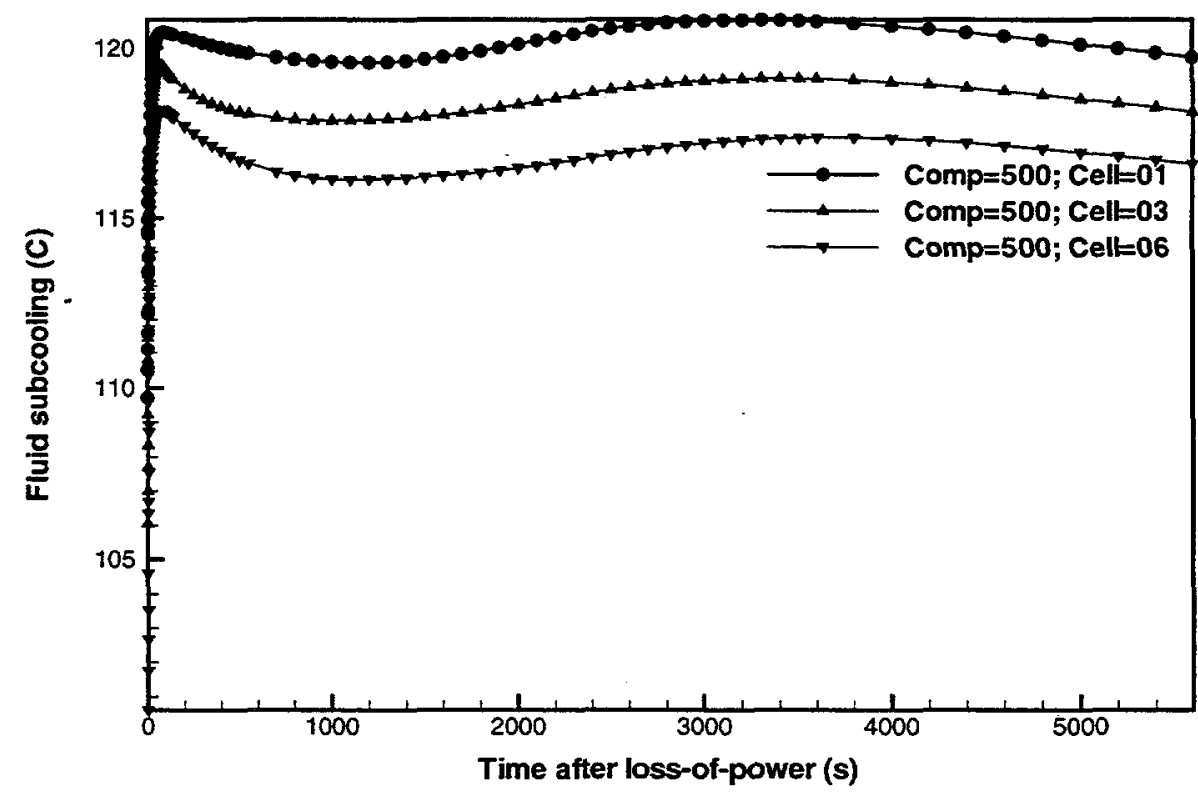

Figure B-22c Module 5 channel fluid subcoolings for a LOFA (Case 2: with beam shutdown only). 
Report:

Section:

BLANKET SAFETY ANALYSIS FOR LOFA

(CASE 2: WITH BEAM SHUTDOWN ONLY)
Date:

Page:
WSRC-TR-98-0085

Appendix B

$07 / 14 / 98$

53 of 72

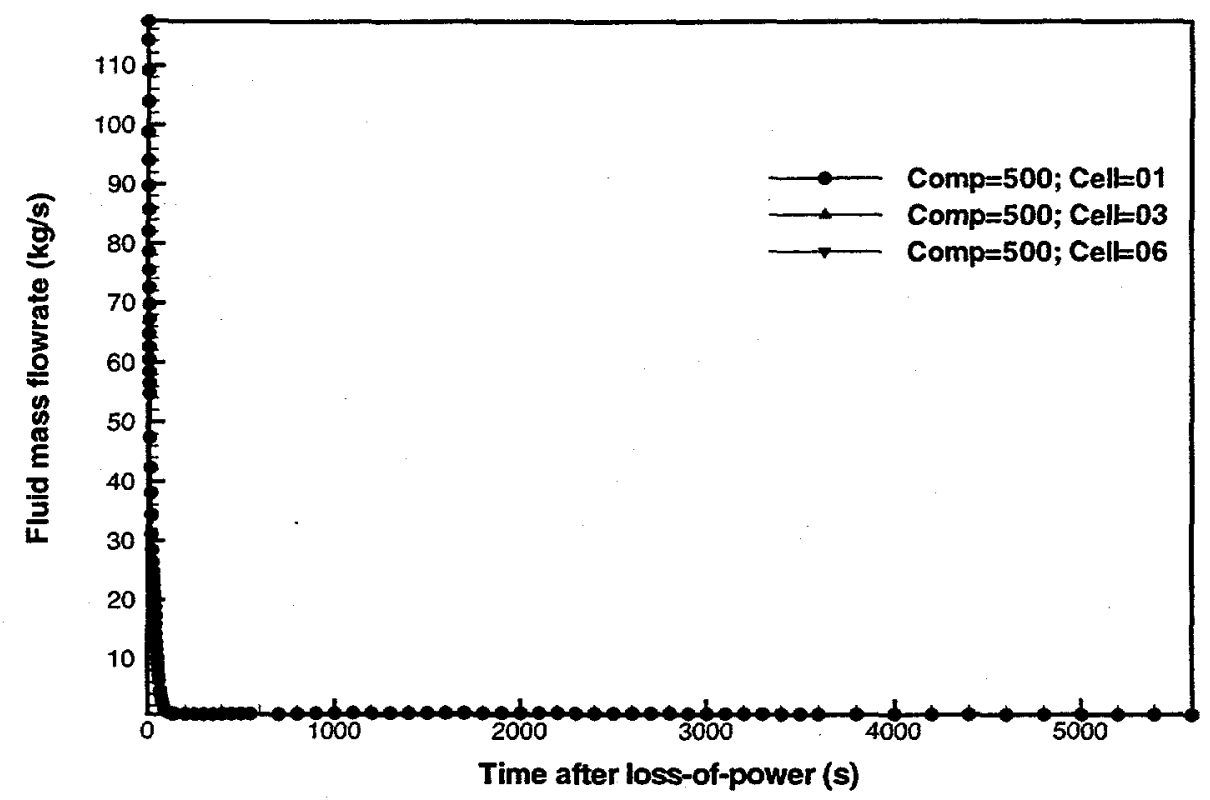

Figure B-22d Module 5 channel liquid mass flowrates for a LOFA (Case 2: with beam shutdown only).

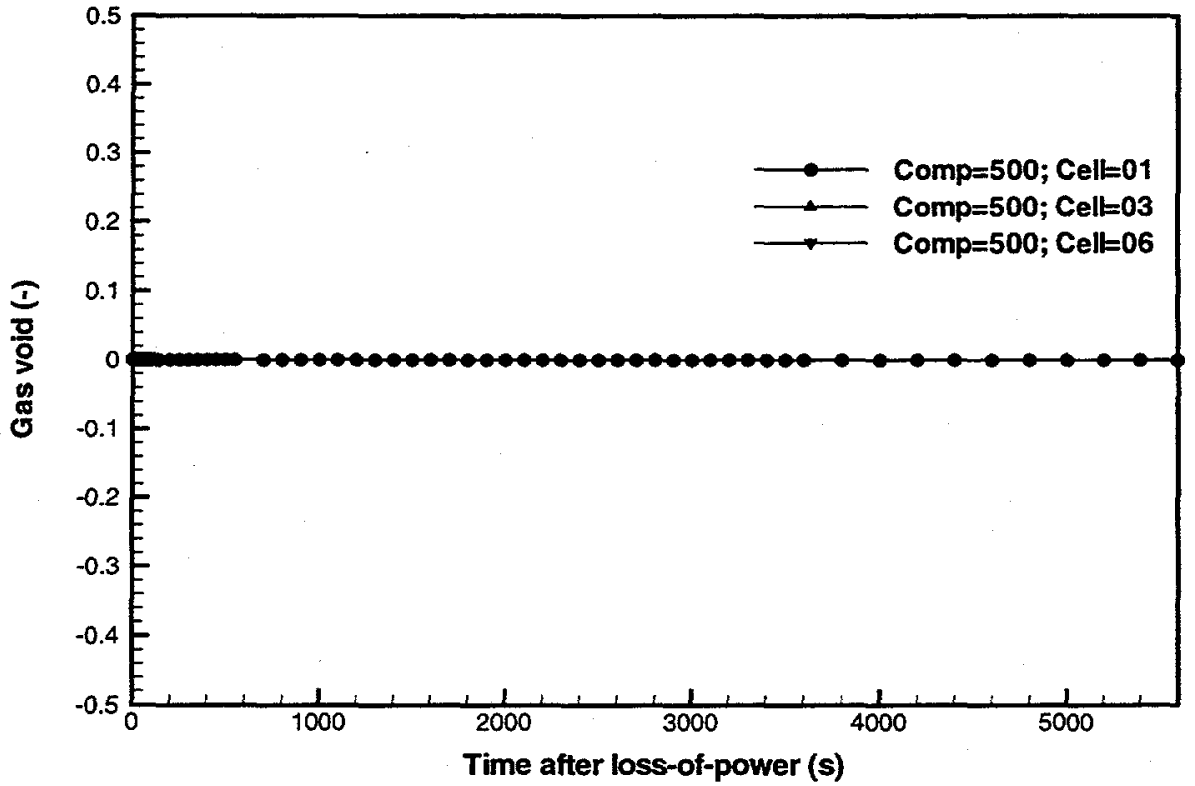

Figure B-22e Module 5 channel void fractions for a LOFA (Case 2: with beam shutdown only). 


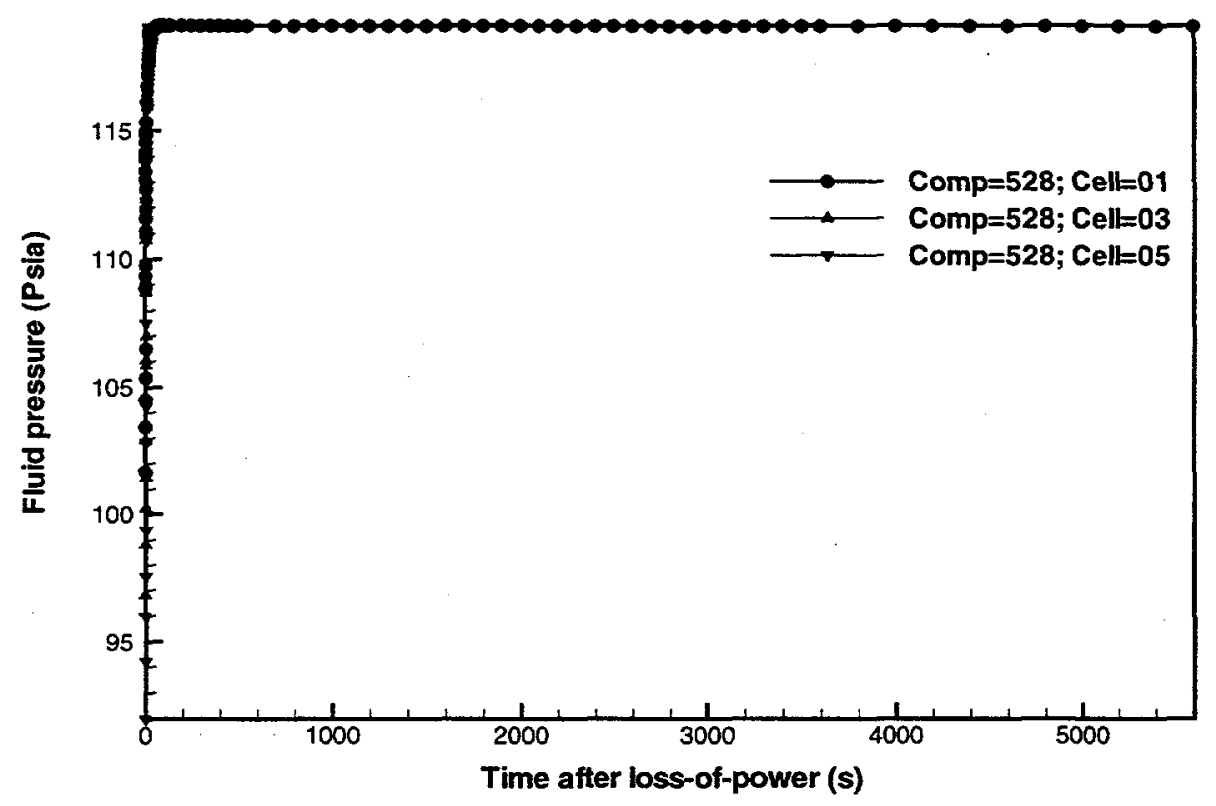

Figure B-23a Module 6 channel fluid pressures for a LOFA (Case 2: with beam shutdown only).

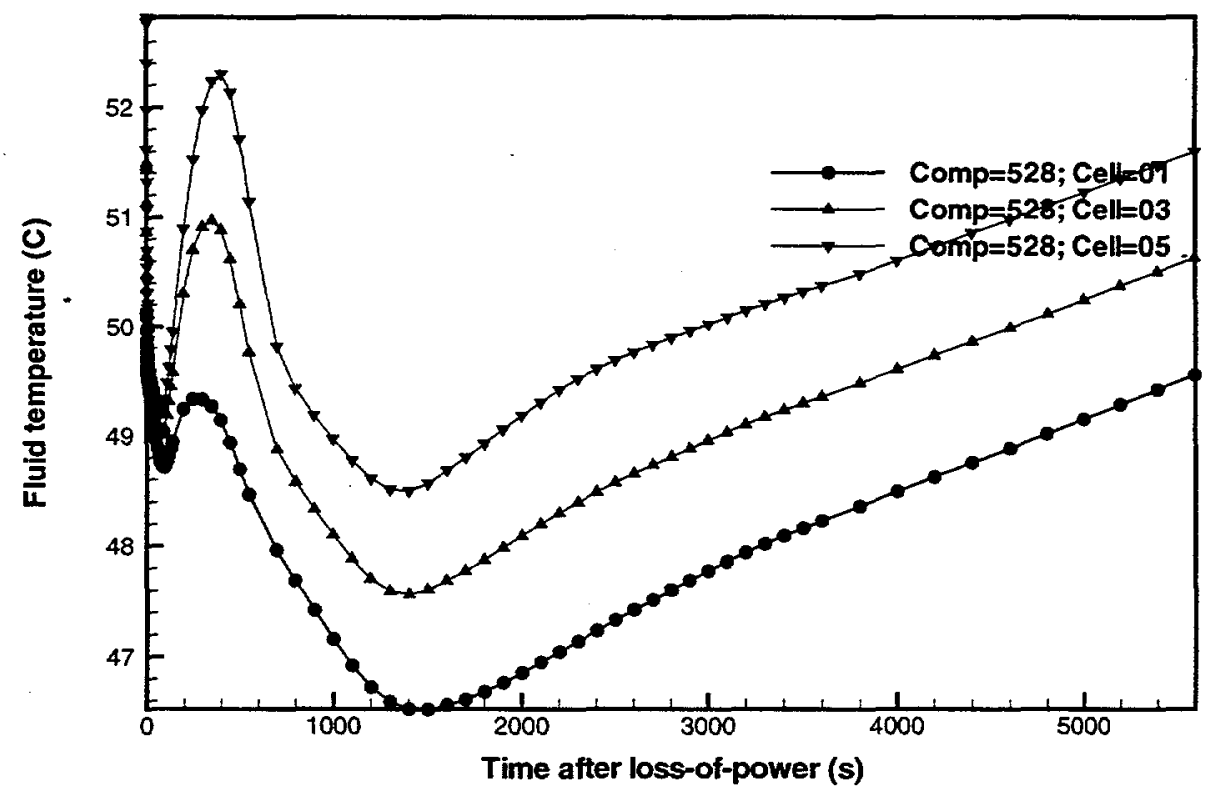

Figure B-23b Module 6 channel fluid temperatures for a LOFA (Case 2: with beam shutdown only). 


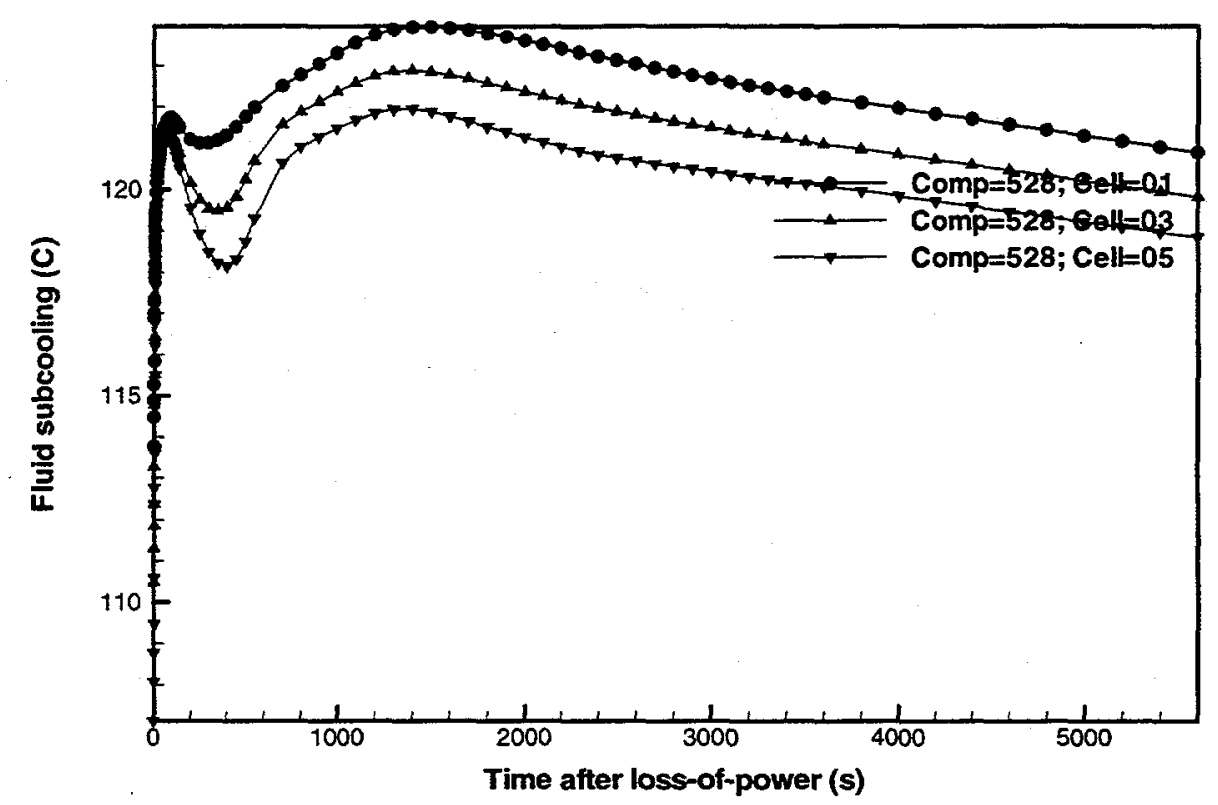

Figure B-23c Module 6 channel fluid subcoolings for a LOFA (Case 2: with beam shutdown only).

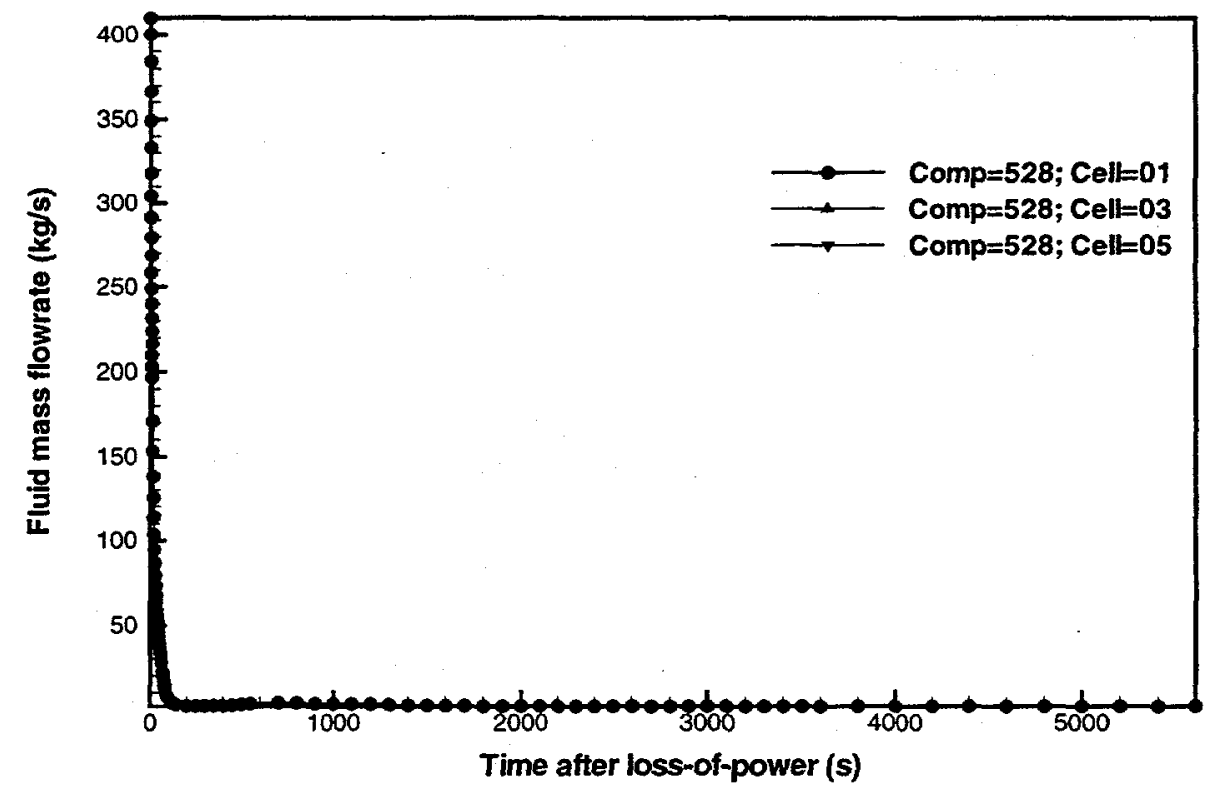

Figure B-23d Module 6 channel liquid mass flowrates for a LOFA (Case 2: with beam shutdown only). 


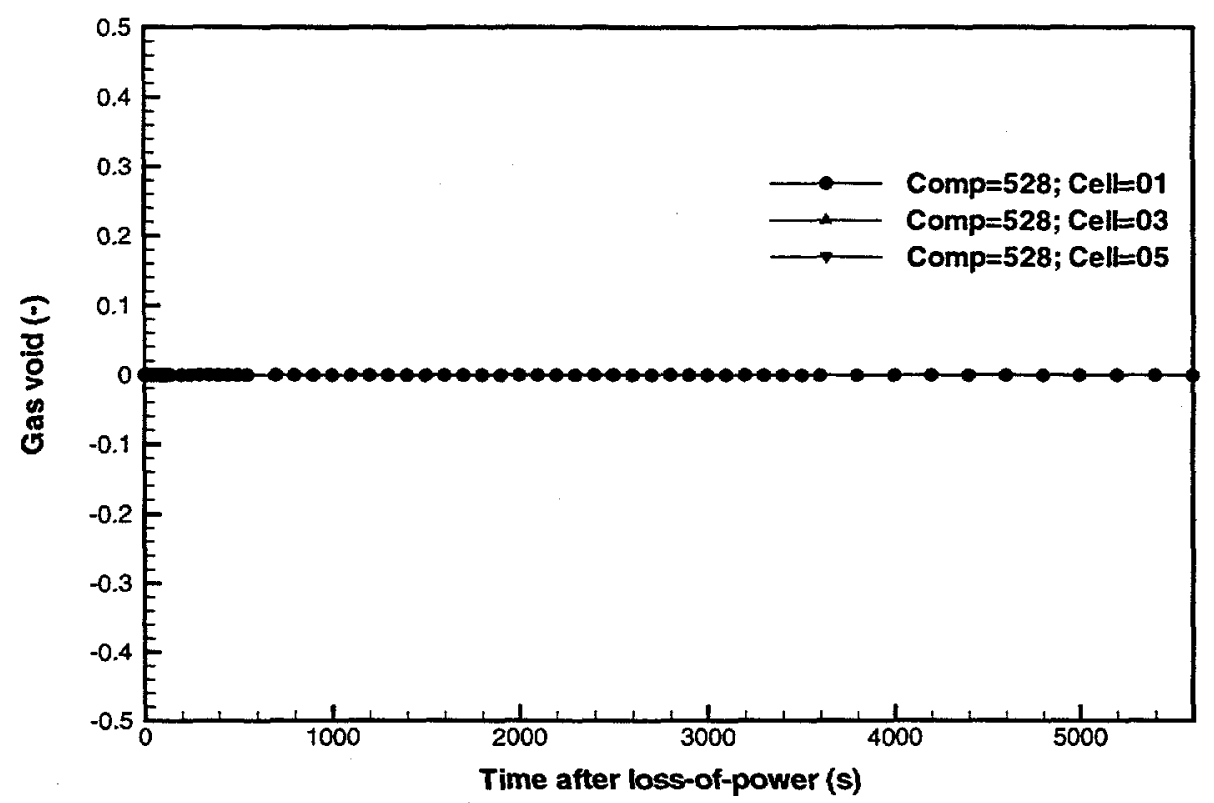

Figure B-23e Module 6 channel void fractions for a LOFA (Case 2: with beam shutdown only).

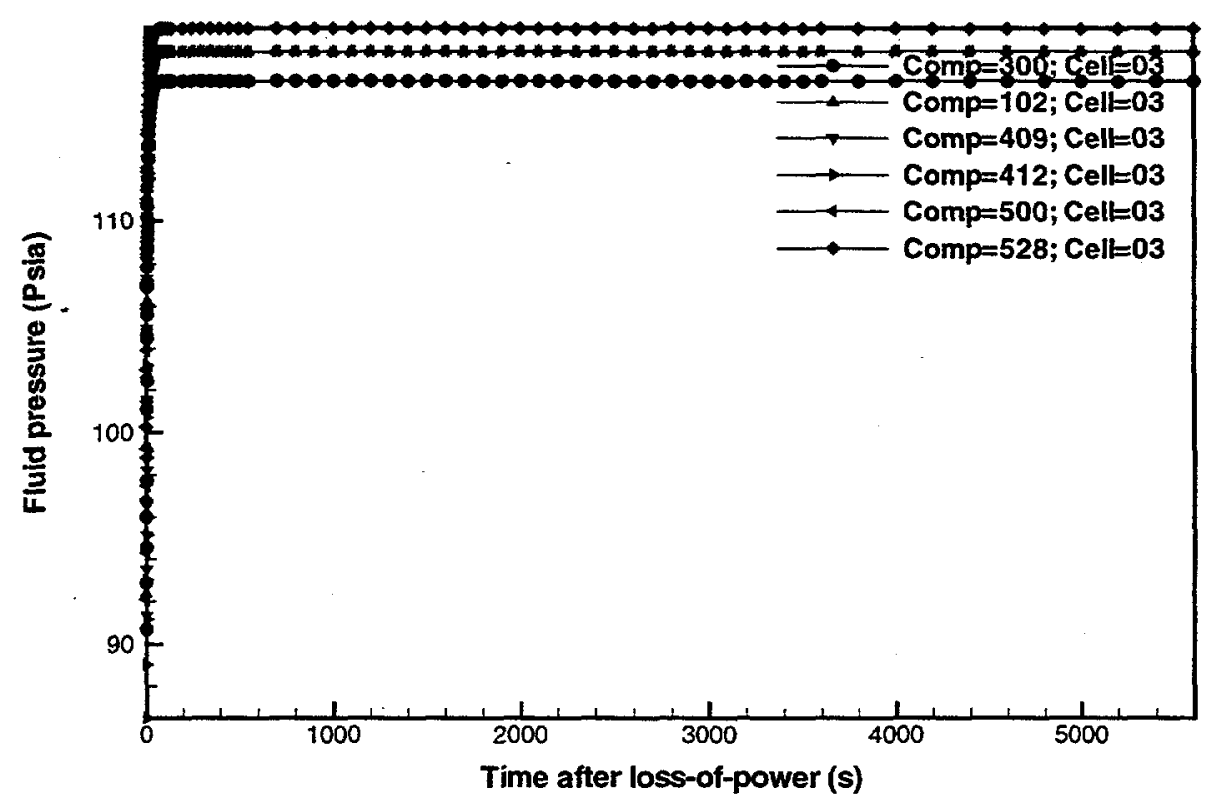

Figure B-24a Mid-plane module fluid pressures for a LOFA (Case 2: with beam shutdown only). 


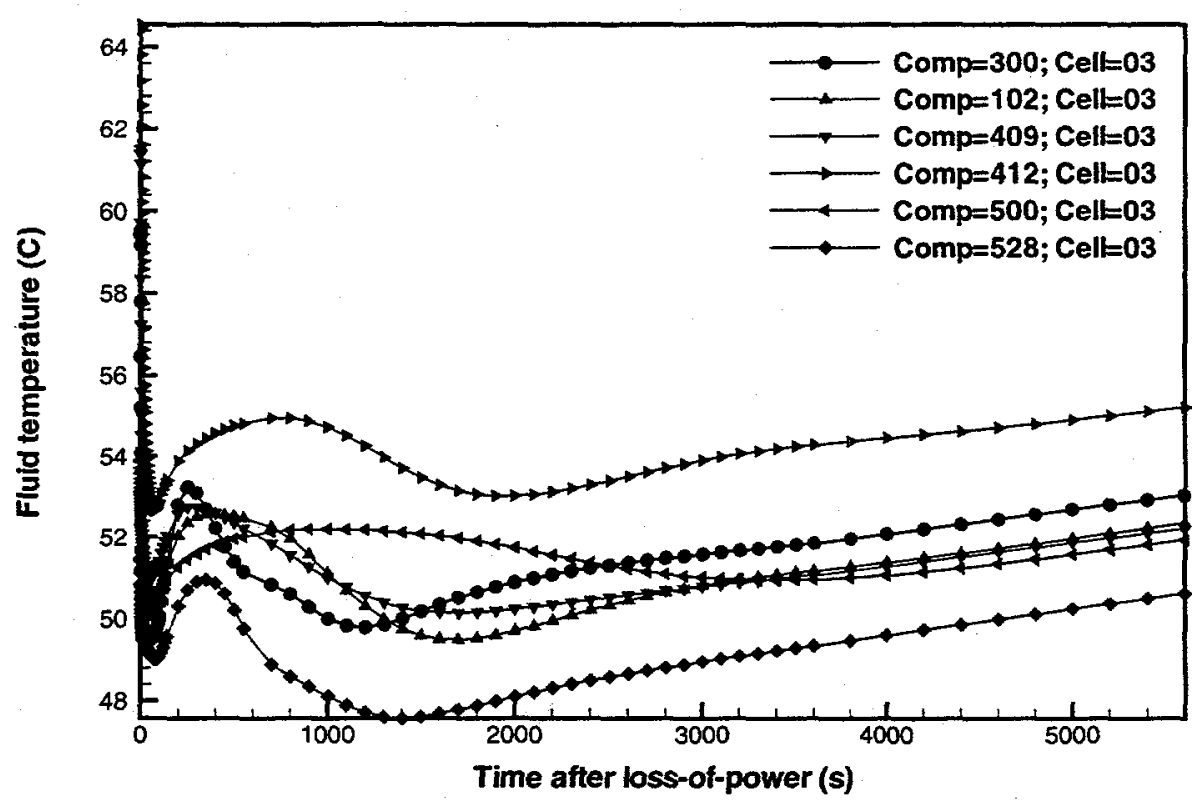

Figure B-24b Mid-plane module fluid temperatures for a LOFA (Case 2: with beam shutdown only).

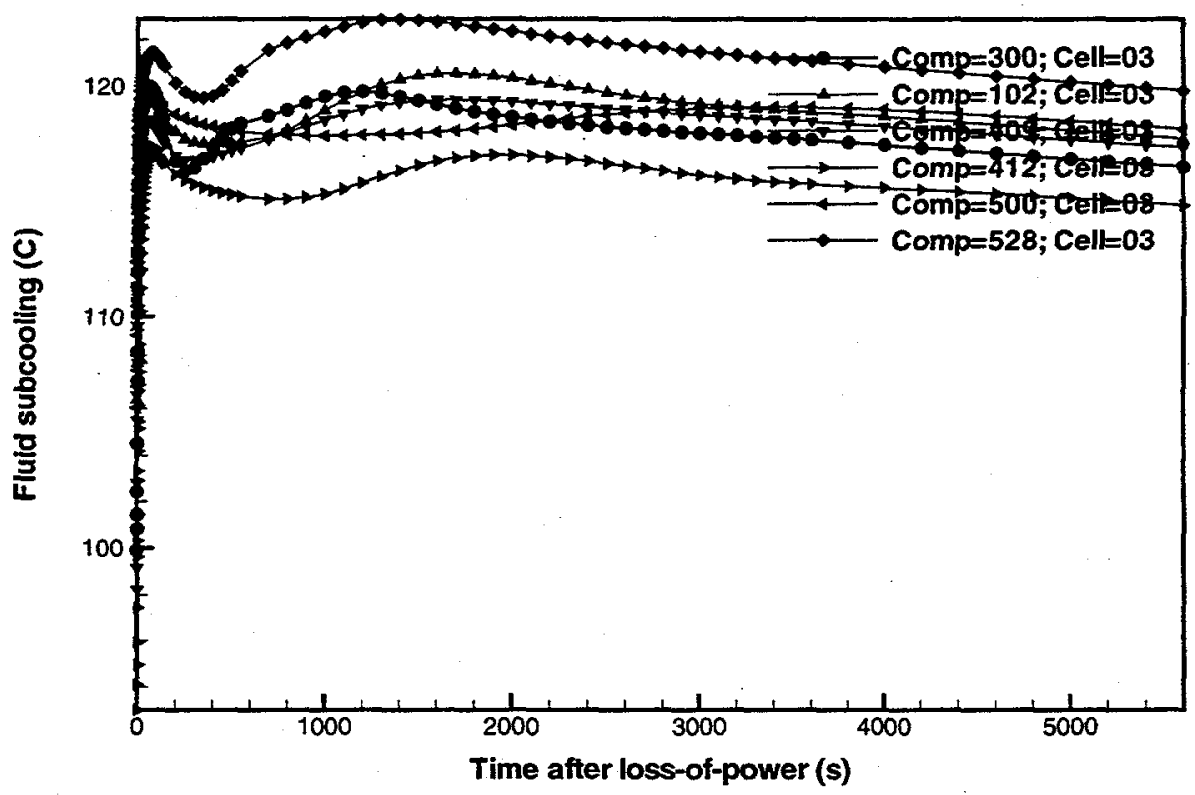

Figure B-24c Mid-plane module fluid subcoolings for a LOFA (Case 2: with beam shutdown only). 


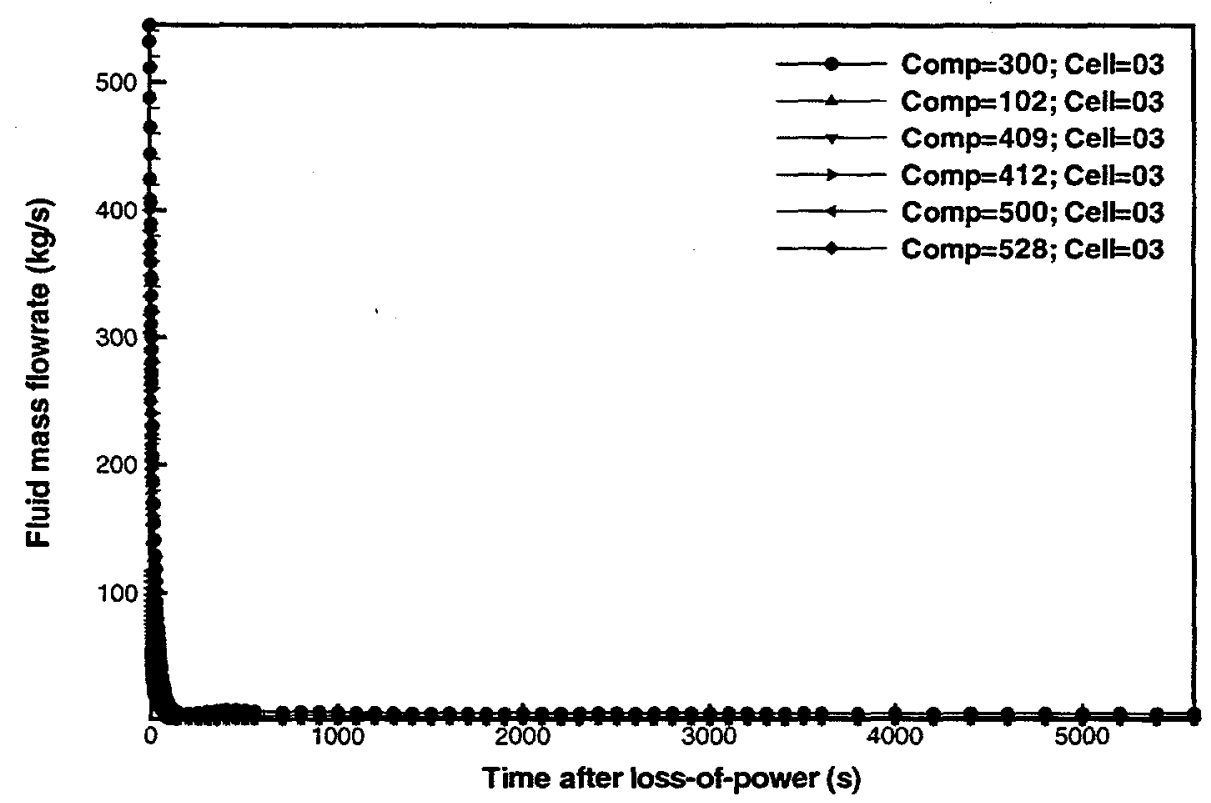

Figure B-24d Mid-plane module liquid mass flowrates for a LOFA (Case 2: with beam shutdown only).

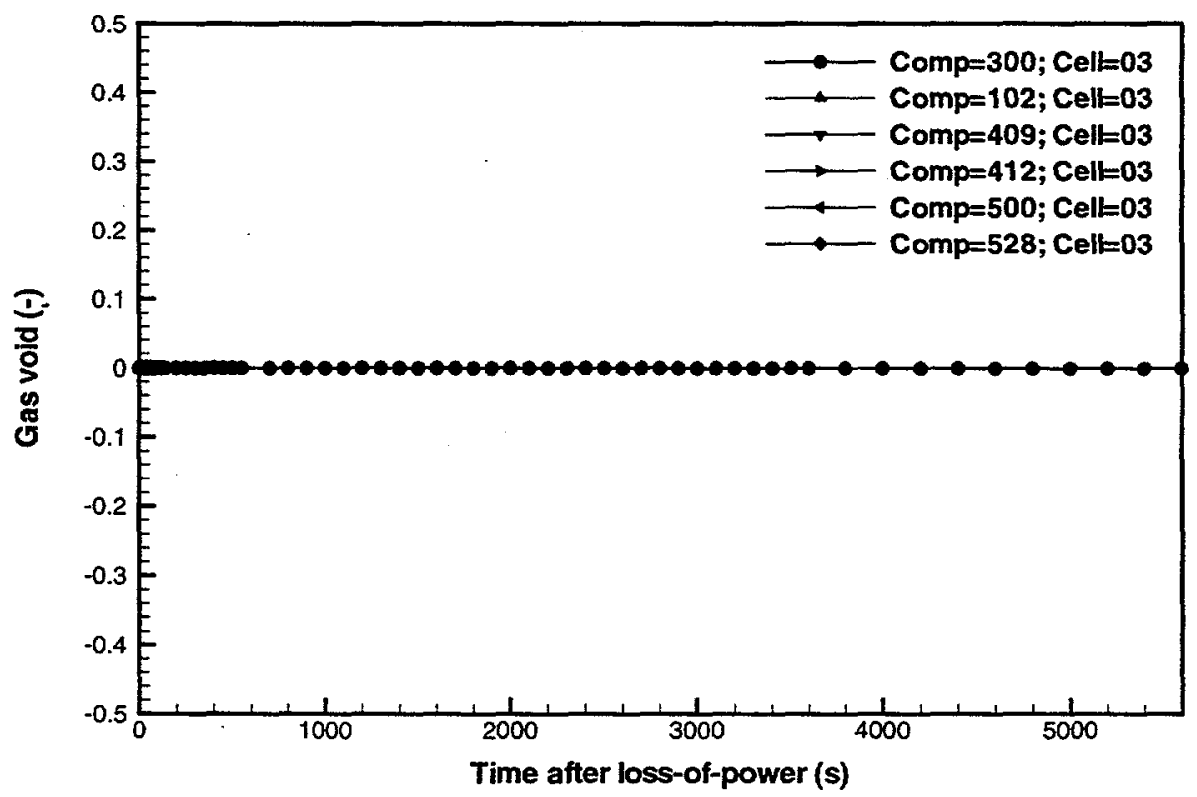

Figure B-24e Mid-plane module void fractions for a LOFA (Case 2: with beam shutdown only). 


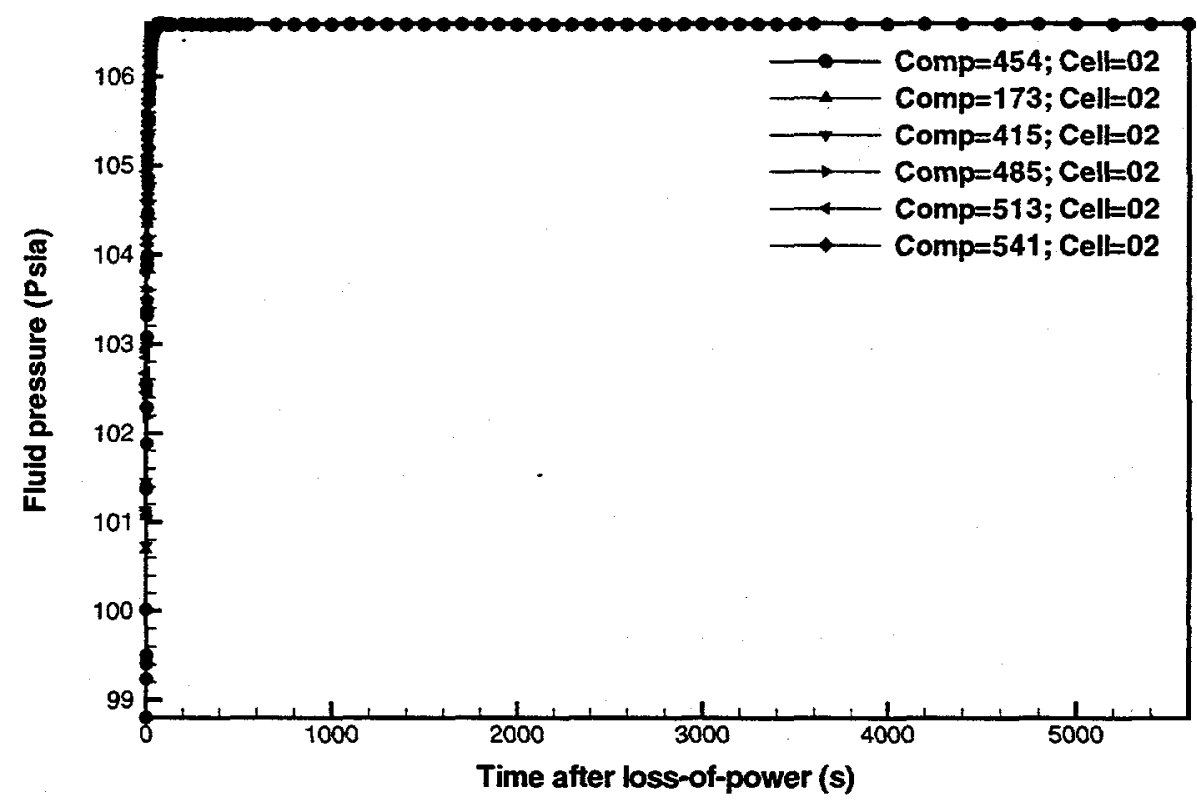

Figure B-25a Module inlet fluid pressures for a LOFA (Case 2: with beam shutdown only).

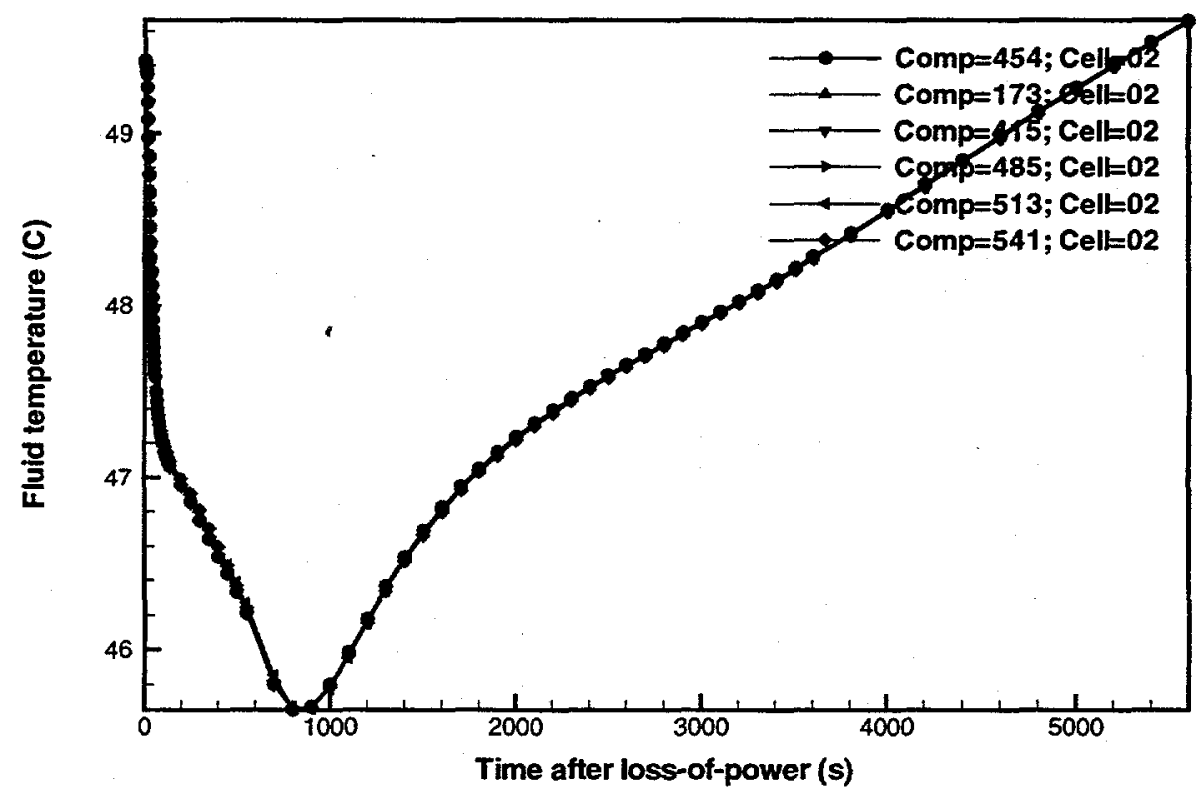

Figure B-25b Module inlet fluid temperatures for a LOFA (Case 2: with beam shutdown only). 


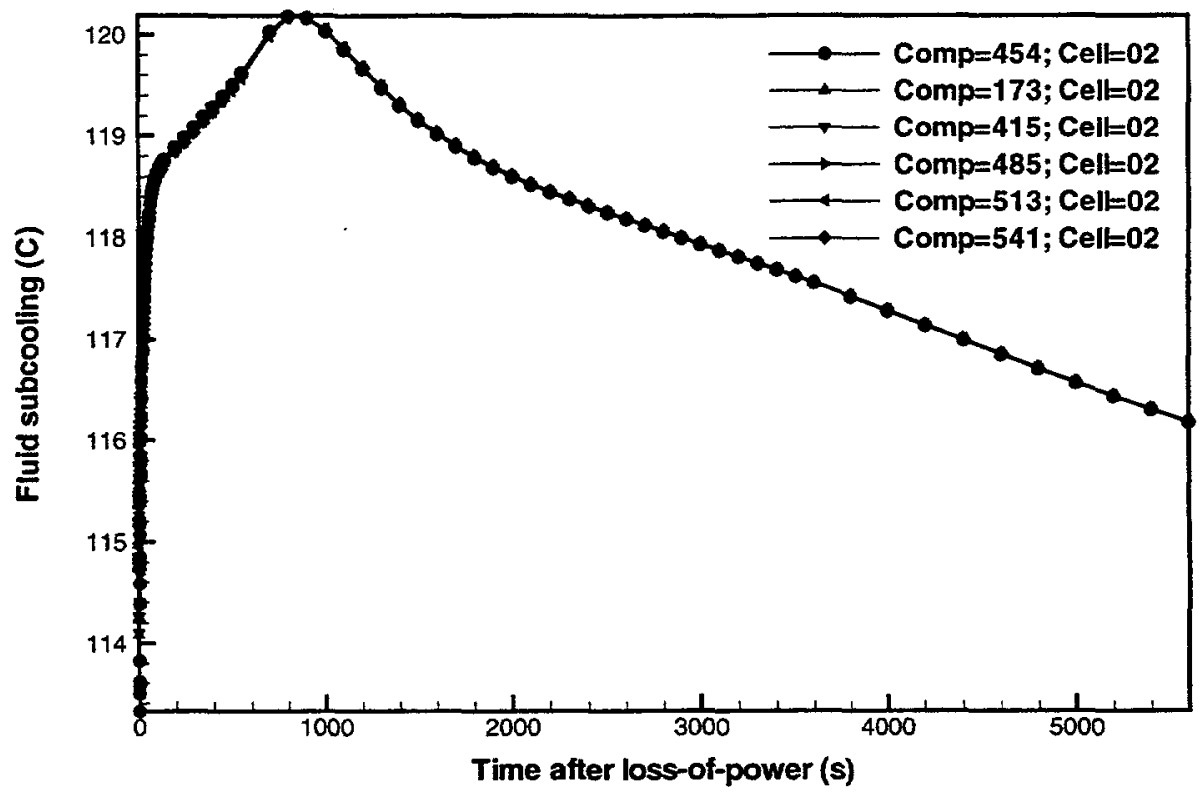

Figure B-25c Module inlet fluid subcoolings for a LOFA (Case 2: with beam shutdown only).

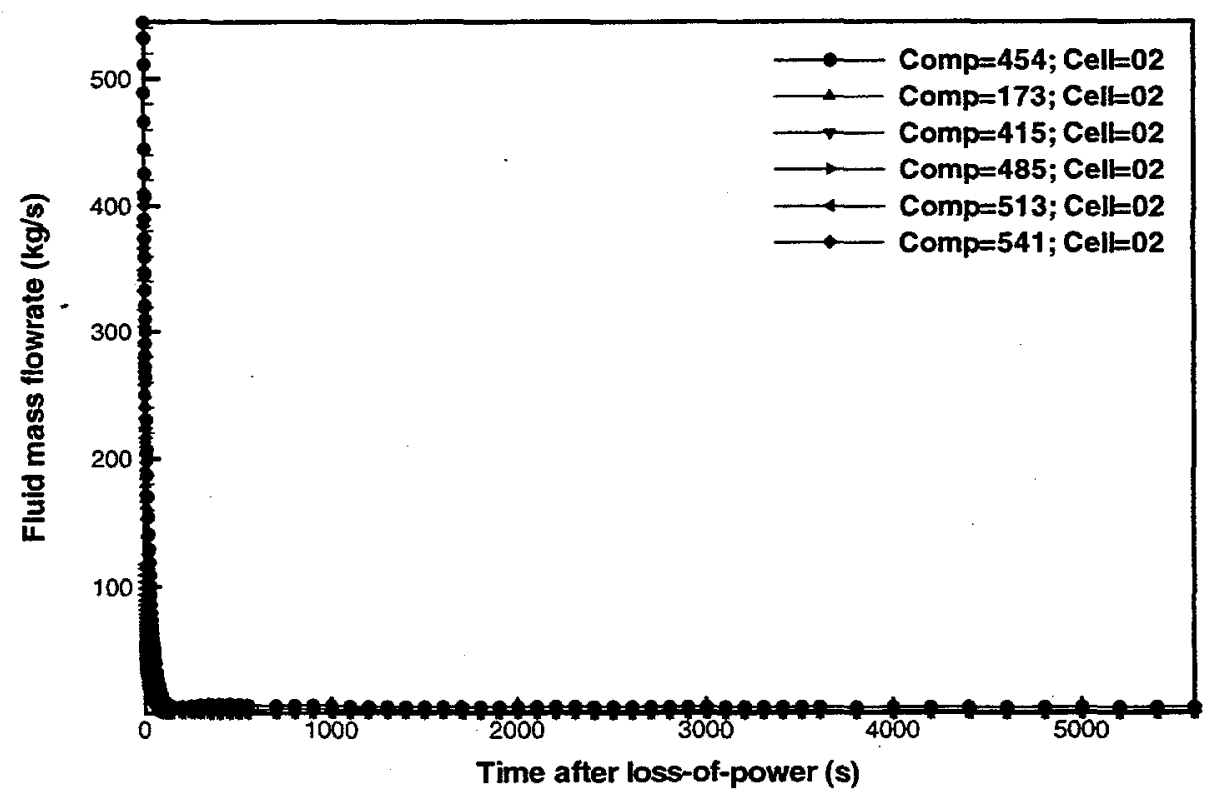

Figure B-25d Module inlet liquid mass flowrates for a LOFA (Case 2: with beam shutdown only). 
Report:

Section:

BLANKET SAFETY ANALYSIS FOR LOFA

(CASE 2: WITH BEAM SHUTDOWN ONLY)
Date:

Page:
WSRC-TR-98-0085

Appendix B

$07 / 14 / 98$

61 of 72

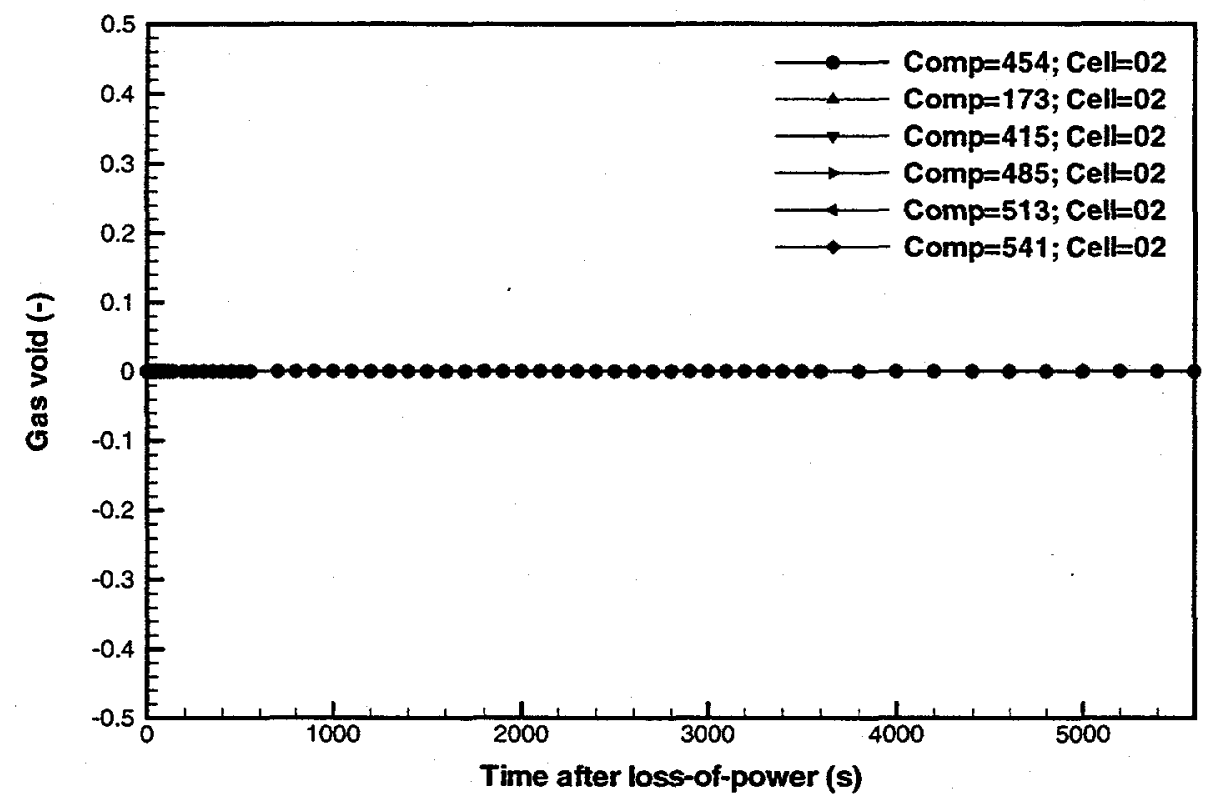

Figure B-25e Module inlet void fractions for a LOFA (Case 2: with beam shutdown only). 


\section{Appendix B3 LOFA (Case 2) TRAC Heat Structure Component Figures}

The following figures are from a TRAC simulation for Case 2 of a LOFA (with beam shutdown only):

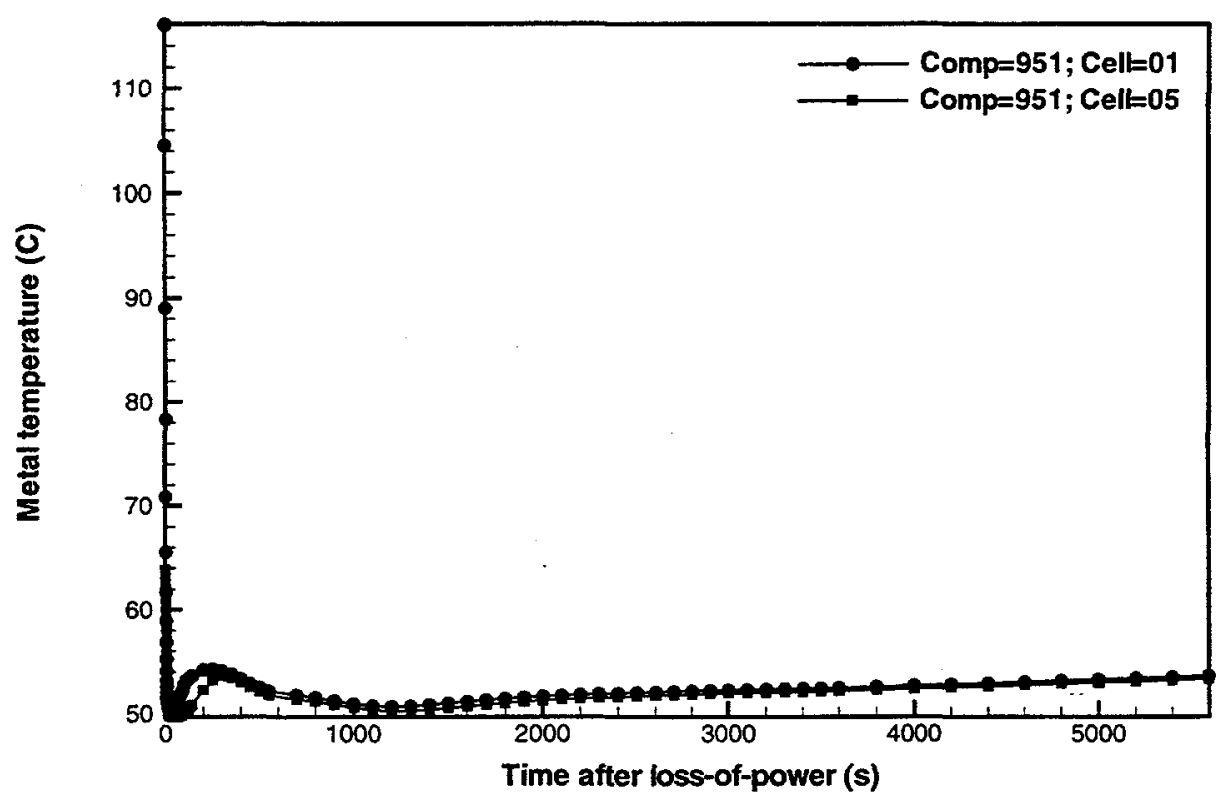

Figure B-26 Module 1 upflow section bottom and top maximum lead metal temperatures for a LOFA (Case 2: with beam shutdown only). 


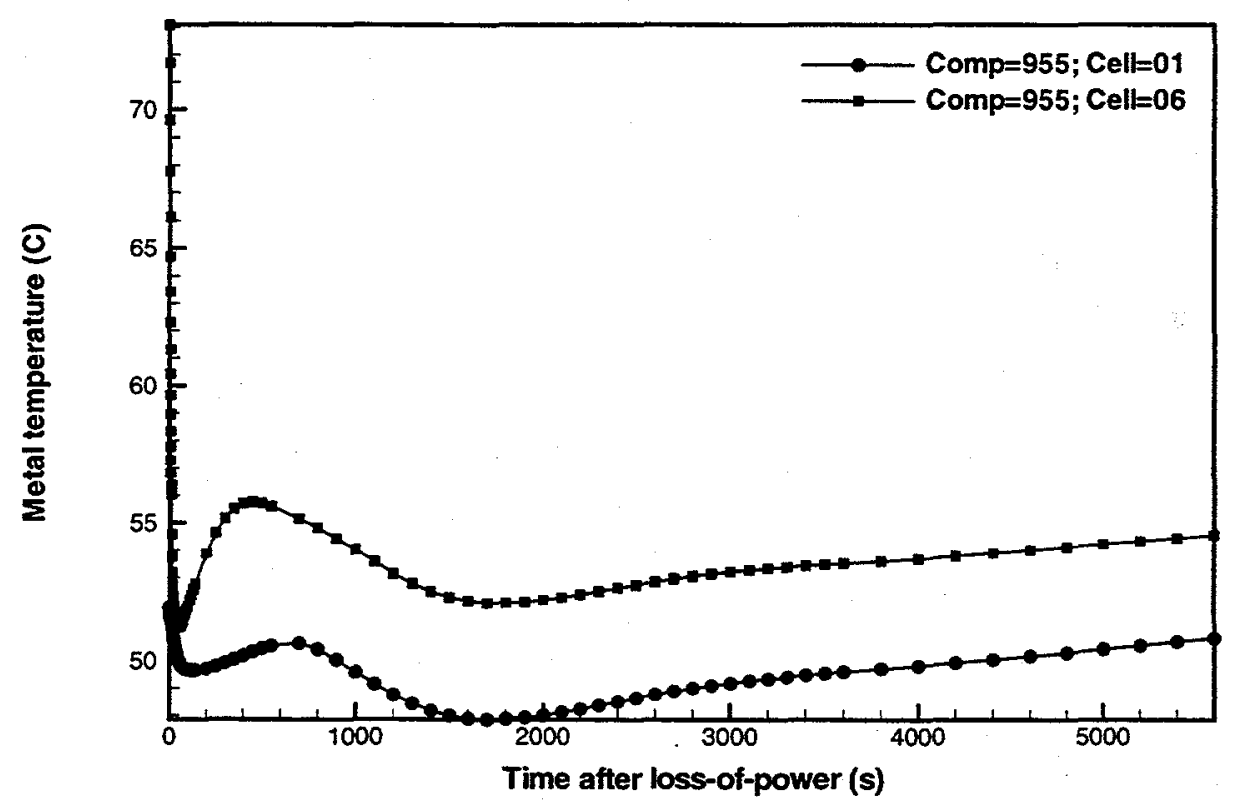

Figure B-27 Module 2 upflow section bottom and top maximum lead metal temperatures for a LOFA (Case 2: with beam shutdown only).

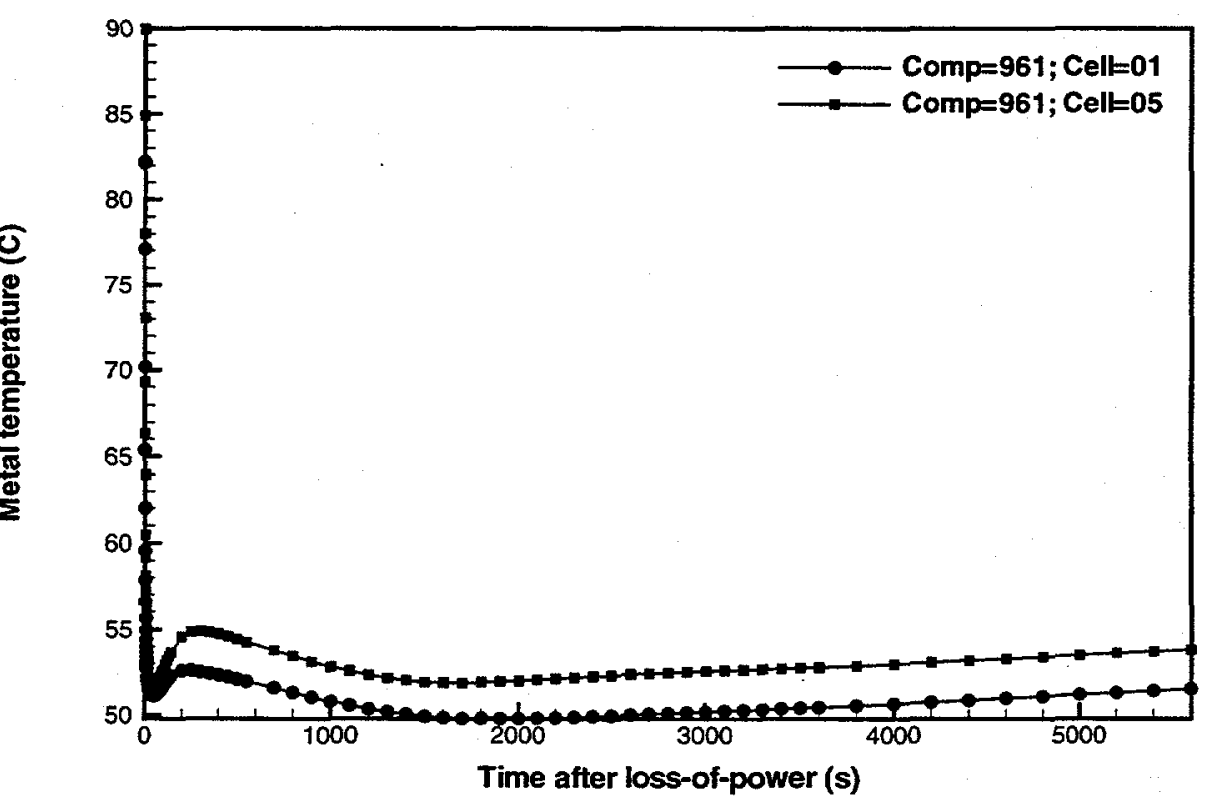

Figure B-28 Module 3 upflow section bottom and top maximum lead metal temperatures for a LOFA (Case 2: with beam shutdown only). 


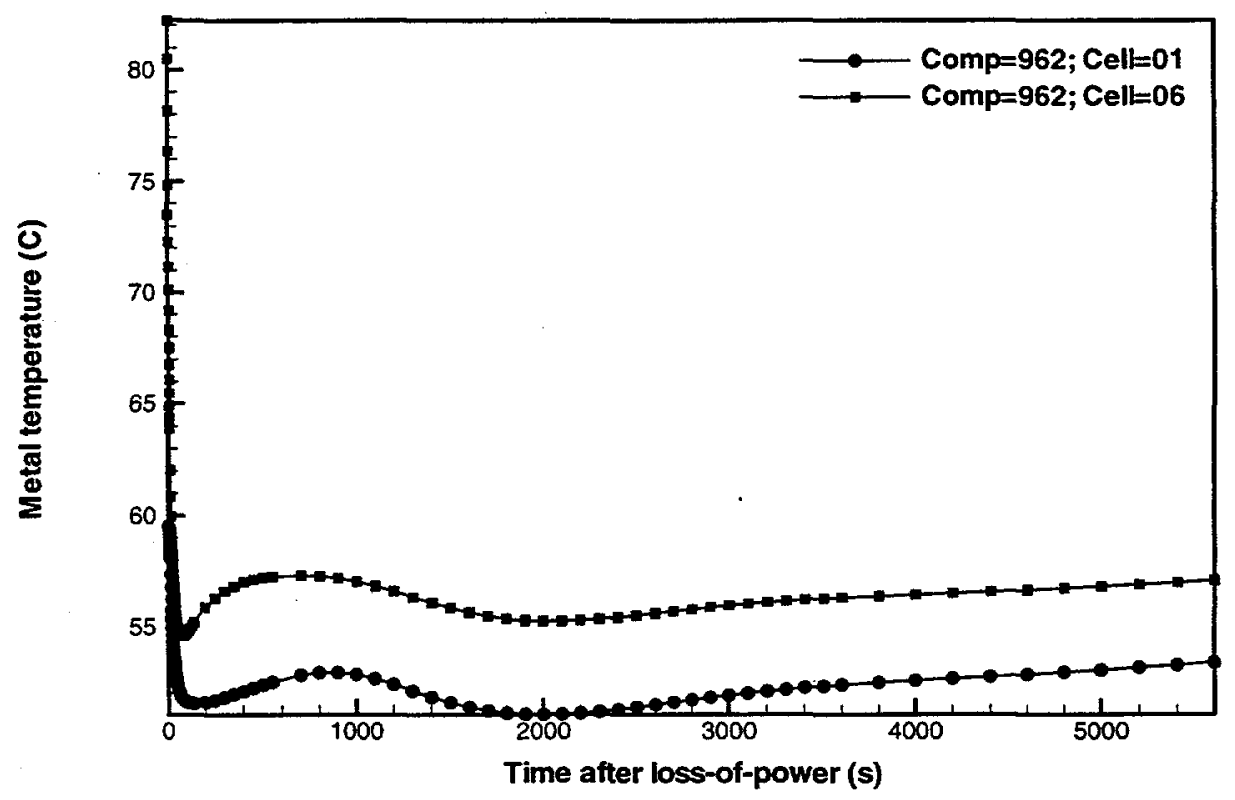

Figure B-29 Module 4 upflow section bottom and top maximum lead metal temperatures for a LOFA (Case 2: with beam shutdown only).

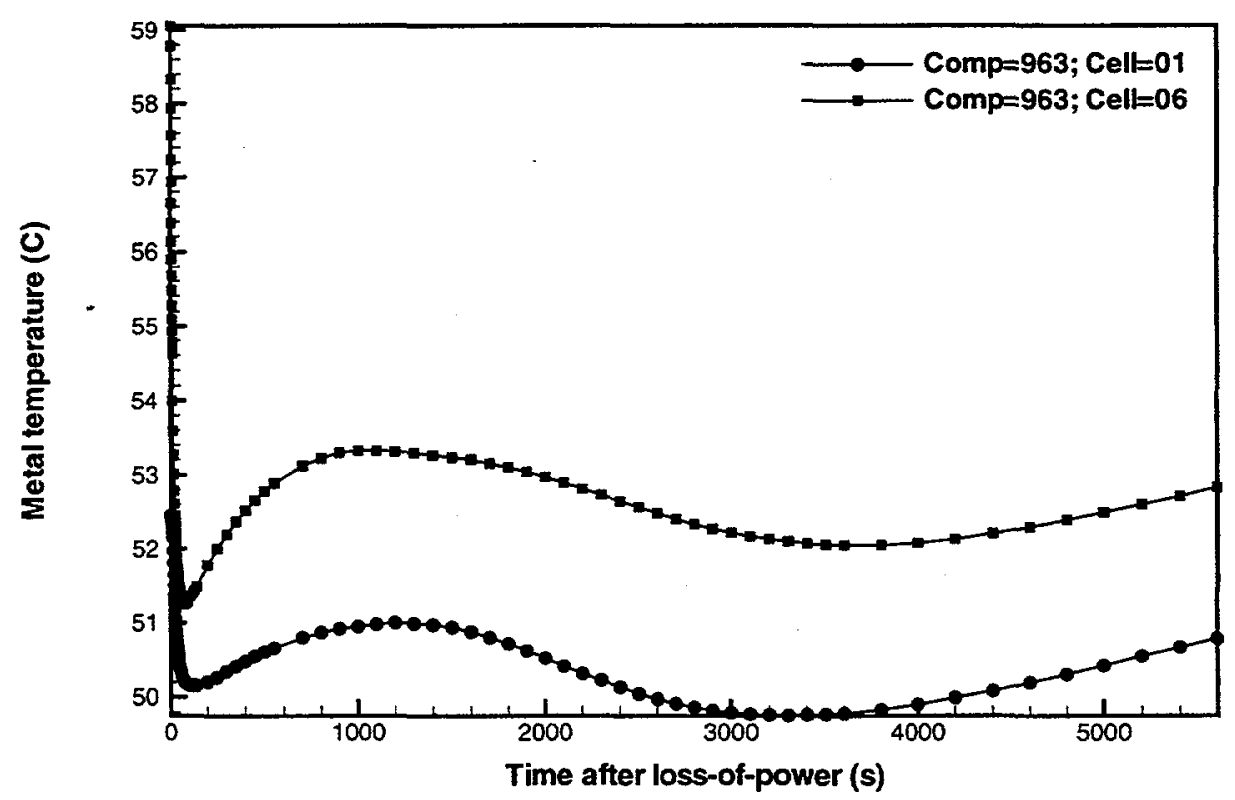

Figure B-30 Module 5 upflow section bottom and top maximum lead metal temperatures for a LOFA (Case 2: with beam shutdown only). 


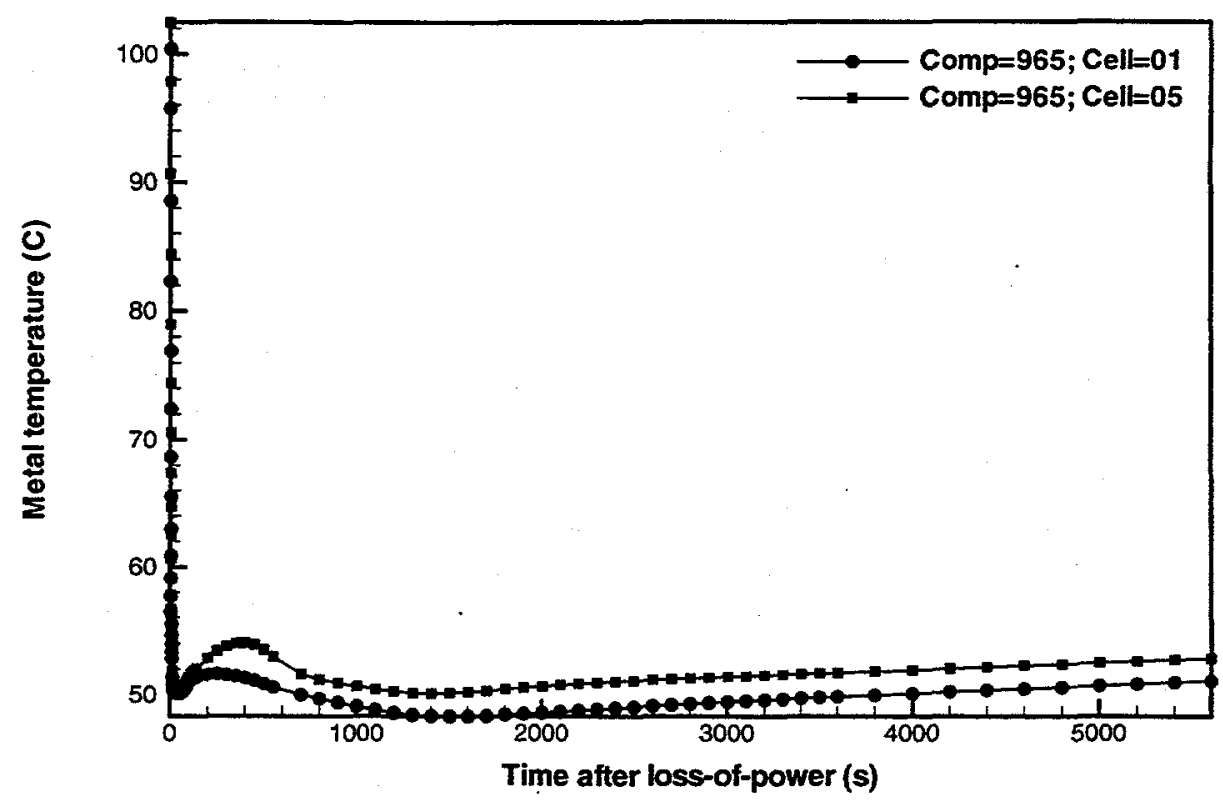

Figure B-31 Module 6 down-stream section bottom and top maximum lead metal temperatures for a LOFA (Case 2: with beam shutdown only).

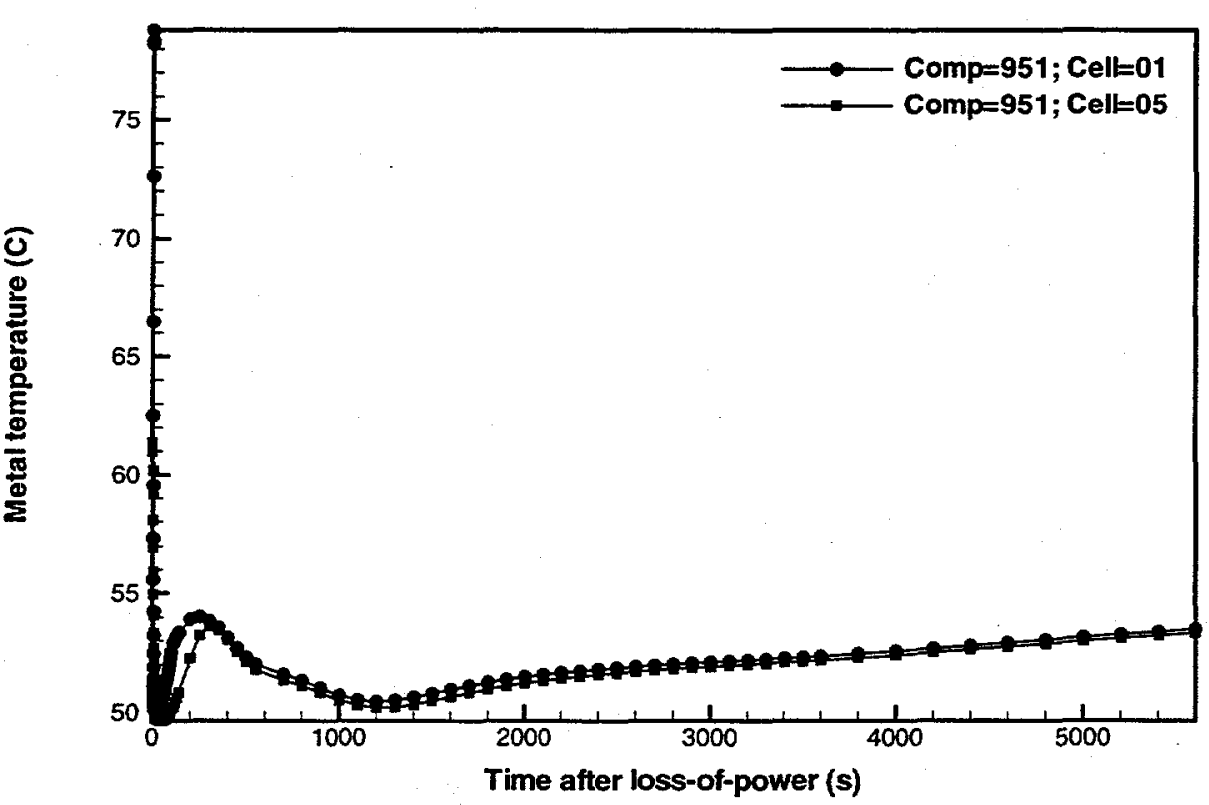

Figure B-32 Module 1 upflow section bottom and top maximum aluminum metal temperatures for a LOFA (Case 2: with beam shutdown only). 


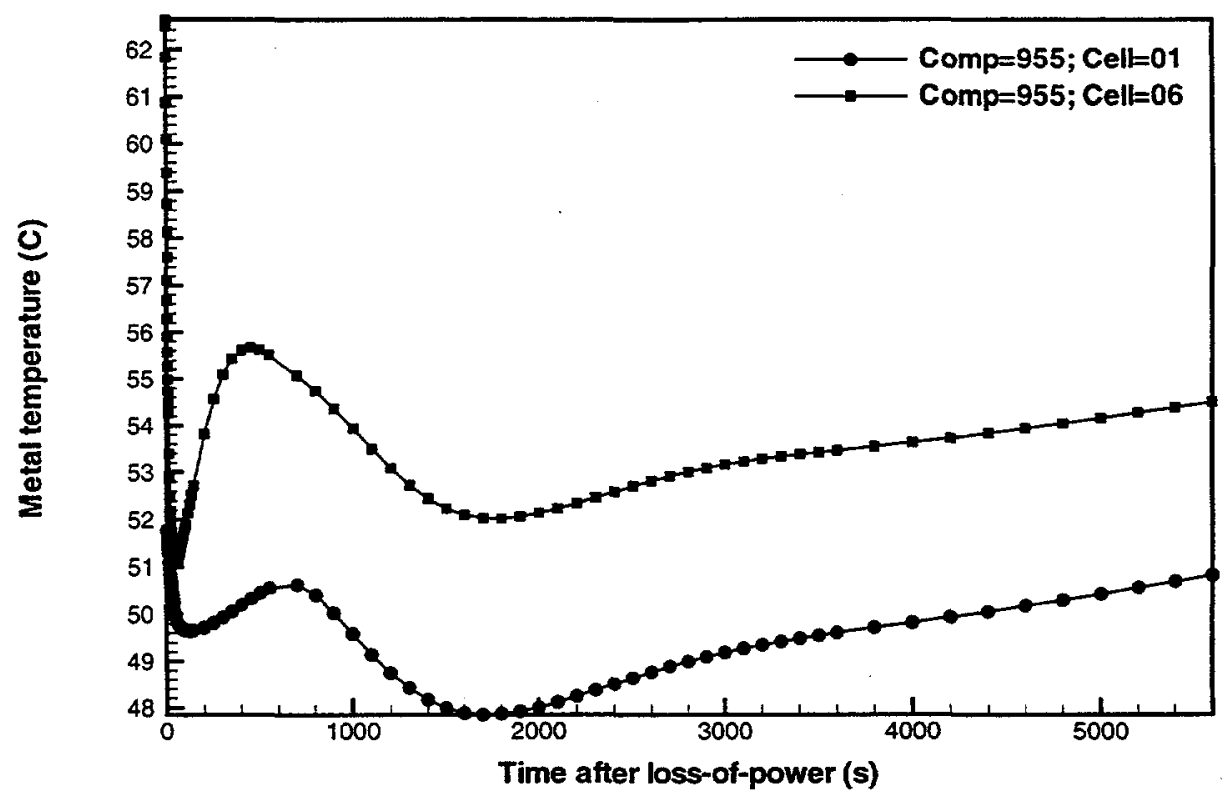

Figure B-33 Module 2 upflow section bottom and top maximum aluminum metal temperatures for a LOFA (Case 2: with beam shutdown only).

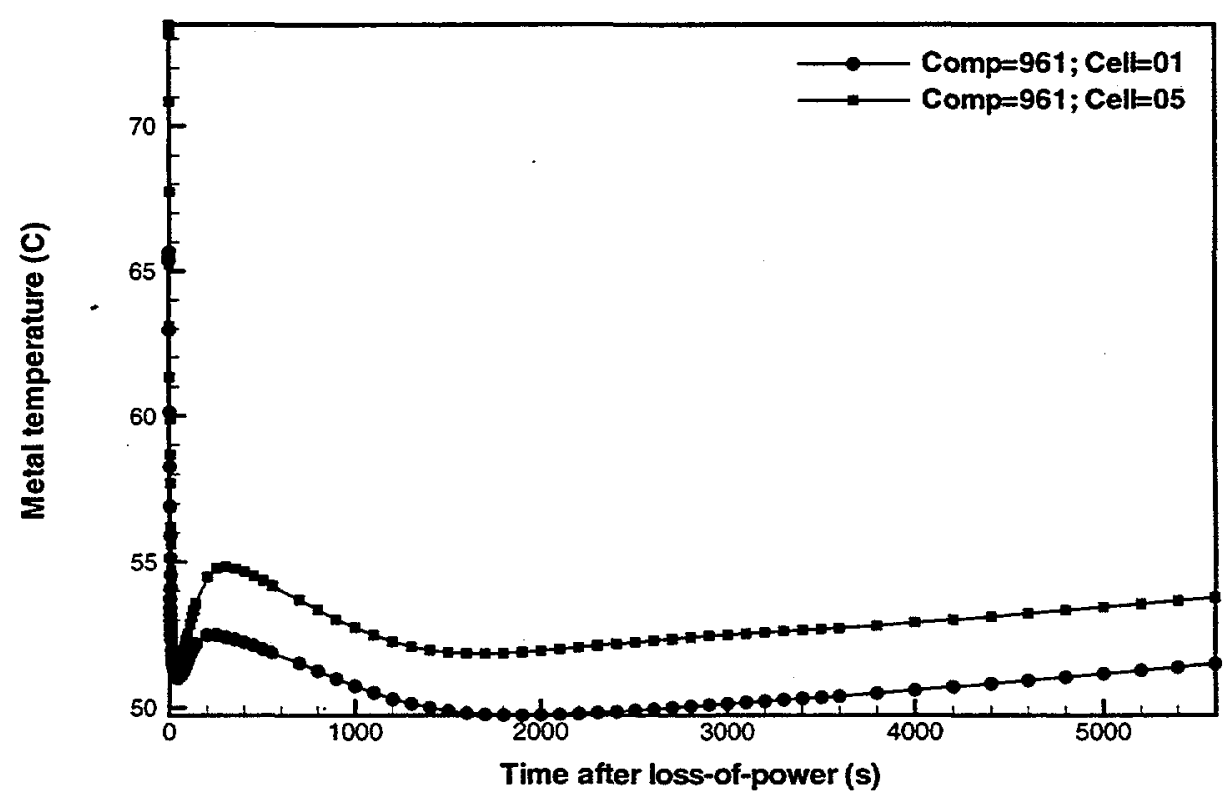

Figure B-34 Module 3 upflow section bottom and top maximum aluminum metal temperatures for a LOFA (Case 2: with beam shutdown only). 


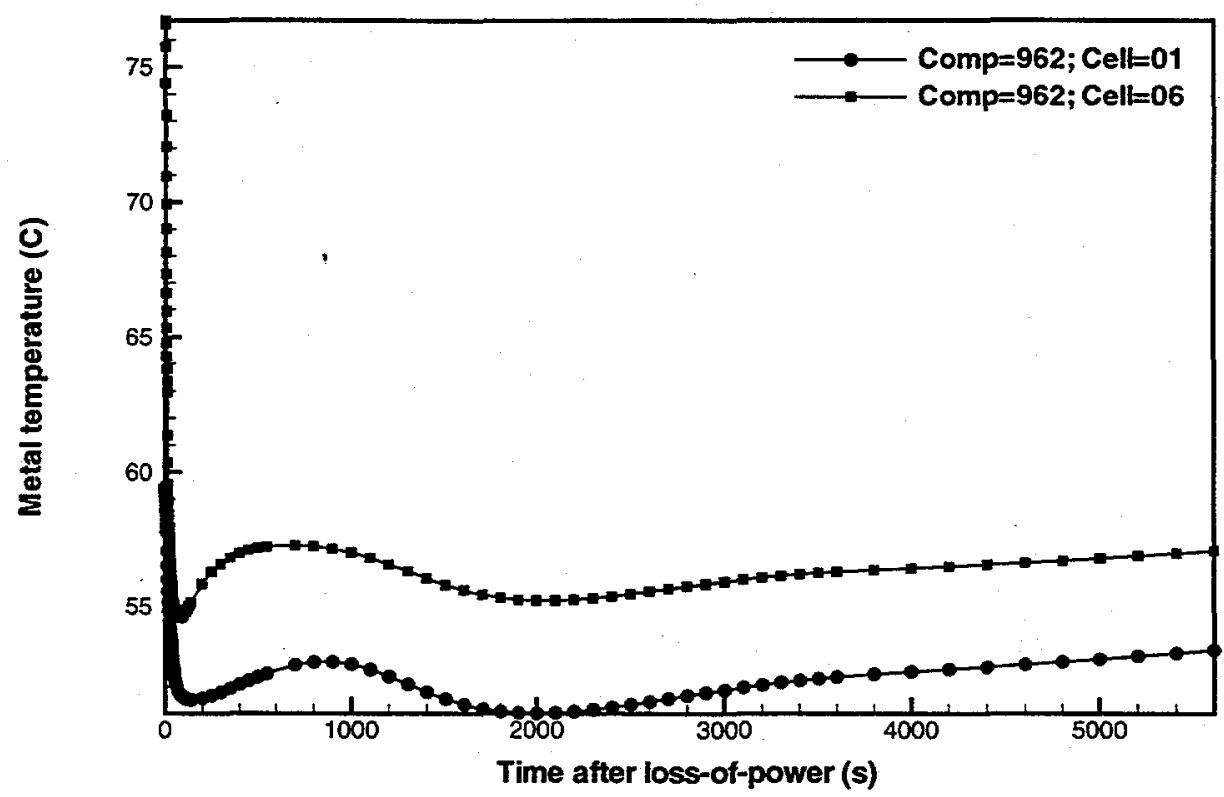

Figure B-35 Module 4 upflow section bottom and top maximum aluminum metal temperatures for a LOFA (Case 2: with beam shutdown only).

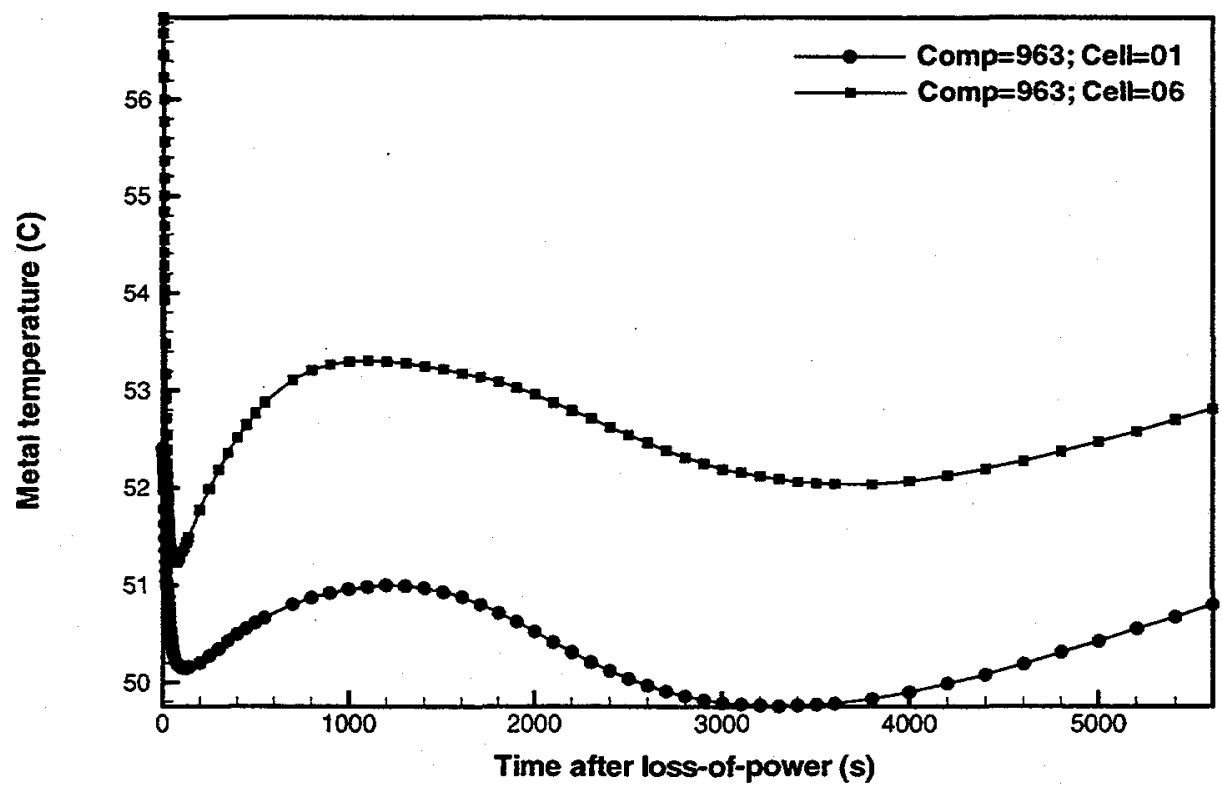

Figure B-36 Module 5 upflow section bottom and top maximum aluminum metal temperatures for a LOFA (Case 2: with beam shutdown only). 


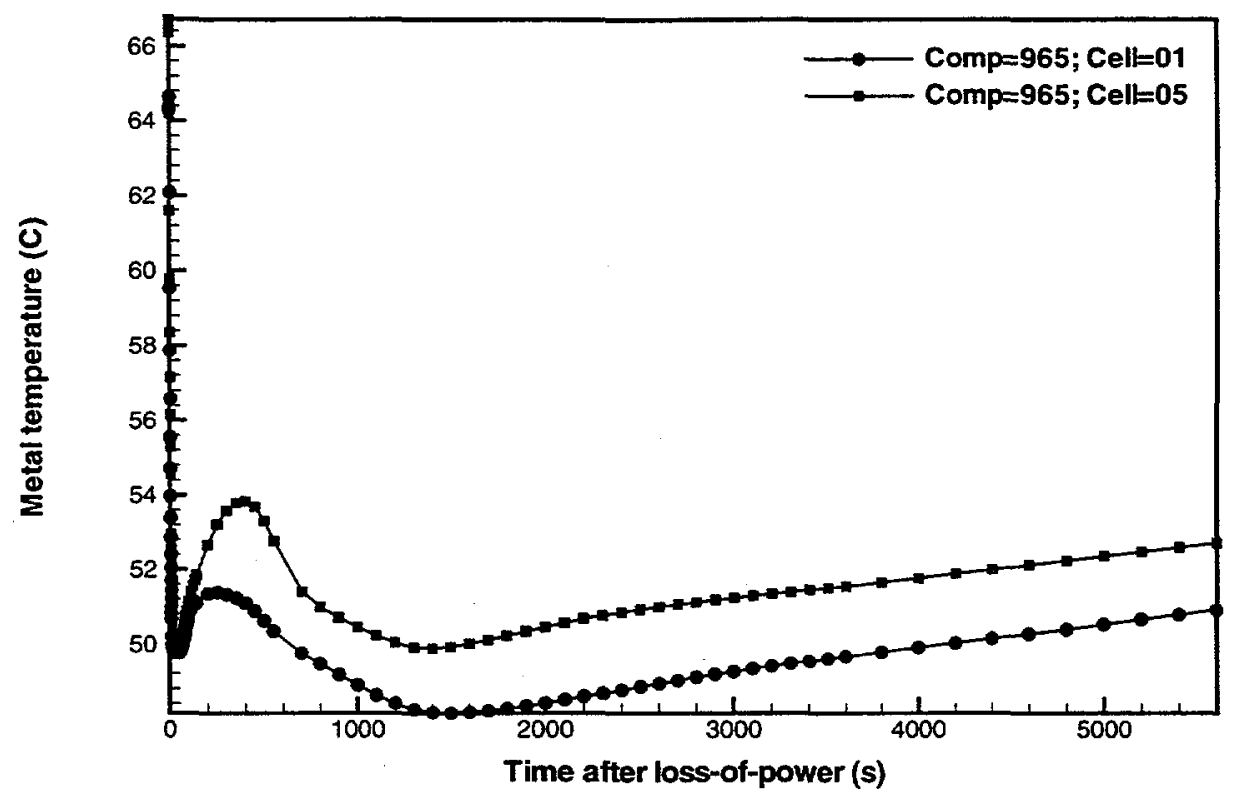

Figure B-37 Module 6 down-stream section bottom and top maximum aluminum metal temperatures for a LOFA (Case 2: with beam shutdown only).

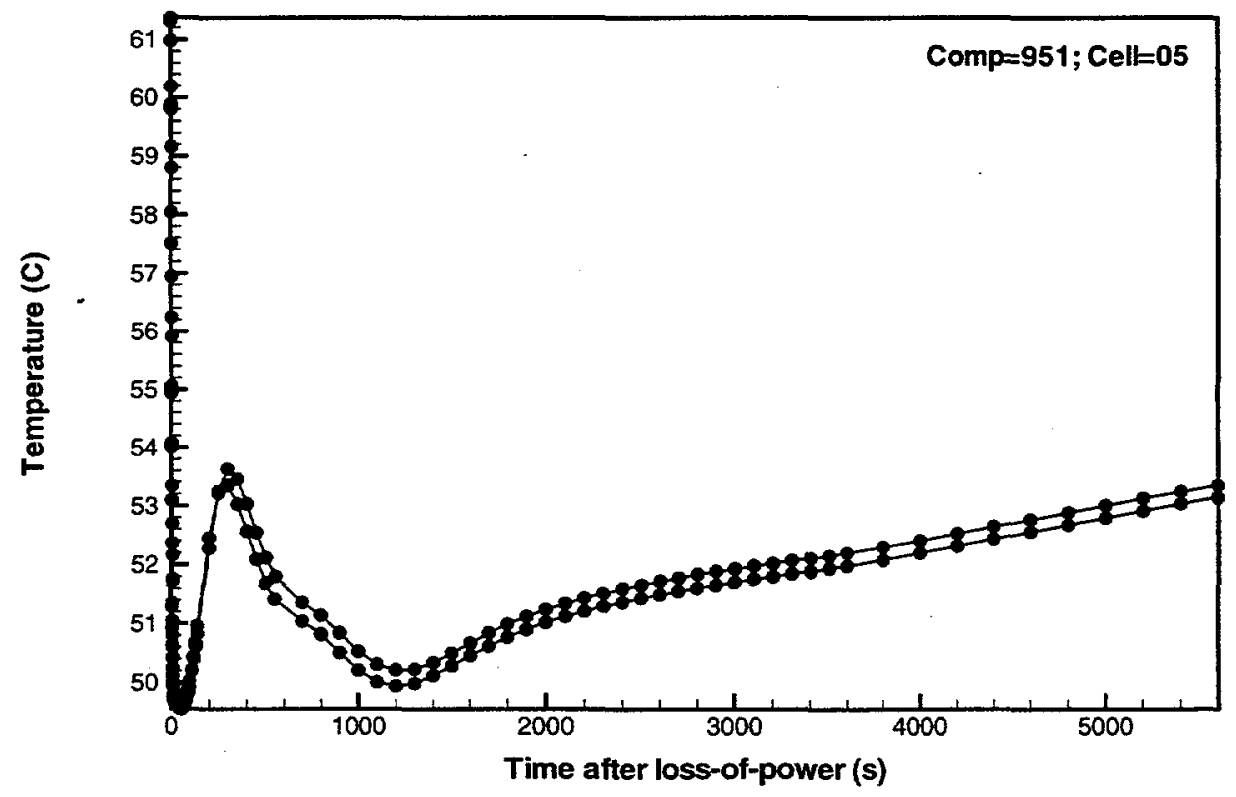

Figure B-38 Module 1 upflow section top-plane surface and fluid temperatures for a LOFA (Case 2: with beam shutdown only). 


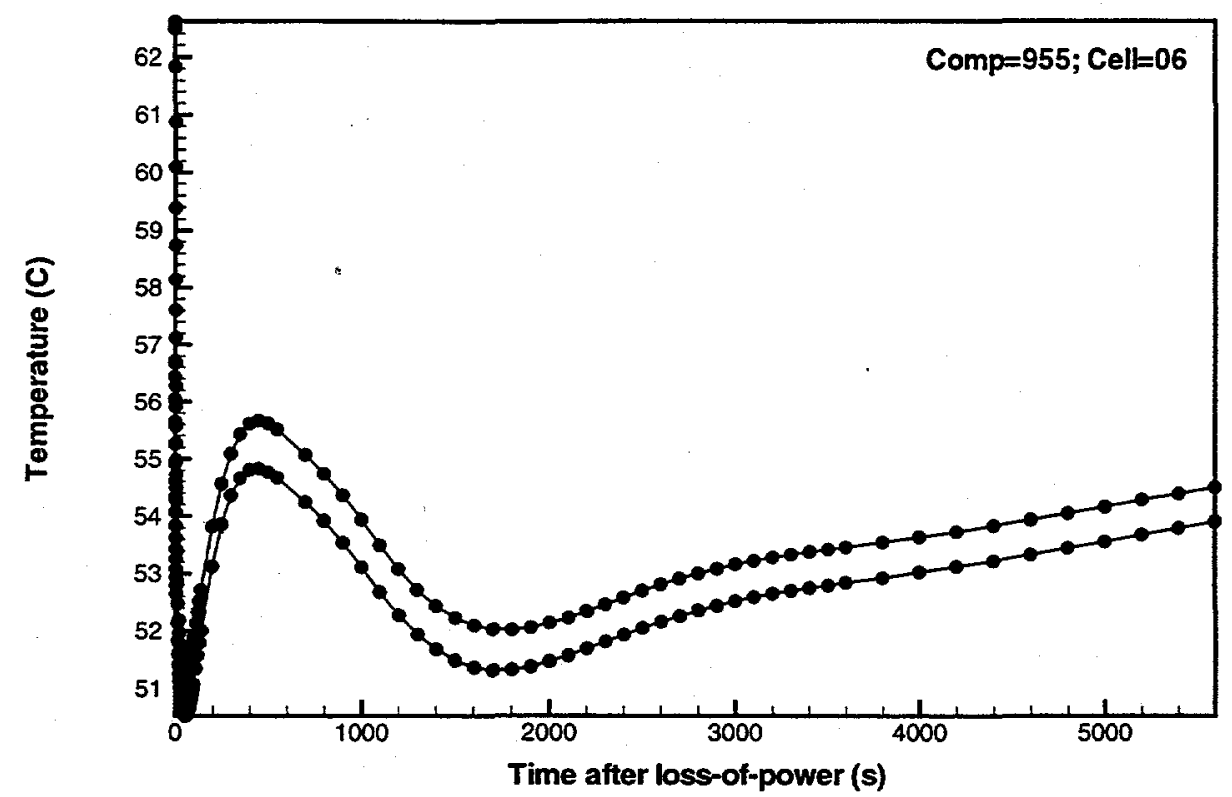

Figure B-39 Module 2 upflow section top-plane surface and fluid temperatures for a LOFA (Case 2: with beam shutdown only).

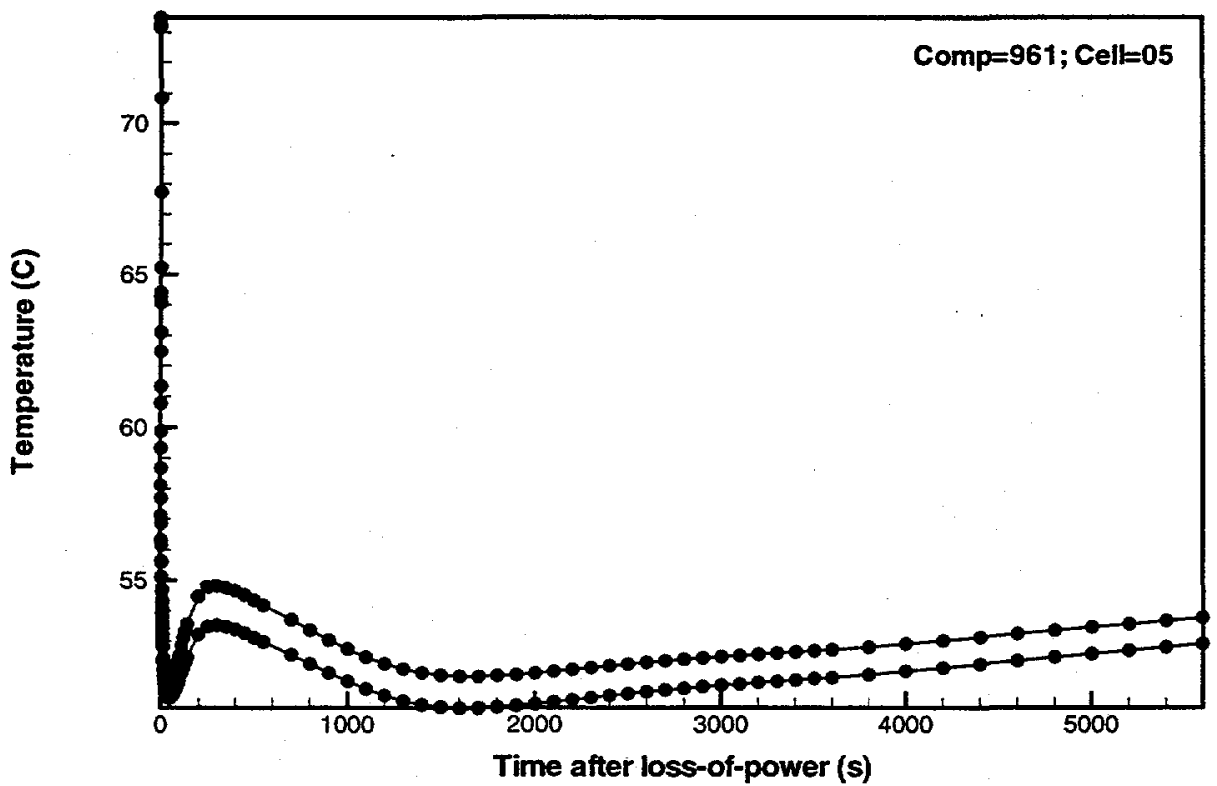

Figure B-40 Module 3 upflow section top-plane surface and fluid temperatures for a LOFA (Case 2: with beam shutdown only). 


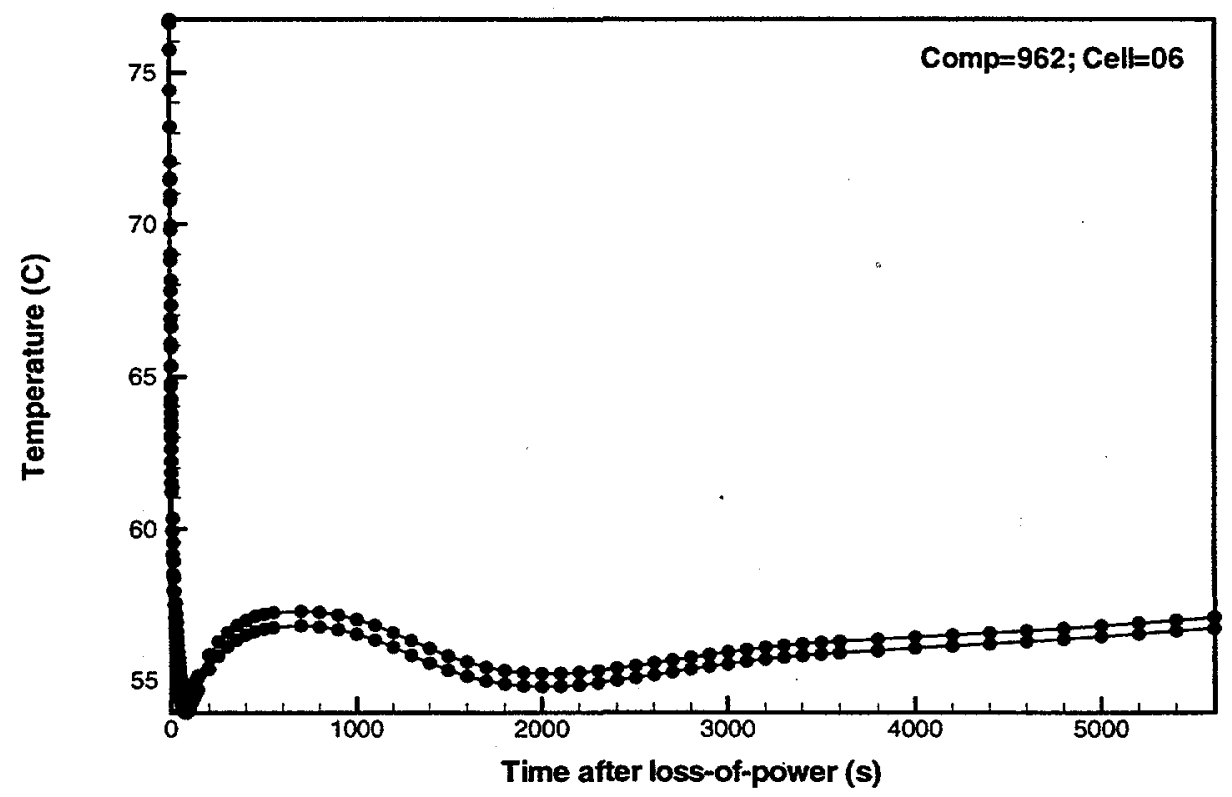

Figure B-41 Module 4 upflow section top-plane surface and fluid temperatures for a LOFA (Case 2: with beam shutdown only).

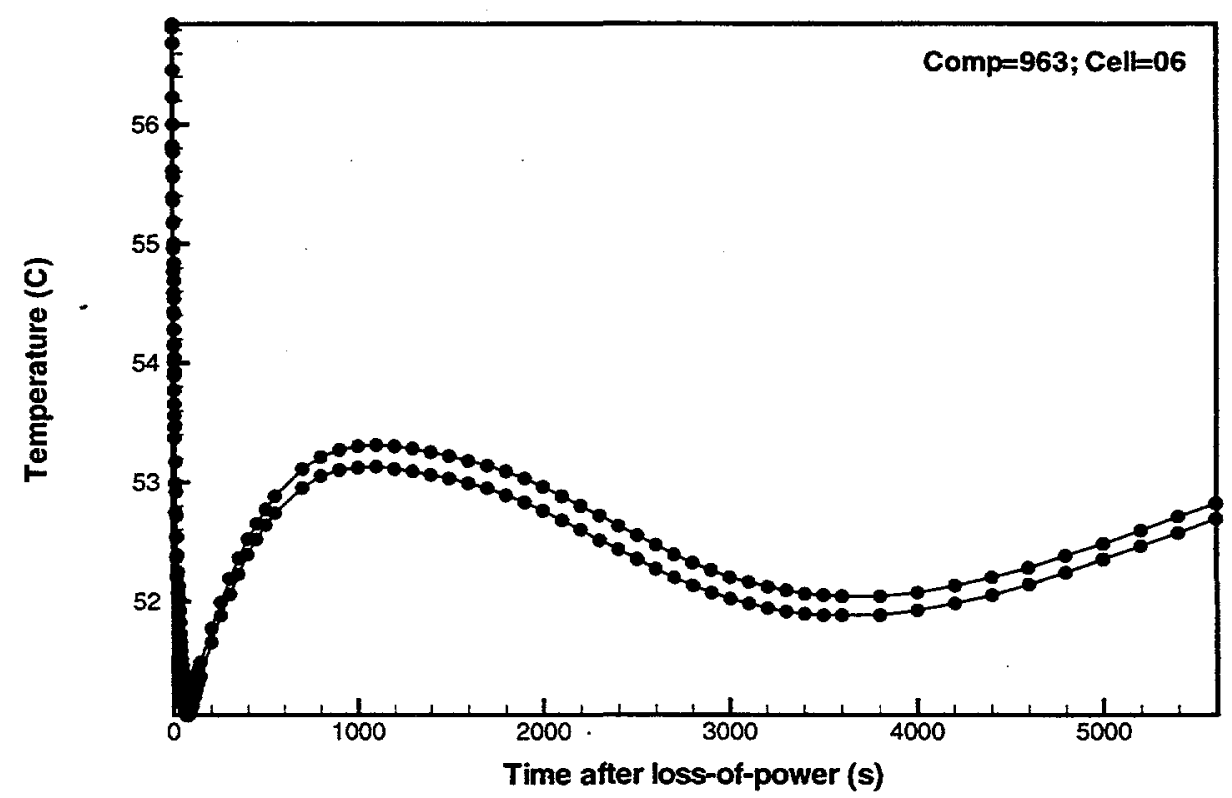

Figure B-42 Module 5 upflow section top-plane surface and fluid temperatures for a LOFA (Case 2: with beam shutdown only). 
Report:

Section:

Date:

Page:

(CASE 2: WITH BEAM SHUTDOWN ONLY)
WSRC-TR-98-0085

Appendix B

$07 / 14 / 98$

71 of 72

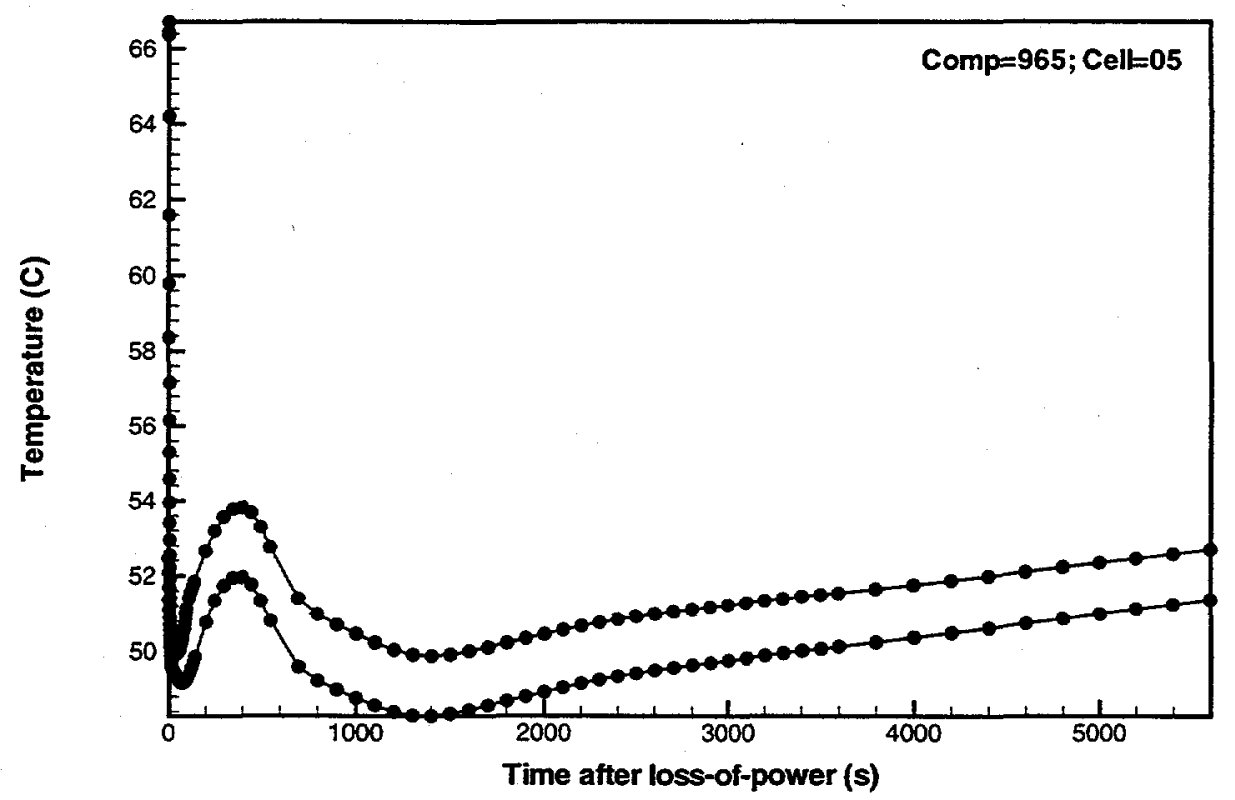

Figure B-43 Module 6 upflow section top-plane surface and fluid temperatures for a LOFA (Case 2: with beam shutdown only). 


\section{Appendix C: TRAC Standard Input File for LOFA Case 2 (with Beam Shutdown only)}

The file listed below represents the TRAC code "tracin" file that corresponds to the LOFA Case 2 (with beam shutdown only) for the blanket system. This input deck assumes that a TRAC restart file ("trcrst") exists based on normal operation (NO).

\section{Input file tracin:}

*

*

$\star * * \star * \star * * * * * * \star * \star$

* main data *

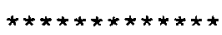

numtcr

ieos

inopt

nmat

ic20

* APT Iumped Blanket Model

6 Module Lumped Model with Primary Coolant Loop and RHR Loop

6 Modules - Lateral(R1/Dec) Module, R2/R3 Module,

3 Backstop Modules, Low Power Module (12/18/1997)

Hydraulic RHR Loop added as of $12 / 22 / 1997$

- This is based on check valve with flow reversal control logic.

Number of material $=2$ ( $\mathrm{Al}$ and $\mathrm{Pb}$ )

- This is single combined mod model without He comp (12/12/1997)

- Aluminum, lead material table got from Ref. (3/5, 1997)

- This is 1 module loop model without prmary coolant and RHR loops

- adding two upper modules (L14B-back / L14F-front) as of 7/18/1997.

- Row2/3 power updated (4/23/1997).

- R2/R3 axial power distribution has been updated as of $4 / 25 / 1997$

- Al and lead material properties updated already.

- Unit cell cal. should be checked.

- K-loss values for each comp and elevation levels need be checked.

- Control signal variable was added (4/25/1997).

- Module 5678 connection to fixed header was updated (5/28/97).

- Blanket primary loop pipe size (14 inch) was updated (5/28/1997).

- Lower modules (module 151617 18) were added/updated (5/29/1997).

- Backstop 1st module was updated (5/29/1997).

- Backstop 2nd and 3rd modules were updated (5/30/1997).

- R2/R3 lateral modules were updated from 9 to 11 bins (6/3/1997).

- Iateral module 1 to 4 decay powers were updated (6/23/1997).

- Power for each module was updated from the $6 / 9 / 97$ e-mail except for snout and top modules $(6 / 26 / 97)$.

- Decay power fraction for each module was updated from the 6/9/97 e-mail except for snout and top mocules $(6 / 26 / 97)$.

- Power for each module was updated from the 6/9/97 e-mail for snout module $(7 / 8 / 97)$.

- Decay power fraction for each module was updated from the 6/9/97 e-mail for snout module (7/8/97).

- Single loop to connect two front lateral modules was updated $(7 / 16 / 97)$.

- Single loop to connect two back lateral modules was updated (7/16/97). 


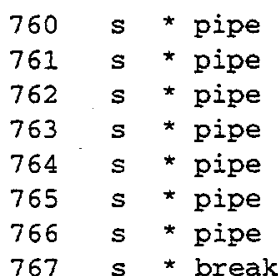

pressurizer surge linel pressurizer surge line2 pressurizer surge line3 pressurizer surge line4 pressurizer surge line5 pressurizer surge line6 primary pressurizer pressurizer boundary

* HR hot leg

\begin{tabular}{|c|c|c|c|}
\hline 20 & $s$ & * & pipe \\
\hline 21 & $s$ & * & plenum \\
\hline 22 & $s$ & * & pipe \\
\hline 23 & $\mathbf{s}$ & * & pipe \\
\hline 24 & $\mathrm{~s}$ & * & pipe \\
\hline 25 & $s$ & * & pipe \\
\hline 26 & $s$ & $\star$ & pipe \\
\hline
\end{tabular}

* Hr pumps .

\begin{tabular}{|c|c|c|}
\hline 27 & $s$ & * plenum \\
\hline 28 & s & * pipe \\
\hline 30 & $s$ & * pump \\
\hline 32 & $\mathbf{s}$ & * pipe \\
\hline 29 & $s$ & * pipe \\
\hline 31 & $s$ & * pump \\
\hline 33 & $\mathbf{S}$ & * pipe \\
\hline 34 & $s$ & * plenum \\
\hline
\end{tabular}

* HR pump-to-hx piping

\begin{tabular}{|c|c|c|}
\hline 36 & $s$ & \\
\hline 37 & $s$ & \\
\hline 38 & $s$ & \\
\hline
\end{tabular}

* HR hx's

\begin{tabular}{|c|c|c|}
\hline 40 & $s$ & * plenum \\
\hline 48 & $s$ & * pipe \\
\hline 50 & $s$ & * pipe \\
\hline 52 & $s$ & * pipe \\
\hline 54 & $s$ & * pipe \\
\hline 56 & $s$ & * pipe \\
\hline 49 & $\mathrm{~s}$ & * pipe \\
\hline 51 & $s$ & * pipe \\
\hline
\end{tabular}

HR pump suction pipe HR pump suction pipe (bk) HR pump suction pipe HR pump suction pipe (bk) HR pump suction pipe HR pump suction pipe (bk) HR pump suction pipe

HR pump suction plenum HR pump \#1 inlet pipe HR pump \#1

HR pump \#1 outlet pipe HR pump \#2 inlet pipe HR pump \#2

HR pump \#2 outlet pipe HR pump discharge plenum

HR pump dicharge pipe HR pump dicharge pipe (bk) HR pump dicharge pipe

HR hx inlet plenum HR $h \times 1$ inlet pipe HR $h \times 1$ tubes 1 st pass HR hx 1 mid-header HR hx 1 tubes 2nd pass HR $h \times 1$ outlet pipe HR hx 2 inlet pipe HR $h \times 2$ tubes 1 st pass 


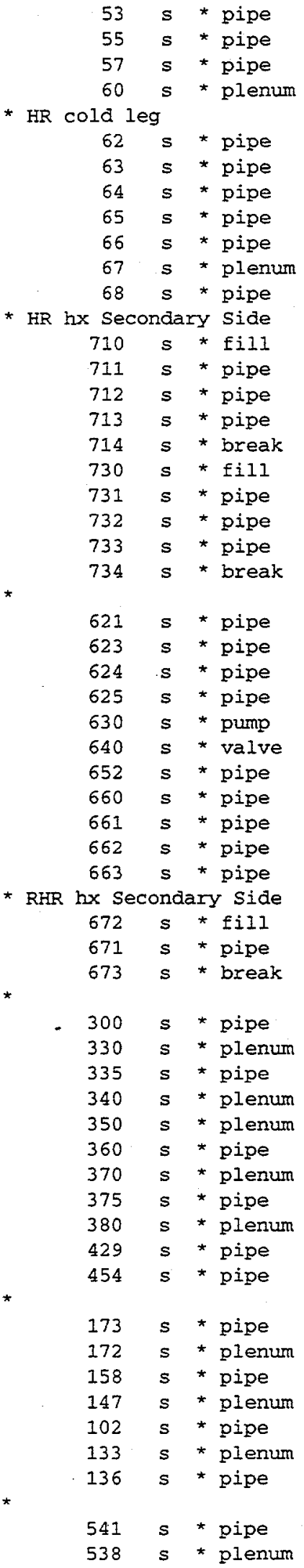

HR hx 2 mid-header $\mathrm{HR}$ hx 2 tubes 2 nd pass HR $h \times 2$ outlet pipe HR $\mathrm{hx}$ outlet plenum

HR hx discharge pipe HR hx discharge pipe (bk) $\mathrm{HR}$ hx discharge pipe HR $\mathrm{hx}$ discharge pipe (bk) HR $\mathrm{hx}$ discharge pipe HR $h x$ discharge pipe (bk) $\mathrm{HR} h \mathrm{hx}$ discharge pipe

HR hx Secondary Side-1 HR hx secondary side-1 HR hx Secondary Side-1 HR hx Secondary side-I HR hx Secondary Side-1 HR hx Secondary Side-2 HR hx Secondary Side-2 HR hx Secondary Side-2 HR $h x$ Secondary Side-2 HR $h x$ Secondary Side-2

RHR hot leg sect 1 (bk) RHR hot leg sect 2 RHR hot leg sect 3 (bk) RHR hot leg sect 4 RHR primary pump RHR pump discharge valve RHR primary heat exchanger tubes RHR cold leg sect 1 RHR cold leg sect 2 (bk) RHR cold leg sect 3 RHR cold leg sect 4 (bk)

RHR hx Secondary Side RHR hx Secondary side RHR hx Secondary Side

L1 Blanket Row1

L1 Blanket Row1 Plenum

L1 pipe conn. $330-340$

L1 outlet header

L1 lower plenum

L1 decoupler

L1 decoupler upper plenum

L1 pipe conn. $370-380$

Ll inlet header

I1 connect hot header-tee

II connect cold header-tee

LI Blanket Row1

Ll Blanket Row1 Plenum

Il pipe conn. $330-340$

I1 outlet header

L1 lower plenum

I1 decoupler

L1 decoupler upper plenum

L1 Blanket Row1

L1 Blanket Row1 Plenum 


\begin{tabular}{|c|c|c|}
\hline 35 & $\mathbf{s}$ & * pipe \\
\hline 531 & $\mathbf{s}$ & * plenum \\
\hline 28 & $\mathbf{s}$ & * pipe \\
\hline 36 & $\mathbf{s}$ & * plenum \\
\hline 39 & $s$ & * pipe \\
\hline 15 & $\mathbf{s}$ & * pipe \\
\hline 9 & $\mathbf{s}$ & * plenum \\
\hline 78 & $\mathbf{s}$ & * pipe \\
\hline 18 & $\mathbf{s}$ & * plenun \\
\hline 09 & $\mathbf{s}$ & * pipe \\
\hline 23 & $s$ & * plenun \\
\hline 17 & $s$ & * pipe \\
\hline 185 & $s$ & * pipe \\
\hline$\$ 89$ & $s$ & * plenur \\
\hline 480 & $s$ & * pipe \\
\hline 419 & $s$ & lenum \\
\hline 12 & $s$ & * pipe \\
\hline 483 & $s$ & * plenur \\
\hline 484 & $s$ & * pipe \\
\hline 513 & $s$ & * pipe \\
\hline 510 & 5 & * plenur \\
\hline 507 & $s$ & * pipe \\
\hline 503 & $s$ & * plenu \\
\hline 500 & $s$ & pipe \\
\hline 508 & $s$ & lenu \\
\hline 511 & $s$ & $\star F$ \\
\hline
\end{tabular}

I1 pipe conn. $330-340$

I1 outlet header

II lower plenum

L1 decoupler

II decoupler upper plenum

I1 Blanket Row1

Il Blanket Row1 Plenum

II pipe conn. $330-340$

Il outlet header

Il lower plenum

II decoupler

I1 decoupler upper plenum

2nd DNS Blanket Row1

2nd DNS Blanket Row1 Plenum

2nd DNS pipe conn. 330 - 340

2nd DNS outlet header

2nd DNS lower plenum

2nd DNS decoupler

2nd DNS dec upper plenum

Third DNS Blanket Row1

Third DNS Row1 Plenum

Third DNS pipe conn. 330-340

Third DNS outlet header

Third DNS lower plenum

Third DNS decoupler

Third DNS dec upper plenum

anrilar aluminum rod
cylindrical lead rod
cylindrical lead rod

annular aluminum rod cylinarical lead rod cylindrical lead rod cylindrical lead rod

annular aluminum rod cylindrical lead rod

annular aluminum rod cylindrical lead rod cylindrical lead rod

annular aluminum rod cylindrical lead rod cylindrical lead rod cylindrical lead rod

annular aluninum rod cylindrical lead rod cylinarical lead rod cylindrical lead rod

annular ss rod annular ss rod annular ss rod annular ss rod annular ss rod 


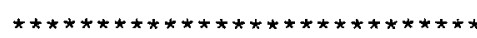

* material-properties data *

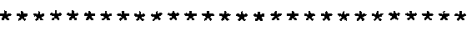

*

* matb *

* ptbln *

\section{1}

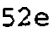

* lead material

* prptb $(1, i)$

$2.7300 e+02 \quad 1.1374 e+04$

$1.0000 e+10 \quad 1.1374 e+04$

e

* aluminum material

* $\operatorname{prptb}(1, i)$

$2.7300 \mathrm{e}+02$

$\operatorname{prptb}(2, i)$

$2.6990 \mathrm{e}+03$

$\operatorname{prptb}(3, i)$

$8.6985 e+02$

$2.6990 \mathrm{e}+03$

$2.6990 e+03$

$3.7300 e+02$

$4.7300 e+02$

$2.6990 e+03$

$6.7300 e+02$

$2.6990 e+03$

$1.0000 e+10$

$2.6990 e+03$

e

$\star$

$\star$

* Css data

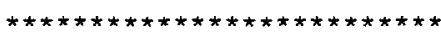

$\star$

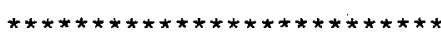

* control-parameter data *

$\star \star * * * * * * * * * * * * * * * * * * * * * * * *$

$\star$

**************************

* Signal variables

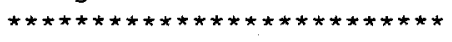

*

* time

idsv

isvm

$8.9000 e+02$

$9.4140 e+02$

$9.9538 e+02$

1. $0900 \mathrm{e}+03$

1. $2000 e+03$ prptb $(3, i)$

$8.9538 e+02$

prptb $(4, i)$

$3.4592 e+01$

$3.3382 e+01$ $\operatorname{prptb}(5, i)$

2. 8000 e- 01

2. 8000 e- 01 $\operatorname{prptb}(4, i)$

$2.1046 e+02$

$2.1046 e+02$

$2.1046 e+02$

2. $2175 e+02$

$2.2845 e+02$

2. $3000 e+02$ prpto $(5, i)$

$5.0000 e-02$

$5.0000 e-02$

$5.0000 e-02$

5.0000 e-02

$5.0000 e-02$

$5.0000 e-02$

*

* pressure difference across RHR check valve

* idsv isvn ilcn

$2 \quad-21 \quad 640$

*

* Elapse time since RHR pump activated

* idsv

isvn

il cn

3

0

0

$\operatorname{icn} 1$

icn2

$i \operatorname{cn} 1$

icn 2

1

2

* Elapse time since HR pumps activated

* Elapse time since HR pumps activated ilcn

$4 \quad-21 \quad 31$

* pressure difference across HR check valve

* pressure

$\begin{array}{rrr}\text { isvn } & 11 \mathrm{cn} \\ 5 & -21 & 32\end{array}$

32

* pressure difference across HR check valve

* idsv isvn ilcn

icnl

icn2

0

$\operatorname{icn} 1$

$i \operatorname{cr} 2$

2

1

icn 1

icn 2

1

2

$i \operatorname{cn} 1$

icn 2 
WESTINGHOUSE SAVANNAH RIVER COMPANY

BLANKET SAFETY ANALYSIS FOR LOFA

(CASE 2: WITH BEAM SHUTDOWN ONLY)
Report:

Section:

Date:

Page:
WSRC-TR-98-0085

Appendix C

$07 / 14 / 98$

pressure.

$$
6
$$

$-21$

33

* pressure, cold leg at plenum, component 761 idsv

isvn

21

ilcn

68

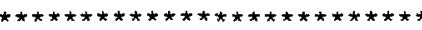

* control-block data *

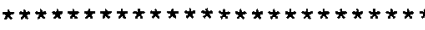

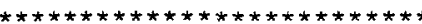

* trips

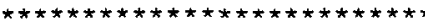

* trips from off to on at time given by $\operatorname{setp}(2)$, fill BC ntse

ntct

ntsf

ntap

1

6 of 8

*

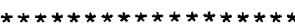

* component data

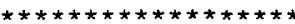

end

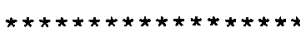

* time-step data *

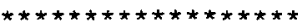

\section{dtmin}

1.0000 e- 07

edint

$1.0000 e-01$

*

* atmin

$1.0000 e-07$

edint

$5.0000 e-01$

*

* demin

1.0000 e- 07

edint

$2.0000 e+00$

* atmin

$1.0000 e-07$

edint

$4.0000 e+00$

* atmin

1. $0000 e-07$

edint

$1.0000 e+01$

*

* atmin

1. 0000 e- 07

edint

$5.0000 e+01$

* demin

1.0000 e- 07

edint

$1.0000 \mathrm{e}+02$

*

$$
\begin{array}{r}
\text { dtmax } \\
1.0000 e-03 \\
\text { gfint } \\
5.0000 e+00 \\
\text { dtmax } \\
2.0000 e-02 \\
\text { gfint } \\
5.0000 e+00 \\
\text { dtmax } \\
3.0000 e-01 \\
\text { gfint } \\
5.0000 e+00 \\
\text { dtmax } \\
3.0000 e-01 \\
\text { gfint } \\
5.0000 e+00 \\
\text { dtmax }
\end{array}
$$

5.0000e-01

gfint

$5.0000 e+00$

dtmax

5. 0000 e-01

gfint

$5.0000 e+00$

dtmax

$1.0000 e+00$

gfint

$2.0000 e+01$ tend

2. $0000 e-02$

ampint

$1.0000 e+06$

tend

$1.0000 e+01$

dmpint

$1.0000 e+06$

tend

$6.0000 e+01$

ampint

$1.0000 e+06$

tend

$1.0000 e+02$

ampint

$1.0000 e+06$

tend

$1.5000 e+02$

ampint

$1.0000 e+06$

tend

$6.0000 e+02$

dmpint

$1.0000 e+06$

tend

3. $6000 e+03$

dmpint

$1.0000 \mathrm{e}+06$ rtwfp

$1.0000 e+01$

sedint

$1.0000 e+06$

rtwfp

sedint

$1.0000 e+06$

rtwfp

$1.0000 e+01$

sedint

$1.0000 e+06$

rtwfp

$1.0000 \mathrm{e}+0 \mathrm{I}$

sedint

$1.0000 e+06$

rtwfp

$1.0000 e+01$

sedint

$1.0000 e+06$

rtwfp

$1.0000 e+01$

sedint

$1.0000 e+06$

$1.0000 e+01$

sedint

$1.0000 e+06$ ntsd

2

icn2

1

0 
WESTINGHOUSE SAVANNAH RIVER COMPANY

BLANKET SAFETY ANALYSIS FOR LOFA

(CASE 2: WITH BEAM SHUTDOWN ONLY)
Report: WSRC-TR-98-0085

Section: Appendix C

Date:

Page:
* atmin

$1.0000 e-07$

edint

$2.0000 e+02$

$\star$

* endflag dtmax tend

$1.0000 e+00 \quad 5.6000 e+03$

dmpint

$2.0000 e+01 \quad 1.0000 e+06$

$-1.0000 e+00$ 


\section{Appendix D: TRAC Graphics Input File for LOFA Case 2 (with Beam Shutdown only)}

The file listed below represents the TRAC code "graphin" file that corresponds to the LOFA case 2 (with beam shutdown only) for the blanket system. This input deck contains the various graphics points selected for output to the "tecsum.grf" file.

Input file tracin:

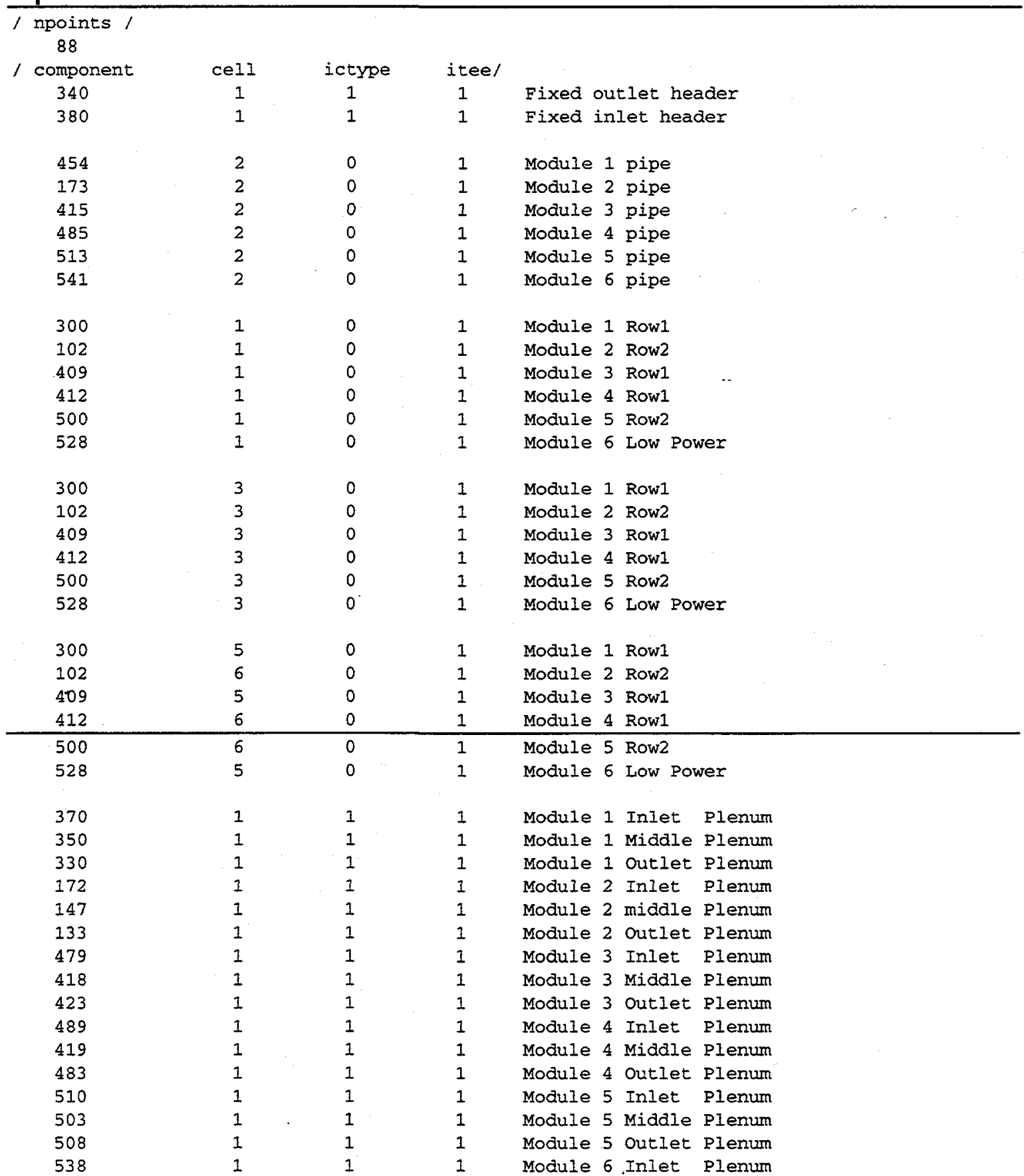


WESTINGHOUSE SAVANNAH RIVER COMPANY

BLANKET SAFETY ANALYSIS FOR LOFA (CASE 2: WITH BEAM SHUTDOWN ONLY)
Report: WSRC-TR-98-0085

Section: Appendix D

Date:

Page:

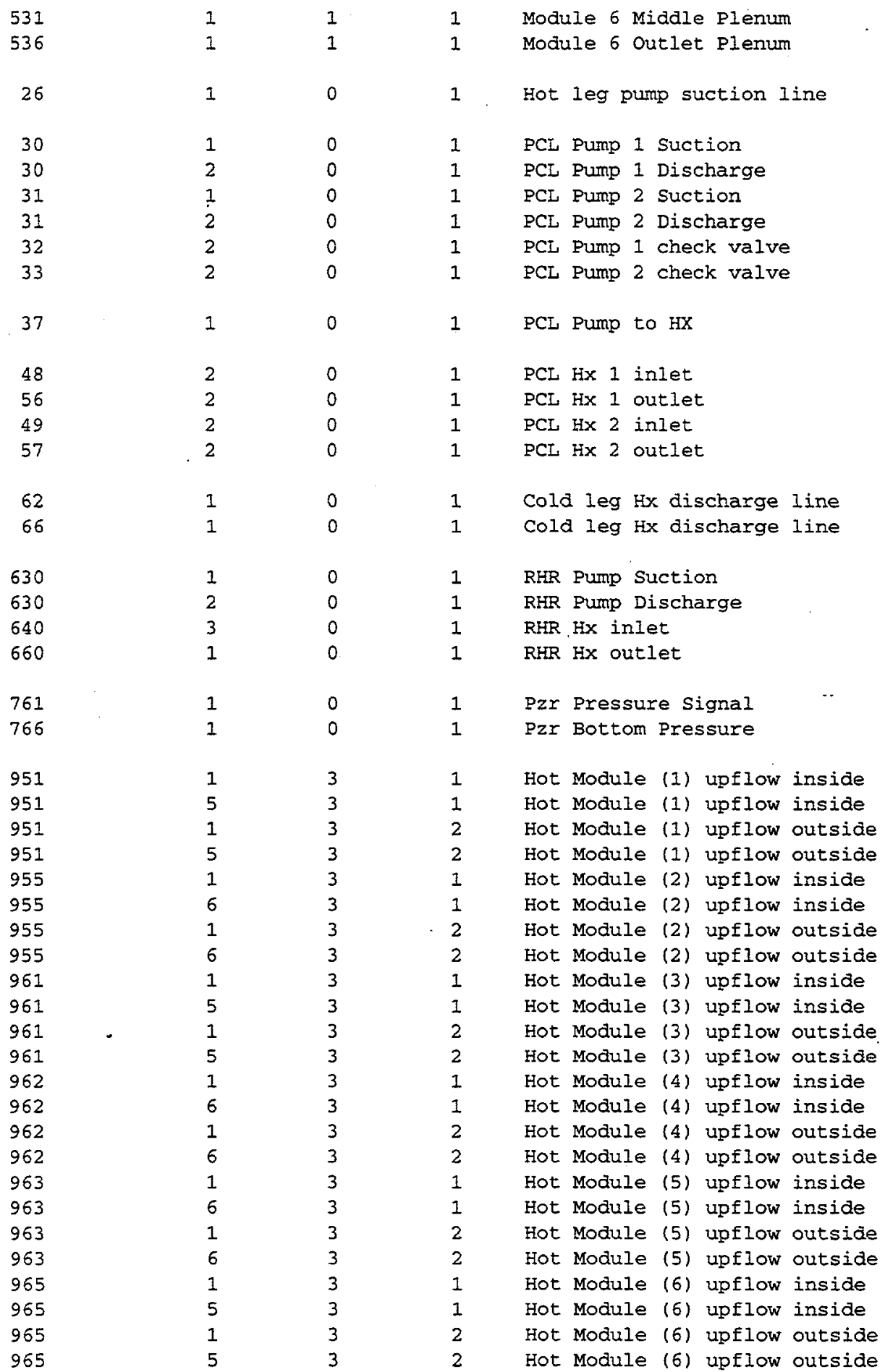

INPUT NOTES:

npoints - number of locations (points) within TRAC model graphics requested component - component id number containing specified graph point

cell - cell number with in component where graphics requested

ictype - type of component: 
(0 for fill, pipe, pressurizer, pump, tee, turb, value)

OUTPUT NOTES:

(1) for plenum)

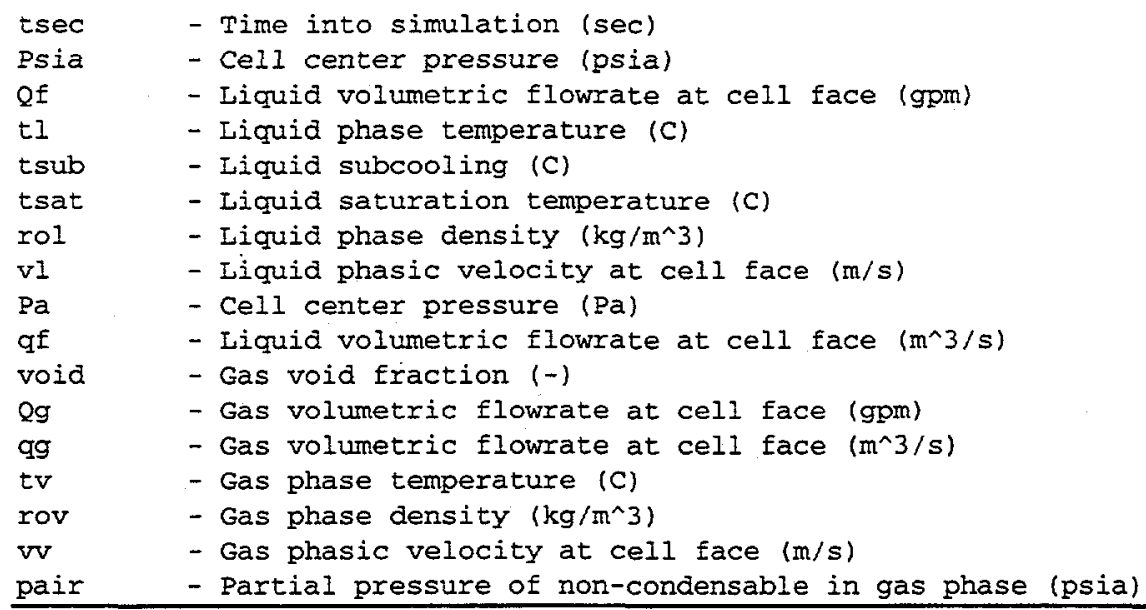


WESTINGHOUSE SAVANNAH RIVER COMPANY

BLANKET SAFETY ANALYSIS FOR LOFA

(CASE 2: WITH BEAM SHUTDOWN ONLY)
Report:

Section:

Date:

Page:
WSRC-TR-98-0085

Appendix D

07/14/98

4 of 4

(This Page Intentionally Left Blank) 